\title{
Regulation of the Cytochrome P450 Gene, CYP81D11, in Arabidopsis thaliana, Subjected to Chemical Stress
}

\author{
Dissertation \\ zur Erlangung des mathematisch-naturwissenschaftlichen Doktorgrades \\ "Doctor rerum naturalium" \\ an der Georg-August-Universität Göttingen
}

\author{
vorgelegt von \\ Julia Köster \\ aus Datteln
}

Göttingen 2010 
Referentin:

Prof. Dr. Christiane Gatz

Koreferent:

Prof. Dr. Ivo Feußner

Tag der mündlichen Prüfung: $\quad$ 24.01.2011 



\section{Contents}

\section{Abbreviations}

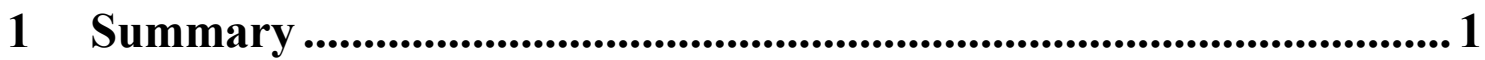

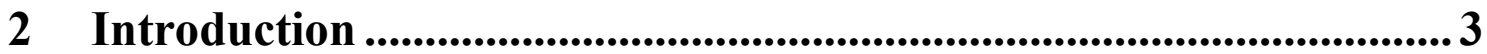

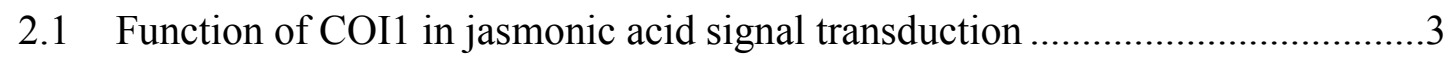

2.2 JA-dependent gene regulation in plant stress responses.................................6

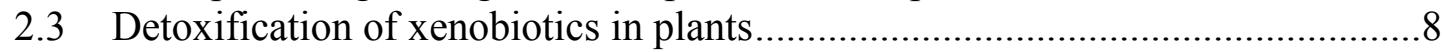

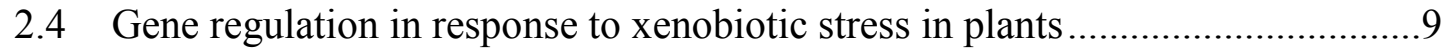

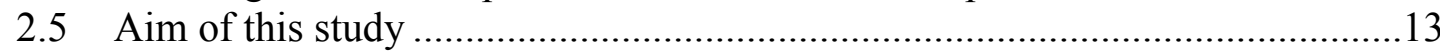

3 Materials and methods...................................................................... 14

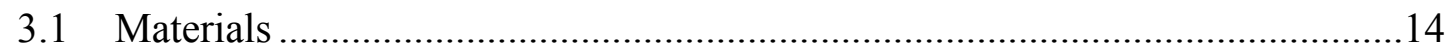

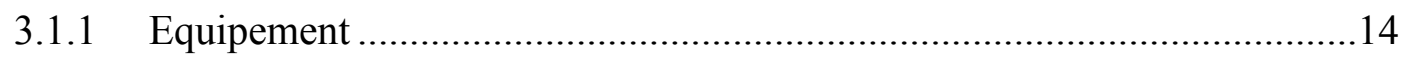

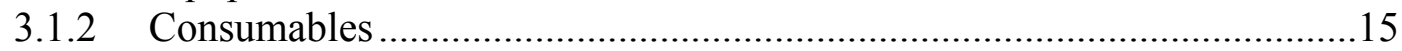

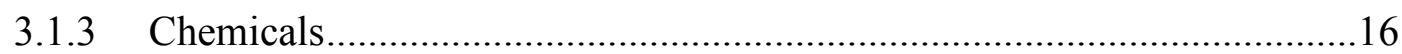

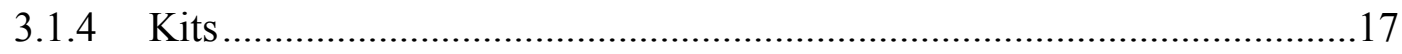

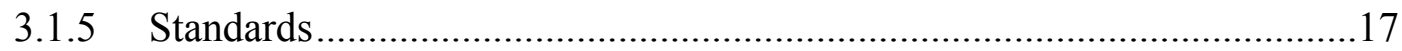

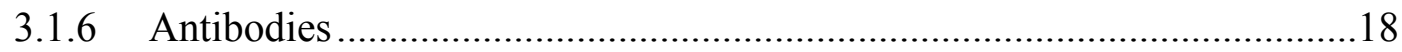

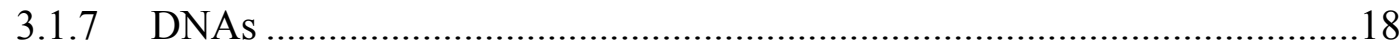

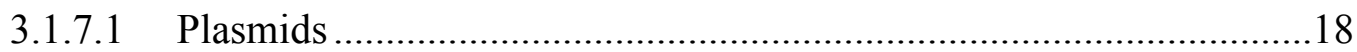

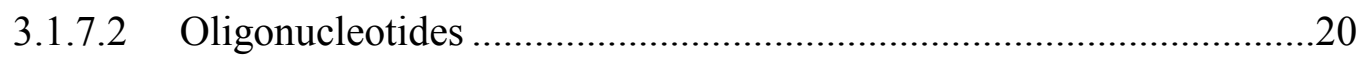

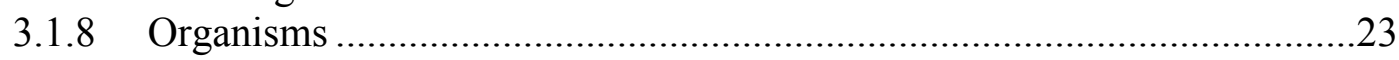

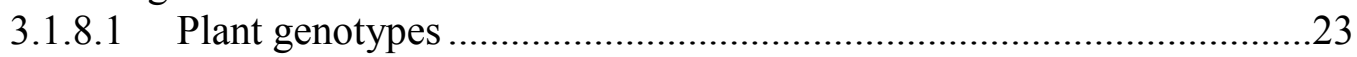

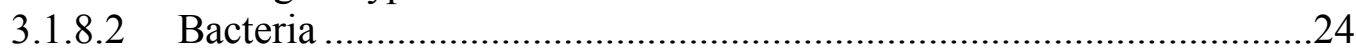

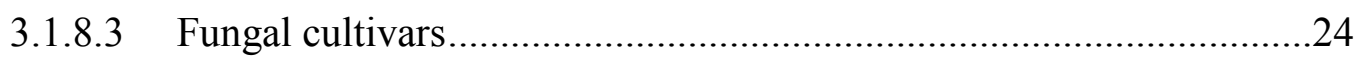

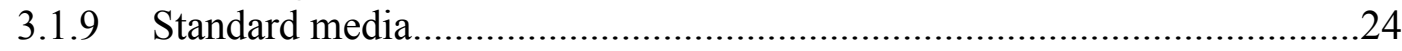

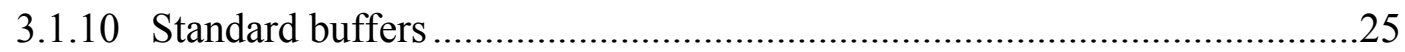

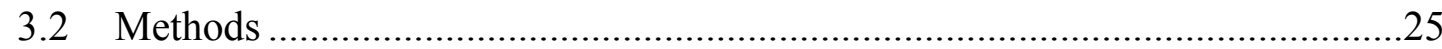

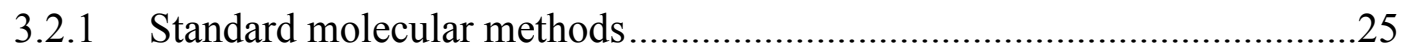

3.2.1.1 Isolation of plasmid DNA from $E$. coli .........................................25

3.2.1.1.1 Alkaline lysis .....................................................................25

3.2.1.1.2 Isolation of high-quality plasmid DNA ......................................26

3.2.1.2 Determination of DNA and RNA concentrations .............................26

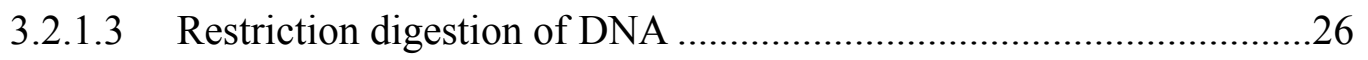

3.2.1.4 Separation of DNA on agarose gels ...............................................27

3.2.1.5 Hybridization of complementary DNA fragments ...........................27

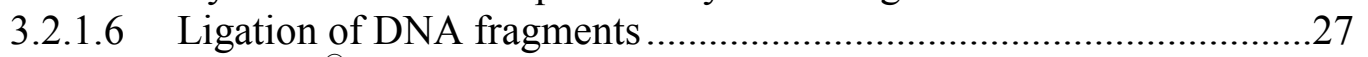

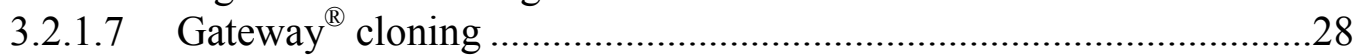

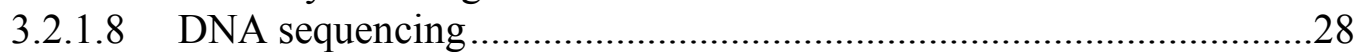

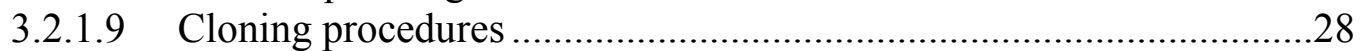

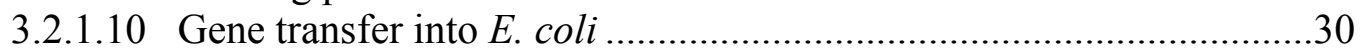

3.2.1.11 Gene transfer into Agrobacterium tumefaciens .................................30

3.2.1.12 Gene Transfer into Arabidopsis thaliana protoplasts .........................31

3.2.1.13 Agrobacterium-mediated gene transfer into Arabidopsis thaliana.....32

3.2.1.14 Isolation of genomic DNA from Arabidopsis thaliana leaves for genotyping. 


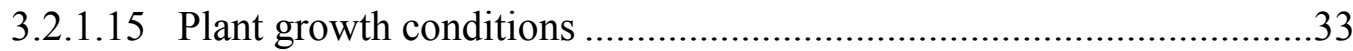

3.2.1.15.1 Growth of transgenic reporter gene lines.................................33

3.2.1.15.2 Plant growth conditions for transient expression studies and

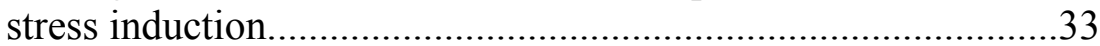

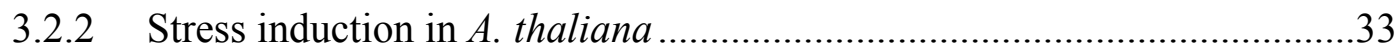

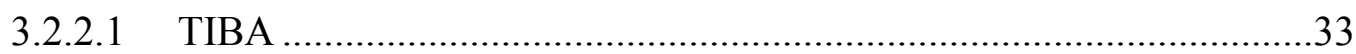

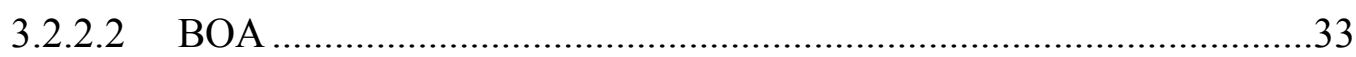

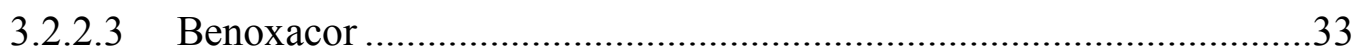

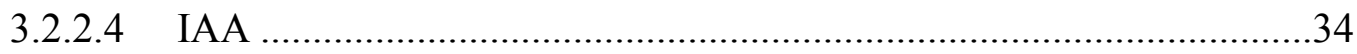

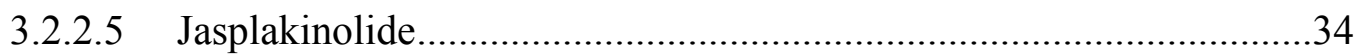

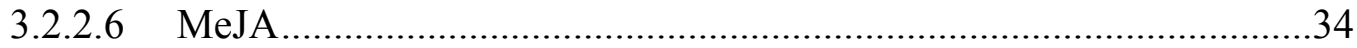

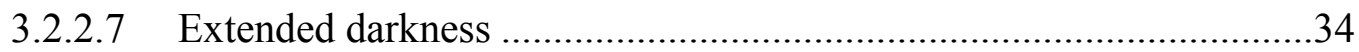

3.2.2.8 Infection of $A$. thaliana with Botrytis cinerea .....................................34

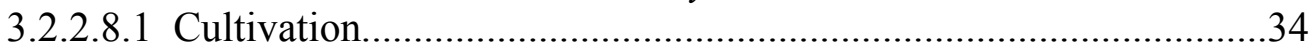

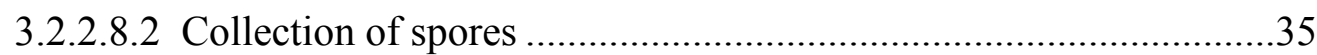

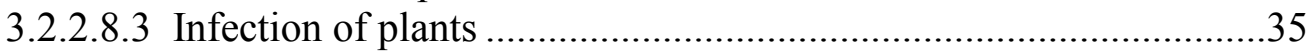

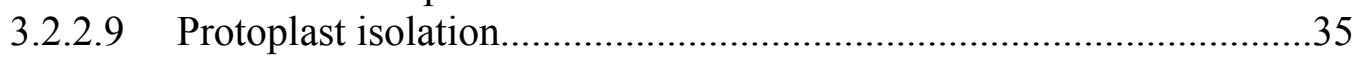

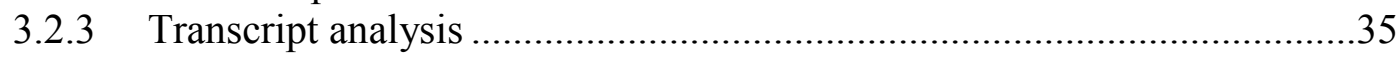

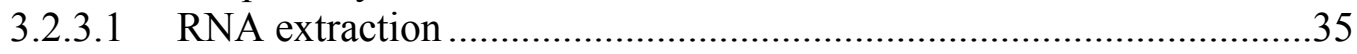

3.2.3.2 Preparation of gDNA-free cDNA for qRT-PCR ...............................36

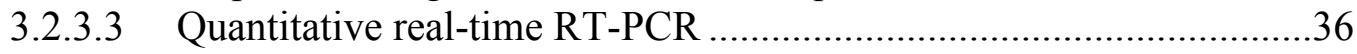

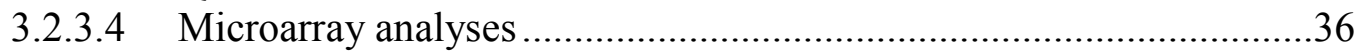

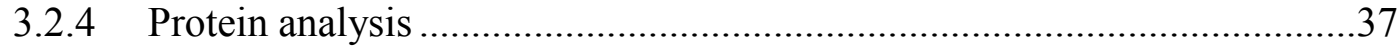

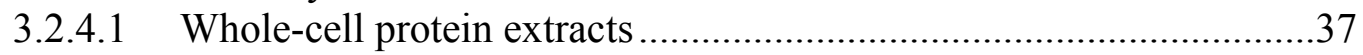

3.2.4.2 Determination of protein concentrations ...........................................37

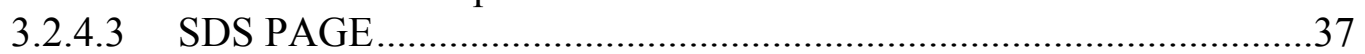

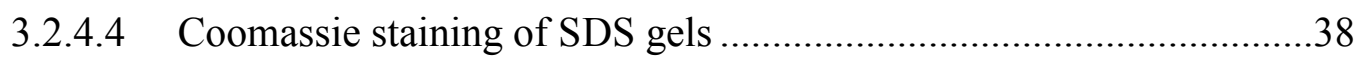

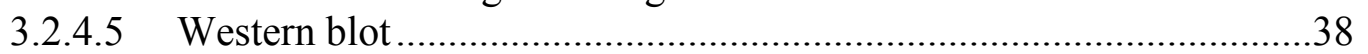

3.2.4.6 Preparation of protein extracts for enzymatic GUS assays...................39

3.2.4.7 Measurement of relative GUS activities ............................................39

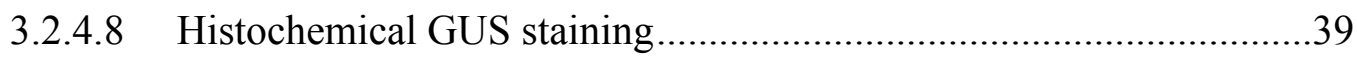

3.2.4.9 Measurement of relative luciferase activities ..................................39

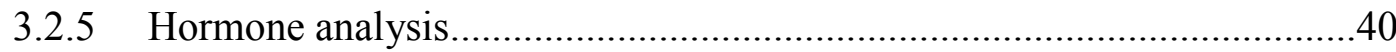

3.2.5.1 Determination of JA and JA-Ile contents in plant material ...............40

4 Results............................................................................................ 41

4.1 CYP81D11 expression depends on the TGA/SCL14 complex in response to jasmonic acid and Botrytis cinerea ..................................................................4

4.2 CYP81D11 shares common properties with the JA marker gene VSP2 2...........46

4.3 TIBA-induced CYP81D11 expression depends on COI1 in the absence of

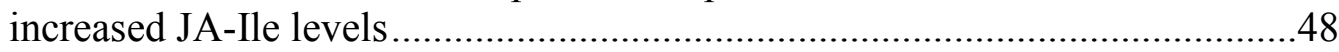

4.4 CYP81D11 expression in response to xenobiotic stress requires a JA-Ileindependent COI1 function ......................................................................50

4.5 Maximum CYP81D11 expression in response to TIBA requires basal JA-Ile

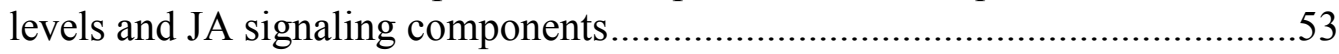

4.6 Mutation of the MYC2 binding site leads to a JA-insensitive but COI1-

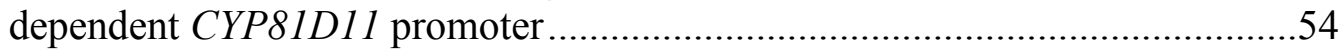

4.7 A large group of genes depends on COI1 and basal JA-Ile levels in

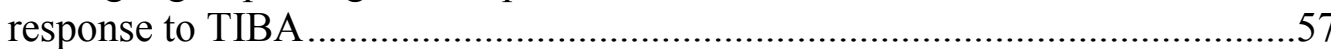

4.8 CYP81D11 is more closely co-regulated with COI1-independent than with COI1-dependent TIBA-inducible genes 
4.9 CYP81D11 and DIN11 show COI1-dependent and JA-Ile-independent

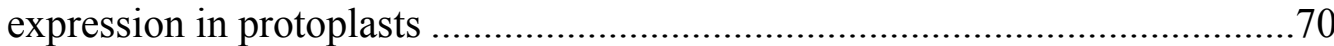

4.10 The expression of many JA-inducible genes is not increased in protoplasts ....71

4.11 Proteasome-dependent protein degradation is essential for CYP81D11 and DIN11 expression in protoplasts.

4.12 ATAF1 and ANAC032 repress basal expression of CYP81D11 ....................75

4.13 HA-ANAC032 F1 generation exhibits increased ANAC032 transcript levels and expresses the HA-ANAC032 protein ............................................77

4.14 ANAC032 negatively regulates TIBA induced CYP81D11 expression ............79

4.15 ANAC032 strongly represses CYP81D11, VSP2 and PDF1.2 transcript

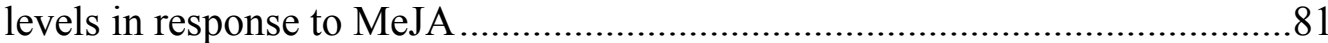

4.16 atafl/anac032 double-knockout mutants do not affect CYP81D11

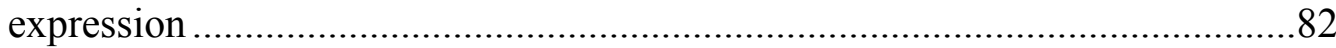

5 Discussion .................................................................................8 85

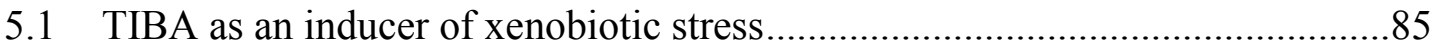

5.2 Basal JA levels and JA signalling are required for full induction of

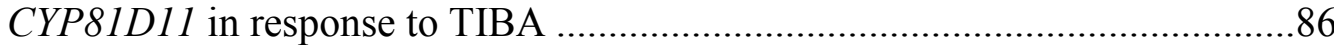

5.3 CYP81D11 is regulated by a JA-Ile-independent COI1 function.......................89

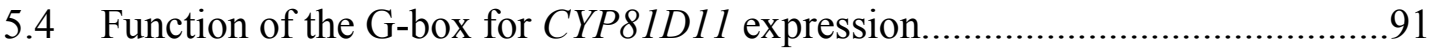

5.5 Expression of JA-responsive genes in protoplasts ..........................................92

5.6 A large group of genes is induced by TIBA in a COI1- and JA-Ile-

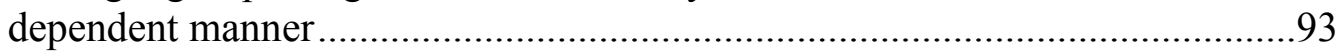

5.7 CYP81D11 is co-regulated with COI1-independent genes .............................95

5.8 ANAC032 negatively regulates CYP81D11 expression .................................96

5.9 ATAF1- and ANAC032-overexpressing plants exhibit severe growth and developmental phenotypes

6 Supplemental data....................................................................................... 101

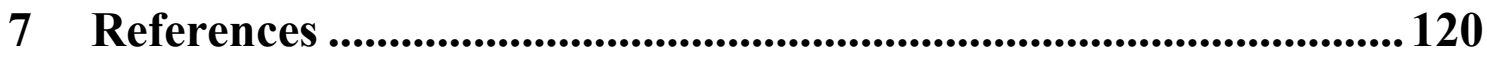

8 Acknowledgement ............................................................................. 129

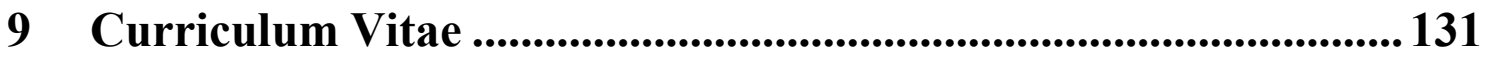




\section{Abbreviations}

2,4-D

aa

A

A

ABA

AD

amp

APS

as -1

ASN1

AT

A. thaliana

A. tumefaciens

B. cinerea

bp

BSA

bZIP

C

CaMV

cDNA

ChIP

COI1

COR

COR78

$\mathrm{C}_{\mathrm{T}}$

C-terminal

Da

DIN11

DMSO

DNA

DNase

dNTP

dpi

EB 2,4-dichlorophenoxyacetic acid

amino acids

Ampere

adenosine

abscisic acid

activation domain

ampicilin

ammoniumpersulfate

activating sequence 1

GLUTAMINE-DEPENDENT ASPARAGINE SYNTHASE 1

marks a protein from Arabidopsis thaliana

Arabidopsis thaliana

Agrobacterium tumefaciens

Botrytis cinerea

base pairs

bovine serum albumine

basic leucine zipper

cytosine

cauliflower mosaic virus

copy DNA

chromatin immunoprecipitation

CORONATINE INSENSITIVE 1

coronatine

COLD REGULATED 78

threshold cycle

carboxy-terminal

Dalton

DARK INDUCIBLE 11

dimethylsulfoxide

desoxyribonucleic acid

desoxyribonuclease

desoxyribonucleotides

days past infection

elusion buffer 


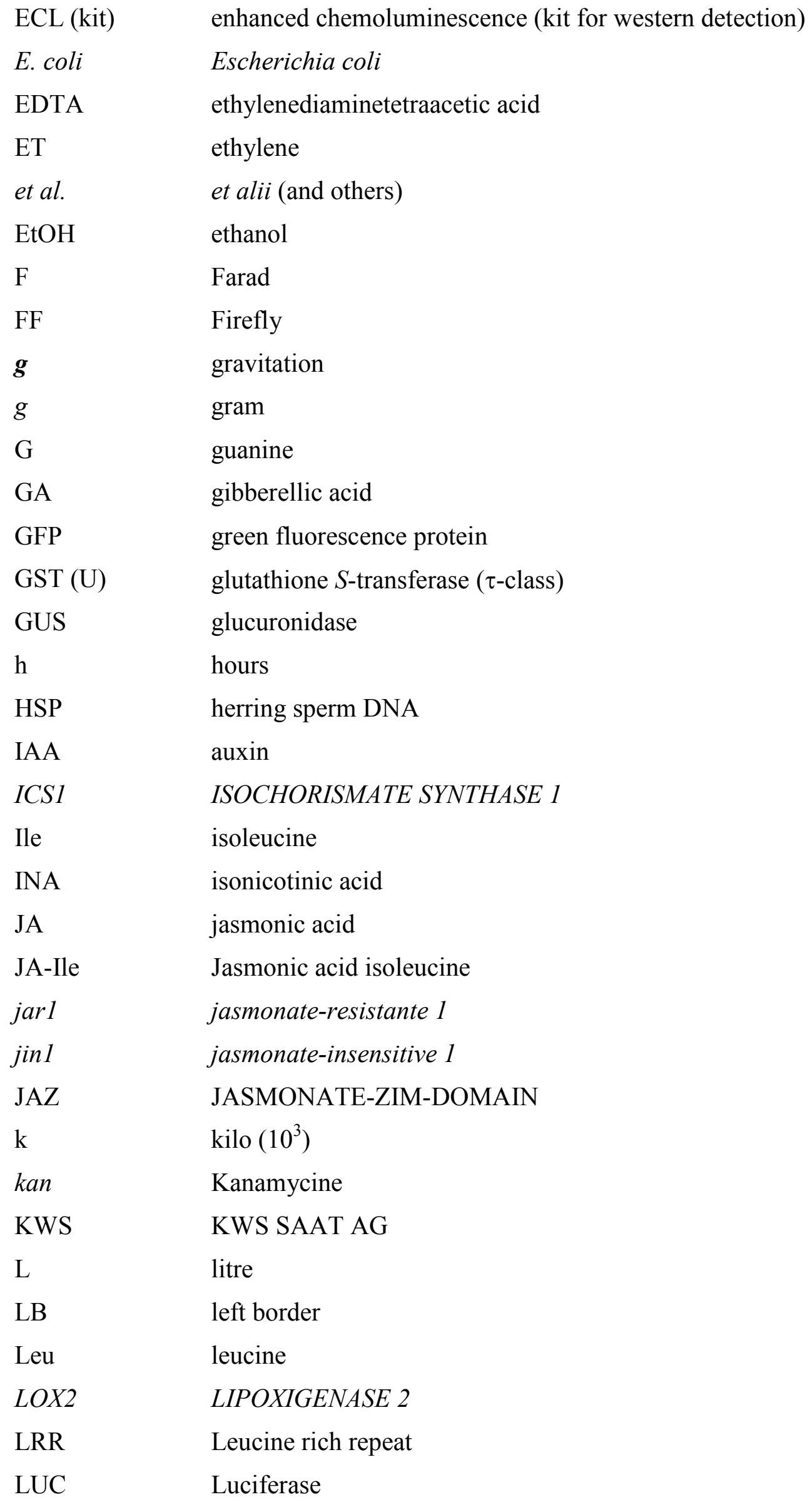




\begin{tabular}{|c|c|}
\hline$\mu$ & $\operatorname{micro}\left(10^{-6}\right)$ \\
\hline $\mathrm{m}$ & $\operatorname{mili}\left(10^{-3}\right)$ \\
\hline $\mathrm{m}$ & meter \\
\hline M & molarity [mol/L] \\
\hline MeJA & methyl jasmonate \\
\hline $\min$ & minutes \\
\hline MtN19-like & MAC9.6, Medicago truncatula N19-like \\
\hline mRNA & messenger RNA \\
\hline MS & Murahige and Skoog \\
\hline $\mathrm{n}$ & nano $\left(10^{-9}\right)$ \\
\hline NPR1 & NON-EXPRESSOR of $P R$-GENES 1 \\
\hline N-terminal & amino-terminal \\
\hline$\Omega$ & Ohm \\
\hline OD & optical density \\
\hline $\mathrm{OE}$ & over expressing \\
\hline $\mathrm{o} / \mathrm{n}$ & over night \\
\hline OPDA & 12-oxophytodienoic acid \\
\hline $\mathrm{p}$ & pico $\left(10^{-12}\right)$ \\
\hline P450 & cytochrome $\mathrm{P} 450$ \\
\hline PAA & polyacrylamide \\
\hline PAGE & polyacrylamide gelelectrophoresis \\
\hline PCR & polymerase chain reaction \\
\hline PDA & potato dextrose agar \\
\hline PDB & potato dextrose broth \\
\hline PDF1.2 & Plant defensin 1.2 \\
\hline $\mathrm{pH}$ & negative $\log ^{10}$ of proton concentration \\
\hline$P R$ & Pathogenesis related \\
\hline qRT-PCR & quantitative real time PCR \\
\hline RB & right border \\
\hline RES & reactive electrophile species \\
\hline RNA & ribonucleic acid \\
\hline RNase & ribonuclease \\
\hline ROS & reactive oxygen species \\
\hline $\mathrm{rpm}$ & rotations per minute \\
\hline RT & room temperature \\
\hline
\end{tabular}


S

SA

SCF

SCL14

SDS

SEM

$\mathrm{T}$

TEMED

TGA

TIBA

TNT

Tris

$\mathrm{u}$

$\mathrm{U}$

UV

$\mathrm{V}$

$\mathrm{v} / \mathrm{v}$

W

WT

$\mathrm{w} / \mathrm{v}$

second

salicylic acid

skip-cullin-F-box

SCARECROW-LIKE 14

sodium dodecylsulfate

Standard error mean

thymine

N,N,N',N'-tetraethylenediamine

as-1 (TGACG motive) binding bZIP transcription factors

2,3,5-triiodobenzoic acid

2,4,6-trinitrotoluene

tris-hydroxymethylamino methane

unit (quantity for enzyme activity)

uracil

ultra violet

Volt

volume per volume

Watt

wild-type

weight per volume 


\section{Summary}

In higher plants, toxic chemicals induce the expression of a set of detoxification genes. In Arabidopsis thaliana, transcriptional activation of a subset of these depends on Class II TGA transcription factors and the TGA-interacting GRAS protein SARECROWLIKE 14 (SCL14). The TGA2,5,6/SCL14-activated cytochrome P450 gene CYP81D11 has been detected in a number of microarray analyses as being highly responsive to treatments with different reactive chemicals, like the auxin transport inhibitor 2,3,5triiodobenzoic acid (TIBA), the allelocemical benzoxazolin-2(3H)-one (BOA), the explosive 2,4,6-trinitrotoluene (TNT) and phytoprostanes (highly reactive compounds generated by non-enzymatic lipid oxidation processes). In contrast to other known TGA2,5,6/SCL14-dependent genes, CYP81D11 is inducible by the plant hormone methyl jasmonate (MeJA), which is a precursor of the active hormone jasonateisoleucine (JA-Ile) that specifically binds to the receptor/co-activator complex CORONATINE INSENSITIVE1 (COI1)/JAZ.

In this thesis, we demonstrate that three distinct mechanisms of COI1 action merge on the CYP81D11 promoter: (i) the well-established function that leads to the activation of MYC2 upon action of COI1 by elevated JA-Ile levels after MeJA and pathogen treatment; (ii) a novel function that requires basal JA-Ile levels, the transcriptional activator MYC2, a MYC2 binding site in the promoter and functional JAZ repressors; and (iii) as second novel function that is independent from all the known components of COI1-dependent signalling including the ligand JA-Ile. Whole genome microarray analysis of TIBA-treated wild-type and coil plants revealed that 73 genes are induced only in the presence of COI1. Real-time RT-PCR and hierarchical cluster analysis indicated that the JA-Ile-independent COI1 function is likely to be unique for the CYP81D11 promoter under these conditions. In contrast, COI1 is important for the expression of a large set of genes even although JA-Ile levels do not increase. DARK IINDUCED11 (DIN11), for example, is expressed under extended night conditions in a COI1-dependent manner although increased JA-Ile levels cannot be detected. This novel COI1 function is constitutively activated in plant protoplasts leading to the expression of CYP81D11 and DIN11. 
While COI1 positively regulates CYP81D11, overexpression of the two NAC transcription factors ATAF1 and ANAC032 negatively effects CYP81D11 expression after TIBA as well as after MeJA treatment. 


\section{Introduction}

\subsection{Function of COI1 in jasmonic acid signal transduction}

The fatty acid-derived plant hormone jasmonic acid (JA) is involved in regulating plant growth (Staswick et al. 1992a), pollen ripening (McConn \& Browse 1996a) and defense responses against herbivorous or necrotrophic pathogens (Farmer et al. 2003). JA and its derivative methyl-jasmonate (MeJA) were long considered as the active hormones. However, the discovery of the JA-insensitive mutant jarl (jasmonate resistant 1) gave the first hint that JA-Ile is the active component in JA signaling. The jarl mutant exhibits a defect in an enzyme converting JA to its amino acid conjugates, preferentially JA-isoleucine (JA-Ile) (Staswick et al. 1992a; Staswick \& Tiryaki 2004). This was supported by studies complementing the jarl mutant by external JA-Ile application (Fonseca et al. 2009).

COI1 (CORONATINE INSENSITIVE 1) has been known for a long time as a key component of JA signaling. coil was discovered in a mutant screen for individuals that are insensitive to the bacterial phytotoxin and JA-Ile analog coronatine (Feys et al. 1994). COI1, an F-box protein, exhibits sequence homology to the auxin receptor TIR1 (TRANSPORT INHIBITOR RESPONSE 1) (Xie et al. 1998; Dharmasiri et al. 2005). F-box proteins are known to determine the specificity of SKP-CULLIN-F-box (SCF) E3 ubiquitin ligase complexes, which ubiquitinylate other proteins and thereby mark them for degradation via the $26 \mathrm{~S}$ proteasome (Moon et al. 2004). SCF ${ }^{\mathrm{TIR} 1}$ is activated by auxin and leads to the ubiquitinylation of AUX/IAA proteins, which function as repressors of auxin signaling (Tan et al. 2007). The sequence identity between COI1 and TIR1 gave the first hint for the involvement of proteasome-dependent protein degradation in JA signaling. Plants that carry defects in components of the SCF complex that are shared by $\mathrm{SCF}^{\mathrm{CO} 1}$ and $\mathrm{SCF}^{\mathrm{TIR} 1}$ are impaired in both JA and auxin signaling (Xu et al. 2002; Tiryaki \& Staswick 2002).

The targets of the $\mathrm{SCF}^{\mathrm{CO} 1}$ complex remained unknown for a long time until a group of functionally redundant JA-inducible ZIM (zinc-finger protein expressed in plant inflorescence meristem) domain proteins were identified by genetic screens and microarray analysis (Chini et al. 2007; Thines et al. 2007). These JAZ (jasmonate-ZIM 
domain) proteins show a high homology based on the conserved ZIM domain and a Cterminal Jas motive. JAZ proteins (JAZ1, JAZ3, and JAZ10) with either a mutated or a deleted Jas motif exhibit a dominant-negative effect on many JA-inducible genes (Thines et al. 2007; Chini et al. 2007). Yeast two-hybrid analysis and in vitro pull-down experiments showed an interaction of COI1 and JAZ proteins in the presence of JA-Ile or coronatine, but not in the presence of JA, MeJA (methyl jasmonate), or the JA precursor 12-oxophytodienoic acid (OPDA) (Thines et al. 2007).

Most recent interaction studies and the crystal structure of the COI1/JAZ1/coronatine complex demonstrated that JAZ proteins are essential for an efficient binding of coronatine to COI1. Furthermore, the crystal structure of this complex revealed that JAZ1 directly binds to the coronatine molecule, which is bound in the ligand binding pocket of COI1. By closing the ligand binding pocket like a clamp, JAZ1 contributes to stable ligand binding. This contribution to ligand recognition is carried out by seven amino acids located in the N-terminal part of the protein (Sheard et al. 2010). This is in contrast to the publication of Melotto et al. (2008) claiming that the C-terminal Jas domain is the COI1-interacting domain. For TIR1, it was known before that an inositol hexakisphosphate $\left(\mathrm{InsP}_{6}\right)$ molecule is bound in the center of the protein underneath the auxin binding pocket (Tan et al. 2007). Due to the high homology between TIR1 and COI1, inositol phosphates were considered as possible co-interactors of the COI1/JAZ/coronatine (JA-Ile) complex. In fact, inositol tetrakisphosphate $\left(\mathrm{InsP}_{4}\right)$ and inositol pentakisphosphate $\left(\mathrm{InsP}_{5}\right)$ were shown to promote the ligand binding of COI1 and JAZ1. As concluded from these data, a three-molecule complex consisting of COI1, a JAZ protein, and an inositol phosphate was identified as the JA-Ile (coronatine) receptor in Arabidopsis (Sheard et al. 2010).

JAZ proteins function as repressors of JA signaling by directly interacting with MYC2. In addition, a JA-Ile-independent interaction of JAZ1 and MYC2 has been shown. MYC2 is a positive transcriptional regulator of JA-responsive genes; it is involved in JA-mediated inhibition of root growth and in response to wounding. Mutants with a defect in the MYC2 transcription factor were named jin1 (jasmonate insensitive 1). Yet, the jin 1 mutant carrying a mutated MYC2 allele is fertile, which is in contrast to the coil mutant and to plants expressing a dominant-negative JAZ protein. It has been concluded that MYC2 is not the only transcriptional activator downstream of the COI1-dependent JA signaling cascade (Lorenzo et al. 2004; Berger et al. 1996). 
The presence of JA-Ile does not only promote the interaction of JAZ proteins and COI1 but also to the degradation of JAZ proteins via the $26 \mathrm{~S}$ proteasome leading to the activation of JA-responsive gene expression by MYC2. Interestingly, the truncated proteins were not only resistant to proteasomal degradation but additionally prevented the degradation of other JAZ proteins. Until now, the reason for the dominant-negative effects has not been entirely deciphered. It is presumed that heterodimers of truncated and wild-type JAZ proteins are protected against degradation and are still able to repress transcriptional activation by MYC2 (Memelink 2009; Chini et al. 2007).

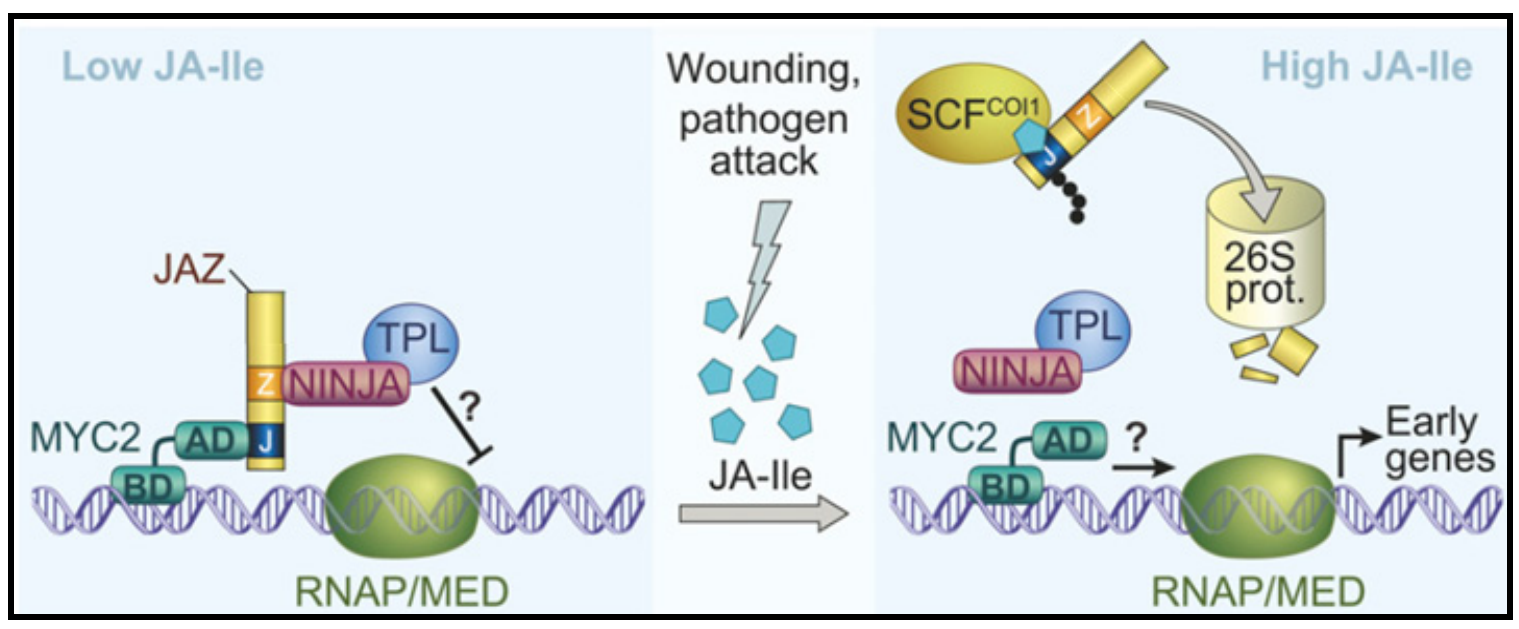

Figure 2.1: Current model of JA signal transduction in Arabidopsis thaliana

JAZ (J, Jas domain; Z, ZIM domain) proteins accumulate under conditions with low JA-Ile levels and bind to the transcription factor MYC2 (BD, DNA-binding domain; AD, activation domain). The subsequent repression of JA response genes is mediated by NINJA, which binds to the JAZ proteins and recruits the corepressor TOPLESS (TPL). The working mechanism of TPL remains unknown, so far. In response to stress, which activates JA synthesis, high levels of JA-Ile promote the interaction of $\mathrm{SCF}^{\mathrm{COI}}$ and JAZ proteins and thus ubiquitination and degradation of JAZs via the 26S proteasome (26S prot.). Upon JAZ degradation, the repression of MYC2 mediated by NINJA and TPL is removed and MYC2 can activate transcription by recruiting RNA polymerase II (RNAP), which possibly requires a mediator complex (MED). (Howe et al. 2010, modified)

A characteristic example for mediating the repression of gene expression was shown in AUX/IAA proteins (repressors of auxin-dependent genes). They comprise an EAR (ETHYLENE RESPONSE FACTOR (ERF)-associated amphiphilic repression) motif to recruit the corepressor TOPLESS (TPL), which leads to the repression of gene expression (Szemenyei et al. 2008). However, JAZ proteins lack this kind of motif. Recently, the adaptor protein NINJA (novel interactor of JAZ), which recruits the corepressor TOPLESS to the JAZ proteins was identified. NINJA interacts with the TIFY domain of JAZ proteins and binds TOPLESS via its EAR motif. This result demonstrates that auxin and JA signaling do not only share the ubiquitinylation of repressors by SCF E3 ubiquitin ligases and their degradation by the $26 \mathrm{~S}$ proteasome, but 
also the repression of their target genes by engagement of the corepressor TOPLESS (Pauwels et al. 2010).

\subsection{JA-dependent gene regulation in plant stress responses}

In plants, adaptation to stress is regulated by plant hormones (Feys \& Parker 2000; Glazebrook 2005). JA is involved in the response to herbivorous insects and to necrotrophic pathogens. To protect the plant against herbivores, JA induces two distinct defense strategies: During direct defense, plants produce enzymes or secondary metabolites that act as feeding deterrents or toxins. Indirect defense, on the other hand, uses the production of volatiles to attract enemies of the herbivores (Dicke 1999; Kessler \& Baldwin 2002). Consistently, mutants in JA synthesis or signaling were shown to be more susceptible to herbivores. Caterpillars of Pieris rapae, e.g., perform much better on coil mutants than on wild-type plants (Reymond et al. 2000). Wounding- and herbivore-induced genes like VSP2 (VEGETATIVE STORAGE PROTEIN 2) and LOX2 (LIPOXYGENASE 2) are activated by JA (Lorenzo et al. 2004).

In contrast to this, genes induced in response to necrotrophic pathogens like the plant defensin gene PDF1.2 require concomitant activation by JA and ethylene (ET). Consistently, PDF1.2 is neither expressed in the coil mutant nor in ET signaling mutants like ein2 (ethylene insensitive 2). Furthermore, both functional JA signaling and functional ET signaling are required for resistance against necrotrophic pathogens like Alternaria brassicicola (Penninckx et al. 1998) or Botrytis cinerea (Thomma et al. 1999).

These two JA-responsive pathways act partly in an antagonistic way. Although ET, in addition to JA, leads to the activation of PDF1.2, VSP2 expression is repressed under these conditions. These divergent branches of JA signaling are regulated by MYC2 on the one side and ERF1 (ET RESPONSE FACTOR 1) and ORA59 (OCTADECANOIDRESPONSIVE ARABIDOPSIS AP2/ERF 59) on the other (Lorenzo et al. 2003; Lorenzo et al. 2004; Pré et al. 2008). MYC2 activates the expression of JA-inducible genes, but at the same time it represses those activated by JA/ET. In contrast to this, ERF1 attenuates the expression of JA-inducible genes while it activates JA/ETinducible genes (Lorenzo et al. 2004). In addition to this, ERF1 overexpression was 
shown to restore resistance against necrotrophic pathogens in the coil and ein2 mutants. Therefore, it was concluded that it acts downstream of both JA and ET signaling (Lorenzo et al. 2003).

Recently, the TGA class II transcription factors, which had been known before for their involvement in salicylic acid (SA) and xenobiotic responses (Zhang et al. 2003; Mueller et al. 2008; Fode et al. 2008), were identified as additional regulators of the JA/ET response. They are required for $P D F 1$ expression in response to JA/ET and Botrytis cinerea, but have no influence on VSP2 or LOX2 (Zander et al. 2010).

Since simultaneous infection with both types of pathogens can occur, crosscommunication between the hormone pathways further fine-tunes the defense responses. SA, which regulates the defense response against biotrophs, suppresses JA and JA/ET signaling (Bostock 2005; Beckers \& Spoel 2006). This mechanism requires TGA class II transcription factors. The NPR1 (NONEXPRESSOR OF PR-GENES 1) protein, a key regulator of SA-dependent signal transduction, is only required in case of low ET levels (Spoel et al. 2003; Ndamukong et al. 2007; Leon-Reyes et al. 2009).

Vice versa, JA is capable of repressing the SA response (Nomura et al. 2005). In contrast to this, ET has a positive effect on SA-dependent defense signaling and increases the accumulation of the marker gene $P R-1$ (De Vos et al. 2005).

Cross-talk experiments using the biotroph Pseudomonas syringae and the necrotroph Alternaria brassicicola demonstrated the biological relevance of the negative influence of SA on the JA response. Due to the different lifestyles of these pathogens, plants are forced to compromise between the induced defense pathways (Spoel et al. 2007). This enables pathogens to manipulate plant defense responses: The phytotoxin coronatine, which is produced by some Pseudomonas syringae strains, mimics JA-Ile (Sheard et al. 2010) to activate JA signaling and thereby suppresses SA-mediated defense responses. The coil mutant was more resistant in these experiments (Nomura et al. 2005).

In addition, abscisic acid (ABA), a plant hormone predominantly involved in abiotic stress, was shown to influence JA responses. In contrast to SA, which represses JA as well as JA/ET signaling, ABA represses JA/ET-mediated gene expression but promotes the expression of the JA-inducible gene VSP2 (Anderson et al. 2004). 


\subsection{Detoxification of xenobiotics in plants}

Xenobiotics ("life-foreign substances") are compounds that do not occur naturally in the respective organisms or at least occur in much lower concentrations. Plants are challenged by different kinds of xenobiotics from diverse sources. Characteristic examples are pathogens producing toxins to harm the plant and gain nutrients, neighboring plants producing allelochemicals to restrict germination or growth of competitors, and humans using agrochemicals or releasing industrial chemicals into the environment. Xenobiotics can cause severe damage to the plants, either after direct application or after being taken up from the soil.

Since the evolutionary arms race between plants or between plants and pathogens created a nearly ubiquitous threat, plants developed pathways to detoxify a variety of harmful substances. In general, the plant process to detoxify a xenobiotic is divided into three phases: phase I, activation; phase II, conjugation; and phase III, compartmentation.

During the first phase, xenobiotics are activated by oxidation, hydrolysis or reduction via enzymes such as cytochrome P450 monooxygenases, esterases, amidases, peroxidases and reductases. The activated metabolites provided by phase I are more reactive, and therefore may be sometimes even more dangerous to the cell (Sandermann Jr. 1992; Cole 1994; Dohn \& Krieger 1981). Their toxicity decreases upon conjugation to hydrophilic endogenous metabolites, mainly to sugars like glucose and malonate or to glutathione. Which conjugates are produced often depends on the reactive chemical groups of the xenobiotics. It is not necessary that all xenobiotics be activated by firstphase reactions; molecules already possessing suitable residues can directly be metabolized in phase II. For example, electrophilic substances can be directly conjugated to glutathione, with the reaction being catalyzed by glutathione $S$ transferases (Armstrong 1991; Dixon et al. 1998). The conjugation of UDP-glucose (uridine diphospho-glucose) to hydroxyl, sulfhydryl, amino and carboxyl groups of xenobiotics by glycosyltransferases represents another conjugation reaction. Although glucose is the most commonly used sugar in this kind of conjugation, various monosaccharides, disaccharides and amino acids may also be conjugated to xenobiotics (Cole 1994; Coleman et al. 1997). The products obtained from these chemical transformations are usually less toxic and more hydrophilic than the parent components. Yet, the conjugates produced are not accumulated in the cytoplasm, because they may inhibit the action of conjugation enzymes by product inhibition. After phase II reactions, 
the xenobiotic conjugates are transported either to the vacuole or to the apoplastic space by $\mathrm{ABC}$-transporters. In the cell wall, xenobiotic conjugates may be further conjugated to lignin or cellulose (Sandermann 1994; Coleman et al. 1997). As detoxification of xenobiotics in plants proceeds analogous to the human liver mechanism, the term "green liver" has been proposed to describe phytotransformation.

\subsection{Gene regulation in response to xenobiotic stress in plants}

The metabolization of diverse xenobiotics has been studied extensively in plants and in mammals, but little is known about the transcriptional regulation of the enzymes involved in this process in plants. In contrast, different ways of transcriptional regulation of genes that are involved in detoxification have been elucidated in mammals. Some of the predominant examples of xenobiotic receptors are the aryl hydrocarbon nuclear receptor (AhR), the pregnane $\mathrm{X}$ receptor (PXR), and the constitutive androstane receptor (CAR), which bind promiscuously to structurally diverse xenobiotics. Upon xenobiotic ligand binding, the cytosolic transcription factor AhR is translocated into the nucleus; there, it dimerizes with its co-activator Arnt (AhR nuclear translocator) to activate the transcription of its target genes (Denison \& Nagy 2003). In a similar way, PXR and CAR dimerize with the 9-cis-retinoic acid receptor upon ligand binding and subsequently lead to transcriptional activation (Kliewer et al. 2002).

Another mammalian system to sense xenobiotics is redox regulated. Since many xenobiotics are electrophilic, they are able to oxidize biomolecules. This leads to redox changes, which are sensed by receptors. For instance, Nrf2 (NF-E2-related factor 2) is tethered in the cytoplasm by binding to reduced Keap1 (Kelch-like ECH-associated protein 1). Electrophilic stress causes the oxidation of two critical cysteine residues of Keap1, resulting in Nrf2 release, which then translocates into the nucleus. In the nucleus, it heterodimerizes with a small Maf protein and binds to the antioxidant response element/electrophile response element (ARE/EpRE) to initiate the transcription of its target genes (Nguyen et al. 2004).

The mechanisms by which xenobiotic stress leads to transcriptional activation in plants remain relatively unknown. Previous studies have reported the involvement of TGA (TGACG motif-binding) transcription factors in this process (Mueller et al. 2008; Fode et al. 2008; Baerson et al. 2005). TGA transcription factors are a group of basic-leucine- 
zipper (bZIP) transcriptional regulators, named after their ability to bind TGACG motifs (Katagiri et al. 1989).

After treatment of plants with phytoprostanes (highly reactive compounds generated by non-enzymatic lipid oxidation processes), a subset of putative detoxification genes was induced. The expression of $60 \%$ of the genes is reduced in the tga2,5,6 mutant (Mueller et al. 2008). Furthermore, TGACG motif enrichment was demonstrated in the promoter regions of genes that are responsive to the allelochemical compound benzoxazolin2(3H)-one (BOA) (Baerson et al. 2005) and the auxin transport inhibitor 2,3,5triiodobenzoic acid (TIBA) (Fode et al. 2008).

TGA transcription factors were initially reported as mediators of the SA response (Zhang et al. 2003). In addition, many genes exhibiting TGA binding sites in their upstream region, among them many GST genes (Wagner et al. 2002) and synthetic promoters containing TGA binding motifs (Redman et al. 2002) are additionally activated by the auxin analog 2,4-dichlorophenoxyacetic acid (2,4-D). While the only SA-inducible genes require the known TGA interacting ankyrin repeat protein NPR1 (NONEXPRESSOR OF PR) (Zhang et al. 2003), the SA- and 2,4-D-inducible promoters are NPR1 independent (Butterbrodt et al. 2006). Since the induction of these promoters by SA and 2,4-D requires unphysiologically high concentrations (Pascuzzi et al. 1998), a general response to xenobiotic stress rather than specific SA or auxin signaling was postulated (Zhang \& Singh 1994).

Previous studies performing yeast two-hybrid assays in order to find proteins interacting with TGA2 identified SCL14 (SCARECROW-LIKE 14) (Siemsen 2005, Fode 2008). SCL14 was demonstrated to be an additional component in the regulation of detoxification genes (Fode et al. 2008). Microarray analysis comparing the transcriptome of scl14 knockout plants with those of Col-0 wild-type plants and plants ectopically expressing SCL14 revealed that SCL14 proteins activate the expression of several genes that are putatively involved in the detoxification of xenobiotics, such as glutathione $S$-transferases, (UDP-)glycosyltransferases and cytochrome P450 proteins (Siemsen 2005; Fode 2008).

SCL14 is a member of the GRAS protein family, named after the founding members GIBBERELLIN ACID INSENSITIVE (GAI), REPRESSOR of GA1 (RGA), and SCARECROW (SCR) (Pysh et al. 1999). The GRAS family of proteins, which is unique to plants, includes 33 members in Arabidopsis. They exhibit diverse functions in plant growth and development (Bolle 2004). GRAS proteins contain a unique 
$\mathrm{N}$ terminus and a conserved C-terminal GRAS domain, which is defined by two leucine-rich regions (LHRI and LHRII) and three characteristic amino acid signatures: VHIID, PFYRE, and SAW (Bolle 2004). Although GRAS proteins were classified as transcriptional regulators, direct DNA binding has not been shown for any of them (Tian et al. 2004). DELLA proteins are a well-investigated group of GRAS proteins, which act as inhibitors of GA signaling (Hartweck 2008). Recently, it was shown that they regulate gene expression via the binding of transcriptional activators, the PIF (PHYTOCHROME-INTERACTING FACTOR) proteins, by preventing their binding to DNA (de Lucas et al. 2008).

Chromatin immunoprecipitation (ChIP) analysis revealed that recruitment of SCL14 to its target promoters of the CYP81D11, MtN19-like and GSTU7 genes depended on TGA2,5,6. In contrast to this, binding of TGA class II transcription factors to TGACG motifs occurred in an SCL14-independent manner. This indicates that the SCL14/TGA complex binds to its target promoters via the DNA binding ability of the TGA factors. Especially $C Y P 81 D 11$ shows strong induction in response to a variety of xenobiotics, such as TIBA, isonicotinic acid (INA), SA and 2,4-D. The involvement of SCL14 and TGA2,5,6 in xenobiotic detoxification is further supported by the ability of ectopically expressed SCL14 to mediate increased tolerance to these xenobiotics (TIBA, INA, SA and 2,4-D) compared to the wild-type, whereas scl14 and tga2,5,6 mutant plants exhibited higher susceptibility (Fode 2008).

Three studies investigating xenobiotic stress in response to TIBA, BOA and phytoprostanes (Mueller et al. 2008; Fode et al. 2008; Baerson et al. 2005) and a study analyzing the response to cis-jasmone $(\mathrm{CJ})$ performed microarray analyses. All of them reveal CYP81D11 as one of the most strongly up-regulated genes. Additionally, serial analysis of gene expression (SAGE) revealed that this gene was up-regulated in response to the explosive agent TNT (Ekman et al. 2003).

Up to now, the catalytic reaction of CYP81D11 has remained unknown. Furthermore, a function for CYP81D11 has only been reported for the attraction of insects after CJ treatment. CJ is a plant-derived volatile released as part of the floral volatile bouquet and in response to herbivore attacks. It attracts the aphid parasitoid Aphidius ervi, as an "indirect induced defense" response. CJ-treated cyp81d11 knockout mutants were unable to attract these aphid parasitoids, while A. ervi spent twice as much time on CJtreated wild-type plants compared to untreated ones. The above observation revealed the 
importance of CYP81D11 in CJ-dependent indirect herbivore defense (Matthes et al. 2010; Bruce et al. 2008). 


\subsection{Aim of this study}

This study is based on the thesis of Benjamin Fode who demonstrated the involvement of a TGA2,5,6/SCL14 complex in gene regulation after chemical-induced stress. As a direct target gene of this complex, he identified the cytochrome P450 gene CYP81D11. He further demonstrated a strong induction of this gene and its co-regulation with further SCL14 target genes in response to several chemicals.

A unique and unusual feature of the CYP81D11 gene was reported by Mueller et al. (2008): In contrast to many xenobiotic-induced genes, CYP81D11 is induced additionally by JA. Moreover, its response to reactive phytoprostanes was dependent on COI1. Based on this observation the following questions were addressed in this thesis:

- What is the role of JA and components of the JA signal transduction pathway in the regulation of the expression of CYP81D11?

- Do this mechanisms control other genes induced by xenobiotic stress?

- Which role plays the SCL14/TGA2,5,6 complex for the regulation of CYP81D11 and other JA-responsive genes after JA treatment?

- Are the transcription factors ATAF1 and ANAC032 that are co-regulated with CYP81D11 in response to xenobiotic, but are independent of COI1, involved in the regulation of CYP81D11? 


\section{$3 \quad$ Materials and methods}

\subsection{Materials}

\subsubsection{Equipement}

\begin{tabular}{|c|c|c|}
\hline Device & Model & Source \\
\hline Autoclave & $3870 \mathrm{ELV}$ & Tuttnauer \\
\hline Automatic pipettes & & Gilson \\
\hline Balance & SPO52; SAC62; 1207MP2 & Scaltec; Satorius \\
\hline Blotting device & & University of Göttingen \\
\hline $\begin{array}{l}\text { Chambers for gel } \\
\text { electrophoresis }\end{array}$ & & University of Göttingen \\
\hline Cooling centrifuge & Sorvall RC 5B Plus & DuPont \\
\hline Cooling centrifuge & Rotina 35R & Hettich \\
\hline Cooling microcentrifuge & Mikro 200R & Hettich \\
\hline Counting chamber & Fuchs-Rosenthal & Brand \\
\hline Counting chamber & Thoma & \\
\hline Digital camera & Powershot A510 & Canon \\
\hline Electroporator & Gene Pulser ${ }^{\circledR}$ II & BioRad \\
\hline Gel documentation device & & MWG Biotech \\
\hline Heating block & & Boekel Scientific \\
\hline Heated stirrer & RCT basic & IKA Labortechnik \\
\hline Heated shaker & Thermomixer 5436 & Eppendorf \\
\hline Ice machine & Af20 & Scotsman \\
\hline Incubator & & WTC binder; Memmert \\
\hline Microcentrifuge & Biofuge pico & Heraeus Christ \\
\hline Microcentrifuge, cooled & 5403 & Eppendorf \\
\hline Microscope & DM 5000B + CTR 5000 & Leica \\
\hline PCR cycler & $\begin{array}{l}\text { MiniCycler }{ }^{\mathrm{TM}} \text { PTC-150, } \\
\text { iCycler }\end{array}$ & MJ Research, Biorad \\
\hline $\mathrm{pH}$ meter & HI 9321 & Hanna Instruments \\
\hline Photometer & Unikon $720 \mathrm{LC}$ & Kontron \\
\hline $\begin{array}{l}\text { Photometer for microtiter } \\
\text { plates }\end{array}$ & MRX Dynex Plate Reader & Dynex \\
\hline Real-time RT-PCR cycler & iCycler & BioRad \\
\hline
\end{tabular}




\begin{tabular}{|l|l|l|}
\hline Device & Model & Source \\
\hline $\begin{array}{l}\text { Photometer for the } \\
\text { calculation of DNA/RNA } \\
\text { concentrations }\end{array}$ & GeneQuant II, NanoVue & Pharmacia, GE Healthcare \\
\hline Scanner & ScanJet 4c & Hewlett-Packard \\
\hline Sequencer & ABI PRISM 3100 & Perkin-Elmer \\
\hline Sonication device & Soniprep 150 & MSE \\
\hline Clean bench & Microflow Laminar & Nunc \\
\hline Clean bench & Microflow Biohazard & Nunc \\
\hline UV transilluminator & FLX-20 M & Vilber Lourmat \\
\hline Water deionization device & Option 4, Maxima & ELGA \\
\hline Vacuum pump & Cyclo 1 & Roth \\
\hline Vortex & L46 & $\begin{array}{l}\text { Labinco BV, The } \\
\text { Netherlands }\end{array}$ \\
\hline
\end{tabular}

\subsubsection{Consumables}

\begin{tabular}{|l|l|}
\hline Product & Source \\
\hline \hline Blotting paper 3MM & Whatman \\
\hline Filter paper Miracloth & Calbiochem \\
\hline $\begin{array}{l}\text { 96-well microtiter plates, white, flat- } \\
\text { bottom }\end{array}$ & Greiner bio-one \\
\hline Microtiter plates & Roth \\
\hline Parafilm M & American National Can \\
\hline Plastics one-way material & $\begin{array}{l}\text { Biozym; Eppendorf; Greiner; Roth; } \\
\text { Sarstedt }\end{array}$ \\
\hline Pump aerosol can & Roth \\
\hline PVDF membrane Immobilon-P & Millipore \\
\hline X-ray film Cronex 5 & Agfa, Belgium \\
\hline
\end{tabular}




\subsubsection{Chemicals}

\begin{tabular}{|c|c|}
\hline Chemical & Source \\
\hline $\begin{array}{l}30 \%(\mathrm{w} / \mathrm{v}) \text { acrylamide/N,N'- } \\
\text { methylenebisacrylamide }(37.5: 1)\end{array}$ & Roth \\
\hline Agarose SeaKem LE & Biozym \\
\hline Ampicillin & AGS \\
\hline APS (ammonium persulfate) & Biometra \\
\hline Benoxacor & Sigma \\
\hline BOA & Sigma \\
\hline Bradford reagent & Roth \\
\hline Bromophenol blue & Roth \\
\hline BSA & Serva \\
\hline Coomassie Brilliant Blue G-250 & BioRad \\
\hline Dimethyl sulfoxide (DMSO) & Sigma \\
\hline dNTPs & MBI; Roth \\
\hline Ethylene diaminetetraacetate (EDTA) & AppliChem \\
\hline Ethidiumbromide & Roth \\
\hline Fat-free milk powder & Glücksklee \\
\hline Fluoresceine & BioRad \\
\hline Gentamycin & Duchefa \\
\hline IAA & Roth \\
\hline Jasplakinolide & Invitrogen \\
\hline Kanamycin & Sigma \\
\hline$\beta$-Mercaptoethanol & Roth \\
\hline Methyl jasmonate & Sigma-Aldrich \\
\hline Murashige and Skoog medium & Duchefa \\
\hline Orange $\mathrm{G}$ & Sigma \\
\hline Phenol & Sigma \\
\hline Rifampicin & Duchefa \\
\hline X-ray developer LX24 & Kodak \\
\hline X-ray fixer AL4 & Kodak \\
\hline Select Agar Life & Technologies \\
\hline Select Yeast Extract & GIBCO BRL \\
\hline SYBR Green I & Cambrex \\
\hline
\end{tabular}




\begin{tabular}{|l|l|}
\hline Chemical & Source \\
\hline TEMED & Roth \\
\hline TIBA & Sigma \\
\hline Triton X-100 & Roth \\
\hline
\end{tabular}

\subsubsection{Kits}

\begin{tabular}{|l|l|}
\hline Enzyme/Kit & Source \\
\hline $\begin{array}{l}\text { BigDye Terminator Cycle Sequencing } \\
\text { Ready Reaction Kit v.3.1 }\end{array}$ & Perkin-Elmer Corporation \\
\hline BioTaq DNA polymerase & Bioline \\
\hline $\begin{array}{l}\text { Desoxyribonuclease I (DNase I) RNase } \\
\text { free }\end{array}$ & MBI Fermentas \\
\hline Dual-luciferase reporter assay system & Promega \\
\hline $\begin{array}{l}\text { Enhanced Chemiluminescence Plus Kit } \\
\text { (ECL+) }\end{array}$ & GE Healthcare \\
\hline HiDi-Mix & ABI PRISM \\
\hline Immolase DNA polymerase & Bioline \\
\hline iProof High-Fidelity DNA Polymerase & BioRad \\
\hline Nucleo Spin Extract II & Macherey-Nagel \\
\hline Nucleo Spin Plasmid & Macherey-Nagel \\
\hline Pierce 660nm Protein Assay Kit & Thermo Scientific \\
\hline Reverse transcriptase H- & MBI Fermentas \\
\hline Restriction enzymes & MBI Fermentas, New England Biolabs \\
\hline RNeasy & Qiagen \\
\hline RNase A (DNase free) & Qiagen \\
\hline T4-DNA ligase & MBI Fermentas \\
\hline
\end{tabular}

\subsubsection{Standards}

\begin{tabular}{|l|l|}
\hline Standard & Source \\
\hline GeneRuler DNA Ladder Mix & MBI Fermentas \\
\hline Prestained Protein Ladder & MBI Fermentas \\
\hline
\end{tabular}




\subsubsection{Antibodies}

\begin{tabular}{|l|l|}
\hline Antibody & Source \\
\hline HA-tag antibody ChIP grade & Abcam \\
\hline
\end{tabular}

\subsubsection{DNAs}

\subsubsection{Plasmids}

\begin{tabular}{|c|c|c|}
\hline Plasmid & Description & Reference \\
\hline pAlligator2 & $\begin{array}{l}\text { gateway }{ }^{\mathrm{TM}} \text { vector for plant } \\
\text { transformation, contains the } C a M V 35 S \\
\text { promoter, the nos terminator, a } 3 \times \mathrm{HA}- \\
\text { tag (N-terminal), and a GFP selection } \\
\text { marker under control of the seed- } \\
\text { specific promoter } A t 2 S 3, \mathrm{spn}^{r}\end{array}$ & $\begin{array}{l}\text { http://www.isv.cn } \\
\text { rs-gif.fr/JG/ } \\
\text { alligator/intro.ht } \\
\text { ml }\end{array}$ \\
\hline pAlligator2-COI1 & $\begin{array}{l}\text { pAlligator } 2 \text { derivative containing the } \\
\text { COI1 coding sequence }\end{array}$ & $\begin{array}{l}\text { Sonja Schöttle, } \\
\text { personal } \\
\text { communication }\end{array}$ \\
\hline pAllogator2-COI1-85 & $\begin{array}{l}\text { pAlligator } 2 \text { derivative containing the } \\
\text { coding sequence for a COI1 protein } \\
\text { with an amino acid substitution of aa } \\
85-88 \text { from RAAM to HFAD }\end{array}$ & $\begin{array}{l}\text { Sonja Schöttle, } \\
\text { personal } \\
\text { communication }\end{array}$ \\
\hline pAlligator2-COI1-G98D & $\begin{array}{l}\text { pAlligator } 2 \text { derivative containing the } \\
\text { coding sequence for a COI1 protein } \\
\text { with an amino acid exchange of aa } 98 \\
\text { from G to D }\end{array}$ & $\begin{array}{l}\text { Sonja Schöttle, } \\
\text { personal } \\
\text { communication }\end{array}$ \\
\hline pB2GW7 & $\begin{array}{l}\text { gateway }{ }^{\mathrm{TM}} \text { vector for plant } \\
\text { transformation, contains the } C a M V 35 S \\
\text { promoter and a BASTA resistance gene } \\
\text { as selection marker, } \text { spn }^{r}\end{array}$ & $\begin{array}{l}\text { (Karimi et al. } \\
\text { 2002) }\end{array}$ \\
\hline pB2GW7-HA & $\begin{array}{l}\text { gateway }{ }^{\mathrm{TM}} \text { vector for plant } \\
\text { transformation, contains the CaMV } 35 S \\
\text { promoter, a } 3 \times \text { HA-tag (N-terminal), } \\
\text { and a BASTA resistance gene as } \\
\text { selection marker, } \text { spn }^{r}\end{array}$ & $\begin{array}{l}\text { C. Thurow, } \\
\text { personal } \\
\text { communication }\end{array}$ \\
\hline pB2GW7-HA-ANAC032 & $\begin{array}{l}\text { pB2GW7-HA derivative containing the } \\
A N A C 032 \text { coding sequence }\end{array}$ & this thesis \\
\hline pB2GW7-HA-ATAF1 & $\begin{array}{l}\text { pB2GW7-HA derivative containing the } \\
\text { ATAF1 coding sequence }\end{array}$ & this thesis \\
\hline pBGWFS7 & $\begin{array}{l}\text { gateway }{ }^{\mathrm{TM}} \text { vector for plant } \\
\text { transformation, contains the GUS } \\
\text { reporter gene and a BASTA resistance } \\
\text { gene as selection marker, } \text { spn }^{r}\end{array}$ & $\begin{array}{l}\text { (Karimi et al. } \\
\text { 2002) }\end{array}$ \\
\hline
\end{tabular}




\begin{tabular}{|c|c|c|}
\hline Plasmid & Description & Reference \\
\hline pBGWL7 & $\begin{array}{l}\text { gateway }{ }^{\mathrm{TM}} \text { vector for plant } \\
\text { transformation, contains the firefly (ff) } \\
\text { luciferase reporter gene and a BASTA } \\
\text { resistance gene as selection marker, } s p n^{r}\end{array}$ & $\begin{array}{l}\text { (Karimi et al } \\
\text { 2002) }\end{array}$ \\
\hline pBGWFS-cyp-prom & $\begin{array}{l}\text { pBGWFS7 derivative containing an } \\
\text { 894-bp CYP81D11 promoter fragment } \\
\text { and the CYP81D11 5' UTR upstream of } \\
\text { the GUS reporter gene, } s p n^{r}\end{array}$ & this thesis \\
\hline pBGWFS-cyp-mas1 & $\begin{array}{l}\text { pBGWFS7 derivative containing an } \\
\text { 894-bp CYP81D11 promoter fragment } \\
\text { with mutated as } 1 \text {-like element and the } \\
\text { CYP81D11 5' UTR upstream of the } \\
\text { GUS reporter gene, } \text { spn }^{r}\end{array}$ & this thesis \\
\hline $\begin{array}{l}\text { pBGWFS-cyp-prom-mG- } \\
\text { box }\end{array}$ & $\begin{array}{l}\text { pBGWFS7 derivative containing an } \\
\text { 894-bp CYP81D11 promoter fragment } \\
\text { with mutated G-boxes and the } \\
\text { CYP81D11 5' UTR upstream of the } \\
\text { GUS reporter gene, } s p n^{r}\end{array}$ & this thesis \\
\hline $\begin{array}{l}\text { pBGWFS-cyp-mas1-mG- } \\
\text { box }\end{array}$ & $\begin{array}{l}\text { pBGWFS7 derivative containing an } \\
\text { 894-bp CYP81D11 promoter fragment } \\
\text { with mutated as } 1 \text {-like element and G- } \\
\text { boxes and the CYP81D11 5' UTR } \\
\text { upstream of the GUS reporter gene, } s p n^{r}\end{array}$ & this thesis \\
\hline pBGWL-cyp-prom & $\begin{array}{l}\text { pBGWL7 derivative containing an } \\
\text { 894-bp CYP81D11 promoter fragment } \\
\text { and the CYP81D11 5' UTR upstream of } \\
\text { the GUS reporter gene, spn }{ }^{r}\end{array}$ & this thesis \\
\hline pBGWL-cyp-mas1 & $\begin{array}{l}\text { pBGWL7 derivative containing an } \\
\text { 894-bp CYP81D11 promoter fragment } \\
\text { with mutated as } 1 \text {-like element and the } \\
\text { CYP81D11 5' UTR upstream of the } f f \\
\text { luciferase reporter gene, } s p n^{r}\end{array}$ & this thesis \\
\hline pBGWL-cyp-prom-mG-box & $\begin{array}{l}\text { pBGWL7 derivative containing an } \\
\text { 894-bp CYP81D11 promoter fragment } \\
\text { with mutated G-boxes and the } \\
\text { CYP81D11 5' UTR upstream of the ff } \\
\text { luciferase reporter gene, } \text { spn }^{r}\end{array}$ & this thesis \\
\hline pBGWL-cyp-mas1-mG-box & $\begin{array}{l}\text { pBGWL7 derivative containing an } \\
\text { 894-bp CYP81D11 promoter fragment } \\
\text { with mutated as } 1 \text {-like element and G- } \\
\text { boxes and the CYP81D11 5' UTR } \\
\text { upstream of the ff luciferase reporter } \\
\text { gene, spn }\end{array}$ & this thesis \\
\hline pDONOR201 & $\begin{array}{l}\text { gateway }{ }^{\mathrm{TM}} \text { entry vector for cloning of } \\
\text { PCR fragments, } \mathrm{km}^{r}\end{array}$ & Invitrogen \\
\hline pDONOR201-cyp-prom & $\begin{array}{l}\text { pDONOR201 derivative containing an } \\
\text { 894-bp CYP81D11 promoter fragment } \\
\text { and the CYP81D11 5' UTR, } \mathrm{km}^{r}\end{array}$ & this thesis \\
\hline
\end{tabular}




\begin{tabular}{|c|c|c|}
\hline Plasmid & Description & Reference \\
\hline pDONOR201-cyp-mas 1 & $\begin{array}{l}\text { pDONOR201 derivative containing an } \\
894-\mathrm{bp} C Y P 81 D 11 \text { promoter fragment } \\
\text { with mutated as } 1 \text {-like element and the } \\
\text { CYP81D11 5' UTR, } \mathrm{km}^{r}\end{array}$ & this thesis \\
\hline $\begin{array}{l}\text { pDONOR201-cyp-prom- } \\
\text { mG-box }\end{array}$ & $\begin{array}{l}\text { pDONOR201 derivative containing an } \\
\text { 894-bp CYP81D11 promoter fragment } \\
\text { with mutated G-boxes and the } \\
\text { CYP81D11 5' UTR, } \mathrm{km}^{r}\end{array}$ & this thesis \\
\hline $\begin{array}{l}\text { pDONOR201-cyp-mas1- } \\
\text { mG-box }\end{array}$ & $\begin{array}{l}\text { pDONOR201 derivative containing an } \\
894-\mathrm{bp} C Y P 81 D 11 \text { promoter fragment } \\
\text { with mutated as } 1 \text {-like element and G- } \\
\text { boxes and the CYP81D11 5' UTR, } \mathrm{km}^{r}\end{array}$ & this thesis \\
\hline p70SRUC & $\begin{array}{l}\text { Plasmid containing the Renilla } \\
\text { luciferase gene controlled by the } \\
70 \text { S promoter, } a m p^{r}\end{array}$ & KWS \\
\hline
\end{tabular}

\subsubsection{Oligonucleotides}

Oligonucleotides were synthesized by Invitrogen. QuantiTect Primer Assays from Qiagen contain both forward and reverse primers. They are indicated as "QPA" and are described at http://www1.qiagen.com/Products/Pcr/QuantiTect/PrimerAssays.aspx.

Oftern used QuantiTect primers were imitated on the basis of sequence analysis of a cloned PCR fragment after amplification with the original assay primers. These primers were diluted and mixed to result in a $4 \mu \mathrm{M}$ stock solution containing forward and reverse primers.

\begin{tabular}{|c|c|c|c|}
\hline Gene & Oligonucleotide & Sequence $5^{\prime} \rightarrow 3^{\prime}$ & Source \\
\hline \multicolumn{4}{|c|}{ Quantitative real-time RT-PCR primers } \\
\hline$A A C T 1$ & QT00846762 & QPA & Qiagen \\
\hline$A N A C 032$ & QT00743561 & QPA & Qiagen \\
\hline$A S N 1$ & $\begin{array}{l}\text { Q_ASN1_forw } \\
\text { Q_ASN1_rev }\end{array}$ & $\begin{array}{l}\text { TTCTTGAGCTTTCTCGCAGAT } \\
\text { CCGTTCTGATATAAGCCACTCC }\end{array}$ & Invitrogen \\
\hline ATAF1 & QT00866439 & QPA & Qiagen \\
\hline ATSIP2 & QT00793912 & QPA & Qiagen \\
\hline COR78 & QT00840406 & QPA & Qiagen \\
\hline CYP81D11 & $\begin{array}{l}\text { Q_CYP81D11_forw } \\
\text { Q_CYP81D11_rev }\end{array}$ & $\begin{array}{l}\text { TTATGATACTTGCCGGGACTG } \\
\text { CGATTTCGTCTTTGCC }\end{array}$ & Invitrogen \\
\hline DIN11 & QT00788424 & QPA & Qiagen \\
\hline GSTU1 & QT00759423 & QPA & Qiagen \\
\hline
\end{tabular}




\begin{tabular}{|c|c|c|c|}
\hline Gene & Oligonucleotide & Sequence $5^{\prime} \rightarrow 3^{\prime}$ & Source \\
\hline GSTU4 & QT00759402 & QPA & Qiagen \\
\hline GSTU7 & QT00759381 & QPA & Qiagen \\
\hline ICS1 & QT00893473 & QPA & Qiagen \\
\hline$J A Z 10$ & QT00828401 & QPA & Qiagen \\
\hline$L O X 2$ & QT00785309 & QPA & Qiagen \\
\hline MYC2 & QT00872333 & QPA & Qiagen \\
\hline$P D F 1.2$ & $\begin{array}{l}\text { PDF1.2 RT fwd } \\
\text { PDF1.2 RT rev }\end{array}$ & $\begin{array}{l}\text { CTTGTTCTCTTTGCTGCTTTC } \\
\text { CATGTTTGGCTCCTTCAAG }\end{array}$ & Invitrogen \\
\hline$V S P 2$ & $\begin{array}{l}\text { VSP2 fwd RT } \\
\text { VSP2 rev RT }\end{array}$ & $\begin{array}{l}\text { CAAACTAAACAATAAACCATACC } \\
\text { ATAA } \\
\text { GCCAAGAGCAAGAGAAGTGA }\end{array}$ & Invitrogen \\
\hline at $3 g 23550$ & QT00777994 & QPA & Qiagen \\
\hline \multicolumn{4}{|c|}{ Primers for genotyping } \\
\hline dde2-2 & $\begin{array}{l}\text { dde2-2_up } \\
\text { dde2-2_rp }\end{array}$ & $\begin{array}{l}\text { AATCGTAGGACCAATCAAAGACC } \\
\text { G } \\
\text { GGTGGTAGACTAAATGTATGGAT } \\
\text { GAGAGG }\end{array}$ & Invitrogen \\
\hline jarl-1 & $\begin{array}{l}\text { jar1-1_up } \\
\text { jar1-1_rp }\end{array}$ & $\begin{array}{l}\text { CGGATAAGAGATGGCAATACAA } \\
\text { GG } \\
\text { AAACTGTGGTCTCAATGGAAACG }\end{array}$ & Invitrogen \\
\hline atafl-1/-2 & $\begin{array}{l}\text { ATAF1_UP } \\
\text { ATAF1_RP }\end{array}$ & $\begin{array}{l}\text { CGCCAAGTTTCAGAGGTAGAGAG } \\
\text { AG } \\
\text { TAAAACGGTCTCGTGTTGCCATA } \\
\text { A }\end{array}$ & Invitrogen \\
\hline SALK_012253 & $\begin{array}{l}\text { SALK_012253_UP } \\
\text { SALK_012253_RP }\end{array}$ & $\begin{array}{l}\text { TTTTTAATTACGGCGGAAAGAGA } \\
\text { ATAG } \\
\text { CTTAATACCAACCGGTTTAGGAC } \\
\text { G }\end{array}$ & Invitrogen \\
\hline SALK_132588 & $\begin{array}{l}\text { SALK_132588_UP } \\
\text { SALK_132588_RP }\end{array}$ & $\begin{array}{l}\text { ACCGGTTTACAATTTACAGACAT } \\
\text { GGC } \\
\text { TTGCTTCCTGAAAATAACAACAC } \\
\text { AATACAG }\end{array}$ & Invitrogen \\
\hline $\mathrm{JAZ} 1 \Delta 3 \mathrm{~A}$ & $\begin{array}{l}\text { JAZ1_up_GW } \\
\text { OCG_42 }\end{array}$ & $\begin{array}{l}\text { GGGGACAAGTTTGTACAAAAAA } \\
\text { GCAGGCTTCATGTCGAGTTCTAT } \\
\text { GGAATGTTCTG } \\
\text { TAGCGATCCAGACTGAATGCCAC } \\
\text { A }\end{array}$ & Invitrogen \\
\hline \multicolumn{4}{|c|}{ Primers for cloning } \\
\hline$A N A C 032$ & $\begin{array}{l}\text { ANAC032_GW_UP } \\
\text { ANAC032_GW_RP }\end{array}$ & $\begin{array}{l}\text { GGGGACAAGTTTGTACAAAAAA } \\
\text { GCAGGCTTCATGATGAAATCTGG } \\
\text { GGCTGATTTG } \\
\text { GGGGACCACTTTGTACAAGAAAG } \\
\text { CTGGGTCTCAGAAAGTTCCCTGC } \\
\text { CTAACCAC }\end{array}$ & Invitrogen \\
\hline
\end{tabular}




\begin{tabular}{|c|c|c|c|}
\hline Gene & Oligonucleotide & Sequence $5^{\prime} \rightarrow 3^{\prime}$ & Source \\
\hline ATAF1 & $\begin{array}{l}\text { ATAF1_GW_UP } \\
\text { ATAF1_GW_UP }\end{array}$ & $\begin{array}{l}\text { GGGGACAAGTTTGTACAAAAAA } \\
\text { GCAGGCTTCATGTCAGAATTATT } \\
\text { ACAGTTGCCTCCAG } \\
\text { GGGGACCACTTTGTACAAGAAAG } \\
\text { CTGGGTCCTAGTAAGGCTTCTGC } \\
\text { ATGTACATGAAC }\end{array}$ & Invitrogen \\
\hline $\begin{array}{l}\text { CYP81D11 } \\
\text { promoter }\end{array}$ & $\begin{array}{l}\text { CYP81D11as1m-low } \\
\text { CYP81D11as1m-up } \\
\text { CYP81D11Prom_72 } \\
\text { 4up } \\
\text { CYP81D11Prom_up } \\
\text { CYP81D11Prom-low } \\
\text { CYPP- } \Delta \text { myc_UP } \\
\text { CYPP- } \Delta \text { myc_RP } \\
\text { CYPP- } \Delta \text { as } 1 \text { - } \\
\Delta \text { myc_UP } \\
\text { CYPP-_as } 1 \text { - } \\
\Delta \text { myc_RP }\end{array}$ & $\begin{array}{l}\text { GTGATTTACTATGTAATCTTGCAT } \\
\text { CTAGAATTGTTTTTTTCTTTCTTT } \\
\text { GTTTTG } \\
\text { CAATTCTAGATGCAAGATTACAT } \\
\text { AGTAAATCACATAATGTTCACGT } \\
\text { GTC } \\
\text { CAATCACGAAATCAATAATCAAT } \\
\text { AATATCC } \\
\text { GGGGACAAGTTTGTACAAAAAA } \\
\text { GCAGGCTAAGGGTAATTTGGTCT } \\
\text { TAACAATCTCC } \\
\text { GGGGACCACTTTGTACAAGAAAG } \\
\text { CTGGGTGACATTGATTAAAAACA } \\
\text { TGTGAGTTATAGCTG } \\
\text { TATGCAATGACGACAAGTAAATC } \\
\text { ACATAATGTTTTCAAGTTTCAAA } \\
\text { GAT } \\
\text { ATCTTTGAAACTTGAAAACATTA } \\
\text { TGTGATTTACTTGTCGTCATTGCA } \\
\text { CTAGATGCAAGATTACATAGTAA } \\
\text { ATCACATAATGTTTTCAAGTTTCA } \\
\text { AAGAT } \\
\text { ATCTTTGAAACTTGAAAACATTA } \\
\text { TGTGATTTACTATGTAATCTTGCA } \\
\text { T }\end{array}$ & Invitrogen \\
\hline \multicolumn{4}{|c|}{ Primers for Sequencing } \\
\hline$G U S$ & OCG_42 & $\begin{array}{l}\text { TAGCGATCCAGACTGAATGCCAC } \\
\text { A }\end{array}$ & Invitrogen \\
\hline$L U C$ & OCG_43 & $\begin{array}{l}\text { ATGCAGTTGCTCTCCAGCGGTTC } \\
\text { C }\end{array}$ & Invitrogen \\
\hline pDonor201 & $\begin{array}{l}\text { Seq-L1 } \\
\text { Seq-L2 }\end{array}$ & $\begin{array}{l}\text { TCGCGTTAACGCTAGCATGGATC } \\
\text { TC } \\
\text { GTAACATCAGAGATTTTGAGACA } \\
\text { C }\end{array}$ & Invitrogen \\
\hline pB2GW7(-HA) & $\begin{array}{l}\text { pB2GW7fwd } \\
\text { pB2GW7rev }\end{array}$ & $\begin{array}{l}\text { CACAATCCCACTATCCTTCGCA } \\
\text { CATGAGCGAAACCCTATAAGAAC } \\
\text { C }\end{array}$ & Invitrogen \\
\hline
\end{tabular}




\subsubsection{Organisms}

\subsubsection{Plant genotypes}

\begin{tabular}{|c|c|c|}
\hline Genotype & Description & Reference \\
\hline Columbia, Col-0 & Wild type & $\begin{array}{l}\text { NASC stock no. N1092, } \\
\text { NASC } 2002\end{array}$ \\
\hline as-1:GUS/35S:SCL14-HA & $\begin{array}{l}\text { Overexpression line, } \\
\text { expressing the } S C L 14 \text { gene } \\
\text { fused to an HA-tag (N- } \\
\text { terminal) under control of } \\
\text { the } C a M V 35 \mathrm{~S} \text { promoter, } \\
\text { expresses } G F P \text { in seeds for } \\
\text { selection, line \#5 was used } \\
\text { in this work }\end{array}$ & (Siemsen 2005) \\
\hline coil-1 & $\begin{array}{l}\text { Knockout line lacking } \\
\text { COI1, impaired in most } \\
\text { JA-dependent responses }\end{array}$ & $\begin{array}{l}\text { (Feys et al. 1994; Xie et al. } \\
\text { 1998) }\end{array}$ \\
\hline coil-t $t$ & $\begin{array}{l}\text { T-DNA insertion within } \\
\text { the COIl gene }\end{array}$ & (Mosblech et al. 2010) \\
\hline dde2-2 & $\begin{array}{l}\text { Mutant with a defect in JA } \\
\text { biosynthesis }\end{array}$ & (Park et al. 2002) \\
\hline DR5:GUS & $\begin{array}{l}\text { Transgenic plant } \\
\text { containing the } G U S \\
\text { reporter gene under the } \\
\text { control of the synthetic } \\
\text { auxin-responsive promoter } \\
D R 5\end{array}$ & (Ulmasov et al. 1997) \\
\hline$H S: A X R 3-1$ & $\begin{array}{l}\text { Transgenic plant } \\
\text { containing a mutated } \\
\text { AXR3 protein under the } \\
\text { control of a heat shock } \\
\text { promoter }\end{array}$ & (Knox et al. 2003) \\
\hline jarl-1 & $\begin{array}{l}\text { Mutant deficient in JA-Ile } \\
\text { biosynthesis }\end{array}$ & (Staswick et al. 1992b) \\
\hline$J A Z 1 \triangle 3 A-G U S$ & $\begin{array}{l}\text { Transgenic plant } \\
\text { containing a JAZ1 protein } \\
\text { with a deletion in domain } \\
3 \text {, exhibiting a JA- } \\
\text { insensitive phenotype }\end{array}$ & $\begin{array}{l}\text { (Thines et al. 2007); } \\
\text { Browse (Washington State } \\
\text { University, USA) }\end{array}$ \\
\hline jinl-1 & $\begin{array}{l}\text { Mutant with a defect within } \\
\text { MYC2 }\end{array}$ & (Berger et al. 1996) \\
\hline $\begin{array}{l}\text { scl14 } \\
(\text { SALK_126931) }\end{array}$ & $\begin{array}{l}\text { Knockout line containing a } \\
\text { T-DNA insertion } 55 \mathrm{bp} \\
\text { upstream of the ATG of } \\
\text { the } S C L 14 \text { gene, } \mathrm{km}^{r}\end{array}$ & (Fode et al., 2008) \\
\hline
\end{tabular}




\begin{tabular}{|l|l|l||}
\hline Genotype & Description & Reference \\
\hline \multirow{5}{*}{$\operatorname{tga} 2,5,6$} & $\begin{array}{l}\text { Knockout line lacking all } \\
\text { three class II TGA } \\
\text { transcription factors, } \\
\text { impaired in systemic } \\
\text { acquired resistance }\end{array}$ & $\begin{array}{l}\text { (Zhang et al., 2003); X. } \\
\text { Dong (Duke University, } \\
\text { Durham, USA) }\end{array}$ \\
\hline
\end{tabular}

\subsubsection{Bacteria}

\begin{tabular}{|c|c|c|}
\hline Genotype & Description & Reference \\
\hline $\begin{array}{l}\text { Agrobacterium } \\
\text { tumefaciens GV3101 }\end{array}$ & $\begin{array}{l}\text { PMP90RK } \\
\text { rif }^{r}, g^{r}\end{array}$ & (Koncz and Schell, 1986) \\
\hline Escherichia coli DB3.1 & 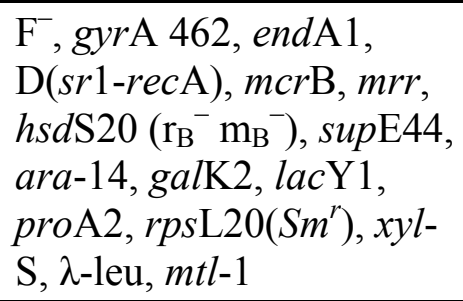 & (Bernard et al. 1993) \\
\hline Escherichia coli $\mathrm{DH} 5 \alpha$ & $\begin{array}{l}\mathrm{F}^{-}, \text {gyrA } 96\left(N_{a l}\right), \text { recA } 1 \text {, } \\
\text { endA1, thi-1, hsd } \mathrm{R} 17 \text { (rk- } \\
\text { mk+), glnV44, deoR, D } \\
(\text { lacZYA-argF) U169 } \\
{[\mathrm{p} 80 \mathrm{dD}(\text { lacZ)M15] }}\end{array}$ & (Hanahan 1983) \\
\hline
\end{tabular}

\subsubsection{Fungal cultivars}

\begin{tabular}{|l|l|}
\hline Genotype & Reference \\
\hline Botrytis cinerea BMM & $\begin{array}{l}\text { provided by Brigitte Mauch-Mani (University of } \\
\text { Neuchatel, Switzerland) }\end{array}$ \\
\hline
\end{tabular}

\subsubsection{Standard media}

\begin{tabular}{|l|l||}
\hline Media & Content/Source \\
\hline dYT medium for bacteria & $20 \mathrm{~g} / \mathrm{L}$ tryptone, $10 \mathrm{~g} / \mathrm{L}$ yeast extract, $10 \mathrm{~g} / \mathrm{L} \mathrm{NaCl}$ \\
\hline LB medium for bacteria & $10 \mathrm{~g} / \mathrm{L}$ tryptone, $5 \mathrm{~g} / \mathrm{L}$ yeast extract, $10 \mathrm{~g} / \mathrm{L} \mathrm{NaCl}$ \\
\hline YEB medium for bacteria & $\begin{array}{l}10 \mathrm{~g} / \mathrm{L} \text { beef extract, } 2 \mathrm{~g} / \mathrm{L} \text { yeast extract, } 5 \mathrm{~g} / \mathrm{L} \text { peptone, } \\
5 \mathrm{~g} / \mathrm{L} \text { sucrose, } \mathrm{pH} 7.0 \text { with } \mathrm{NaOH} \rightarrow \text { autoclave } \\
2 \mathrm{mM} \mathrm{MgSO}_{4}(\text { sterile })\end{array}$ \\
\hline
\end{tabular}




\begin{tabular}{|l|l||}
\hline Media & Content/Source \\
\hline MS medium for plants & $\begin{array}{l}4.4 \mathrm{~g} / \mathrm{L} \text { MS medium, } \mathrm{pH} 5.7 \text { with } \mathrm{KOH}, 6.8 \mathrm{~g} / \mathrm{L} \text { select } \\
\text { agar }\end{array}$ \\
\hline PDA for fungi & Merck \\
\hline PDB for fungi & Fulda \\
\hline
\end{tabular}

\subsubsection{Standard buffers}

\begin{tabular}{|c|c|}
\hline Buffer B+ & $\begin{array}{l}10 \mathrm{mM} \text { Tris- } \mathrm{HCl}\left(\mathrm{pH} 7.5 \text { at } 37^{\circ} \mathrm{C}\right), 10 \mathrm{mM} \mathrm{MgCl} 2,0.1 \mathrm{mg} / \mathrm{mL} \\
\text { BSA }\end{array}$ \\
\hline Buffer G+ & $\begin{array}{l}10 \mathrm{mM} \text { Tris- } \mathrm{HCl}\left(\mathrm{pH} 7.5 \text { at } 37^{\circ} \mathrm{C}\right), 10 \mathrm{mM} \mathrm{MgCl}_{2}, 50 \mathrm{mM} \mathrm{NaCl} \text {, } \\
0.1 \mathrm{mg} / \mathrm{mL} \mathrm{BSA}\end{array}$ \\
\hline Buffer O+ & $\begin{array}{l}50 \mathrm{mM} \text { Tris- } \mathrm{HCl}\left(\mathrm{pH} 7.5 \text { at } 37^{\circ} \mathrm{C}\right), 10 \mathrm{mM} \mathrm{MgCl}_{2}, 100 \mathrm{mM} \mathrm{NaCl} \text {, } \\
0.1 \mathrm{mg} / \mathrm{mL} \text { BSA }\end{array}$ \\
\hline Buffer R+ & $\begin{array}{l}10 \mathrm{mM} \text { Tris- } \mathrm{HCl}\left(\mathrm{pH} 8.5 \text { at } 37^{\circ} \mathrm{C}\right), 10 \mathrm{mM} \mathrm{MgCl}_{2}, 100 \mathrm{mM} \mathrm{KCl} \text {, } \\
0.1 \mathrm{mg} / \mathrm{mL} \mathrm{BSA}\end{array}$ \\
\hline Buffer Y+ & $\begin{array}{l}33 \mathrm{mM} \text { Tris-acetate }\left(\mathrm{pH} 7.9 \text { at } 37^{\circ} \mathrm{C}\right), 10 \mathrm{mM} \text { magnesium acetate, } \\
66 \mathrm{mM} \text { potassium acetate, } 0.1 \mathrm{mg} / \mathrm{mL} \mathrm{BSA}\end{array}$ \\
\hline TAE $(20 \times)$ & $0.8 \mathrm{M}$ Tris, $2.3 \%$ (v/v) acetic acid, $20 \mathrm{mM}$ EDTA \\
\hline TBS $(10 \times)$ & $24.2 \mathrm{~g}$ Tris, $80 \mathrm{~g} \mathrm{NaCl}$, pH 7.6 \\
\hline TBS-T $(1 \times)$ & $1 \times \mathrm{TBS}+0.1 \%$ Tween 20 \\
\hline $\begin{array}{l}\text { GUS extraction } \\
\text { buffer }\end{array}$ & $\begin{array}{l}50 \mathrm{mM} \mathrm{NaPO}_{4} \text { buffer } \mathrm{pH} 7.5\left(80.95 \mathrm{ml} \mathrm{Na}_{2} \mathrm{HPO}_{4}(0.5 \mathrm{M})+19.05\right. \\
\left.\mathrm{ml} \mathrm{NaH} \mathrm{PO}_{4}(0.5 \mathrm{M})\right), 10 \mathrm{mM} \text { EDTA, } 0.1 \% \text { Triton-X100, } 0.1 \% \\
\text { N-lauryl-sarkosine }\end{array}$ \\
\hline
\end{tabular}

\subsection{Methods}

\subsubsection{Standard molecular methods}

\subsubsection{Isolation of plasmid DNA from $E$. coli}

\subsection{Alkaline lysis}

Plasmid DNA for was isolated from E. coli using a modified alkaline lysis method. First, $1.5 \mathrm{ml}$ of E. coli overnight culture (stationary phase) were collected by 
centrifugation at 13,000 rpm for $1 \mathrm{~min}$. The supernatant was removed and the cells were resuspended in $100 \mu \mathrm{L}$ buffer I $(50 \mathrm{mM}$ Tris-HCl pH 8.0, $10 \mathrm{mM}$ EDTA, $100 \mu \mathrm{g} / \mu \mathrm{L}$ RNase A). Next, $200 \mu \mathrm{L}$ buffer II $(0.2 \mathrm{M} \mathrm{NaOH}, 1 \%$ (w/v) SDS) were added to the cell suspension and incubated for $5 \mathrm{~min}$ on ice. The suspension was neutralized by adding $150 \mu \mathrm{L}$ buffer III (29.4 g potassium acetate, $5 \mathrm{~mL}$ formic acid and water to $100 \mathrm{~mL})$ and inverting 6-8 times. The suspension was centrifuged for $10 \mathrm{~min}$ at 13,000 rpm at room temperature, and the aqueous solution $(\sim 400 \mu \mathrm{L})$ was transferred into a new microcentrifuge tube containing $1 \mathrm{~mL} 96 \%(\mathrm{v} / \mathrm{v})$ ethanol. The DNA was precipitated from the solution by incubating for $20 \mathrm{~min}$ at $-20^{\circ} \mathrm{C}$. Plasmid DNA was collected by centrifugation for $10 \mathrm{~min}$ at $13,000 \mathrm{rpm}$ and $4{ }^{\circ} \mathrm{C}$. The pellet was washed with $70 \%$ $(\mathrm{v} / \mathrm{v})$ ethanol and air-dried for $10 \mathrm{~min}$ at $37^{\circ} \mathrm{C}$. The DNA was dissolved in $20 \mu \mathrm{L}$ EB buffer (10 mM Tris-HCl pH 8.5).

\subsection{Isolation of high-quality plasmid DNA}

For sequencing and gateway ${ }^{\circledR}$ cloning purposes, high-purity plasmid DNA was isolated using the Nucleospin Mini Kit (Macherey-Nagel), following the manufacturer's instructions. Optional steps were always performed according to the manufacturer's recommendation. A 5-mL overnight culture was used to isolate plasmids and the isolated DNA was eluted with $50 \mu \mathrm{L}$ (high-copy plasmids) or $30 \mu \mathrm{L}$ (low-copy plasmids) EB buffer or water (ultra-pure).

To isolate larger amounts of plasmid DNA from E. coli, Macherey-Nagel Midi or Maxi Kit were used. The manufacturer's protocol, including the optional recommendations, was followed.

\subsubsection{Determination of DNA and RNA concentrations}

The concentration of nucleic acids was determined by measuring their absorption in a spectrophotometer at a wavelength of $260 \mathrm{~nm}$ (maximum nucleic acid absorption value; due to the $\pi$-electron systems of the nucleotide heterocycles). An $\mathrm{OD}_{260}$ reading of 1 in a cuvette with $10 \mathrm{~mm}$ path length corresponds to 50 and $40 \mu \mathrm{g} / \mathrm{mL}$ double-stranded DNA and RNA, respectively. Absorption at $280 \mathrm{~nm}$ (due to the presence of aromatic rings from amino acids and phenol compounds) was used to give information on the purity of the DNA or RNA sample, with the optimal ratio of $\mathrm{OD}_{260} / \mathrm{OD}_{280}$ being in the range of 1.9-2.0 for RNA and 1.8 for DNA. DNA concentrations less than $100 \mathrm{ng} / \mu \mathrm{L}$ were measured on an agarose gel using the Gene Ruler Ladder Mix as a standard.

\subsubsection{Restriction digestion of DNA}

Type II endonucleases were used to digest double-stranded DNA molecules for analytical and cloning purposes. The enzymes cleave the DNA resulting in either 5' or 3' "sticky" overhangs or in blunt ends. The digestion reactions were incubated in the buffer system optimized for the enzyme used or, in the case of double digestion, a universal buffer was used. The activity of the restriction enzymes was given in "units" 
$(\mathrm{U})$, where $1 \mathrm{U}$ is defined as the amount of enzyme completely cutting $1 \mu \mathrm{g}$ of $\lambda$ DNA in 60 min under optimal conditions. The minimal amount of enzyme necessary for each restriction digest was determined according to the following formula: $U=(b p[\lambda] \times$ number of restriction sites in target DNA)/(number of restriction sites in $[\lambda] \times$ bp of target DNA), with $\lambda=48,500 \mathrm{bp}$.

The incubation temperature was $37^{\circ} \mathrm{C}$ unless otherwise mentioned for a particular restriction enzyme. Due to the adverse effects of high glycerol concentrations, the total volume of the restriction enzymes did not exceed $10 \%$ of the restriction mix.

\subsubsection{Separation of DNA on agarose gels}

The electrophoretic separation of DNA for analytical and preparative purpose was done in a horizontal agarose gel $(10 \mathrm{~cm} \times 7 \mathrm{~cm} \times 0.3 \mathrm{~cm}, 16$ lanes $)$ with $1 \times \mathrm{TAE}$ as running buffer. DNA fragments ranging between $500 \mathrm{bp}$ and $14 \mathrm{~kb}$ were run on a $1 \%$ agarose gel, whereas DNA fragments of lower size were run on a $2 \%$ agarose gel. DNA samples were mixed with $1 / 10$ the volume of $10 \times$ DNA loading buffer, loaded into separate lanes and run at $120 \mathrm{~V}$ for $40-45 \mathrm{~min}$. Ethidium bromide solution $(0.1 \% \mathrm{w} / \mathrm{v})$ was used to stain the DNA fragments. The detection of DNA was done under UV light $(260 \mathrm{~nm})$. When a preparative gel was run and DNA fragments of a particular band had to be cut out, e.g. for cloning purposes, detection was done using larger-wavelength UV light $(320 \mathrm{~nm})$. Before exposure to UV light, the gel was rinsed briefly in $\mathrm{H}_{2} \mathrm{O}$ to reduce the background staining. In a gel documentation station, the gels were visualized on a UV-transilluminator. The sizes and amounts of the DNA fragments were determined using DNA standards.

Elution of DNA fragments from an agarose gel was done using the Nucleospin Extract II Gel Extraction Kit following the manufacturer's instructions. The eluted fragments were verified by electrophoresis as described above.

\subsubsection{Hybridization of complementary DNA fragments}

For hybridization $1 \mathrm{nmol}$ of complementary DNA oligonucleotides (in a total volume of $20 \mu \mathrm{L}$ ) was added into a screw-cap reaction tube and heated for $10 \mathrm{~min}$ in a $100^{\circ} \mathrm{C}$ water bath. The samples were then allowed to cool down to room temperature overnight.

\subsubsection{Ligation of DNA fragments}

Conventional cloning of a DNA fragment into a selected vector was performed using the T4-DNA ligase enzyme, which is able to catalyze the formation of a phosphodiester chemical bond between free 5'-phosphate and 3'-OH groups of double-stranded DNA fragments and vectors. The donor DNA fragment (10× excess over the vector) was incubated with the vector DNA, $2 \mu \mathrm{L}$ of ligation buffer and $1 \mu \mathrm{L}$ of T4-DNA ligase, for $2 \mathrm{~h}$ at room temperature. Ligation of blunt ended DNA fragments was performed in the ligation mixture descibed above supplemented with $5 \%(\mathrm{w} / \mathrm{v})$ PEG 4000. Ligase activity was destroyed by incubating at $65^{\circ} \mathrm{C}$ for $10 \mathrm{~min}$. 


\subsubsection{Gateway ${ }^{\circledR}$ cloning}

The cloning of binary vectors for transient and stable plant transformation purposes was performed with the gateway ${ }^{\circledR}$ cloning system from Invitrogen. The gateway ${ }^{\circledR}$ technology is based on the site-specific recombination of bacteriophage $\lambda$ and thereby provides a fast method to move DNA sequences between multiple vector systems without the use of restriction enzymes (Landy 1989; Hartley et al. 2000). All cloning steps were performed as described in the Invitrogen manual, Version E, September 22, 2003.

\subsubsection{DNA sequencing}

DNA sequencing was done using the BigDye Terminator RR Mix Cycle Sequencing Kit. The principle of DNA sequencing is based on the chain termination method (Sanger et al. 1977). In the chain termination method, dideoxynucleotides (terminators) are incorporated into a newly synthesized complementary chain, thus stopping its elongation in a PCR reaction. Each kind of dideoxynucleotide is labeled with a specific fluorescent dye, and the terminated chains can be specifically detected using an ABI Prism 3100 Capillary Sequencer (Applied Biosystems). The PCR sequencing reaction was performed using 500-1000 ng plasmid DNA, 5 pmol primer, $2 \mu \mathrm{L}$ ready reaction (RR) mix and $\mathrm{H}_{2} \mathrm{O}$ up to $10 \mu \mathrm{L}$. The samples were subjected to 25 cycles of $10 \mathrm{~s}$ at $95^{\circ} \mathrm{C}, 5 \mathrm{~s}$ at $50^{\circ} \mathrm{C}$, and $4 \mathrm{~min}$ at $60^{\circ} \mathrm{C}$ in a thermocycler. The DNA product was precipitated using $9.5 \mu \mathrm{L}$ water and $30.5 \mu \mathrm{L}$ absolute ethanol and left for $1 \mathrm{~h}$. The DNA was collected by centrifugation for $20 \mathrm{~min}$ at $13,000 \mathrm{rpm}$. The pellet was washed using $125 \mu \mathrm{L} 70 \%$ ethanol and then centrifuged for $10 \mathrm{~min}$ at 13,000 rpm. The pellet was dried at $95^{\circ} \mathrm{C}$ for $1 \mathrm{~min}$ and resuspended in $10 \mu \mathrm{L}$ of HiDi reagent. The samples were placed on ice. The reactions were loaded onto an ABIPrism 3100 capillary electrophoresis sequencing station for analysis.

\subsubsection{Cloning procedures}

\begin{tabular}{|c|c|}
\hline Vector & Construction \\
\hline $\begin{array}{l}\text { pDONOR201- } \\
\text { ANAC032 }\end{array}$ & $\begin{array}{l}\text { ANAC032 CDS was amplified by PCR from cDNA using the } \\
\text { iProof TM High-Fidelity PCR Kit from Bio-Rad and } \\
\text { ANAC032_GW_UP and ANAC032_GW_RP primers, using the } \\
\text { standard protocol and PCR cycler program recommended by the } \\
\text { manufacturer; the PCR product was cloned into pDONOR } 201 \text { by } \\
\text { BP reaction. }\end{array}$ \\
\hline pDONOR201-ATAF1 & $\begin{array}{l}\text { ATAF1 CDS was amplified by PCR from cDNA using the } \\
\text { iProof TM High-Fidelity PCR Kit from Bio-Rad and } \\
\text { ATAF1_GW_UP and ATAF1_GW_UP primers, using the } \\
\text { standard protocol and PCR cycler program recommended by the } \\
\text { manufacturer; the PCR product was cloned into pDONOR } 201 \text { by } \\
\text { BP reaction. }\end{array}$ \\
\hline
\end{tabular}




\begin{tabular}{|c|c|}
\hline Vector & Construction \\
\hline pDONOR201-cyp-prom & $\begin{array}{l}\text { The CYP81D11 promoter fragment was amplified from gDNA } \\
\text { using the iProof } \mathrm{TM} \text { High-Fidelity PCR Kit from Bio-Rad and the } \\
\text { CYP81D11Prom_up and CYP81D11Prom_low primers, using the } \\
\text { standard protocol and PCR cycler program recommended by the } \\
\text { manufacturer; the PCR product was cloned into pDONOR201 by } \\
\text { BP reaction. }\end{array}$ \\
\hline pDONOR201-cyp-mas1 & $\begin{array}{l}\text { The substitution of the as-1-like element was obtained via overlap } \\
\text { extension PCR. For this, two different fragments were utilized } \\
\text { seperately in two iProof }{ }^{\mathrm{TM}} \text { PCRs, using the standard protocol and } \\
\text { PCR cycler program recommended by the manufacturer (primers: } \\
\text { fragment 1: CYP81D11Prom_724up and CYP81D11as1m-low; } \\
\text { fragment 2: CYP81D11as1m-up and Seq-L2). The two fragments } \\
\text { yielded from the first PCR were purified after separation on a } 1 \% \\
\text { agarose gel and diluted 1:200. The two diluted fragments were } \\
\text { used as templates in a second PCR (primers: } \\
\text { CYP81D11Prom_724up and Seq-L2). The mutated fragment was } \\
\text { cloned into pDONOR201-cyp-prom cleaved by BcuI and PstI. }\end{array}$ \\
\hline $\begin{array}{l}\text { pDONOR201-cyp-prom- } \\
\text { mG-box }\end{array}$ & $\begin{array}{l}\text { Oligonucleotides CYPP-mmyc_UP and CYPP-mmyc_RP } \\
\text { containing the CYP81D11 promoter fragment with the mutated G- } \\
\text { box were hybridized and cloned into pDONOR201-cyp-prom } \\
\text { using the NdeI and EcoRV restriction sites. }\end{array}$ \\
\hline $\begin{array}{l}\text { pDONOR201-cyp-mas1- } \\
\text { mG-box }\end{array}$ & $\begin{array}{l}\text { Oligonucleotides CYPP-mas1-mmyc_UP and CYPP_mas1- } \\
\text { mmyc_RP containing the CYP } 81 D 11 \text { promoter fragment with the } \\
\text { mutated G-box were hybridized and cloned into pDONOR201- } \\
\text { cyp-prom using the XbaI and EcoRV restriction sites. }\end{array}$ \\
\hline pBGWFS-cyp-prom & $\begin{array}{l}\text { LR reaction was performed using pBGWFS7 and pDONOR201- } \\
\text { cyp-prom. }\end{array}$ \\
\hline pBGWFS-cyp-mas 1 & $\begin{array}{l}\text { LR reaction was performed using pBGWFS7 and pDONOR201- } \\
\text { cyp-mas } 1 .\end{array}$ \\
\hline $\begin{array}{l}\text { pBGWFS-cyp-prom- } \\
\text { mG-box }\end{array}$ & $\begin{array}{l}\text { LR reaction was performed using pBGWFS7 and pDONOR201- } \\
\text { cyp-prom-mG-box. }\end{array}$ \\
\hline $\begin{array}{l}\text { pBGWFS-cyp-mas1- } \\
\text { mG-box }\end{array}$ & $\begin{array}{l}\text { LR reaction was performed using pBGWFS7 and pDONOR201- } \\
\text { cyp-mas1-mG-box. }\end{array}$ \\
\hline pBGWL-cyp-prom & $\begin{array}{l}\text { LR reaction was performed using pBGWL7 and pDONOR201- } \\
\text { cyp-prom. }\end{array}$ \\
\hline pBGWL-cyp-mas1 & $\begin{array}{l}\text { LR reaction was performed using pBGWL7 and pDONOR201- } \\
\text { cyp-mas1. }\end{array}$ \\
\hline $\begin{array}{l}\text { pBGWL-cyp-prom-mG- } \\
\text { box }\end{array}$ & $\begin{array}{l}\text { LR reaction was performed using pBGWL7 and pDONOR201- } \\
\text { cyp-prom-mG-box. }\end{array}$ \\
\hline $\begin{array}{l}\text { pBGWL-cyp-mas1-mG- } \\
\text { box }\end{array}$ & $\begin{array}{l}\text { LR reaction was performed using pBGWL7 and pDONOR201- } \\
\text { cyp-mas1-mG-box. }\end{array}$ \\
\hline pB2GW7-HA & $\begin{array}{l}3 \times \text { HA-tag was inserted into pB2GW7 by three-fragment ligation } \\
\text { of pB2GW7 Eco147I/EcoRI, pB2GW7 Eco147I/SalI, and pE-HA } \\
\text { XhoI/EcoRI. }\end{array}$ \\
\hline $\begin{array}{l}\text { pB2GW7-HA- } \\
\text { ANAC032 }\end{array}$ & $\begin{array}{l}\text { LR reaction was performed using } \mathrm{pB} 2 \mathrm{GW} 7-\mathrm{HA} \text { and } \\
\text { pDONOR201-ANAC032. }\end{array}$ \\
\hline
\end{tabular}




\begin{tabular}{|l|l|}
\hline Vector & Construction \\
\hline pB2GW7-HA-ATAF1 & $\begin{array}{l}\text { LR reaction was performed using pB2GW7-HA and } \\
\text { pDONOR201-ATAF1. }\end{array}$ \\
\hline
\end{tabular}

\subsubsection{Gene transfer into $E$. coli}

E. coli cells are not naturally competent, i.e. they are not able to accept foreign DNA molecules from the environment. To enable the bacterial cells to take up circular vector DNA, they have to be made competent using special treatments. For transformation of E. coli bacteria the heat shock method was used (Hanahan 1983).

To preduce chemical competent $E$. coli cells for heat shock transformation, $5 \mathrm{ml}$ of liquid culture were incubated over night $\left(37^{\circ} \mathrm{C}, 250 \mathrm{rpm}\right)$ and transferred to $300 \mathrm{ml}$ SOK media. Absorbance at $600 \mathrm{~nm}$ was monitored, and when the $\mathrm{OD}_{600}$ reached 0.22 the culturing temperature was decreased to $18^{\circ} \mathrm{C}$. When the $\mathrm{OD}_{600}$ reached $0.4-0.5$ the cells were harvested by centrifugation $\left(10 \mathrm{~min}, 4^{\circ} \mathrm{C}, 4000 \mathrm{rpm}\right)$ in six $50 \mathrm{ml}$ tubes. All following steps were performed on ice. Cells were resuspended in with $15 \mathrm{ml}$ of transformation buffer, incubated for $15 \mathrm{~min}$ and again centrifuged (two tubes with $45 \mathrm{ml}$ each). Pellets were resuspended in $15 \mathrm{ml}$ of transformation buffer and subsequently $2 \mathrm{x}$ $525 \mu 1$ of DMSO were added with 5 min of incubation in between. Cell suspension was portioned into $1.5 \mathrm{ml}$ tubes $(200 \mu \mathrm{leach})$ and frozen in liquid nitrogen before storing at $70^{\circ} \mathrm{C}$

In brief, $200 \mu \mathrm{L}$ competent $E$. coli cells were thawed on ice for $20 \mathrm{~min} ; 50 \mathrm{ng}$ of plasmid DNA were added to the cells and mixed gently. The mixture was incubated on ice for $30 \mathrm{~min}$. The cells were heat shocked for $90 \mathrm{~s}$ at $42^{\circ} \mathrm{C}$. Next, $700 \mu \mathrm{L} \mathrm{LB}$ medium were added to the tube and the suspension was incubated for $45-60 \mathrm{~min}$ at $37^{\circ} \mathrm{C}$. The cultures were spread on plates containing LB medium supplemented with antibiotics. The plates were incubated overnight at $37^{\circ} \mathrm{C}$.

\begin{tabular}{|c|c|}
\hline SOK media (300 ml) & $\begin{array}{l}2 \% \text { Trypton, } 0.5 \% \mathrm{~g} \text { Yeastextract, } 10 \mathrm{mM} \mathrm{NaCl} \text {, } \\
2.5 \mathrm{mM} \mathrm{KCl} \rightarrow \text { autoclaved } \\
10 \mathrm{mM} \mathrm{MgCl}, 10 \mathrm{mM} \mathrm{MgSO}, 20 \mathrm{mM} \text { glucose } \\
\text { (separately autoclaved) }\end{array}$ \\
\hline Transformation buffer & $\begin{array}{l}10 \mathrm{mM} \text { PIPES, } 15 \mathrm{mM}, 250 \mathrm{mM} \mathrm{KCl}, \rightarrow \mathrm{pH} 6,7 \\
55 \mathrm{mM} \mathrm{MnCl}_{2} \rightarrow \text { sterile filtration }\end{array}$ \\
\hline
\end{tabular}

\subsubsection{Gene transfer into Agrobacterium tumefaciens}

A. tumefaciens GV3101 cells were transformed by electroporation. To generate electrocompetent $A$. tumefaciens cells, $10 \mathrm{ml}$ of liqid culture (YEB medium) were grown over night $\left(28^{\circ} \mathrm{C}, 250 \mathrm{rpm}\right)$, transferred to $250 \mathrm{ml}$ of YEB medium and again cultivated over night. When the $\mathrm{OD}_{600}$ reached 0.5 the culture was cooled on ice and subsequently centrifuged $\left(5 \mathrm{~min} 5000 \mathrm{rpm}, 4^{\circ} \mathrm{C}\right.$ ). The supernatant was discarded and the pellet was washed twice using $50 \mathrm{ml}$ of sterile $\mathrm{H}_{2} \mathrm{O}$ and twice using $10 \mathrm{ml}$ of $15 \%$ glycerine. Next the pellet was resuspended in $1 \mathrm{ml}$ of $15 \%$ of glycerine and transferred 
to $1.5 \mathrm{ml}$ tubes with $40 \mu \mathrm{l}$ per tube, before tubes were frozen in liquid nitrogen and stored at $-70^{\circ} \mathrm{C}$.

For transformation, cells were thawed on ice, mixed with the respective plasmid DNA (ca. $100 \mathrm{ng}$ ) and transferred into an electroporation cuvette. An electric pulse $(2.5 \mathrm{kV}$, $25 \mu \mathrm{F}, 400 \Omega$ ) was applied for $\sim 5 \mathrm{~s}$. Subsequently, the cells were incubated with $1 \mathrm{~mL}$ LB medium for $2 \mathrm{~h}$ at $30^{\circ} \mathrm{C}$ and spread on selective YEB plates. Incubation of plates was performed for $2-3$ days at $30^{\circ} \mathrm{C}$. Transformed cells from the plates were grown in $25 \mathrm{~mL}$ selective YEB liquid medium o/n at $30^{\circ} \mathrm{C}$. From $5 \mathrm{~mL}$ of this pre-culture, plasmid DNA was extracted (QIAprep Kit, Qiagen) to check the transformed cells. The rest of the pre-culture was transferred into $400 \mathrm{~mL}$ selective YEB liquid medium and incubated $\mathrm{o} / \mathrm{n}$ at $30^{\circ} \mathrm{C}$. Cells were harvested by centrifugation $(2500 \mathrm{rpm}, 30 \mathrm{~min})$ and suspended in $5 \%$ sucrose solution to an $\mathrm{OD}_{600}$ of 0.8 . Silvet-L77 $(0.05 \%)$ was added to this solution prior to Arabidopsis thaliana transformation by floral dip transformation.

\subsubsection{Gene Transfer into Arabidopsis thaliana protoplasts}

Protoplast isolation and transformation was performed according to the method described by (Sheen 2001). Rosette leaves of 4- to 6-week-old plants were harvested (1 leaf / 4 transformation reactions) and the lower surface was lightly scored with a razor blade. The scored leaves were placed in a Petri dish containing $5 \mathrm{ml}$ of enzyme solution and incubated over night. Filtration $(75-\mu \mathrm{m}$ mesh) of the digested leaves was used to separate protoplasts from undigested material. To wash the protoplasts they were pelleted by centrifugation ( $2 \mathrm{~min}, 780 \mathrm{rpm}$, soft start (Rotina 35R, Hettich)) and the pellet was resuspended in $10 \mathrm{ml}$ solution W5. This process was repeated twice and the protoplasts were subsequently incubated for at least $4 \mathrm{~h}$ on ice.

Solution W5 was removed and the protoplasts were resuspended in solution $\mathrm{MMg}$ $(250 \mu 1 /$ transformation reaction). Next, $200 \mu 1$ protoplast suspension were added to $11 \mu \mathrm{g}$ plasmid DNA (10 $\mu \mathrm{g}$ of promoter:firefly luciferase plasmids (pBGW7L derivatives) and for standardization $1 \mu \mathrm{g}$ of 35S:Renilla luciferase (p70SRUC, provided by D. Stahl of the KWS SAAT AG (Einbeck, Germany)) in a $2 \mathrm{ml}$ reaction tube and inverted gently before addition of $220 \mu \mathrm{l}$ of PEG solution. After $30 \mathrm{~min}$ of incubation, the transfection mixture was carefully diluted with $800 \mu \mathrm{l}$ of solution W5. The protoplasts were sedimented stepwise by 3 x centrifugation ( $1 \mathrm{~min}, 780 \mathrm{rpm}$, soft start) and the supernatant was removed, before they were immediately resuspended in $200 \mu 1$ of solution WI. After over night incubation, the WI solution was removed and protoplasts were frozen in liquid nitrogen. Whenever protoplasts were pipetted, cut tips were used.

Buffers used for protoplast transformation:

\begin{tabular}{|l|l|}
\hline Solution & Content \\
\hline \hline & $1.3 \%$ cellulase R10 (w/v) \\
& $0.3 \%$ macerozyme R10 (w/v) \\
Enzyme solution & $0.4 \mathrm{M} \mathrm{mannitol}$ \\
& $20 \mathrm{mM} \mathrm{KCl}$ \\
& $20 \mathrm{mM} \mathrm{MES}(\mathrm{pH} 5.7)$ \\
& $10 \mathrm{mM} \mathrm{CaCl}$ \\
\hline
\end{tabular}




\begin{tabular}{|c|c|}
\hline Solution & Content \\
\hline PEG solution & $\begin{array}{l}40 \% \text { PEG4000 (w/v) } \\
0.8 \mathrm{M} \mathrm{mannitol} \mathrm{M} \mathrm{CaCl}_{2}\end{array}$ \\
\hline Incubation solution WI & $\begin{array}{l}0.5 \mathrm{M} \text { mannitol } \\
4 \mathrm{mM} \mathrm{MES} \mathrm{(pH} \mathrm{5.7)} \\
20 \mathrm{mM} \mathrm{KCl}\end{array}$ \\
\hline Washing solution W5 & $\begin{array}{l}154 \mathrm{mM} \mathrm{NaCl} \\
125 \mathrm{mM} \mathrm{CaCl}_{2} \\
5 \mathrm{mM} \mathrm{KCl} \\
2 \mathrm{mM} \mathrm{MES} \mathrm{(pH} \mathrm{5.7)}\end{array}$ \\
\hline Transformation solution $\mathrm{MMg}$ & $\begin{array}{l}0.4 \mathrm{M} \text { mannitol } \\
15 \mathrm{mM} \mathrm{MgCl}_{2} \\
4 \mathrm{mM} \mathrm{MES}(\mathrm{pH} 5.7)\end{array}$ \\
\hline
\end{tabular}

\subsubsection{Agrobacterium-mediated gene transfer into Arabidopsis thaliana}

Transformation of $A$. thaliana with Agrobacterium was performed according to Clough (2005). Flowering plants were dipped into an Agrobacterium solution $\left(\mathrm{OD}_{600}=0.8\right)$. The plants were subsequently cultured until seed development. Selection of the primary transformants was performed using the appropriate selection markers.

\subsubsection{Isolation of genomic DNA from Arabidopsis thaliana leaves for genotyping}

This "quick and dirty" method was used for PCR-based genotyping of the F2 generation plants. A leaf disc was cut out using the lid of a microcentrifuge tube, making sure to avoid crosscontamination with foreign plant material. The tissue was ground in $100 \mu \mathrm{L}$ of extraction buffer (200 mM Tris- $\mathrm{HCl} \mathrm{pH} 7.5,250 \mathrm{mM} \mathrm{NaCl}, 25 \mathrm{mM}$ EDTA, $0.5 \%$ SDS) using a small pestle (Roth) that fits within a $1.5-\mathrm{mL}$ centrifuge tube. An additional $300 \mu \mathrm{L}$ of extraction buffer were added and mixed by inversion before centrifugation $\left(15,000 \mathrm{rpm}, 5 \mathrm{~min}, 4^{\circ} \mathrm{C}\right)$. Of the supernatant, $300 \mu \mathrm{L}$ were transferred into a new microcentrifuge tube and supplemented with $300 \mu \mathrm{L} 2$-propanol. After inverting the tube several times, the samples were centrifuged $(13,000$ $\mathrm{rpm}, 5 \mathrm{~min}, \mathrm{RT})$. The supernatant was removed and the pellet was washed with $200 \mu \mathrm{L} 70 \%$ $\mathrm{EtOH}$. After removing the supernatant, the pellet was dried at $37^{\circ} \mathrm{C}$ for $10 \mathrm{~min}$ and subsequently dissolved in $100 \mu \mathrm{L}$ of water (ultra-pure) by incubating for $10 \mathrm{~min}$ at $65^{\circ} \mathrm{C}$. After a last centrifugation step $(13,000 \mathrm{rpm}, 5 \mathrm{~min}, \mathrm{RT})$, the supernatant containing the isolated genomic DNA was transferred to a new microcentrifugation tube and stored at $-20^{\circ} \mathrm{C}$. 


\subsubsection{Plant growth conditions}

\subsection{Growth of transgenic reporter gene lines}

Approximately 100 F2 seeds of selected reporter gene lines were surface sterilized and sown on sterile MS plates. The plants were grown for 16 days at $22^{\circ} \mathrm{C}$ under long-day conditions ( $14 \mathrm{~h} \mathrm{light} / 10 \mathrm{~h}$ dark, $60 \mu \mathrm{mol}$ photons $/ \mathrm{m}^{2} \mathrm{x} \mathrm{sec}$ ) and at $60 \%$ humidity.

\subsection{Plant growth conditions for transient expression studies and stress induction}

Plants for protoplast transformation and stress induction were grown on steamed soil (Archut, Fruhstorfer Erde, T25, Str1 fein) under $12 \mathrm{~h}$ light/12 h dark low-light conditions $\left(37-45 \mu \mathrm{mol}\right.$ photons $\left./ \mathrm{m}^{2} \mathrm{x} \mathrm{sec}\right)$ over a period of $6-7$ weeks at $22^{\circ} \mathrm{C}$ and $60 \%$ humidity. For each square pot $(8.5 \mathrm{~cm} \times 8.5 \mathrm{~cm})$, for four seeds were sown.

\subsubsection{Stress induction in $A$. thaliana}

\subsubsection{TIBA}

Plants were sprayed with $0.1 \mathrm{mM}$ TIBA $(0.1 \%$ DMSO) and incubated for $8 \mathrm{~h}$ under conditions. Control plants were sprayed with water + DMSO (0.1\%) and incubated for the same time span or harvested before treatment (time course).

\subsubsection{BOA}

Plants were sprayed with $2 \mathrm{mM} \mathrm{BOA}(0.2 \% \mathrm{EtOH})$ and incubated for $8 \mathrm{~h}$ under normal growth conditions. Control plants were sprayed with water $+\mathrm{EtOH}(0.2 \%)$ and incubated for the same time span.

\subsubsection{Benoxacor}

Plants were sprayed with $0.05 \mathrm{mM}$ benoxacor (0.1\% DMSO) and incubated for $8 \mathrm{~h}$ under normal growth conditions. Control plants were sprayed with water + DMSO $(0.1 \%)$ and incubated for the same time span. 


\subsubsection{IAA}

Plants were sprayed with $0.01 \mathrm{mM}$ IAA and incubated for $8 \mathrm{~h}$ under normal growth conditions. Control plants were sprayed with water and incubated for the same time span.

\subsubsection{Jasplakinolide}

Leaves of 6-7-week-old plants were cut which a scalpel, and the petioles were submerged in $10 \mu \mathrm{M}$ jasplakinolide (1\% DMSO) and incubated under normal growth conditions for $24 \mathrm{~h}$. Control leaves were treated with $\mathrm{H}_{2} \mathrm{O}+1 \%$ DMSO and incubated for the same time span.

\subsubsection{MeJA}

Plants were transferred into a gas-proof tank, and $1 \mu \mathrm{L} \mathrm{MeJA} / \mathrm{L}_{\text {air volume was added to ten }}$ filter paper pieces sticking to the inner glass surface. The tank was immediately sealed with grease. The plants were incubated for 8 or $24 \mathrm{~h}$. Control plants were incubated for the same time span in a sealed tank without MeJA.

\subsubsection{Extended darkness}

Plants were covered at the beginning of the dark phase and kept in the dark for $36 \mathrm{~h}$. Control plants stayed in the normal light cycle ( $12 \mathrm{~h}$ light $/ 12 \mathrm{~h}$ dark). The plants were harvested at the beginning of the light phase.

\subsubsection{Infection of $\boldsymbol{A}$. thaliana with Botrytis cinerea}

\subsection{Cultivation}

Pieces of mycelium from a PDA plate (growing plate) or spores from a glycerol stock $\left(-80^{\circ} \mathrm{C}\right)$ were transferred to fresh malt extract plates (sporulation plate). Growing of the fungi was carried out in the dark at $20-24^{\circ} \mathrm{C}$ for about $7-14$ days, until full sporulation. The collected spores (see below) were frozen as glycerol stocks $(30 \%)$ in $50-\mu \mathrm{L}$ aliquots at $-80^{\circ} \mathrm{C}$. 


\subsection{Collection of spores}

Of quarter-strength PDB medium, $5 \mathrm{~mL}$ were dropped onto a plate with fungi in full sporulation. The fungal hyphae were scraped off with a Drygalski spatula and the medium containing the hyphae and the spores was filtered through three layers of gauze bandage. The spores were counted under a microscope in a Thoma counting chamber and diluted with quarter-strength PDB medium to $2 \times 10^{5}$ spores $/ \mathrm{mL}$.

\subsection{Infection of plants}

The collected spores in quarter-strength PDB medium were incubated in the light for $2-$ $3 \mathrm{~h}$, at RT. Plants with fully expanded leaves were inoculated with $6 \mu \mathrm{L}$ of spore solution $\left(2 \times 10^{6}\right.$ spores $\left./ \mathrm{mL}\right)$ or $6 \mu \mathrm{L}$ of quarter-strength PDB (mock) on each leaf. The plants were transferred to a gas-proof tank, which was sealed with exsiccator grease to obtain high humidity, and incubated for 3 days before the infected leaves were harvested.

\subsubsection{Protoplast isolation}

Protoplast isolation and transformation was performed according to the method described by Sheen (2001). Instead of transformation, the protoplasts were only incubated for $30 \mathrm{~min}$ in buffer MMG (see also Section 3.2.1.12: Gene Transfer into Arabidopsis thaliana protoplasts). For RNA isolation, six protoplast samples were pooled.

\subsubsection{Transcript analysis}

\subsubsection{RNA extraction}

The TRIZOL extraction method can be used to extract RNA, DNA, and proteins from plants (Chomczynski 1993). This method uses phenol/chloroform (dichloromethane) extraction to dissolve RNA in the aqueous phase while other compounds like proteins are dissolved in the hydrophobic chloroform phase. The two thiocyanate compounds in the extraction buffer inhibit RNAse activity. Plant tissue was ground to fine powder in liquid nitrogenusing using pre cooled mortar and pestle. To $\sim 150 \mathrm{mg}$ ground plant material $1.3 \mathrm{~mL}$ extraction buffer $(380 \mathrm{~mL} / \mathrm{L}$ phenol saturated with $0.1 \mathrm{M}$ citrate buffer $\mathrm{pH} 4.3,0.8 \mathrm{M}$ guanidiniumthiocyanate, $0.4 \mathrm{M}$ ammoniumthiocyanate, $33.4 \mathrm{~mL} 3 \mathrm{M} \mathrm{Na}$ acetate $\mathrm{pH} 5.2,5 \%$ glycerol) was added. After shaking for $15 \mathrm{~min}$ at RT, chloroform $(260 \mu \mathrm{L})$ was added to each sample. After an additional shaking step (15 min, RT) and centrifugation $\left(12,000 \mathrm{rpm}, 30-60 \mathrm{~min}, 4^{\circ} \mathrm{C}\right)$, the supernatant $(900 \mu \mathrm{L})$ was transferred into new microcentrifuge tubes. Precipitation buffer (HSPB, 1.2 M NaCl, 0.8 M Nacitrate) and 2-propanol ( $325 \mu \mathrm{L}$ each) were added, the tubes were inverted several times and the samples were incubated for $10 \mathrm{~min}$ at RT and centrifuged $(12,000 \mathrm{rpm}, 20 \mathrm{~min}$, 
$4^{\circ} \mathrm{C}$ ). The pellets were washed with with $70 \%$ ethanol. After removing the supernatant, the samples were dried at room temperature and afterwards dissolved in 50-100 $\mu \mathrm{L}$ water (ultra-pure). The concentration was measured as described in Section 3.2.1.2.

\subsubsection{Preparation of gDNA-free cDNA for $q R T-P C R$}

To analyze gene expression by PCR, it is necessary to synthesize cDNA from RNA. In order to prevent gDNA contamination, DNase I digestion was done before cDNA synthesis. First, $1 \mu \mathrm{g}$ RNA template together with $1 \mu \mathrm{L} 10 \times$ DNase I reaction buffer and $1 \mu \mathrm{L}$ DNase I (RNase free) was added with water to a final reaction volume of $10 \mu \mathrm{L}$. The mixture was incubated at $37^{\circ} \mathrm{C}$ for $30 \mathrm{~min}$. To deactivate the DNase I enzyme, $1 \mu \mathrm{L}$ $25 \mathrm{mM}$ EDTA was added and incubated at $65^{\circ} \mathrm{C}$ for $10 \mathrm{~min}$. cDNA synthesis was performed with $1 \mu \mathrm{g}$ total RNA (DNA free), 20 pmol oligo-dT primer, and 200 pmol random nonamer oligonucleotides. Water was added to a final reaction volume of 12.5 $\mu \mathrm{L}$. For annealing of the primers, the mixture was heated to $70^{\circ} \mathrm{C}$ for $10 \mathrm{~min}$ and immediately cooled down on ice. Subsequently, $20 \mathrm{nmol}$ dNTPs, $4 \mu \mathrm{L}$ RT $5 \times$ firststrand reaction buffer and $60 \mathrm{U}$ reverse transcriptase $\mathrm{H}-$ were added and brought to a final volume of $20 \mu \mathrm{L}$ with $\mathrm{H}_{2} \mathrm{O}$. The mixture was incubated at $42^{\circ} \mathrm{C}$ for $70 \mathrm{~min}$ and then heated to $70^{\circ} \mathrm{C}$ for $10 \mathrm{~min}$.

\subsubsection{Quantitative real-time RT-PCR}

This highly sensitive method was used to investigate gene expression on the RNA level. cDNA was diluted 1:10 with sterile water. The amplification mix consisted of $1 \times \mathrm{NH}_{4}-$ reaction buffer, $2 \mathrm{mM} \mathrm{MgCl} 2,100 \mu \mathrm{M}$ dNTPs, $0.4 \mu \mathrm{M}$ primers, $0.25 \mathrm{U}$ BIOTaq DNA polymerase, $10 \mathrm{nM}$ fluoresceine, 100,000× diluted SYBR Green I solution, $1 \mu \mathrm{L}$ of the diluted cDNA as template, and water (ultra-pure) added to a total volume of $25 \mu \mathrm{L}$. The PCR consisted of a 6-min initial denaturation step at $95^{\circ} \mathrm{C}$ followed by 40 cycles of $20 \mathrm{~s}$ at $95^{\circ} \mathrm{C}, 20 \mathrm{~s}$ at $55^{\circ} \mathrm{C}$ (annealing) and $40 \mathrm{~s}$ at $72^{\circ} \mathrm{C}$ (elongation). A final elongation step was done for $4 \mathrm{~min}$ at $72^{\circ} \mathrm{C}$, followed by a melting curve analysis. During the elongation and annealing phases, measurement of the fluorescence intensity was performed in the Biorad icycler. The housekeeping gene UBQ5 (At3G62250) was used as control. Data analysis was done with the help of the 2- $\Delta \Delta \mathrm{CT}$ method (Schmittgen and Livak 2008) to quantify the relative expression levels.

\subsubsection{Microarray analyses}

The transcriptomes of Col-0 and coil-t plants after mock and TIBA treatment was compared by microarray analyses. Plants were grown and treated according to Sections 3.2.1.15.2 and 3.2.2.1. Eight plants of each kind of treatment and genotype were combined. Total RNA was extracted according to the TRIZOL method (Section 3.2.3.1) and purified using the RNeasy Kit (Qiagen). Quality control and hybridizations were performed by the NASC's International Affymetrix Service (Nottingham Arabidopsis 
Stock Centre, University of Nottingham, UK), using "Affymetrix Arabidopsis ATH1 Genome Array" chips.

Raw data analysis and data quality control were performed using Robin (Lohse et al. 2010). Normalization of the raw data and an estimation of signal intensities were carried out using the Robust Multichip Average (RMA) methodology. Genes that showed an absolute $\log 2$ fold-change value of at least 1 and a $P$ value lower than 0.05 were considered as significantly differentially expressed. Subsequently, criteria for "TIBA inducible" were defined as "Col-0 TIBA/Col-0 mock $\geq 3$ " and for "COI1 dependent" as "coil- $t$ TIBA/Col-0 TIBA $\leq 0.3$ ".

\subsubsection{Protein analysis}

\subsubsection{Whole-cell protein extracts}

Extraction of proteins was performed under denaturing conditions. An extraction buffer containing urea (4 $\mathrm{M}$ urea, $16.6 \%$ glycerol, $5 \%$ SDS, $0.5 \% \beta$-mercaptoethanol) was used to extract the proteins. After grinding the plant material under liquid nitrogen, 450 $\mu \mathrm{L}$ of extraction buffer were added to $\sim 150 \mathrm{mg}$ plant material. The samples were incubated at $65^{\circ} \mathrm{C}$ for $10 \mathrm{~min}$ and centrifuged $(13,000 \mathrm{rpm}, 20 \mathrm{~min}, \mathrm{RT})$. The supernatant was transferred into new microcentrifuge tubes and used for SDS-PAGE.

\subsubsection{Determination of protein concentrations}

Protein concentrations were determined by two different methods. A colorimetric assay was used to determine the concentration of proteins extracted without detergent usage according to Bradford and Williams (1976). The assay was conducted by pipetting equal amounts of protein extract into a microtiter plate containing $200 \mu \mathrm{L}$ of 5 -fold diluted Bradford reagent and the $\mathrm{OD}_{595}$ was measured with a plate reader. Protein concentrations were calculated using a standard curve derived from different BSA protein amounts (1, 3 and $6 \mu \mathrm{g})$.

Proteins isolated using buffers containing detergents were measured with the Pierce 660 $\mathrm{nm}$ protein assay kit (Thermo Scientific) according to the instruction manual.

\subsubsection{SDS PAGE}

In sodium dodecyl sulfate-polyacrylamide gel electrophoresis (SDS-PAGE), proteins are separated mostly on the basis of their polypeptide length. Electrophoresis was performed using a discontinuous buffer system, in which a non-restrictive large-pore gel, called a stacking gel, is layered on top of a separating gel called a resolving gel. The recipe for the resolving gel is as follows: $7-8 \%(\mathrm{w} / \mathrm{v})$ acrylamide/bisacrylamide (37.5:1), $400 \mathrm{mM}$ Tris-HCl pH 8.8, $0.1 \%(\mathrm{w} / \mathrm{v})$ SDS, $0.1 \%(\mathrm{w} / \mathrm{v})$ TEMED, and $0.1 \%$ $(\mathrm{w} / \mathrm{v})$ APS. The stacking gel consisted of: $5 \%$ (w/v) acrylamide/bisacrylamide (37.5:1), 
$125 \mathrm{mM}$ Tris-HCl $\mathrm{pH}$ 6.8, $0.1 \%$ (w/v) SDS, $0.2 \%(\mathrm{w} / \mathrm{v})$ TEMED, and $0.1 \%(\mathrm{w} / \mathrm{v})$ APS. The denatured protein extract samples $(\sim 10 \mu \mathrm{L}$ each, or equal amounts of protein defined after a first Coomassie-stained gel) were boiled with $15 \mu \mathrm{L} 2 \times$ SDS sample buffer $(0.09 \mathrm{M}$ Tris, $20 \%$ glycerol, $2 \%$ SDS, $0.02 \%$ bromophenol blue, $0.1 \mathrm{M}$ DTT) at $95^{\circ} \mathrm{C}$ for $5 \mathrm{~min}$, then cooled on ice. Electrophoresis was performed at $120 \mathrm{~V}$ with $1 \times$ SDS running buffer (250 mM Tris, $2 \mathrm{M}$ glycine, $1 \% \mathrm{SDS}$ ) until the bromophenol blue band reached the lower end of the gel. A pre-stained protein ladder $(6 \mu \mathrm{L})$ was used for estimating the size of the separated proteins.

\subsubsection{Coomassie staining of SDS gels}

The Coomassie Brilliant Blue G-250 dye was used to detect proteins separated by SDSPAGE. The gels were incubated with $40 \mathrm{ml}$ of Coomassie staining solution (colloidal Coomassie) and $10 \mathrm{~mL}$ of methanol overnight. Colloidal Coomassie consists of $400 \mathrm{~mL}$ solution A (40 g ammonium sulfate and $8 \mathrm{~mL}$ phosphoric acid) and $10 \mathrm{~mL}$ solution $\mathrm{B}$ (0.5 g Coomassie Brilliant Blue G-250; this has to be dissolved by shaking for at least $0.5 \mathrm{~h})$. The gels were destained in water overnight.

\subsubsection{Western blot}

The proteins separated by SDS-PAGE were blotted onto a PVDF membrane using the semi-dry blotting method, applying an electric field between two graphite plates. The PVDF membrane was activated by $\mathrm{MeOH}$ before blotting. For the transfer of proteins from the gel to the membrane, the gel on top of the membrane was sandwiched between three layers of Whatman paper (pre-soaked with transfer buffer). The whole arrangement was placed within a blotting apparatus, and the transfer was performed at an amperage of $1 \mathrm{~mA} / \mathrm{cm}^{2}$ for $1.4 \mathrm{~h}$. (Optional: Ponceau S staining was done to observe the success of the transfer $(2 \mathrm{~g}$ Ponceau S, $30 \mathrm{~g}$ trichloroacetic acid and $30 \mathrm{~g}$ sulfosalicylic acid in $100 \mathrm{~mL} \mathrm{H}_{2} \mathrm{O}$ )) After blotting, the membrane was dried between two layers of Whatman paper. The standard was marked on the membrane with an iMark (pen containing rabbit pre-immune serum) for later detection of standard bands with the second antibody and an ECL kit to visualize them on the film. After $5 \mathrm{~min}$, the membrane was reactivated in $\mathrm{MeOH}$ and nonspecific binding to proteins on the membrane was prevented by blocking the membrane with non-fat dried milk powder $(5 \%$ in $1 \times \mathrm{TBST}) \mathrm{o} / \mathrm{n}$ at $4{ }^{\circ} \mathrm{C}$ on a shaking platform. The detection of specific proteins on the membrane was performed using an antibody directed against the protein of interest at 1:4000 dilution in 1× TBST (with $0.5 \%$ milk powder). The membrane was incubated with the respective antibody for $2 \mathrm{~h}$ at RT on a shaking platform. Incubation with the second antibody (anti-rabbit 1:25,000 in 1× TBST) was performed for $1 \mathrm{~h}$ at RT on a shaking platform. This second antibody was conjugated to horseradish peroxidase (HRP). HRP can utilize the enhanced chemiluminescent substrate (ECL, GE Healthcare; incubation of the membrane in ECL mix for $5 \mathrm{~min}$ ) to generate a luminescence-emitting product, which allows visualization of the membrane-bound proteins on autoradiography films. The films were exposed to the membrane in detection cassettes between $30 \mathrm{~s}$ to $10 \mathrm{~min}$, depending on the strength of the chemiluminescence signal generated by the respective amount of bound protein. 


\subsubsection{Preparation of protein extracts for enzymatic GUS assays}

Extraction of proteins for GUS assays was conducted by the addition of $700 \mu \mathrm{L}$ GUS extraction buffer $\mathrm{pH} 7.5$ (supplemented with $0.05 \% \beta$-mercaptoethanol, see section $3.1 .10)$ to frozen (liquid nitrogen) and ground plant material (300-500 mg). Subsequently, the samples were centrifuged $\left(10 \mathrm{~min}, 12,000 \mathrm{rpm}\right.$ at $\left.4^{\circ} \mathrm{C}\right)$, and the supernatant was transferred to a new $1.5-\mathrm{ml}$ reaction tube. The samples were stored at $80^{\circ} \mathrm{C}$

\subsubsection{Measurement of relative GUS activities}

For the determination of GUS activities from protein extracts, $1 \mu \mathrm{L}$ of a 1:100 dilution was analysed in a GUS assay using a flat-bottom multititer plate. After addition of 99 $\mu \mathrm{L}$ MUG extraction buffer $\mathrm{pH} 7.5+\beta$-mercaptoethanol, $100 \mu \mathrm{L}$ of MUG solution were added to each well and the plate was placed in a $37^{\circ} \mathrm{C}$ incubator to start the enzymatic reaction. After $10 \mathrm{~min}$, a $\mathrm{t}_{0}$ value was taken by pipetting $100 \mu \mathrm{L}$ of the sample to $100 \mu \mathrm{L}$ of GUS-stop buffer ( $200 \mathrm{mM} \mathrm{Na} \mathrm{CO}_{3}$ ). The remaining reaction was stopped $60 \mathrm{~min}$ later to gain a $t_{60}$ value. The $t_{0}$ and $t_{60}$ values were used to calculate the relative GUS activities of the samples.

\subsubsection{Histochemical GUS staining}

GUS staining was used to examine the tissue-specific expression of transcriptional promoter:GUS ( $\beta$-glucuronidase) fusions. GUS activity was assayed using X-gluc (5bromo-4-chloro-3-indolyl $\beta$-D-glucuronide). After hydrolysis by the GUS enzyme, oxidation of the indole derivative causes dimerization and the production of an insoluble indigo dye.

Whole seedlings were incubated for $20 \mathrm{~min}$ in $90 \%$ precooled acetone $\left(-20^{\circ} \mathrm{C}\right)$ at room temperature. The acetone was discarded and the plant material was washed three times with GUS staining buffer $\left(50 \mathrm{mM} \mathrm{Na} \mathrm{HPO}_{4} / \mathrm{NaH}_{2} \mathrm{PO}_{4}\right.$ pH 7.2, $0.2 \%$ Triton $\mathrm{X}-100$, $\left.0.5 \mathrm{mM} \mathrm{K}_{3} \mathrm{Fe}(\mathrm{CN})_{6}, 0.5 \mathrm{mM} \mathrm{K}{ }_{4} \mathrm{Fe}(\mathrm{CN})_{6}\right)$. Subsequently, GUS staining solution $(2 \mathrm{mM}$ X-Gluc, $50 \mathrm{mM} \mathrm{Na} \mathrm{HPO}_{4} / \mathrm{NaH}_{2} \mathrm{PO}_{4} \mathrm{pH} 7.2,0.2 \%$ Triton X-100, $0.5 \mathrm{mM} \mathrm{K} 3{ }_{3} \mathrm{Fe}(\mathrm{CN})_{6}$, $\left.0.5 \mathrm{mM} \mathrm{K} \mathrm{K}_{4} \mathrm{Fe}(\mathrm{CN})_{6}\right)$ was vacuum-infiltrated for $20 \mathrm{~min}$. The plant material was incubated $\mathrm{o} / \mathrm{n}$ at $37^{\circ} \mathrm{C}$ and washed with increasing concentrations of $\mathrm{EtOH}(20,35$, and $50 \%$ ).

Root tips were analyzed by microscopy (DM 5000B + CTR 5000, Leica).

\subsubsection{Measurement of relative luciferase activities}

Transfected and frozen protoplasts (see 3.2.1.12) were resolved in $50 \mu$ l of cell lysis buffer (Promega) and subsequently luciferase activity tests were performed using the "Dual luciferase kit" (Promega) according to the instruction manual. 


\subsubsection{Hormone analysis}

\subsubsection{Determination of $\mathrm{JA}$ and JA-Ile contents in plant material}

Determination of JA and JA-Ile concentations was performed by the Department of Plant Biochemistry (Prof. Dr. I. Feußner) of the University of Göttingen (Germany), by GC-MS/MS analyses (Luo et al. 2009). 


\section{$4 \quad$ Results}

\subsection{CYP81D11 expression depends on the TGA/SCL14 complex in response to jasmonic acid and Botrytis cinerea}

Expression of CYP81D11 in response to the auxin transport inhibitor TIBA strongly depends on the TGA class II transcription factors TGA2, TGA5 and TGA6 (TGA2,5,6) as well as on the GRAS family protein SCL14 (Fode et al. 2008). In addition, CYP81D11 is inducible by MeJA in a TGA2,5,6-dependent manner (Mueller et al. 2008), although TGA2,5,6 are not part of the known JA signaling cascade. To elucidate if SCL14 plays a role for CYP81D11 expression in response to MeJA, Col-0 wild-type and tga2,5,6 and scl14 mutant plants were treated with MeJA. The effects on the CYP81D11 expression elicited by the mutations were analyzed by quantitative real-time RT-PCR (Figure 4. 1). TIBA treatment was performed under the same conditions in order to reproduce the results published previously. As a control, VSP2 expression in response to MeJA and TIBA was investigated. VSP2 (VEGETATIVE STORAGE PROTEIN 2) is a well-investigated JA-inducible gene, often used as a marker gene for response to JA, e.g. in pharmacological treatments, wounding, or herbivore attack (McConn et al. 1997a; Lorenzo et al. 2004). 


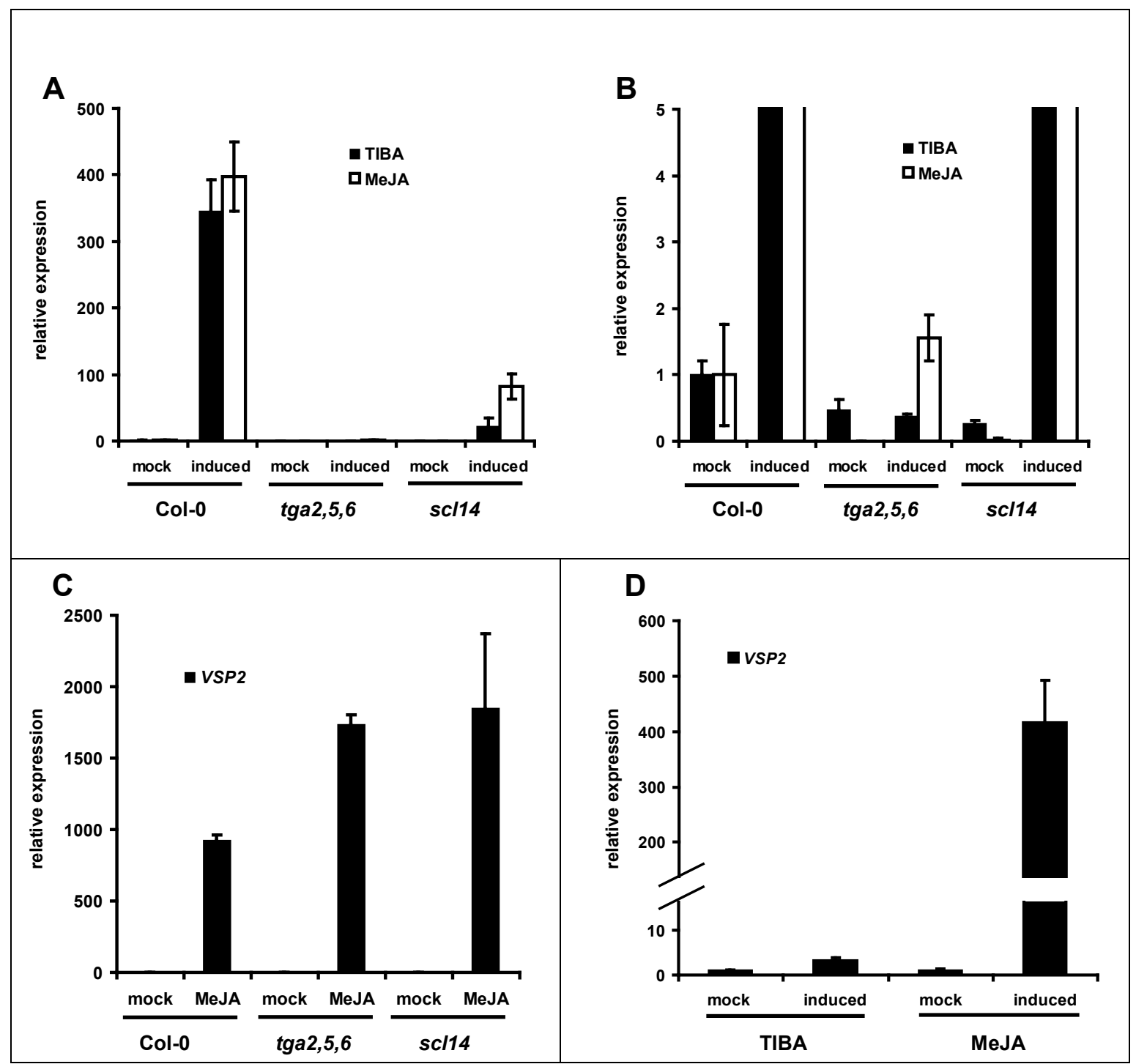

Figure 4. 1: Expression of CYP81D11 and VSP2 in the tga2,5,6 and scl14 mutants in response to TIBA and MeJA

Quantitative real-time RT-PCR analysis of CYP81D11 and VSP2 transcript levels (normalized to the housekeeping gene UBQ5) in Col-0 wild-type and tga2,5,6 and scl14 mutant plants. 6-7-week-old soilgrown plants were either sprayed with $100 \mu \mathrm{m}$ TIBA for $8 \mathrm{~h}$ or treated with MeJA (1 $\mu \mathrm{L} / \mathrm{L}$ air) for $24 \mathrm{~h}$. During the MeJA treatment, plants were kept in a gas-proof tank; liquid MeJA was applied to Whatman paper that was attached to the inner glass surface. Whole rosettes were harvested for RNA isolation. Transcript values in mock-treated Col-0 plants were set to 1 .

(A, B) CYP81D11 expression in Col-0 wild-type, tga2,5,6 and scl14 plants. No transcript could be detected in mock-treated (MeJA) tga2,5,6 samples. Each bar represents the average \pm SEM of three (MeJA) or four (TIBA) biological replicates. In (B) the scale was changed to visualize low values.

(C) VSP2 expression in Col-0, tga2,5,6 and scl14 plants. Each bar represents the average \pm SEM of three biological replicates.

(D) VSP2 expression in response to TIBA and MeJA treatment in Col-0 plants. Bars represent the average \pm SEM of eight (TIBA), five (MeJA mock) or nine (MeJA induced) biological replicates.

CYP81D11 expression in the tga2,5,6 mutant was nearly abolished in response to MeJA as well as in response to TIBA. For many mock-treated samples, the transcript levels 
were even below detection levels. Nevertheless, in response to MeJA, an induction was achieved. The scll4 mutant shows less stringent effects. After treatment with TIBA or MeJA, increased CYP81D11 expression levels were observed. Nevertheless, MeJA leads to a stronger CYP81D11 induction in the scl14 mutant than TIBA, indicating a less stringent SCL14 dependency in response to MeJA than in response to TIBA.

VSP2 expression in response to MeJA shows no reduction in the tga2,5,6 and scll4 mutants compared to the Col-0 wild type. These mutants rather exhibit a two times stronger VSP2 induction. This demonstrates that TGA class II transcription factors and SCL14 have distinct functions in regulating CYP81D11 and VSP2 transcription in response to JA and that they have no general function in JA signal transduction.

In TIBA-treated wild-type plants, VSP2 transcript levels were only slightly increased compared to mock-treated plants (about 3-fold). In contrast, MeJA treatment induced VSP2 transcript levels by about 400-fold. Thus, JA-inducible genes are not in general inducible by TIBA, as confirmed by the Genevestigator database (www.genevestigator.com).

In addition to pharmacological treatments, CYP81D11 expression is also inducible by pathogens like the necrotrophic fungal pathogen Botrytis cinerea. To investigate a more natural situation, A. thaliana wild-type, scl14 and tga2,5,6 plants were drop-inoculated with $B$. cinerea. At 3 days post infection, inoculated leaves were harvested and four leaves (of different plants) were pooled as one sample. CYP81D11 transcript levels were investigated by quantitative real-time RT-PCR (Figure 4. 2). 


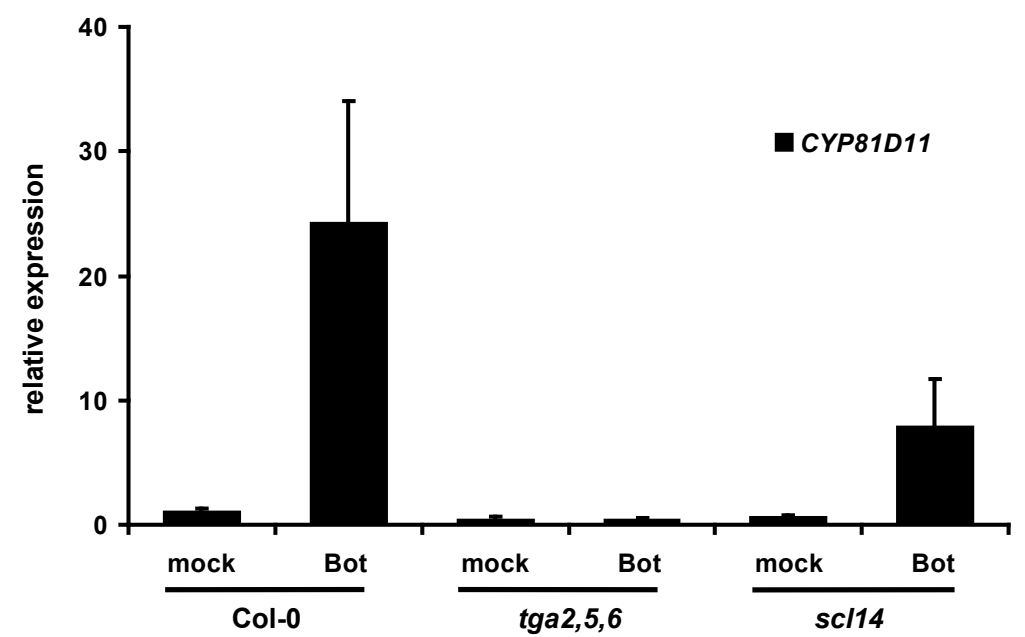

Figure 4. 2: Expression analysis of CYP81D11 after infection with Botrytis cinerea

Quantitative real-time RT-PCR analysis of relative CYP81D11 transcript levels (normalized to the housekeeping gene $U B Q 5$ ) in wild-type, $\operatorname{tga2,5,6}$ mutant and scl14 mutant plants 3 days after inoculation with $B$. cinerea. 6 -week-old soil-grown plants were drop-inoculated with $6 \mu \mathrm{L}$ of a $B$. cinerea spore solution $\left(2 \times 10^{5}\right.$ spores $\left./ \mathrm{mL}\right)$ (Bot) or with $6 \mu \mathrm{L}$ of quarter-strength potato dextrose broth (mock). Four inoculated leaves were pooled as one sample for RNA extraction. Each bar represents the average \pm SEM of two to three (mock) or four to seven samples (Bot).

After B. cinerea infection, CYP81D11 expression was clearly induced, although the transcript levels were notably weaker than in response to the chemical treatments. Nevertheless, the $\operatorname{tga2,5,6}$ and scl14 mutants show similar behavior compared to the treatment with TIBA and MeJA (Figure 4. 1). The tga2,5,6 mutant displayed a reduced expression background in mock-treated leaves that was no longer inducible by B. cinerea infection. The scl14 mutant on the other hand exhibited inducible CYP81D11 expression; however, it only reached about $30 \%$ of the wild-type level. These results indicate that infection with Botrytis cinerea is more closely reflected by MeJA than by TIBA treatment.

Fode et al. (2008) demonstrated that SCL14 binds to the CYP81D11 promoter via the TGA2,5,6 transcription factors, which themselves bind to the as-1-like element contained in the promoter of CYP81D11 and other SCL14 target genes. Considering the extraordinary importance of TGA2,5,6 for CYP81D11 expression, the as-1-like element was expected to be indispensable for the transcription of CYP81D11.

To elucidate the role of the as-1-like element, CYP81D11 promoter:GUS reporter gene constructs were generated. The 894-bp fragment upstream of the CYP81D11 transcription start and the 5' UTR were isolated. The as-1-like element (position -243 to -225) was modified by overlapping PCR. The wild-type promoter fragment (WT) and the one with the mutated as-1-like element (mas-1) were inserted by gateway ${ }^{\circledR}$ cloning 
into an A. thaliana expression vector upstream of the GUS reporter gene. Transgenic A. thaliana plants containing these constructs were generated by Agrobacterium tumefaciens-mediated gene transfer and primary transformants were selected by the herbicide BASTA. F1 generation plants, representing a pool of homozygous and heterozygous transformants as well as wild-type plants, were analyzed after TIBA and MeJA treatment (Figure 4. 3).

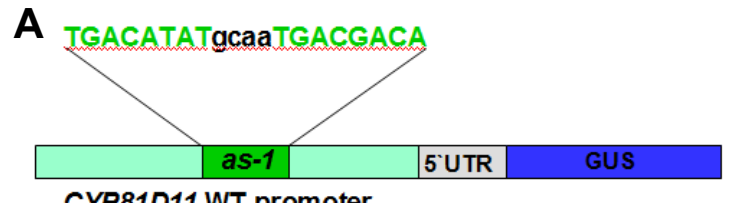

CYP81D11 WT promoter

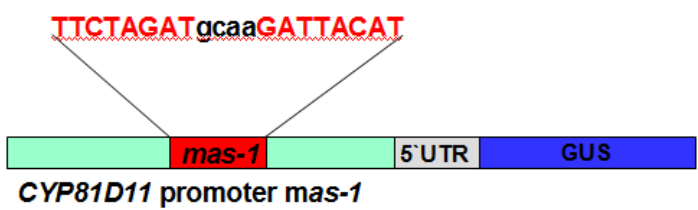

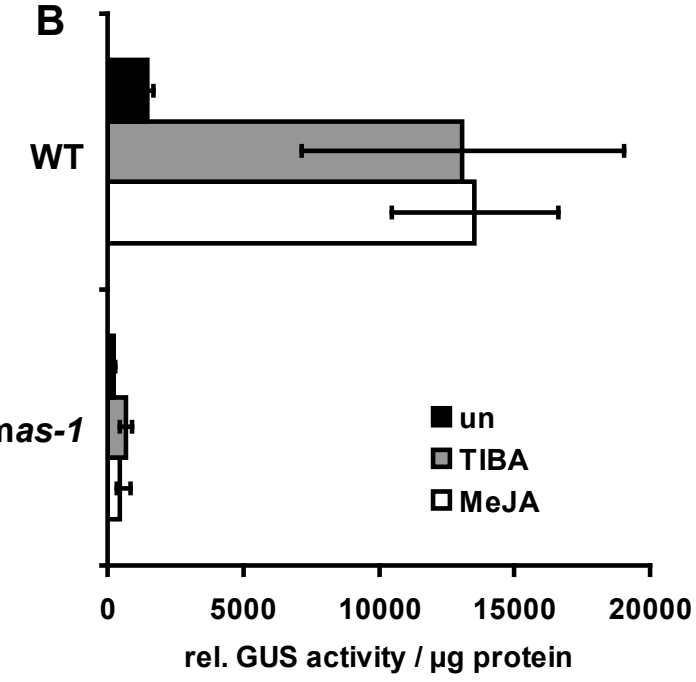

Figure 4. 3: Average activities of CYP81D11 WT promoter constructs and a construct lacking the as-1-like element in response to TIBA and MeJA

(A) Scheme of the CYP81D11 promoter:GUS reporter gene constructs, which were used to generate the transgenic lines. The light green box indicates the CYP81D11 promoter fragment 894 bp upstream of the transcription start; the as-1-like element (position -243 to -225) is marked in green while the mutated sequence is marked in red. The grey box depicts the 5' UTR of the CYP81D11 gene and the GUS reporter gene is indicated in blue.

(B) GUS activities obtained from transgenic plants containing the CYP81D11 promoter:GUS constructs depicted in (A), in response to TIBA and MeJA treatment. Seedlings were grown for 16 days on MS agar under long-day conditions ( $14 \mathrm{~h} \mathrm{light,} 10 \mathrm{~h}$ dark) and either sprayed with $100 \mu \mathrm{m}$ TIBA for $8 \mathrm{~h}$ or treated with gaseous MeJA $(1 \mu \mathrm{L} / \mathrm{L}$ air) for $24 \mathrm{~h}$. Control plants remained untreated. Whole seedlings were harvested for protein extraction. Each bar represents the average \pm SEM of 17 (mas-1) or 18 (WT) transgenic lines.

While the WT CYP81D11 promoter:GUS construct was well inducible by TIBA and MeJA, the mas- 1 construct led to GUS activities that were even lower than those of the uninduced WT construct. It is concluded that the as-1-like element is of essential importance for the expression of CYP81D11. 


\subsection{CYP81D11 shares common properties with the JA marker gene VSP2}

Mutation of the JA-Ile receptor COI1 leads to a very strong JA-insensitive phenotype and strongly reduces the expression of JA-inducible genes (Ellis \& Turner 2002; Devoto et al. 2005; Feys et al. 1994). CYP81D11 expression was previously reported to be dependent on COI1 in response to MeJA treatment. This indicates that CYP81D11 is regulated by the known JA signaling pathway. This pathway activates two groups of JA-inducible genes: only JA-inducible genes like VSP2 and JA/ET-inducible genes like PDF1.2. To classify CYP81D11, Col-0 wild-type plants were treated with the ET precursor 1-aminocyclopropane-1-carboxylic acid (ACC) in addition to MeJA. Transcription levels of CYP81D11, VSP2 and PDF1.2 were determined by quantitative real-time RT-PCR (Figure 4. 4). To reproduce the previously published result that MeJA induction of CYP81D11 is COI1 dependent (Mueller et al. 2008), also CYP81D11 and VSP2 expression in the coil-1 (Xie et al. 1998) mutant in response to MeJA were investigated. The coil-1 mutant exhibits an additional mutation in the GLABROUS gene, which leads to a defect in trichome development (Larkin et al. 1994). Therefore, gll plants carrying the same mutation were used as control. 
A

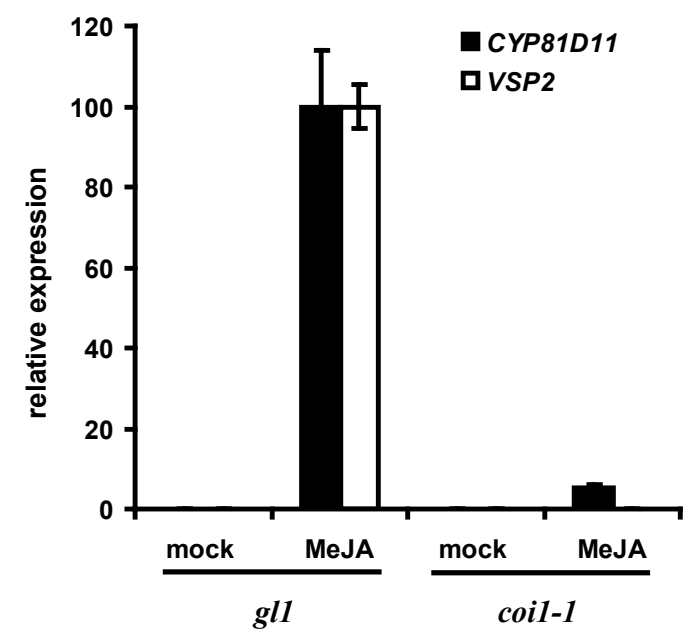

B

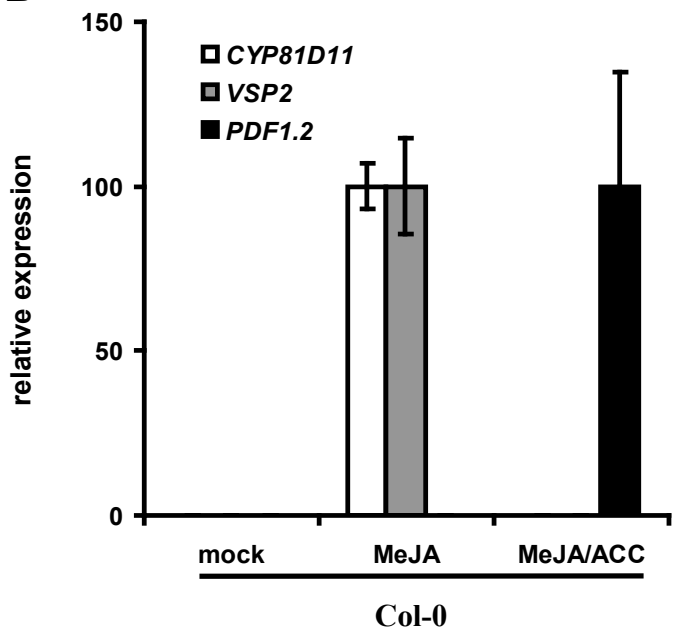

Figure 4. 4 : Expression analyses of CYP81D11, VSP2 and PDF1.2 after treatment with MeJA and the ethylene precursor $\mathrm{ACC}$

Quantitative real-time RT-PCR analyses of CYP81D11, VSP2 and PDF1.2 transcript levels (normalized to the housekeeping gene UBQ5).

(A) gll and coil-1 plants were grown on MS agar under short-day conditions; for coil-1, the MS medium contained $50 \mu \mathrm{M}$ MeJA to select homogeneous individuals. After 3 weeks, they were transferred to soil and grown for another 4 weeks under 12-h day and 12-h night conditions. The plants were treated with gaseous MeJA ( $1 \mu \mathrm{L} / \mathrm{L}$ air) for $24 \mathrm{~h}$. During MeJA treatment, the plants were kept in a gas-proof tank; liquid MeJA was applied to Whatman paper that was attached to the inner glass surface, and evaporated into the gas phase. Whole rosettes were harvested for RNA isolation. Transcript values of MeJA-treated Col-0 plants were set to 100. Each bar represents the average \pm SEM of four biological replicates.

(B) 6-7-week-old soil-grown Col-0 wild-type plants were treated with gaseous $\mathrm{MeJA}(1 \mu \mathrm{L} / \mathrm{L}$ air) for $24 \mathrm{~h}$ and sprayed with $5 \mathrm{mM}$ ACC. Whole rosettes were harvested for RNA isolation. For each gene, the highest transcript level was set to 100. Each bar represents the average \pm SEM of four biological replicates.

In the coil-1 mutant, the expression of CYP81D11 in response to MeJA is reduced to $5 \%$ compared to the $g l 1$ plants, indicating that JA-induced CYP81D11 expression depends on the known JA signaling pathway. Nevertheless, VSP2 transcript levels were reduced to about $0.1 \%$ of those of MeJA-treated gll plants, both in mock- and MeJAtreated coil-1 plants. This indicates an additional way of JA induction for CYP81D11 expression.

VSP2 as well as CYP81D11 expression are well inducible by application of JA alone, while this treatment only leads to a very slight increase in PDF1.2 expression. In contrast to this, JA/ACC treatment abolishes the increased transcription levels of VSP2 and CYP81D11 obtained by JA, but strongly induces the transcription of PDF1.2. Thus, CYP81D11 is classified as an only JA-inducible gene. 


\subsection{TIBA-induced CYP81D11 expression depends on COI1 in the absence of increased JA-Ile levels}

CYP81D11 expression requires COI1 not only in response to MeJA, but also in response to phytoprostanes (Mueller et al. 2008). This contradicts the current model of COI1 function as JA-Ile receptor (Memelink 2009). To investigate the COI1 dependency in response to TIBA, gll and coil-1 plants were treated with $100 \mu \mathrm{M}$ TIBA; CYP81D11 expression levels were monitored by quantitative real-time RT-PCR and compared to those of three other TIBA-inducible SCL14 target genes (Figure 4. 5).
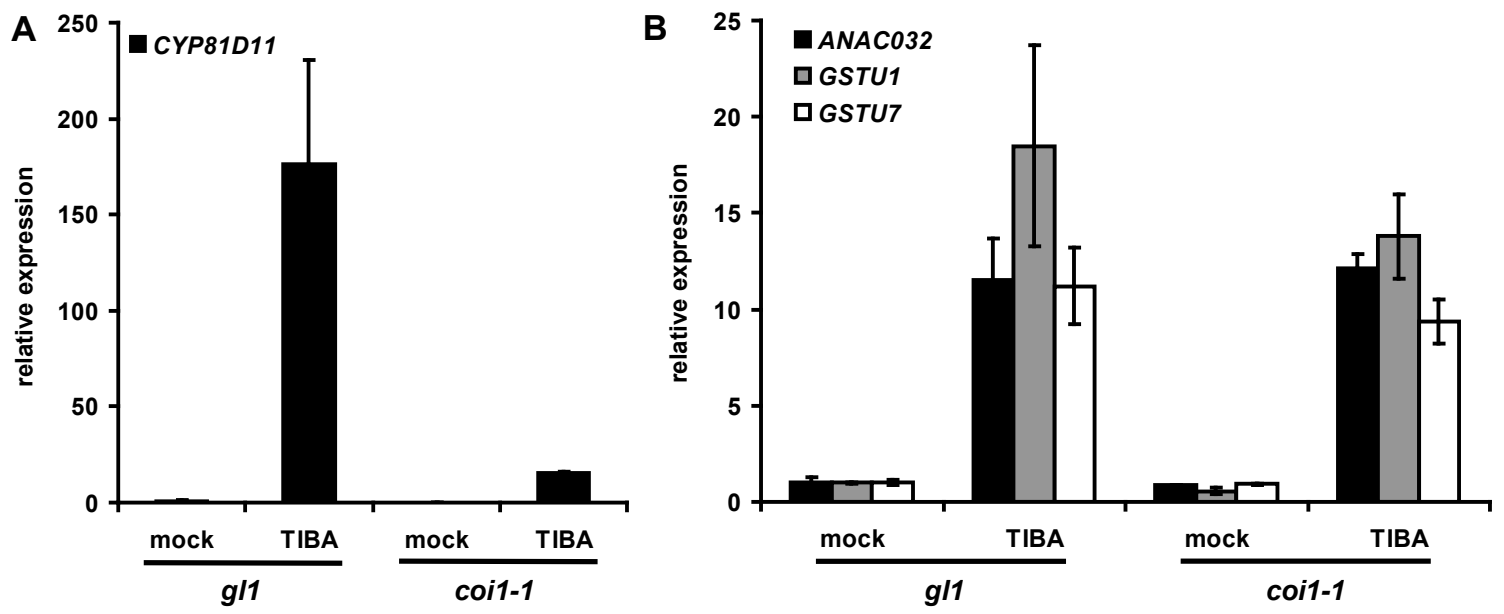

Figure 4. 5: Expression analysis of SCL14 target genes in response to TIBA

Quantitative real-time RT-PCR analysis of relative CYP81D11, ANAC032, GSTU1 and GSTU7 transcript levels (normalized to the housekeeping gene UBQ5) in gll and coil-1 mutant plants. 6-7-week-old plants were sprayed with $100 \mu \mathrm{M}$ TIBA. Whole rosettes were harvested for RNA isolation. Transcript values in mock-treated Col-0 plants were set to 1. Each bar represents the average \pm SEM of two (mock) or three (TIBA) biological replicates.

In TIBA-treated coil-1 plants, CYP81D11 expression is reduced to about $10 \%$ compared to the corresponding "wild-type" $g l 1$. This result is consistent with the COI1dependent $C Y P 81 D 11$ expression in response to phytoprostanes. Except for this result, the COI1 protein has only been reported to be involved in JA signaling, and no reports about its involvement in the xenobiotic response are known. Furthermore, the transcript of three other SCL14 target genes, ANAC032, GSTU1 and GSTU7, were not reduced in the coil-1 mutant. Therefore, a general involvement of COI1 in the xenobiotic response seems unlikely.

An explanation for the involvement of COI1 in CYP81D11 expression in response to TIBA would be an accumulation of JA-Ile after TIBA treatment. Thus, JA-Ile levels in 
mock- and TIBA-treated soil-grown plants were determined by HPLC-MS/MS (Figure 4.6).
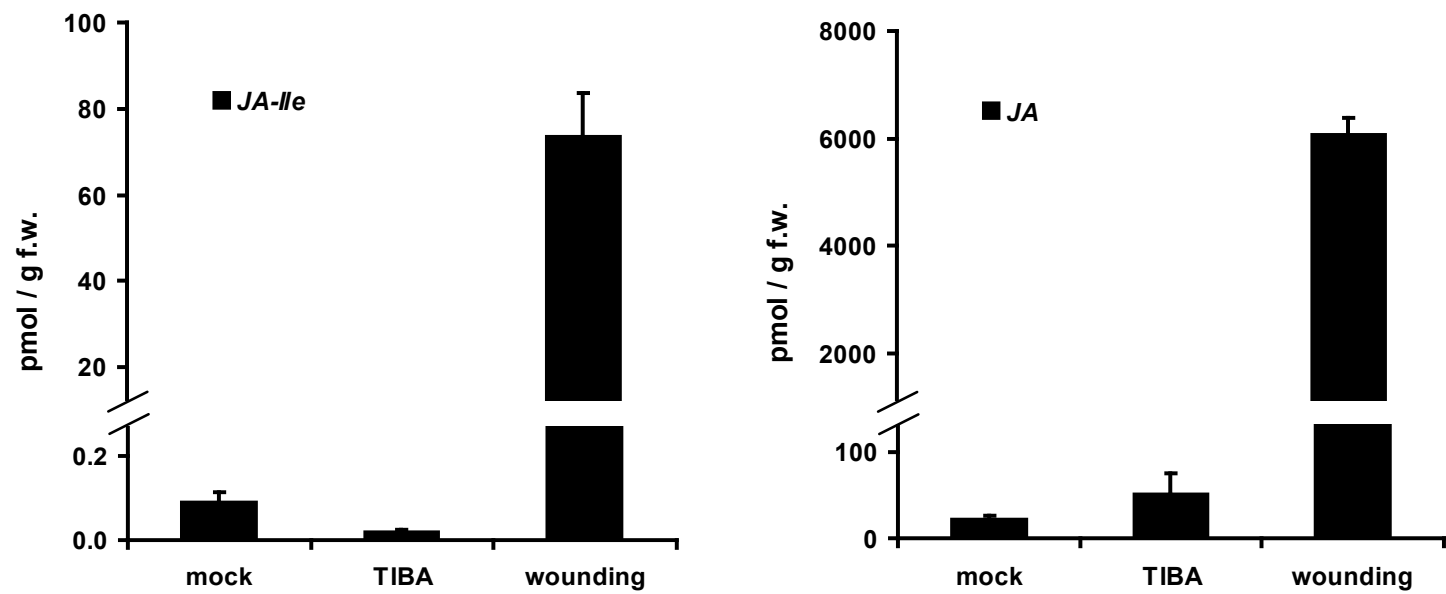

Figure 4. 6: JA-Ile and JA levels in mock- and TIBA-treated $A$. thaliana

Determination of JA-Ile and JA levels by HPLC-MS/MS was performed in Col-0 wild-type plants grown on soil for 6-7 weeks under 12-h light/12-h dark conditions. The plants were sprayed with either $100 \mu \mathrm{M}$ TIBA or $0.1 \%$ DMSO and incubated for $8 \mathrm{~h}$. Whole rosettes were harvested. As a control, leaves were wounded by squeezing with forceps and incubated for $2 \mathrm{~h}$. In this case, only the wounded leaves were harvested. For JA (mock and TIBA), each bar represents the average \pm SEM of seven biological replicates from two independent experiments. In case of JA-Ile (mock and TIBA), each bar represents the average \pm SEM of four biological replicates from one experiment. As in the second experiment, the JA-Ile levels were below detectable levels. Wounding experiments were only performed once with two biological replicates. JA-Ile and JA amounts are depicted as pmol/g fresh weight.

JA-Ile levels are not increased in TIBA-treated compared to mock-treated plants; in contrast, they are even slightly decreased. Under comparable conditions, wounding leads to a high accumulation of JA-Ile. TIBA also does not elicit accumulation of JA, although for JA the variation among the samples was higher. Still, in comparison to wounded plants, JA levels in mock-induced as well as in TIBA-induced plants were very low. This finally proves that JA-Ile accumulation is not the reason for the COI1 dependency of CYP81D11 expression in response to TIBA.

The described function of COI1 in response to JA-Ile accumulation is to mark JAZ proteins for degradation. To trace this process, fusion proteins of JAZ proteins and the beta-glucuronidase protein (GUS) or the green fluorescing protein (GFP) have been used successfully (Thines et al. 2007; Chini et al. 2007). JAZ stability in response to TIBA was monitored in transgenic plants expressing a JAZ1-GUS fusion protein (Thines et al. 2007). The concentration of JAZ1-GUS was determined by quantitative measurements of GUS activity in protein extracts prepared from A. thaliana seedlings $8 \mathrm{~h}$ after TIBA treatment. MeJA-treated JAZ1-GUS seedlings were used as positive control. 


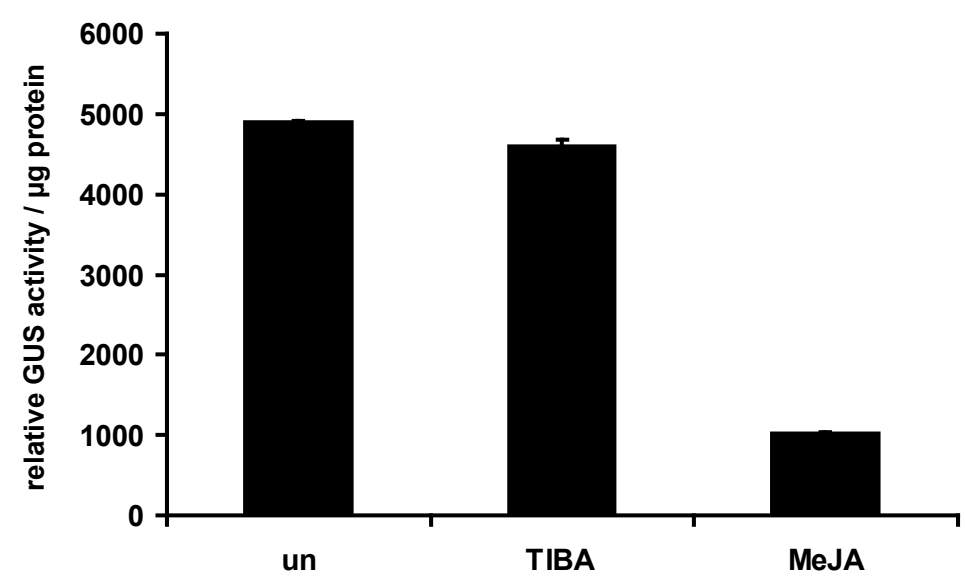

Figure 4. 7: Relative JAZ1-GUS levels after treatment with TIBA and MeJA

16-day-old seedlings ectopically expressing JAZ1-GUS fusion proteins, grown on MS agar, were either sprayed with $100 \mu \mathrm{m}$ TIBA for $8 \mathrm{~h}$ or treated with gaseous MeJA $(1 \mu \mathrm{L} / \mathrm{L}$ air $)$ for $8 \mathrm{~h}$. About 50 seedlings grown on the same agar plate were pooled for protein extraction and GUS activity tests. The GUS activity was normalized to the protein concentration. Each bar represents the average \pm SEM of two independent seedling pools.

TIBA treatment of JAZ1-GUS seedlings did not lead to a decrease in GUS activity, demonstrating that no increased JAZ1 degradation occurs. Still, this assay only reflects the JAZ1:GUS protein concentrations; a possible constant turnover of JAZ proteins cannot be monitored.

As positive control, protein extracts of the MeJA-treated JAZ1-GUS plants show a clear reduction in GUS activity, thereby providing evidence that increased JA-Ile levels indeed reduced the JAZ1 levels in this experiment (Figure 4. 7).

\subsection{CYP81D11 expression in response to xenobiotic stress requires a JA-Ile-independent COI1 function}

JA-Ile measurements demonstrated that no JA-Ile accumulation occurs in response to TIBA. Nevertheless, CYP81D11 expression is strongly dependent on the JA-Ile receptor COI1. To answer the question whether JA-Ile is required, the JA synthesis mutant dde2-2 was used. The DDE2 gene encodes the enzyme allene oxide synthase (AOS) which converts 13(S)-hydroperoxylinolenic acid to 12,13-epoxylinolenic acid (Park et al. 2002). The dde2-2 mutant was used to assess the impact of the basal JA levels in mock- and TIBA-treated plants on the TIBA-induced CYP81D11 expression. Soilgrown plants were treated with TIBA and incubated for $8 \mathrm{~h}$. RNA was isolated to allow profiling of the CYP81D11 transcript by quantitative real-time RT-PCR (Figure 4. 8). 


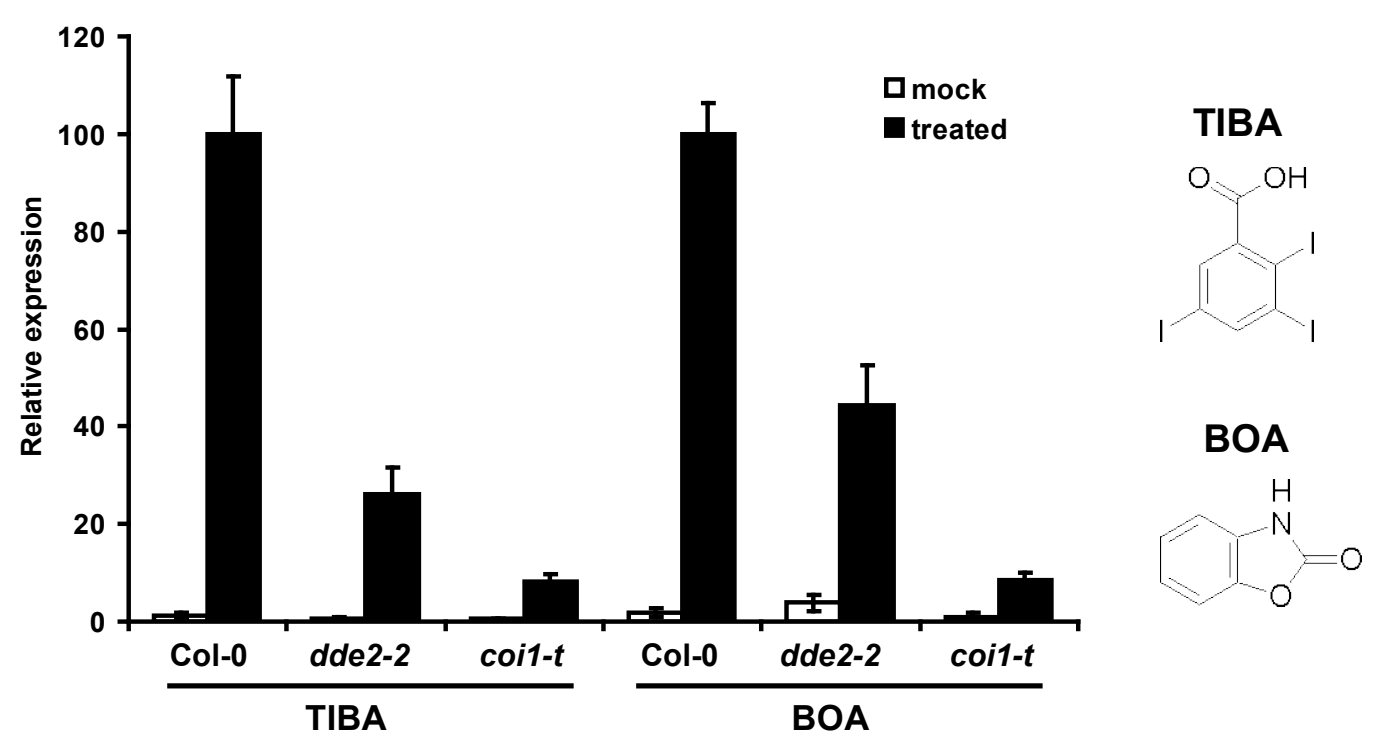

Figure 4. 8: CYP81D11 transcript levels after TIBA and BOA treatment in the dde2-2 and coil-t mutants

Quantitative real-time RT-PCR analysis of relative CYP81D11 transcript levels (normalized to the housekeeping gene UBQ5) in Col-0 (wild-type), dde2-2 and coil-t (Mosblech et al. 2010) plants. 6-7week-old plants were sprayed with $100 \mu \mathrm{M}$ TIBA or $2 \mathrm{mM}$ BOA and, $8 \mathrm{~h}$ after induction, whole rosettes were harvested for RNA isolation. Transcript values of treated Col-0 plants were set to 100. Each bar represents the average \pm SEM of three to eight biological replicates.

The chemical structures of TIBA and BOA are indicated.

CYP81D11 transcript levels in TIBA-treated dde2-2 plants were reduced to about $30 \%$ of the Col-0 wild type. This indicates that basal JA-Ile levels have an important influence on TIBA induction of CYP81D11 expression. Nevertheless, CYP81D11 transcript levels in the dde2-2 mutant are still three times higher than in the coil-t mutant. Comparable to the previous experiment using the coil-1 mutant (Figure 4. 5), CYP81D11 levels are reduced to about $10 \%$. Based on these data, it is concluded that the absence of JA has less severe consequences for CYP81D11 expression than the absence of the F-box protein COI1. This result was unexpected as it implicates that the COI1 protein, which so far has only been known to function as a JA-Ile receptor in JA signal transduction, exhibits a function independent of JA.

To determine whether this effect is specific for TIBA, the allelochemical benzoxazolin2(3H)-one (BOA) was used for the induction of CYP81D11 expression. BOA has previously been identified as an inducer for CYP81D11 (Baerson et al. 2005), but has no similarity to TIBA regarding the chemical structure. Comparable effects concerning the different strengths of CYP81D11 expression in the dde2-2 and coil-t mutants were observed in response to BOA and TIBA. This demonstrates that the differential CYP81D11 expression in the dde2-2 and coil-t mutants in response to xenobiotic treatment is not specific to TIBA. 
To support the result that the absence of JA-Ile affects CYP81D11 expression less severely than the absence of COI1, another JA-Ile-deficient A. thaliana mutant, jar1-1 (jasmonate resistant 1), was used for TIBA treatment (Figure 4. 9). The jar1-1 mutant exhibits a defect in an enzyme converting JA to its amino acid conjugate JA-Ile. Additionally, it should be excluded that minor JA levels, which might still be produced in the dde2-2 mutant, are responsible for the observed CYP81D11 expression. Therefore, a dde2-2/jar1-1 double mutant, in which potential minor JA levels will not be converted to JA-Ile, was created. By quantitative real-time RT-PCR, CYP81D11 transcript levels were determined in the dde2-2 and jarl-1 single mutants and the dde2-2/jar1-1 double mutant, in response to TIBA (Figure 4. 9).

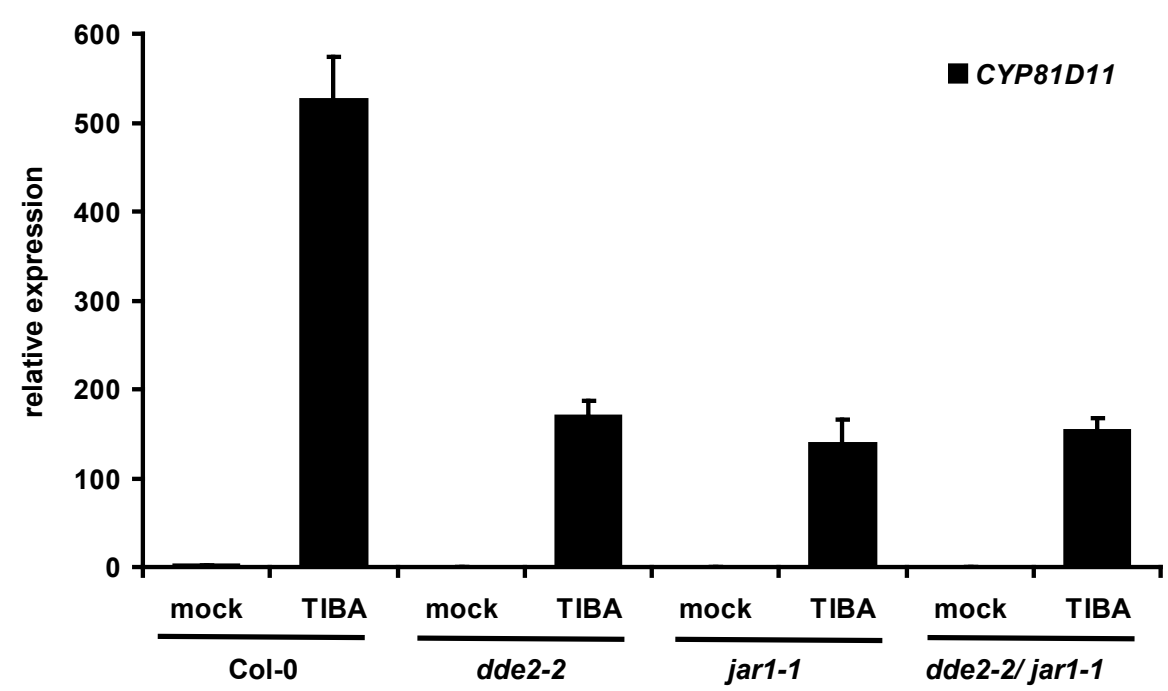

Figure 4. 9: Expression analysis of CYP81D11 in JA synthesis mutants after TIBA

Quantitative real-time RT-PCR analysis of relative CYP81D11 transcript levels (normalized to the housekeeping gene UBQ5) in Col-0 (wild-type), dde2-2, jar1-1 and dde2-2/jar1-1 mutant plants. 6-7week-old plants were sprayed with $100 \mu \mathrm{M}$ TIBA. Whole rosettes were harvested for RNA isolation. Transcript values in mock-treated Col-0 plants were set to 1. Each bar represents the average \pm SEM of four (Col-0, dde2-2 and jar 1-1) or eight (dde2-2/jar1-1) biological replicates.

The jar 1-1 mutant exhibits reduced CYP81D11 expression to the same extent as the dde2-2 mutant, underlining the importance of basal JA-Ile levels for CYP81D11 expression and supporting the result that JA-Ile deficiency reduces CYP81D11 expression less severely than the absence of COI1. The idea that the differences in CYP81D11 expression in JA-Ile synthesis mutants and the JA signaling mutant coil- $t$ might be due to an induction by minor residual JA-Ile levels synthesized by alternative reactions was excluded by the dde2-2/jar 1-1 mutant. The CYP81D11 expression level in 
this double mutant resembles the expression levels in the single mutants and was not further reduced.

\subsection{Maximum CYP81D11 expression in response to TIBA requires basal JA-Ile levels and JA signaling components}

As the previous experiments have indicated a JA-Ile-independent COI1 function in response to TIBA, it was investigated if this depends on JA signaling downstream of COI1, which is mediated by JAZ proteins and the transcription factor MYC2. For MYC2, the mutant line jin1-1 (jasmonate insensitive 1) is available. The degradation of $\mathrm{JAZ}$ proteins is abolished in transgenic plants expressing a JAZ protein with a deletion in the C-terminal Jas domain (e.g. JAZ1 $\Delta 3$ A (Thines et al. 2007)). On the one hand, these proteins themselves were shown to be resistant to degradation; on the other hand, they exhibited a dominant-negative effect that also blocks the degradation of other JAZ proteins, leading to a strong JA-insensitive phenotype. TIBA treatment of jin 1-1 mutants and JAZ1 $\triangle 3 \mathrm{~A}$ plants and subsequent quantitative real -time RT-PCR revealed the effect of JA-Ile signaling components downstream of COI1 on the TIBA-dependent expression of CYP81D11 (Figure 4. 10). 


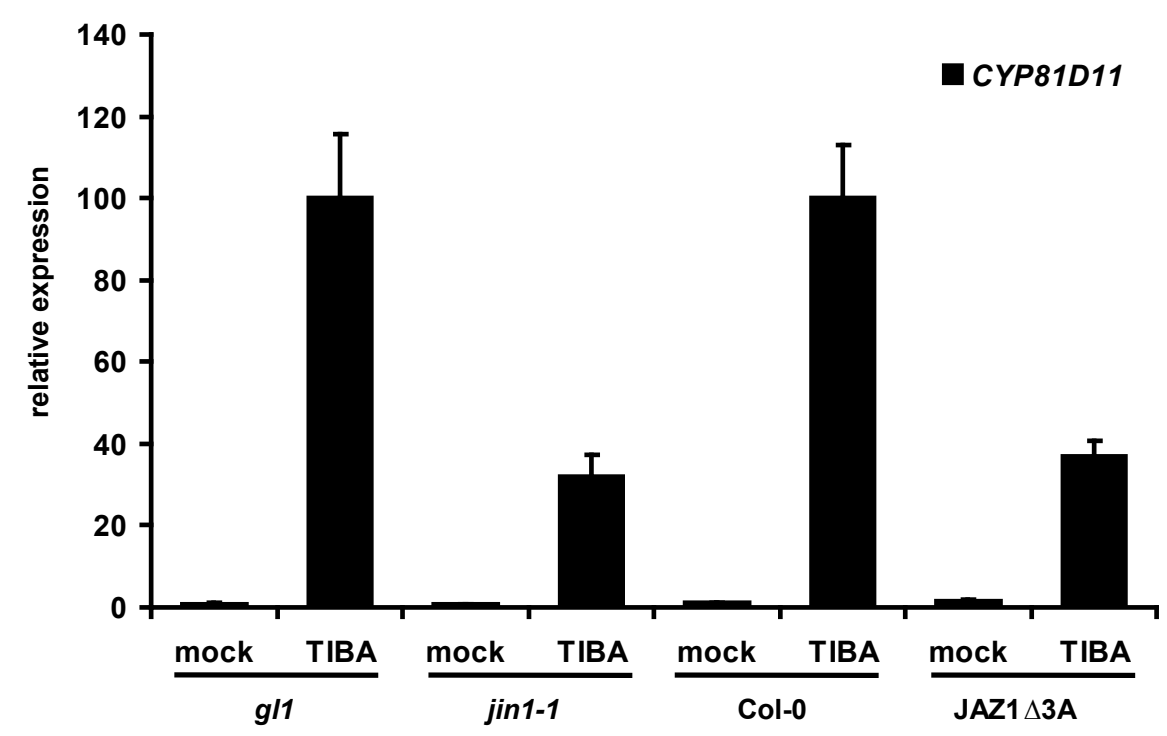

Figure 4. 10: Expression analysis of CYP81D11 in plants deficient in JA signal transduction after TIBA

Quantitative real-time RT-PCR analysis of relative CYP81D11 transcript levels (normalized to the housekeeping gene UBQ5) in gll ("wild-type") and jin1-1 mutant plants as well as Col-0 (wild-type) plants ectopically expressing JAZ $\triangle 3 \mathrm{~A}$, a JAZ1 protein lacking the Jas domain. 6-7-week-old plants were sprayed with $100 \mu \mathrm{M}$ TIBA and, after $8 \mathrm{~h}$, whole rosettes were harvested for RNA isolation. Transcript values in mock-treated Col-0 plants were set to 1 . Each bar represents the average \pm SEM of four ( $g l l$ and jin 1-1), five (Col-0 mock), six (Col-0 TIBA and JAZ1 $\triangle 3$ A TIBA), or seven (JAZ1 33 A mock) biological replicates.

The jin1-1 mutant and the JAZ1 3 A plants exhibit CYP81D11 transcript levels in response to TIBA that are reduced to about one-third of those of the corresponding wild type (Figure 4. 10). This is consistent with the reduction in JA-Ile-deficient mutants (Figure 4. 9), indicating that MYC2, together with degradation of the JAZ proteins, is involved in the signaling response to basal JA levels, but is not involved in the signaling downstream of the new, JA-Ile-independent COI1 function.

\subsection{Mutation of the MYC2 binding site leads to a JA-insensitive but COI1-dependent CYP81D11 promoter}

MYC2 transcription factors bind to sequence motifs called G-boxes (Abe et al. 2003; Abe et al. 1997; Dombrecht et al. 2007). To investigate the role of the G-boxes in the CYP81D11 promoter, reporter gene constructs with mutated G-boxes were designed. The CYP81D11 promoter contains two neighboring G-boxes (position -206 to -193 ) separated by only one base pair; one G-box exhibits the sequence CACGTG and the other is represented by CACATG. They were replaced by TTCAAG and TTCAAA (Abe et al. 1997) as replacement with these sequences creates no other known 
transcription factor binding sites (http://www.dna.affrc.go.jp/PLACE/). CYP81D11 promoter:GUS constructs in binary plant vectors were created, either using an 894-bp promoter fragment exhibiting the wild-type sequence or the promoter sequence with mutated G-boxes. Transgenic plants were produced by A. tumefaciens-mediated gene transfer into $A$. thaliana Col-0 plants. The seedlings of the F1 generation grown on agar plates were used for TIBA and MeJA treatment (Figure 4. 11).

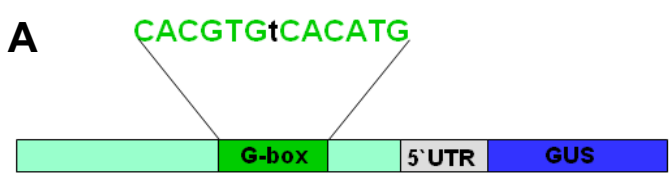

CYP81D11 WT promoter

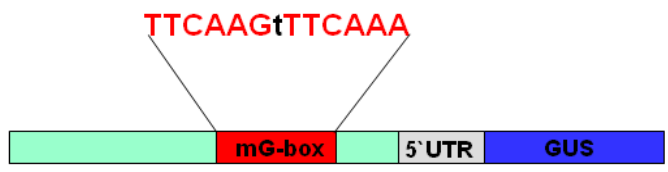

CYP81D11 promoter $\mathrm{mG}-\mathrm{box}$

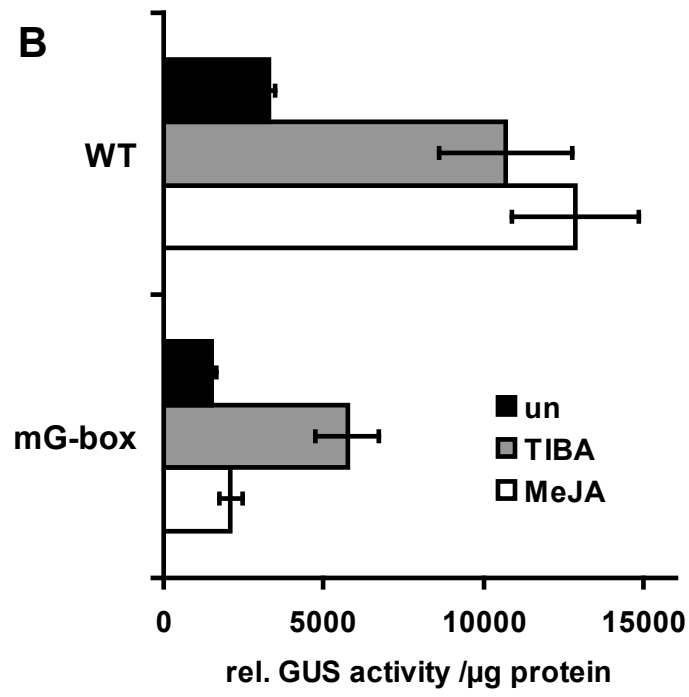

Figure 4. 11: Average activities of a CYP81D11 WT promoter construct and a construct lacking the G-boxes in response to TIBA and MeJA

(A) Scheme of the distinct CYP81D11 promoter:GUS reporter gene constructs that were used to generate the transgenic lines employed in this experiment. The light green box indicates an 894-bp fragment upstream of the CYP81D11 transcription start. The double G-box (position -206 to -193 ) is marked in green, while the altered sequence is marked in red; both sequences are indicated. The grey box depicts the 5' UTR of the CYP81D11 gene and the GUS reporter gene is indicated in blue.

(B) GUS activities in response to TIBA and MeJA treatment obtained from transgenic plants containing the CYP81D11 promoter:GUS constructs depicted in (A). Seedlings were grown for 16 days on MS agar and either sprayed with $100 \mu \mathrm{m}$ TIBA for $8 \mathrm{~h}$ or treated with gaseous MeJA $(1 \mu \mathrm{L} / \mathrm{L}$ air) for $24 \mathrm{~h}$. Control plants remained untreated. Whole seedlings were harvested for protein extraction. Each bar represents the average \pm SEM of two experiments, each carried out with 19-20 transgenic lines.

The GUS activity in transgenic plants encoding the CYP81D11 WT promoter:GUS construct was inducible to similar extents in response to TIBA and MeJA. Plants containing the CYP81D11 mG-box promoter:GUS construct were not inducible by MeJA. This result indicates that the double G-box is absolutely essential for JA-induced CYP81D11 expression. The non-induced and the TIBA-induced levels were reduced about two times. This leads to the suggestion that the G-boxes play a role as elements for constitutive activation, but not as activated elements in response to TIBA.

The substitution of the G-boxes in the CYP81D11 promoter generated a promoter construct insensitive to JA. To investigate the COI1 dependency of this promoter 
construct, transfection experiments in Col-0 and coil-t protoplasts were performed (Figure 4. 12).

A

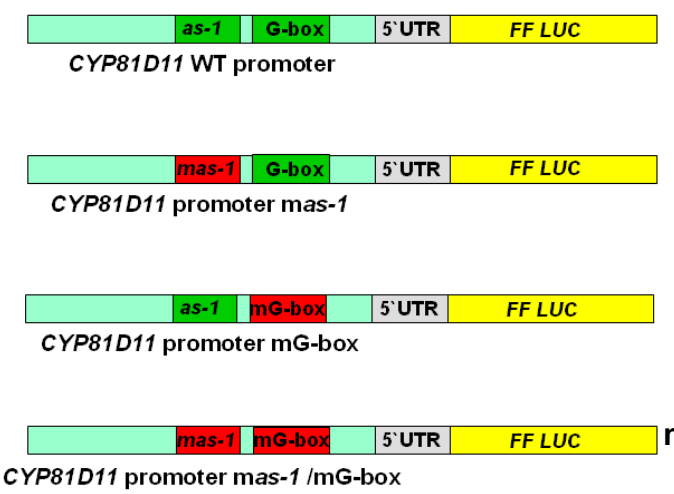

B

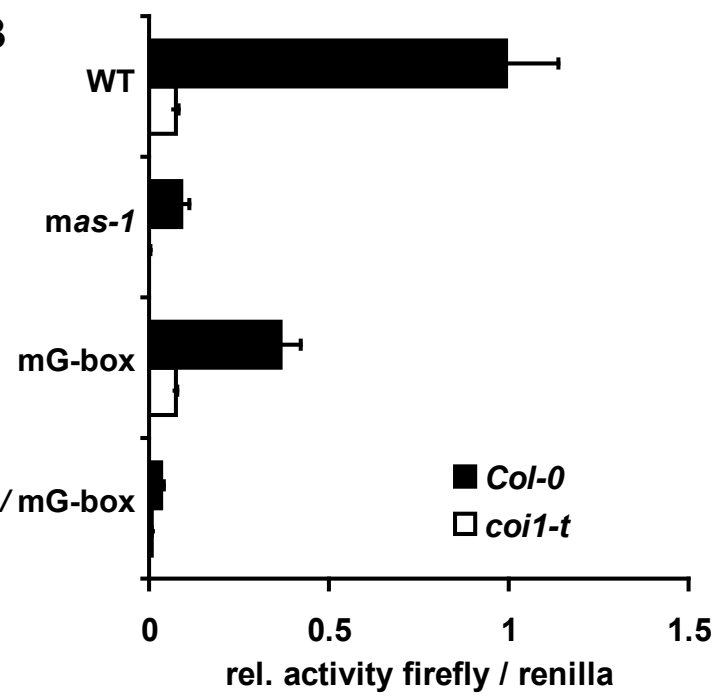

Figure 4. 12: Transient expression analysis of distinct CYP81D11 promoter constructs carrying sequence alterations at the site of the as-1-like element and the site of the G-boxes

(A) Schematic illustration of the distinct CYP81D11 promoter:firefly luciferase constructs used for protoplast transfection. The light blue box indicates an 894-bp fragment upstream of the CYP81D11 transcription start site; wild-type sequences of the as- 1 element (position -243 to -225 ) and the double G-box (position -206 to -193) are marked in green while the altered sequences are depicted by red boxes. The grey box marks the 5' UTR of the CYP81D11 gene and the yellow box indicates the firefly luciferase (FF LUC) reporter gene. The construct referred to as WT contains the 894-bp fragment upstream of the CYP81D11 transcription start site and the 5' UTR of the CYP81D11 gene. The mas-1 construct contains sequence alterations within the $a s-1$ element (position -243 to -225) while the mG-box construct contains alterations in the sequence of the double G-box (position -206 to -193 ). The mas-1/mG-box construct exhibits alterations in both elements.

(B) Luciferase activities obtained from transfection of distinct promoter:firefly luciferase constructs in A. thaliana Col-0 and coil-t protoplasts. Leaves of 7-week-old soil-grown and non-induced plants were used for protoplast isolation. The x-coordinate demonstrates the ratio of the firefly luciferase activity to the internal Renilla luciferase standard.

In protoplasts CYP81D11 is constitutively expressed. Therefore they allow expression analyses in the absence of additional treatments. In coil-t protoplasts, the activity of the WT promoter construct is strongly reduced in comparison to the Col-0 protoplasts. This demonstrates a similar COI1 dependency in protoplasts as in whole plants. Additionally, the reduced activity of the mG-box construct compared to the WT construct in wildtype protoplasts also reflects the results obtained by TIBA treatments in whole plants.

A comparison of the reporter gene expression of the mG-box construct in Col-0 and coil-t protoplasts demonstrated the COI1 dependency of this construct. This result leads to the assumption that COI1 carries out its JA-Ile-independent function via another promoter element than the G-boxes which are responsible for JA-Ile-dependent CYP81D11 expression. 
Nevertheless, the fact that in coil-t protoplasts the WT construct and the mG-box construct have the same activity demonstrates that the G-boxes only function in the presence of COI1.

The activities of the mas- 1 and the mas $-1 / \mathrm{mG}$-box constructs are still strongly reduced in the coil-t mutant compared to the wild-type protoplasts. Thus, it was assumed that COI1 regulates the CYP81D11 promoter not via the TGA binding site.

\subsection{A large group of genes depends on COI1 and basal JA-Ile levels in response to TIBA}

In response to TIBA, COI1-dependent regulation of CYP81D11 expression depends on basal JA-Ile levels and on a novel JA-Ile-independent COI1 function. In order to identify other genes showing this type of regulation, mock- and TIBA-treated Col-0 and coil-t plants were compared by transcriptome analyses (Figure 4. 13). As a control, CYP81D11 expression was investigated by quantitative real-time RT-PCR. 


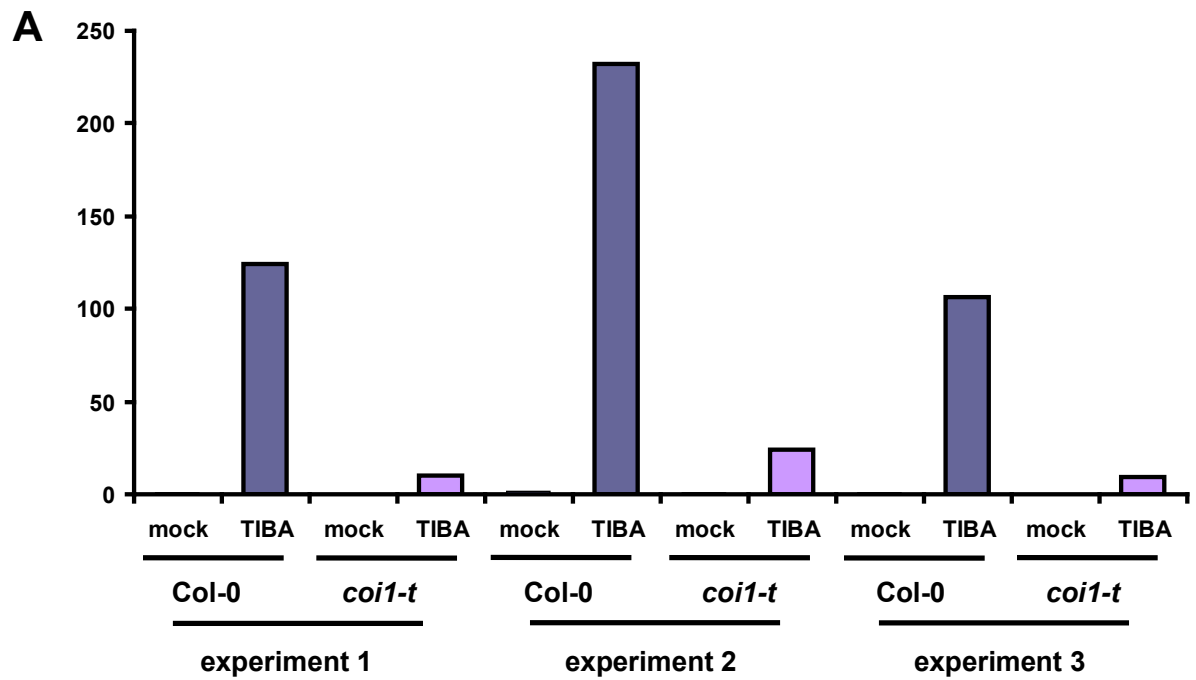

B

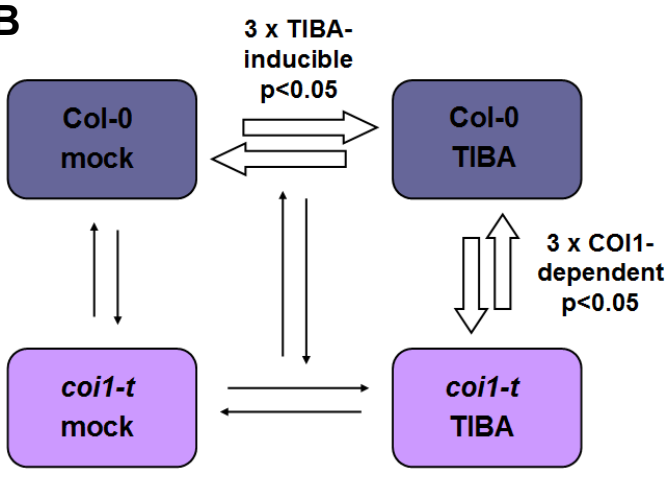

C

173 TIBA-inducible genes

$\square$ COI1-independent $\square$ COI1-dependent

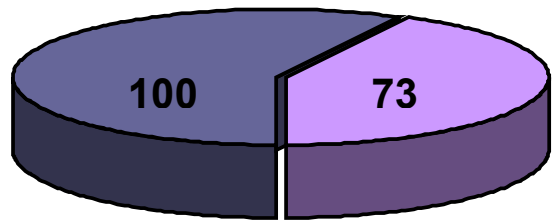

Figure 4. 13: Microarray analyses of TIBA-treated Col-0 and coil-t plants

Plants for the microarray analyses are grown on MS agar under short-day conditions; to select homozygous coil-t plants, the MS medium contained $50 \mu \mathrm{M}$ MeJA. After 3 weeks, JA-insensitive plants were transferred to soil and grown for another 4 weeks under 12-h light/12-h dark conditions. Plants were either sprayed with $100 \mu \mathrm{M}$ TIBA or $0.1 \%$ DMSO (mock) and were harvested after $8 \mathrm{~h}$ as pools of eight plants. Three independent experiments were performed. Hybridizations were performed by NASC's International Affymetrix Service using "Arabidopsis ATH1 Genome Array" chips. Raw data were analyzed by Robin (Lohse et al. 2010).

(A) Quantitative real-time RT-PCR analysis of relative CYP81D11 transcript levels (normalized to the housekeeping gene $U B Q 5$ ).

Scheme (B) is indicating the investigated samples and the comparison made between the different mutants and treatments. All further results were obtained by comparing Col-0 mock and Col- 0 TIBA to define genes inducible by TIBA, and by comparing Col-0 TIBA and coil- $t$ TIBA to define COI1dependent genes.

Diagramm (C) is indicating the numbers genes which are at least 3-fold TIBA-inducible and are COI1 dependent or independent. Genes with expression levels in the coil- $t$ mutant after TIBA treatment reaching less than $30 \%$ of the Col- 0 expression level (P-value $<0.05$ ) were defined as COI1 dependent.

Although CYP81D11 expression varied among the independent experiments, the ratio between Col-0 and coil-t is consistent within each experiment.

By comparing the transcript levels of mock-treated and TIBA-treated Col-0 plants, 173 genes were identified whose expression is at least 3-fold induced by TIBA (P-value $<0.05)$. These were classified into COI1-dependent and COI1-independent genes by comparing TIBA-treated wild-type and TIBA-treated coil-t plants. Genes whose 
expression in the coil-t mutant after TIBA treatment reached less the $30 \%$ of the Col- 0 expression ( $\mathrm{P}$-value $<0.05)$ were defined as COI1 dependent. This sorting resulted in 100 COI1-independent and 73 COI1-dependent genes.

Table 4. 1: Compolation of those ten COI1-dependent genes, which show the strongest expression after TIBA treatment

\begin{tabular}{||l|l|l|c|c|c|c||}
\hline Gene code & Symbol & Description & $\frac{\underline{\text { Col-0 TIBA/ }}}{\text { Col-0 WT }}$ & $\underline{\text { P-value }}$ & $\frac{\text { coil-t TIBA/ }}{\text { Col-0 TIBA }}$ & $\underline{\text { P-value }}$ \\
\hline at3g28740 & CYP81D11 & monooxygenase & 55.64 & $8.6 \mathrm{E}-09$ & 0.12 & $1.0 \mathrm{E}-05$ \\
\hline at1g43160 & RAP2.6 & transcription factor & 30.96 & $1.1 \mathrm{E}-12$ & 0.03 & $9.3 \mathrm{E}-13$ \\
\hline at5g13220 & JAZ10 & jasmonate-ZIM-domain protein & 28.62 & $2.0 \mathrm{E}-10$ & 0.02 & $4.8 \mathrm{E}-11$ \\
\hline at3g49620 & DIN11 & oxidoreductase & 23.70 & $3.5 \mathrm{E}-07$ & 0.01 & $1.2 \mathrm{E}-08$ \\
\hline at1g10585 & & transcription factor & 18.92 & $1.4 \mathrm{E}-10$ & 0.06 & $3.4 \mathrm{E}-10$ \\
\hline at5g63450 & CYP94B1 & monooxygenase & 16.61 & $7.1 \mathrm{E}-12$ & 0.06 & $7.0 \mathrm{E}-12$ \\
\hline at2g34600 & JAZ7 & jasmonate-ZIM-domain protein & 12.90 & $7.2 \mathrm{E}-09$ & 0.07 & $5.1 \mathrm{E}-09$ \\
\hline at4g21680 & & $\begin{array}{l}\text { proton-dependent oligopeptide } \\
\text { transport (POT) family protein }\end{array}$ & 10.93 & $2.9 \mathrm{E}-10$ & 0.12 & $1.4 \mathrm{E}-09$ \\
\hline at3g23550 & & MATE efflux family protein & 9.95 & $3.1 \mathrm{E}-10$ & 0.10 & $3.1 \mathrm{E}-10$ \\
\hline at3g09940 & ATMDAR3 & monodehydroascorbate reductase & 8.92 & $1.4 \mathrm{E}-07$ & 0.07 & $1.8 \mathrm{E}-08$ \\
\hline
\end{tabular}

With more than 55-fold induction in wild-type plants, CYP81D11 is the most strongly TIBA-inducible gene identified in this array. In the coil- $t$ mutant it shows $12 \%$ of the wild-type transcript levels after TIBA treatment. In contrast to this, the genes that are next strongly induced by TIBA are very strictly dependent on COI1 (Table 4. 1). Therefore, those genes were selected for further analyses, which resemble CYP81D11 either for their strong inducibility by TIBA or for their less strict COI1 dependency (Table 4. 2).

Table 4. 2: COI1-dependent TIBA-inducible genes that are either very strongly induced by TIBA or show only weak COI1 dependency

\begin{tabular}{||l|l|l|c|c|c|c||}
\hline \hline Gene code & Symbol & Description & $\frac{\text { Col-0 TIBA/ }}{\text { Col-0 WT }}$ & $\underline{\text { P-value }}$ & $\frac{\text { coil-t TIBA/ }}{\text { Col-0 TIBA }}$ & P-value \\
\hline at3g28740 & CYP81D11 & monooxygenase & 55.64 & $8.6 \mathrm{E}-09$ & 0.12 & $1.0 \mathrm{E}-05$ \\
\hline at5g13220 & JAZ10 & jasmonate-ZIM-domain protein & 28.62 & $2.0 \mathrm{E}-10$ & 0.02 & $4.8 \mathrm{E}-11$ \\
\hline at3g49620 & DIN11 & oxidoreductase & 23.70 & $3.5 \mathrm{E}-07$ & 0.01 & $1.2 \mathrm{E}-08$ \\
\hline at3g23550 & & MATE efflux family protein & 9.95 & $3.1 \mathrm{E}-10$ & 0.10 & $3.1 \mathrm{E}-10$ \\
\hline at3g57520 & AtSIP2 & hydrolase & 7.63 & $1.1 \mathrm{E}-06$ & 0.28 & $1.2 \mathrm{E}-04$ \\
\hline at3g47340 & ASN1 & asparagine synthase & 6.75 & $9.0 \mathrm{E}-05$ & 0.24 & $1.1 \mathrm{E}-03$ \\
\hline at2g29460 & ATGSTU4 & glutathione transferase & 6.71 & $1.3 \mathrm{E}-05$ & 0.22 & $1.1 \mathrm{E}-04$ \\
\hline at5g61160 & AACT1 & acyltransferase & 6.61 & $1.2 \mathrm{E}-06$ & 0.07 & $2.4 \mathrm{E}-08$ \\
\hline
\end{tabular}


In order to distinguish whether basal JA-Ile levels or the JA-Ile-independent COI1 function contributes to the induction of the COI1-dependent genes, the transcription levels of a selection of COI1-dependent genes were monitored in Col-0 wild-type, coil-t and dde2-2 plants after TIBA treatment by quantitative real-time RT-PCR in an experiment independent of that used for the microarray (Figure 4. 14). 

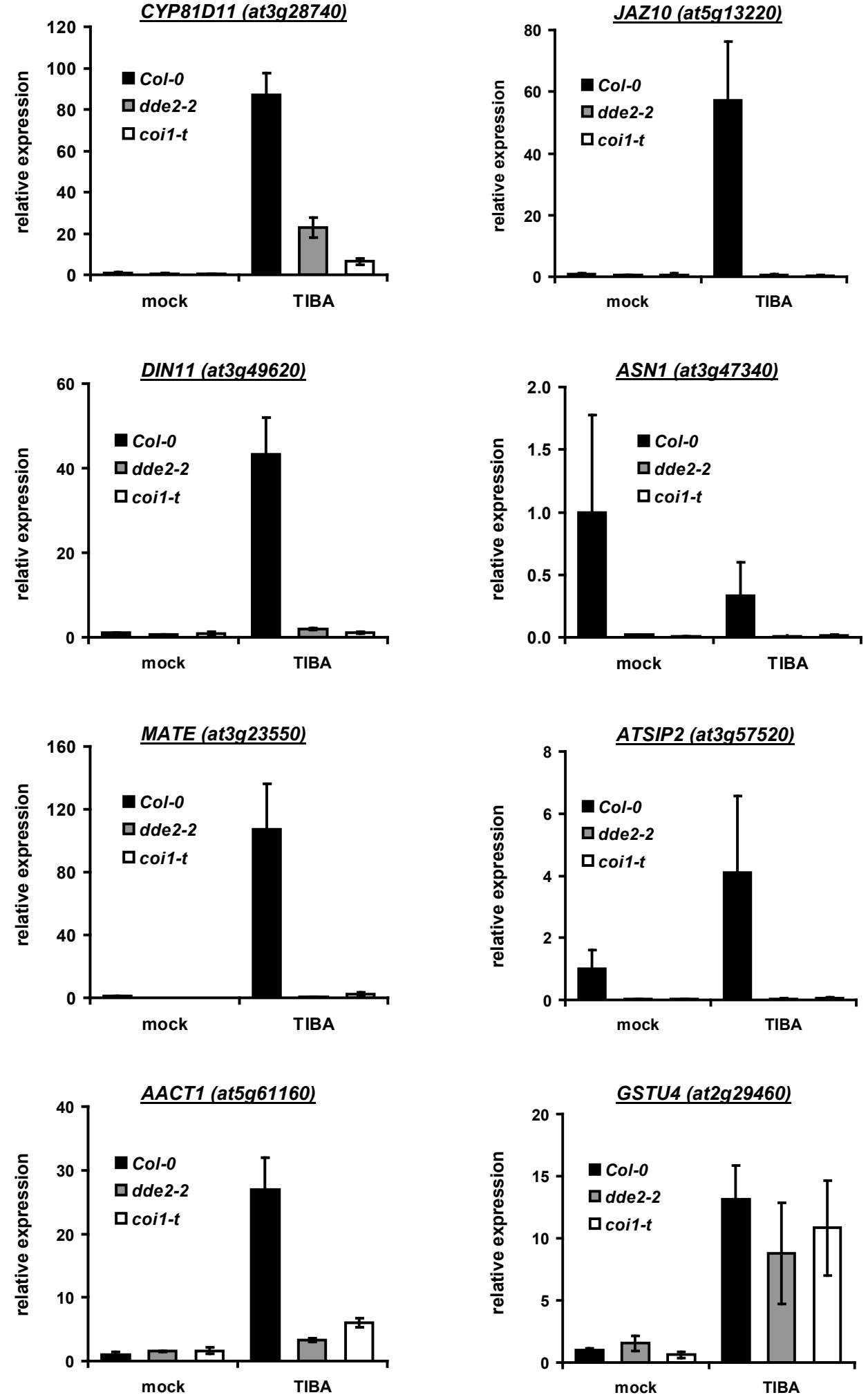

Figure 4. 14: Transcript levels of TIBA-inducible genes in Col-0, dde2-2 and coil-t plants

Quantitative real-time RT-PCR analysis of the relative CYP81D11, JAZ10, DIN11, ASN1, MATE (at3g23550, gene coding for a MATE family protein), ATSIP1, AACT1 and GSTU4 transcript levels (normalized to the housekeeping gene UBQ5) in Col-0 (wild-type), $d d e 2-2$ and coil-t plants. 6-7-weekold plants were sprayed with $100 \mu \mathrm{M}$ TIBA and, $8 \mathrm{~h}$ after induction, whole rosettes were harvested for RNA isolation. The average transcript level of mock-treated Col-0 plants was set to 1. Each bar represents the average \pm SEM of four (coil-t mock, three) independent plants, if all samples exhibited detectable transcript levels. In some samples, like all the mock-treated dde2-2 and coil-t samples of MATE (at3g2350), no transcript could be detected. 
CYP81D11, JAZ10, DIN11, ASN1, MATE (at3g23550), ATSIP1, AACT1 and GSTU4 transcript levels were analyzed via quantitative real-time RT-PCR in Col-0, dde2-2 and coil-t plants in response to TIBA treatment. For CYP81D11, JAZ10, DIN11, MATE (at3g23550), ATSIP1 and AACT1, the TIBA inducibility and the COI1 dependency shown in the microarray analyses were reproduced. However, except for CYP81D11 and $A A C T 1$, all show a very strict COI1 dependency, without notable differences between the expression levels in the dde2-2 and coil-t mutants. AACT1 expression depends less stringently on COI1; still, no stronger expression in the dde2-2 mutant than in the coil-t mutant is observed. These results indicate that JAZ10, DIN11, MATE (at3g23550), ATSIP1 and AACT1 expression in response to TIBA require COI1 activity and basal JA-Ile levels, but none of them is regulated by a JA-Ile-independent COI1 function. So far, this regulation mode remains unique for CYP81D11.

For $A S N 1$ and GSTU4, the results obtained from the microarray experiments were not reproduced: $A S N 1$ expression is strongly dependent on COI1, but in this experiment it is not induced by TIBA. In contrast to this, GSTU4 expression is induced by TIBA, but no dependency on COI1 or JA-Ile is shown.

\subsection{CYP81D11 is more closely co-regulated with COI1-independent than with COI1-dependent TIBA-inducible genes}

Although a JA-Ile-independent COI1 function is not required for the regulation of the more closely investigated COI1-dependent TIBA-inducible genes except for CYP81D11, most of them shared the dependency on the basal JA-Ile levels. Hierarchical cluster analysis was performed (https://www.genevestigator.ethz.ch/) to identify the genes most closely co-regulated with CYP81D11, as these could be candidate gens, which might be under the same control. 


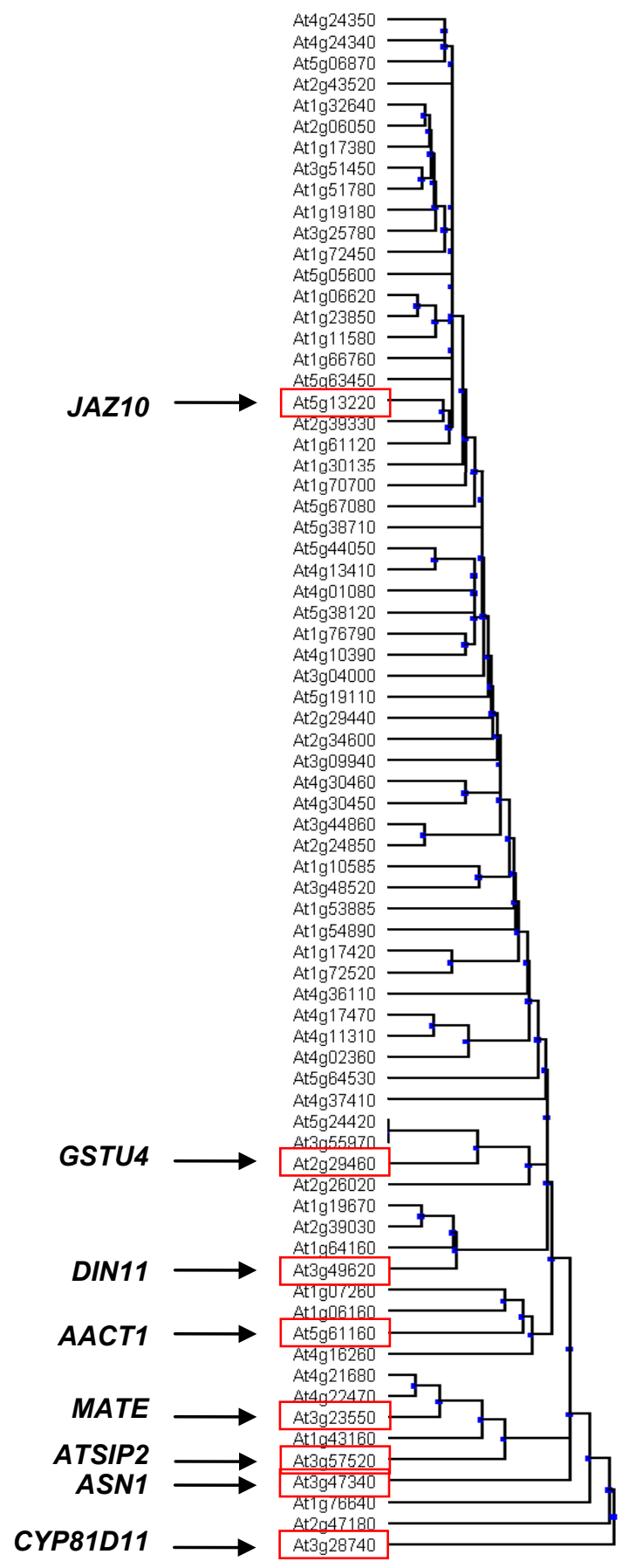

Figure 4. 15: Co-regulation of COI1-dependent TIBA-inducible genes after various stimuli

Hierarchical cluster analysis of all COI1-dependent TIBA-inducible genes identified by microarray analysis. The analysis was performed by the Genevestigator cluster analysis tool, choosing the adjustment "stimulus". Results are depicted as tree model.

Genes that were more closely investigated in the dde2-2 and coil-t mutants by quantitative real-time RTPCR are highlighted by a red box. Gene symbols of the highlighted genes are indicated.

The tree model depicted in Figure 4. 15 was calculated based on hierarchical cluster analyses investigating the co-regulation of single genes within the group of COI1dependent TIBA-inducible genes after diverse stimuli. CYP81D11 is placed at the outmost edge of the tree, without being grouped to any other genes. This indicates a low correlation of regulation in comparison to all other COI1-dependent TIBA-inducible 
genes. Closer examination of the induction patterns of the COI1-dependent genes revealed no co-regulation under conditions not related to JA.

Since CYP81D11 shares the feature to be co-regulated with TGA-dependent genes that are independent of COI1, we performed Hierarchical cluster analysis with CYP81D11 and the COI1-independent genes (Figure 4.16). 


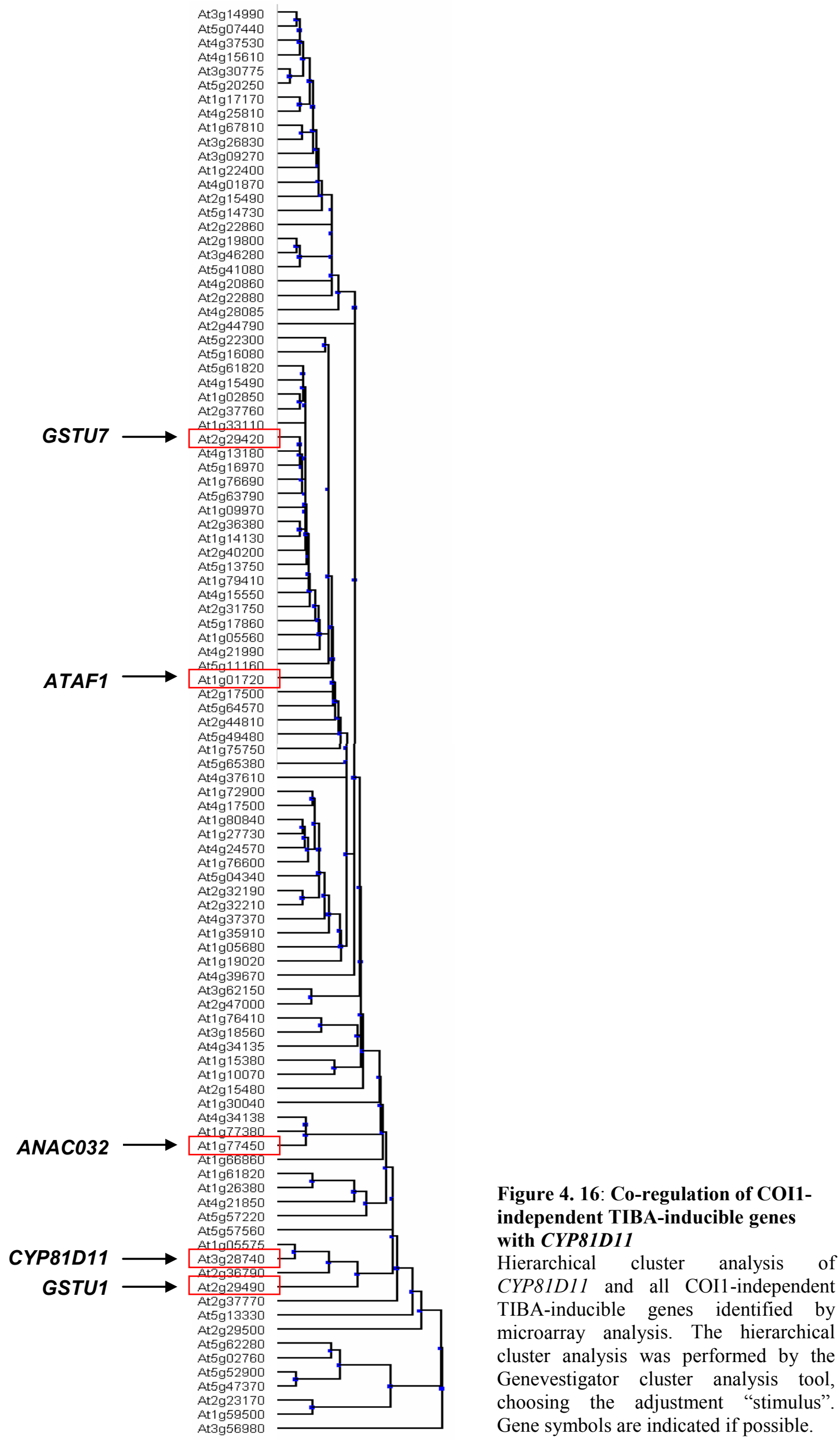


By comparison of CYP81D11 expression with the expression of COI1-independent TIBA-inducible genes, CYP81D11 was indeed grouped to four other genes. The one most closely co-regulated with CYP81D11 encodes an unknown protein. Two other genes in this group code for known proteins: UGT73C6 encodes a UDP-glycosyl transferase, while ATGSTU1 codes for a glutathione $S$-transferase. Both of these proteins are putatively involved in detoxification (Poppenberger et al. 2006; Fode et al. 2008), which is consistent with the induction of CYP81D11 in response to a variety of xenobiotics. Furthermore, ATGSTU1 was identified as an SCL14 target gene by Fode et al. (2008), and also the genes UGT73C6 and At $\lg 05575$ exhibit putative TGA binding (TGACG) motifs in their promoters.

In a time course experiment, CYP81D11 expression was compared with COI1dependent and COI1-independent genes. 6-7-week-old soil-grown Col-0 plants were sprayed with $100 \mu \mathrm{M}$ TIBA and rosettes were harvested 1-24 h later. CYP81D11, DIN11, JAZ10, ANAC032, GSTU1 and GSTU7 transcript levels were elucidated by quantitative real-time RT-PCR (Figure 4. 17). 

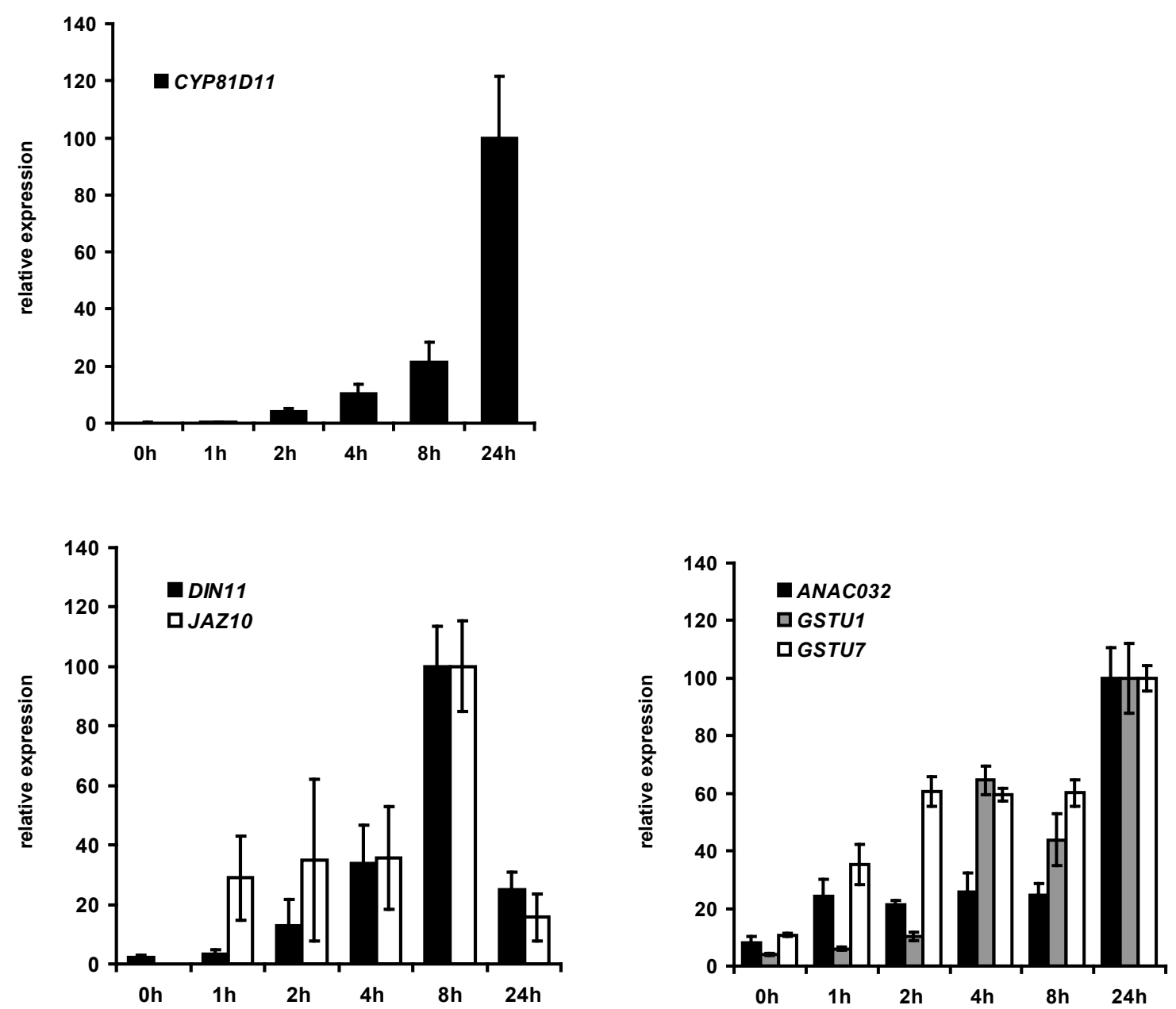

Figure 4. 17: Time course experiment of TIBA treatment in Col-0 plants

Quantitative real-time RT-PCR analysis of relative CYP81D11, DIN11, JAZ10, ANAC032, GSTU1 and GSTU7 transcript levels (normalized to the housekeeping gene UBQ5) in Col-0 wild-type plants. 6-7week-old plants were sprayed with $100 \mu \mathrm{M}$ TIBA and whole rosettes were harvested for RNA isolation at the indicated time points; for the 0 -h time point, the plants remained untreated. Highest transcript levels were set to 100 . Each bar represents the average \pm SEM of four independent plants.

CYP81D11 transcript levels rise continuously after treatment with TIBA and show their maximum at $24 \mathrm{~h}$ after treatment. In contrast, DIN11 and $J A Z 10$ transcript levels reach a peak at $8 \mathrm{~h}$ and transcription decreases again between 8 and $24 \mathrm{~h}$. Although the timedependent development of expression varies among the COI1-independent TIBAinducible and TGA2,5,6/SCL14-dependent genes, ANAC032, GSTU1 and GSTU7 exhibit the highest transcript levels during the investigated time span of $24 \mathrm{~h}$ after treatment. Thus, expression of CYP81D11 shows a similar time dependent behavior as that of the COI1-independent genes.

To investigate the TGA and SCL14 dependency of a TIBA-inducible and COI1dependent gene, DIN11 expression was monitored in TIBA-treated plants ectopically 
expressing SCL14 and in tga2,5,6 mutant plants, in comparison to expression of CYP81D11 (Figure 4. 18).

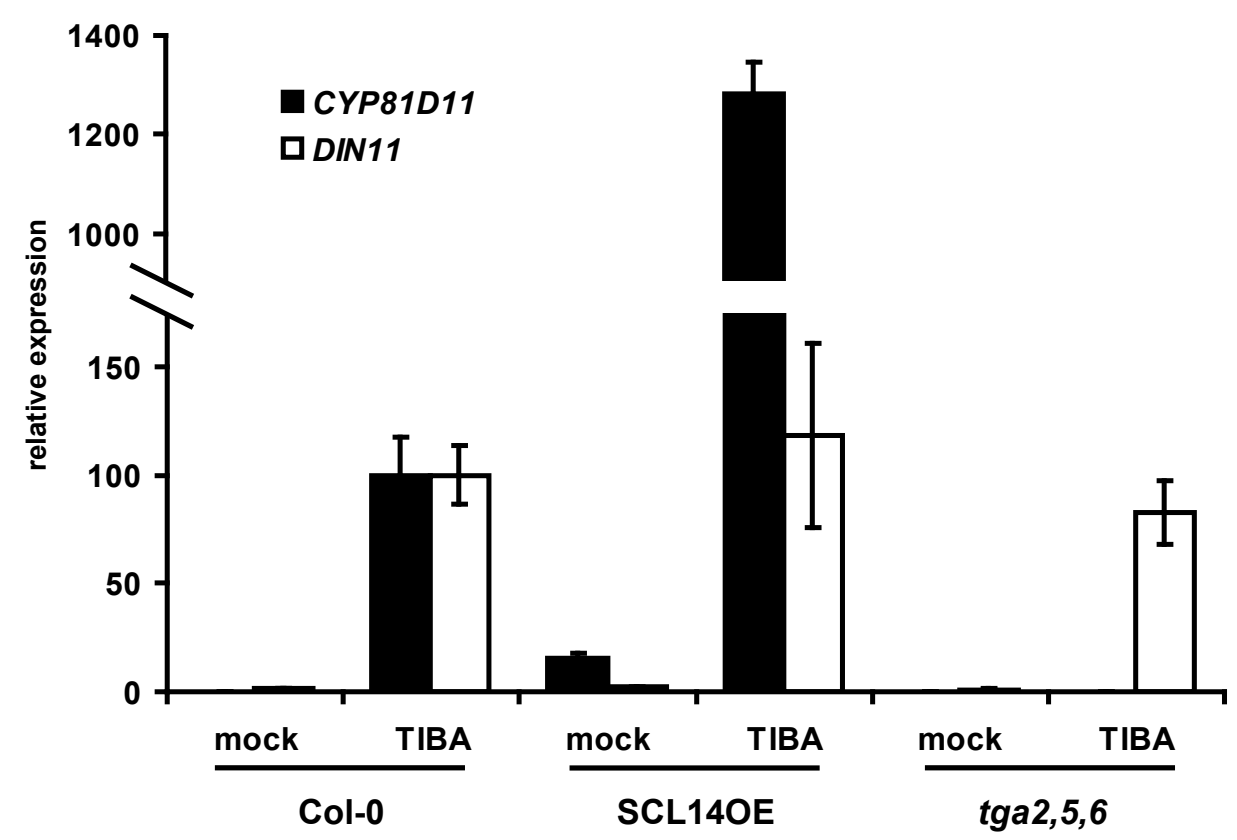

Figure 4. 18: CYP81D11 and DIN11 transcript levels in SCL14-overexpressing and tga2,5,6 mutant plants

Quantitative real-time RT-PCR analysis of relative CYP81D11 transcript levels (normalized to the housekeeping gene UBQ5) in Col-0 (wild-type) plants, plants ectopically expressing SCL14 (SCL14OE), and tga2,5,6 mutant plants. 6-7-week-old plants were sprayed with $100 \mu \mathrm{M}$ TIBA and, $8 \mathrm{~h}$ after induction, whole rosettes were harvested for RNA isolation. Transcript levels of TIBA-treated Col-0 plants were set to 100 . Each bar represents the average \pm SEM of four independent plants.

The SCL14-overexpressing plants exhibit increased CYP81D11 expression even in mock-treated plants and also after TIBA treatment. CYP81D11 transcript levels are about 13 times higher than in Col-0 wild-type plants. As shown before (Figure 4. 1), CYP81D11 expression is nearly abolished in the tga2,5,6 mutant both after mock and TIBA treatment. DIN11 expression is influenced neither in the SCL14-overexpressing plants nor in the tga256 plants compared to wild-type.

In order to obtain more information about the functions of COI1-dependent, TIBAinducible genes, functional categorizations were performed and compared to the functional distribution of all genes in the A. thaliana genome (Figure 4. 19). 


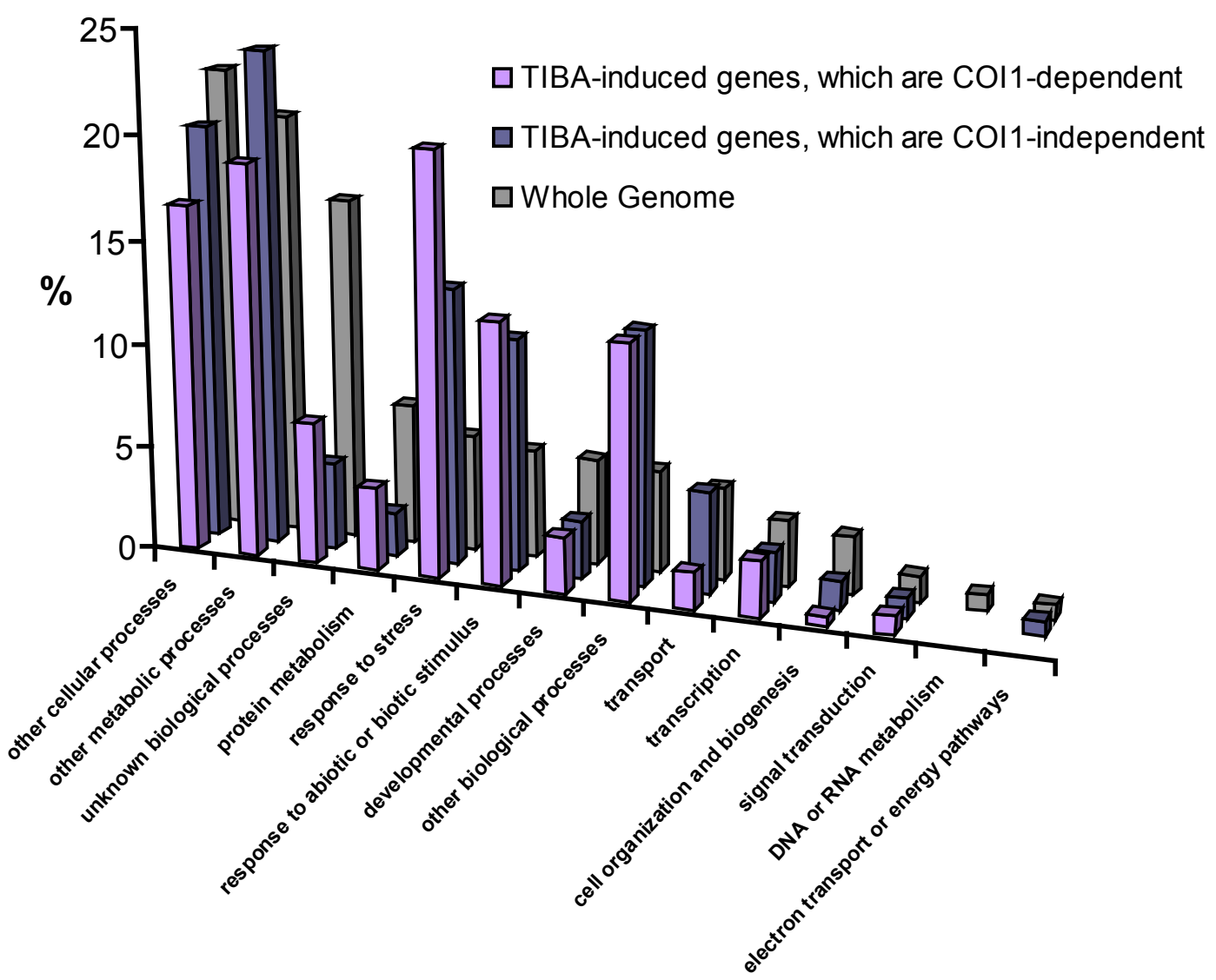

Figure 4. 19: Functional categorization of COI1-dependent and COI1-independent TIBA-inducible genes

The functional distribution of genes that are TIBA-induced in a COI1-dependent manner as compared to all genes of the $A$. thaliana genome. The classification was performed with the TAIR GO classification database tool.

Genes up-regulated in a COI1-dependent and COI1-independent manner show a relatively similar functional distribution. In both groups, genes involved in "response to stress", in "response to abiotic and biotic stimulus", and in "other biological processes" are overrepresented. In case of the COI1-dependent genes, the list of genes "responsive to stress" includes the genes "responsive to abiotic and biotic stimulus" (Table 6. 5). Interestingly, both lists include mainly JA-responsive genes, genes involved in JA signaling, and even some involved in JA biosynthesis. This result demonstrates that JAinduced stress-responsive genes represent an important part of the group of COI1dependent TIBA-induced genes. 


\subsection{CYP81D11 and DIN11 show COI1-dependent and JA-Ile- independent expression in protoplasts}

A large number of TIBA-inducible genes are induced in protoplasts, irrespective of whether their expression depents on COI1 (https://www.genevestigator.ethz.ch/). This is also the case for CYP81D11 whose expression in protoplasts is COI1 dependent (Figure 4. 12). To elucidate if the requirement for COI1 of CYP81D11 corresponds to a requirement JA-Ile, protoplasts were isolated from Col-0, dde2-2 and coil-t plants (Figure 4. 20). After overnight incubation, RNA was isolated to perform quantitative real-time RT-PCR analyses.

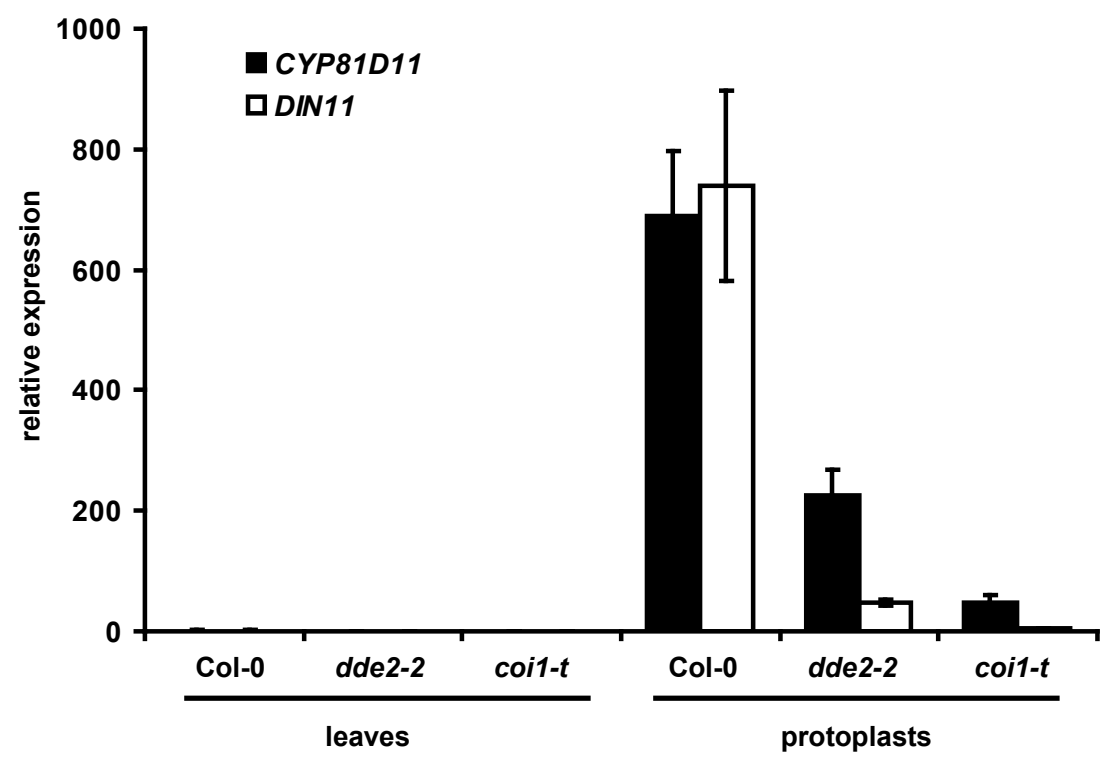

Figure 4. 20: Expression analysis of CYP81D11 and DIN11 in leaf protoplasts of Col-0, dde2-2 and coil-t plants

Quantitative real-time RT-PCR analysis of relative CYP81D11 and DIN11 transcript levels (normalized to the housekeeping gene UBQ5) in whole leaves and leaf protoplasts of Col-0 (wild-type), dde2-2 and coil- $t$ mutant plants. Leaves of 6-7-week-old plants were used for protoplast preparation. The leaves were incubated overnight in a cell wall-degrading enzyme solution, extracted, washed and again incubated for another $16 \mathrm{~h}$. Whole leaves harvested before protoplast extraction served as control. Transcript levels in whole Col-0 leaves were set to 1 . Each bar represents the average \pm SEM of five replicates from two independent experiments.

CYP81D11 was about 700-800-fold induced in protoplasts compared to intact leaves in Col-0 plants. CYP81D11 expression in the dde2-2 mutant is reduced to about $33 \%$, while in the coil-t mutant CYP81D11 expression is reduced to $7 \%$. This indicates that also in protoplasts the JA-Ile-independent COI1 function is involved in the induction of CYP81D11 expression. 
In comparison, also DIN11 expression in protoplasts was analyzed and showed similar expression as CYP81D11 in the wild-type. Interestingly, also DIN11 expression is more severely reduced in the coil-t mutant $(0.6 \%)$ than in the dde2-2 mutant $(6 \%)$. In contrast to CYP81D11, this was not the case after TIBA treatment. However, DIN11 transcript levels are more strongly compromised in comparison to CYP81D11 levels in both the dde2-2 and coil-t mutants.

\subsection{The expression of many $\mathrm{JA}$-inducible genes is not increased in protoplasts}

The reduction of CYP81D11 and DIN11 transcript levels in protoplasts derived from dde2-2 mutant plants demonstrates that either basal or increased JA-Ile levels contribute to maximal expression. It was tested whether JA-inducible genes like $M Y C 2, L O X 2$, $V S P 2$ and $P D F 1.2$ are induced in response to protoplasting (Figure 4. 21).

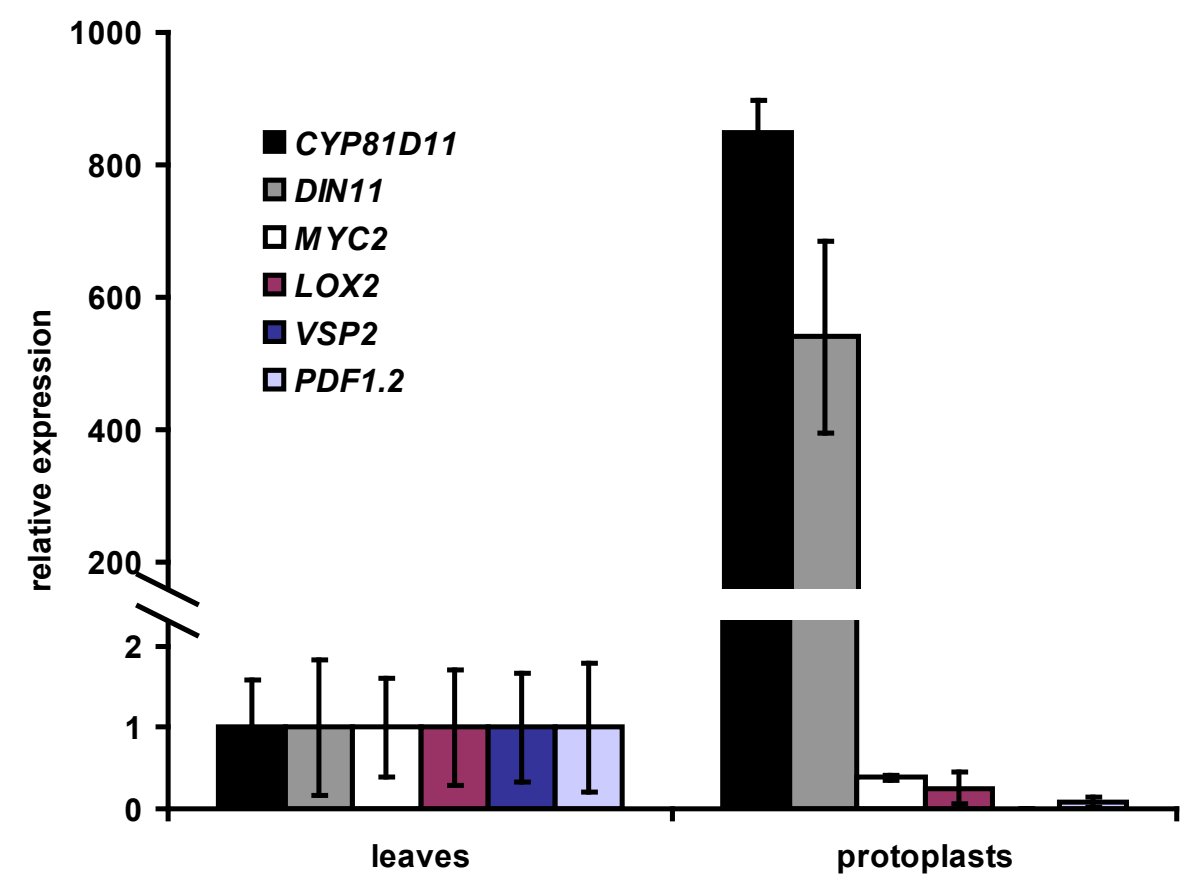

Figure 4. 21: Expression analysis of JA-inducible genes in leaves and protoplasts

Quantitative real-time RT-PCR analysis of relative CYP81D11, DIN11, MYC2, LOX2, VSP2 and PDF1.2 transcript levels (normalized to the housekeeping gene $U B Q 5$ ) in whole leaves and leaf protoplasts of Col-0 (wild type). Leaves of 6-7-week-old plants were either harvested and immediately frozen as a control or used for protoplast preparation. The leaves were incubated overnight in a cell wall-degrading enzyme solution, extracted, washed and again incubated for another $16 \mathrm{~h}$. Transcript levels in Col-0 leaves were set to 1 . Each bar represents the average \pm SEM of three replicates. For the LOX2 gene, only two protoplast samples showed detectable transcript values, while for the VSP2 gene transcript levels of all protoplast samples were below the limit of detection. 
As shown before, CYP81D11 and DIN11 are well induced in protoplasts. In contrast, $M Y C 2, L O X 2, V S P 2$ and $P D F 1.2$ expression levels were reduced to different extents. In case of VSP2, no transcript was detectable in protoplasts.

Since the severe wounding during protoplast isolation strongly suggests increased contents of JA-Ile in protoplasts, JA and JA-Ile levels were determined by HPLCMS/MS. After digestion of the cell wall (overnight) and washing, Col-0 protoplasts were incubated for another $16 \mathrm{~h}$ (Figure 4. 22).
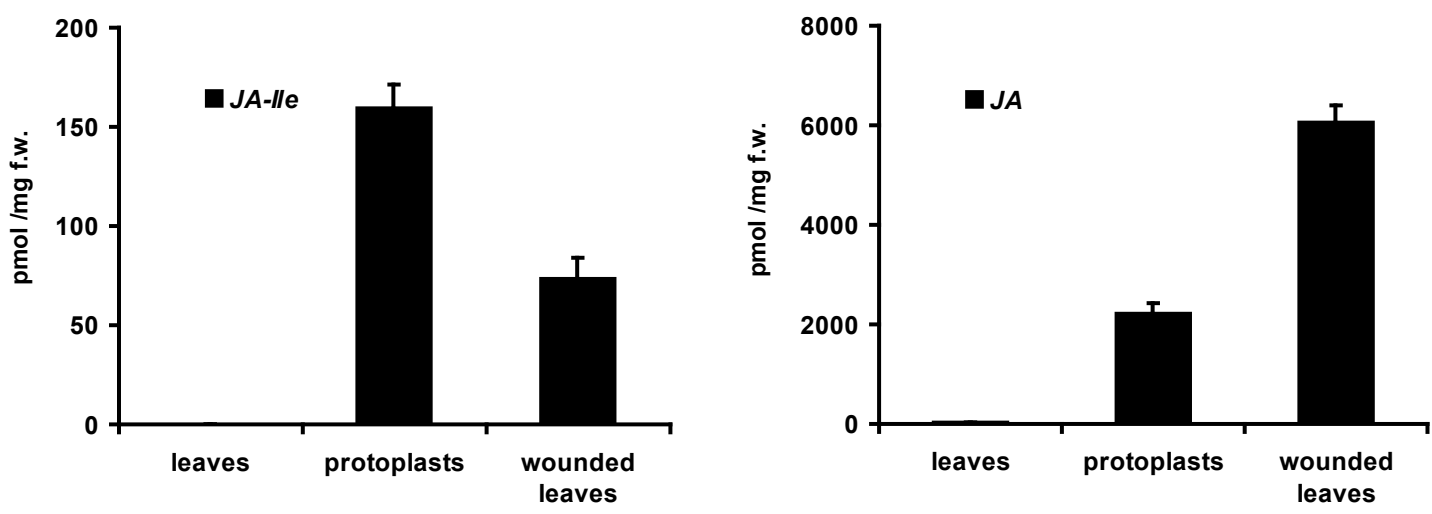

Figure 4. 22: JA-Ile and JA levels in A. thaliana protoplasts

HPLC-MS/MS analyses for JA-Ile and JA levels were performed in whole leaves and leaf protoplasts of Col-0 wild-type plants. Leaves of 6-7-week-old plants were used for protoplast preparation. The leaves were incubated overnight in a cell wall-degrading enzyme solution, extracted, washed and again incubated for another $16 \mathrm{~h}$. Whole leaves harvested before protoplast extraction served as control. As additional control, leaves wounded by squeezing and incubated for $2 \mathrm{~h}$ were used. Each bar represents the average \pm SEM of four (leaves), three (protoplasts), and two (wounded leaves) biological replicates. JAIle and JA amounts are depicted as pmol/g fresh weight. For the protoplasts, the weight of whole leaves was determined before protoplast isolation, and $40 \%$ loss during the washing steps was estimated.

Protoplasts accumulate two times higher JA-Ile levels than leaves wounded for $2 \mathrm{~h}$. Consistently, the levels of free JA were also heavily increased, but were more than two times lower than in wounded leaves.

The high endogenous JA-Ile levels in protoplasts do not induce expression of JA marker genes. To elucidate if JA signaling is generally functional, the exogenous application of the JA-Ile mimic coronatine was tested. Coronatine was added to the buffer used for overnight incubation of the protoplasts. Protoplasts of transgenic JAZ1-GUS plants were used to monitor JAZ1 stability by quantitative GUS activity tests. Therefore, fractions of the protoplast samples were used for RNA isolation and protein extraction (Figure 4.23). 

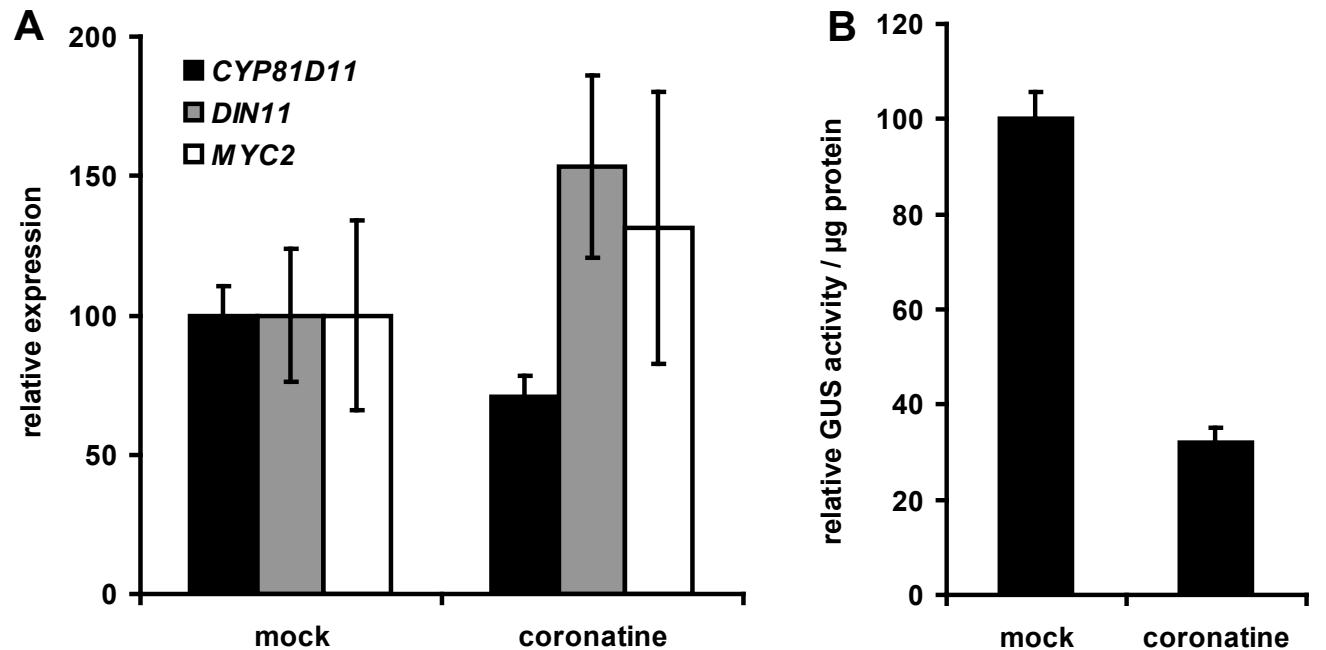

Figure 4. 23: JAZ1-GUS amounts and CYP81D11, DIN11 and MYC2 transcript levels in coronatinetreated protoplasts

Protoplasts were isolated from 4-week-old JAZ1-GUS plants, washed and incubated overnight (16 h) in buffer containing $10 \mu \mathrm{M}$ coronatine. Mock-treated protoplasts were incubated in buffer without any additives.

(A) CYP81D11, DIN11 and MYC2 transcript levels (normalized to the housekeeping gene UBQ5) in mock- and coronatine-treated protoplasts obtained by quantitative real-time RT-PCR. Each bar represents the average \pm SEM of four samples from two independent experiments. The average transcript level of the mock-treated samples was set to 100 .

(B) GUS activity of protein extracts of these protoplasts normalized to protein concentration. Each bar represents the average \pm SEM of eight samples from three independent experiments. The average GUS activity of the mock-treated samples was set to 100 .

The decrease in GUS activity in the JAZ1-GUS protoplasts after coronatine treatment demonstrates the functional response to coronatine. Thus the enhanced JA-Ile levels in the protoplasts are not sufficient for COI1 mediated protein degradation (Figure 4. 23A). Neither the genes CYP81D11 and DIN11, which are already induced in protoplasts without any additional treatment, nor $M Y C 2$ show increased induction after coronatine treatment.

\subsection{Proteasome-dependent protein degradation is essential for CYP81D11 and DIN11 expression in protoplasts}

The effects of inhibition of the $26 \mathrm{~S}$ proteasome and subsequent protein stabilization were investigated by addition of the proteasome inhibitor MG132 to JAZ1-GUS protoplasts before overnight incubation. In the morning, material was harvested and CYP81D11 and DIN11 transcription was investigated by quantitative real-time RTPCR. Transcript levels of both CYP81D11 and DIN11 are strongly decreased (CYP81D11: $10 \%$; DIN11: $4 \%$ ) after treatment with MG132, which indicates the 
importance of proteasome-dependent protein degradation for their induction. Since the reduction of CYP81D11 and DIN11 expression after MG132 treatment is stronger than in the dde2-2 mutant, it is concluded that both COI1 functions that drive the CYP81D11 and DIN11 genes may lead to the degradation of negative regulators.

Increased GUS activity in protein extracts obtained from these MG132-treated JAZ1GUS protoplasts demonstrated the stabilization of JAZ proteins and thus the functional inhibition of proteasome-dependent protein degradation (Figure 4. 24).
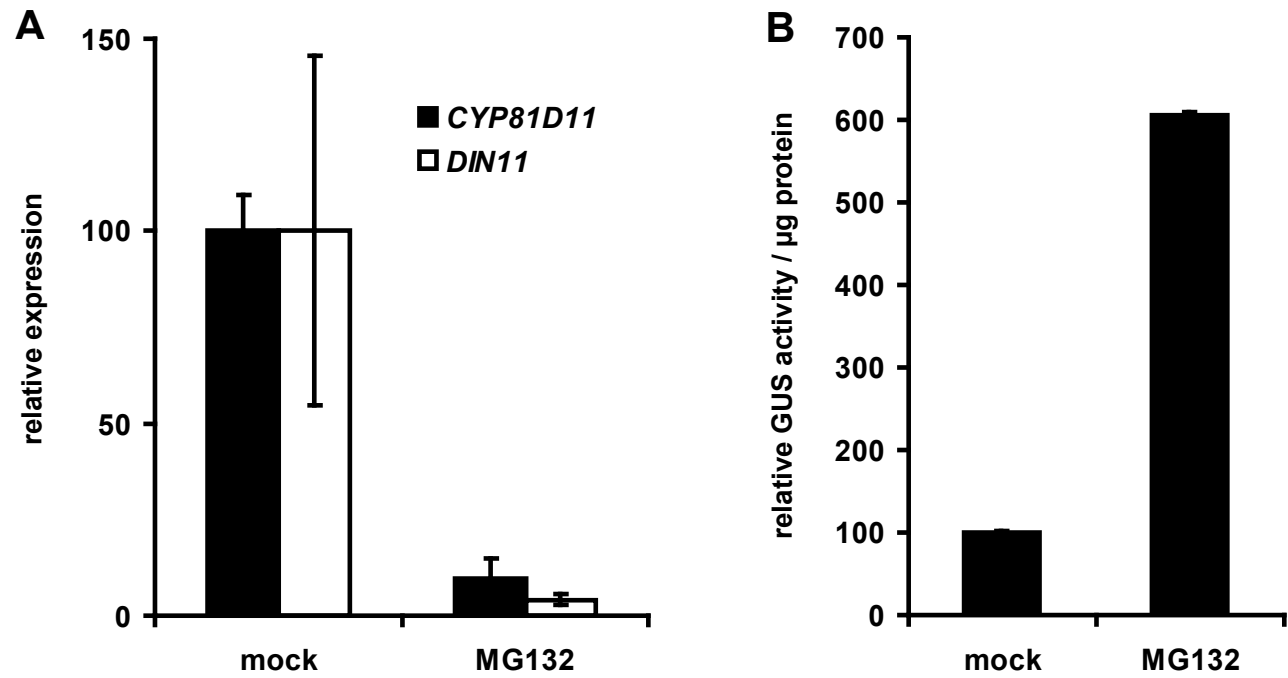

Figure 4. 24: Transcription levels of CYP81D11 and DIN11 and JAZ1-GUS levels in protoplasts after treatment with proteasome inhibitor

Transgenic JAZ1-GUS plants were grown for 4 weeks under low-light and long-day conditions. Protoplast were isolated, washed and incubated overnight $(16 \mathrm{~h})$ with or without $50 \mu \mathrm{M}$ of the proteasome inhibitor MG132.

(A) Transcript levels of CYP81D11 and DIN11 (normalized to the housekeeping gene UBQ5) investigated by quantitative real-time RT-PCR. Each bar represents the average \pm SEM of two samples.

(B) GUS activity of total protein extracts of the JAZ1-GUS protoplasts. GUS activity is taken as a measure for the degree of JAZ1-GUS levels. Each bar represents the average \pm SEM of two samples.

The reduction of CYP81D11 expression in protoplasts obtained from dde2-2 and coil-t mutants demonstrates that both a COI1 function in response to JA-Ile (basal or elevated levels) and the JA-Ile-independent COI1 function take place. 


\subsection{ATAF1 and ANAC032 repress basal expression of CYP81D11}

Apart from CYP81D11, the two closely related NAC transcription factor genes ATAF1 and ANAC032 were found to be regulated by the TGA2,5,6/SCL14 complex. ATAF1 was shown to be involved in the response to abiotic and biotic stress, like drought and abscisic acid (ABA) treatment (Lu et al. 2007; Jensen et al. 2008; Wu et al. 2009), and upon pathogen attack (Wu et al. 2009; Wang et al. 2009; Jensen et al. 2008). Less is known about ANA032. Since it is the closest relative to ATAF1 and since it is coregulated with ATAF1, functional redundancy has been proposed (Kleinow et al. 2009). A function in the xenobiotic stress response has not been reported for either of them. Expression of both genes is up-regulated by TIBA in a COI1-independent manner.

In order to assess whether ATAF1 and ANAC032 regulate the expression of SCL14dependent, TIBA-inducible genes, transgenic plants ectopically expressing HA-ATAF1 or HA-ANAC032 controlled by the CMV35S promoter were generated.

Transformation of Col-0 plants was carried out by A.tumefaciens-mediated gene transfer and primary transformants were selected by spraying the plants with the herbicide BASTA.

Primary transformants expressing HA-ATAF1 were either indistinguishable from Col-0 wild-type plants or exhibited a strong dwarf phenotype with strongly upwards-bent leaves or short, heavily branched inflorescences, which developed only late (Figure 4. 25). All of these dwarf plants were sterile and exhibited an extended lifetime.

HA-ANAC032 primary transformants showed similar effects as the HA-ATAF1 plants. Many primary transformants selected by BASTA treatment showed the wild-type phenotype, but also here dwarfism occurred. Dwarf plants exhibited less severe upwards-bending of the leaves, but the leaves were crinkled and showed early yellowing patches. Again, the inflorescences developed late and were short and the plants exhibited extended lifetimes. The described phenotype was observed in different degrees of severity. Most of the dwarf plants were sterile, but some individuals with less severe symptoms produced seeds.

CYP81D11 expression was investigated in the pimary transformants. Two to three leaves were harvested from six plants exhibiting a wild-type phenotype ( 3 weeks old) and from six plants exhibiting dwarfism (6 weeks old). As the dwarf plants grew much slower, leaf material had to be harvested at different time points to obtain material from similarly sized plants. 
Quantitative real-time RT-PCR was performed to determine the transcript levels of the overexpressed genes and of CYP81D11 (Figure 4.25).

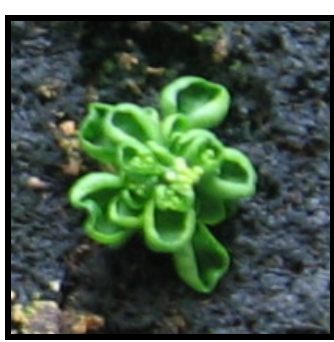

HA-ATAF1

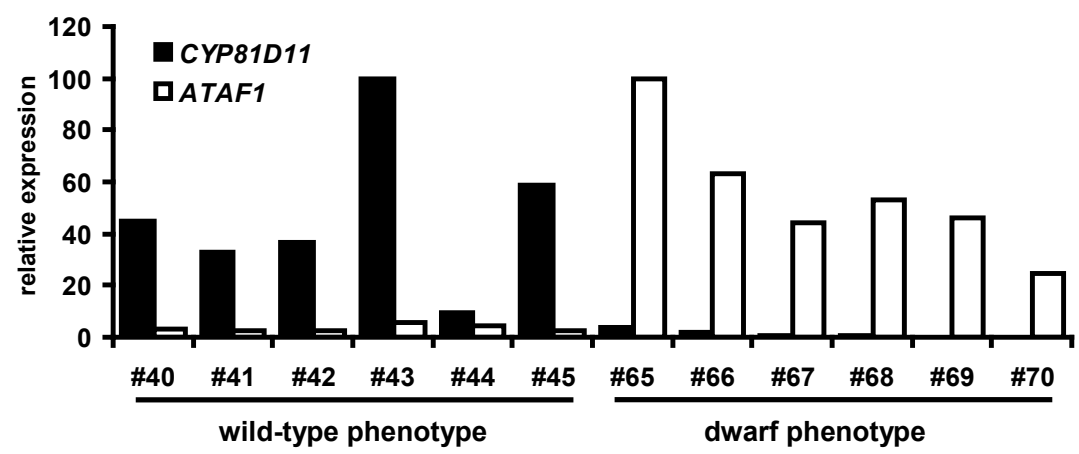

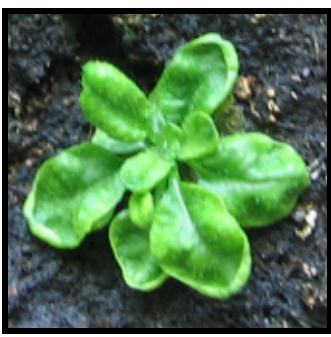

HA-ANAC032

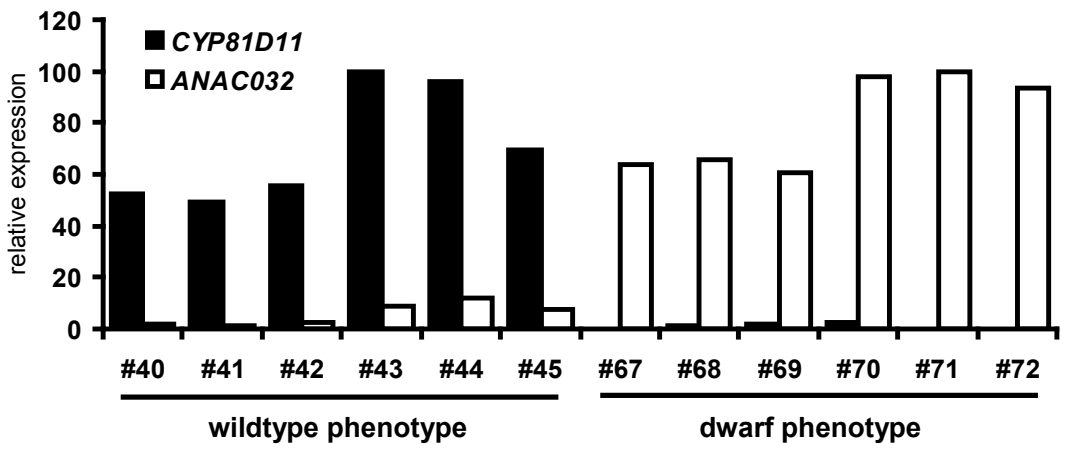

Figure 4. 25: Phenotype and transcript levels of CYP81D11, ATAF1 and ANAC032 of primary transformants ectopically expressing HA-ATAF1 or HA-ANAC032

Primary transformants exhibiting HA-ATAF1 or HA-ANAC032 were grown under long-day conditions and selected by treatment with BASTA. Plants surviving BASTA treatment showed either wild-type growth or dwarfism, curly leaves, an extended lifetime, and late flowering. RNA was isolated from six plants exhibiting the wild-type phenotype ( 3 weeks old) and from six plants exhibiting dwarfism (six weeks old) from each transformation and quantitative real-time RT-PCR analysis was performed using primers specific for $A T A F 1, A N A C 032$ and $C Y P 81 D 11$. Transcript level values were normalized to the housekeeping gene $U B Q 5$. Each bar represents the transcription level of one primary transformant. For each gene, the highest transcript level was set to 100 .

Transcript levels of the corresponding overexpressed genes in HA-ATAF1 and HAANAC032 primary transformants strictly correlated with the phenotype. All plants exhibiting wild-type growth showed relatively low $A T A F 1$ or $A N A C 032$ expression. In contrast to this, all dwarf individuals exhibited high ATAF1 or ANAC032 transcript levels.

Interestingly, the CYP81D11 expression behavior was opposite to the expression of ATAF1 and ANAC032. Dwarf plants containing high levels of ATAF1 and ANAC032 transcript levels showed strongly repressed levels of CYP81D11 compared to the individuals looking like the wild type. It is concluded that ATAF1 and ANAC032 act as negative regulators at least of the basal CYP81D11 expression. 


\subsection{HA-ANAC032 F1 generation exhibits increased ANAC032 transcript levels and expresses the HA-ANAC032 protein}

Although most of the HA-ANAC032 primary transformants were sterile, seeds from some plants showing a less severe dwarf phenotype could be obtained. The F1 generation represents a pool composed of wild-type individuals, heterozygous transformants, and homozygous transformants. The genotype of the individuals was estimated based on their phenotype. Homozygous HA-ANAC032 plants showed dwarfism and crinkling as well as early yellowing at the leaf edges and between the leaf vessels. Heterozygous individuals exhibited wild-type-like growth and were mainly identified by the crinkling and early yellowing of the leaves, which was again mainly present at the leaf edges and between the vessels (Figure 4. 26). Due to their wild-type growth and thus good comparability of heterozygous individuals to the wild type, all following results were obtained from heterozygous HA-ANAC032 plants.

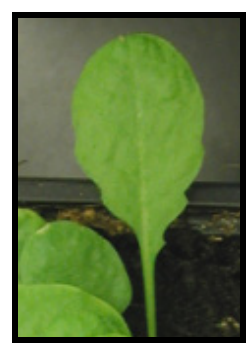

Col-0

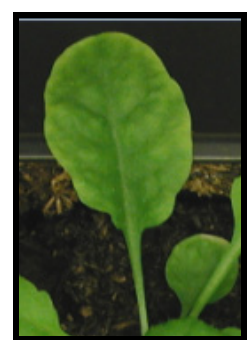

HA-ANAC032\#68 heterozygous

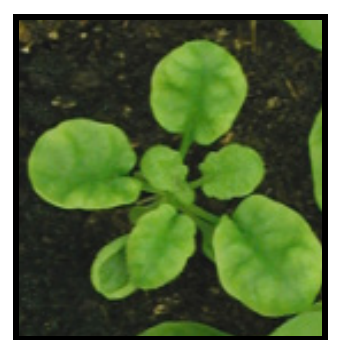

HA-ANAC032\#68 homozygous

Figure 4. 26: Phenotype of HA-ANAC032-overexpressing plants

Col-0 and HA-ANAC032\#68 (F1 generation) plants were grown for 6 weeks under 12-h light/12-h dark conditions. Homozygous and heterozygous pants were distinguished by the severity of dwarfism and leaf yellowing.

Untreated plants of three independent HA-ANAC032 lines (\#47, \#67, and \#68) grown on soil for 6 weeks were investigated by quantitative real-time RT-PCR, to compare their ANAC032 expression to that of Col-0 wild-type plants. 


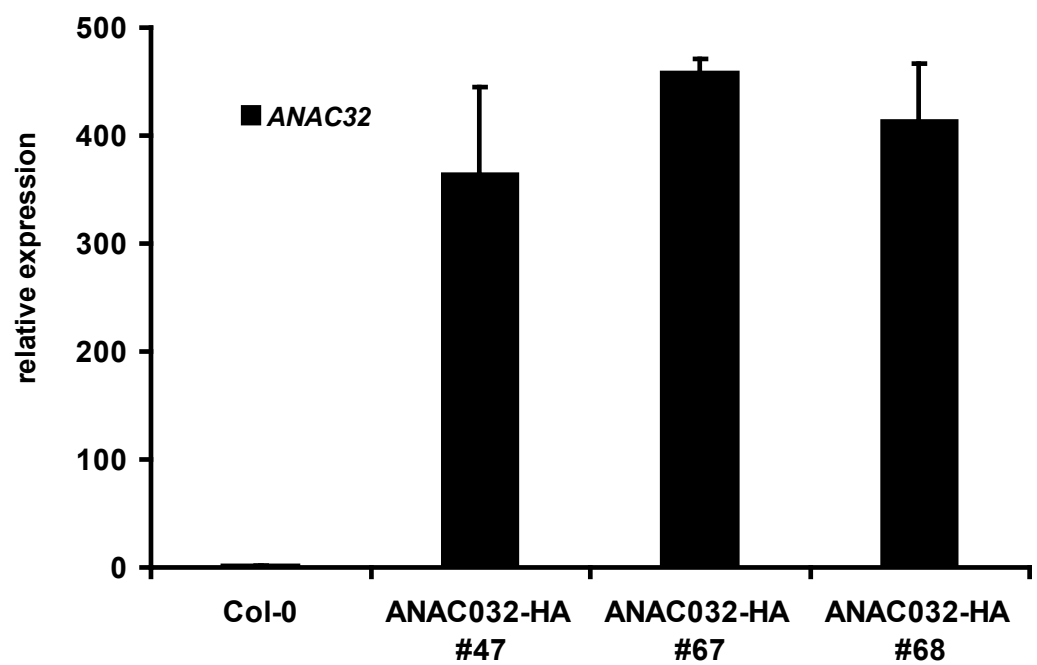

Figure 4. 27: Transcript levels of $A N A C 032$ in plants overexpressing HA-ANAC032

Quantitative real-time RT-PCR to assess ANAC032 transcript levels in transgenic plants ectopically expressing HA-ANAC032 controlled by the CMV35S promoter. Transcript levels were normalized to the housekeeping gene $U B Q 5$. Each bar represents the average \pm SEM of two to four independent plants. The average transcript level of the Col-0 plants was set to 1 .

All three investigated HA-ANAC032 lines exhibit similar amounts of ANAC032 transcript, which are about 400 -fold higher than in the wild-type.

In order to prove that not only the $H A-A N A C 032$ transcript but also the protein is produced, Western blot analyses were performed. 6-7-week old HA-ANAC032 plants of three independent lines were sprayed with TIBA and incubated for $8 \mathrm{~h}$. Whole protein extracts were prepared and the proteins were separated by SDS-PAGE.

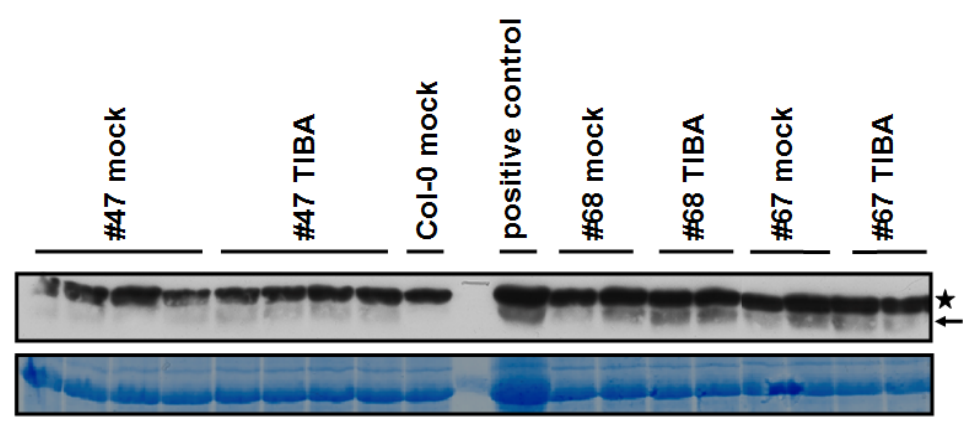

Figure 4. 28: Western blot analyses of HA-ANAC032-overexpressing plants

Three independent lines (\#47, \#67, and \#68) ectopically expressing ANAC032 were treated with $100 \mu \mathrm{M}$ TIBA for $8 \mathrm{~h}$ and whole protein extracts were prepared. An antibody against the HA-tag was used for Western blot analyses. The specific band is indicated by an arrow; an unspecific band is marked by an asterisk. As positive control, plant material of a sterile primary transformant with a strong dwarf phenotype was used.

The Coomassie blue-stained SDS-PAGE gel (12\% acrylamide) is shown as loading control.

Western blot analyses revealed that the HA-ANAC032 protein is produced in all the tested transgenic lines (Figure 4. 28), although protein amounts differ. Lines \#67 and \#68 exhibit similar protein amounts while the HA-ANAC032 signal is weaker in line 
\#47. Col-0 protein extracts were used as negative control; this line also showed the strong unspecific band. The specific band is detected below the unspecific one and is not contained in the Col- 0 control sample. As positive control, plant material of a sterile primary ANAC032 individual was used. The strengths of the HA-ANAC032 signals differ slightly between individuals within one transgenic line, but these differences do not correlate with the treatment of the individuals. Thus, TIBA treatment does not influence the protein stability of ANAC032.

\subsection{ANAC032 negatively regulates TIBA induced CYP81D11 expression}

In the primary transformants, only basal CYP81D11 expression could be investigated. This was strongly reduced in HA-ANAC032-overexpressing plants (Figure 4. 25). Next, CYP81D11 expression was investigated under inducing conditions. Heterozygous HAANAC032 plants from independent lines were grown on soil for 6-7 weeks, sprayed with TIBA and incubated for $8 \mathrm{~h}$. Quantitative real-time RT-PCR revealed reduced transcript levels of CYP81D11 in the HA-ANAC032 lines \#47, \#67, and \#68 (Figure 4. 29).

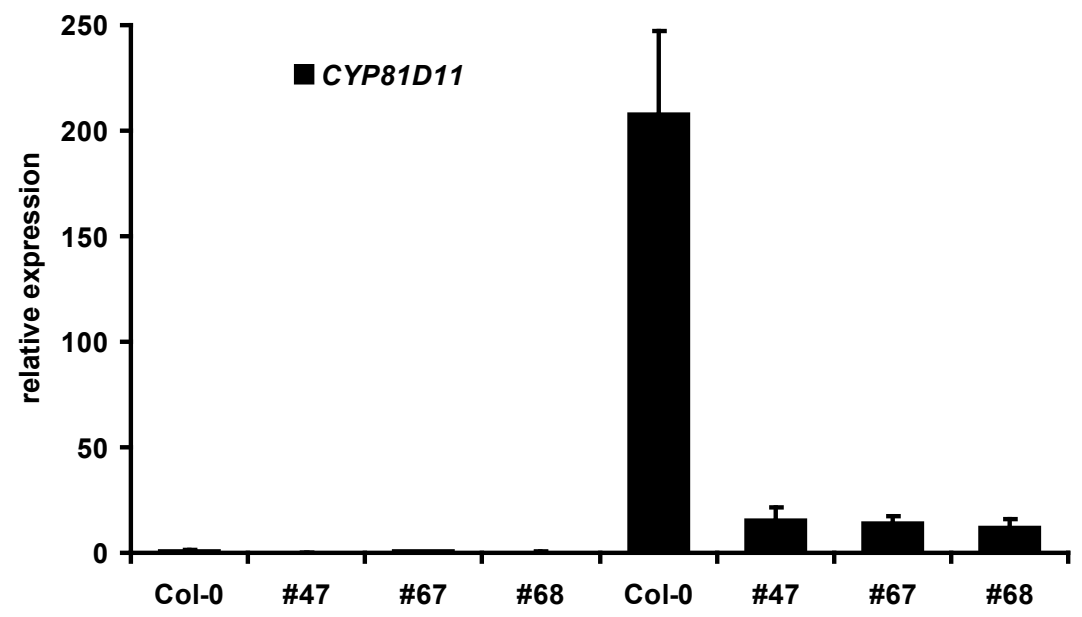

Figure 4. 29: CYP81D11 transcript levels in HA-ANAC032-overexpressing plants in response to TIBA

Quantitative real-time RT-PCR analysis of CYP81D11 transcript levels in transgenic plants ectopically expressing HA-ANAC032 after treatment with $100 \mu \mathrm{M}$ TIBA. $8 \mathrm{~h}$ after induction, whole rosettes were harvested for RNA isolation. The numbers (\#47, \#67, and \#68) symbolize independent transgenic lines; only heterozygous individuals were analyzed in this experiment. Each bar, except that of \#67 mock, represents the average \pm SEM of two to six independent plants; for line $\# 67$, only one mock-treated plant was investigated. The average transcript level of the mock-treated Col-0 plants was set to 1 . The transcript levels were normalized to the housekeeping gene UBQ5. 
CYP81D11 transcript levels were strongly reduced in untreated and TIBA-treated HAANAC032-overexpressing plants. It is concluded that ANAC032 negatively regulates CYP81D11 expression in untreated plants as well as in response to xenobiotic stress.

The regulation of CYP81D11 differs from that of other SCL14-dependent TIBAinducible genes with respect to its COI1 dependency. Thus, GSTU1, GSTU7 and ATAF1 expression, but also the expression of the COI1-dependent and SCL14-independent gene DIN11, were investigated by quantitative real-time RT-PCR in TIBA-treated HAANAC032 plants. cDNA from the same experiment as shown in Figure 4. 29 was used (Figure 4.30).

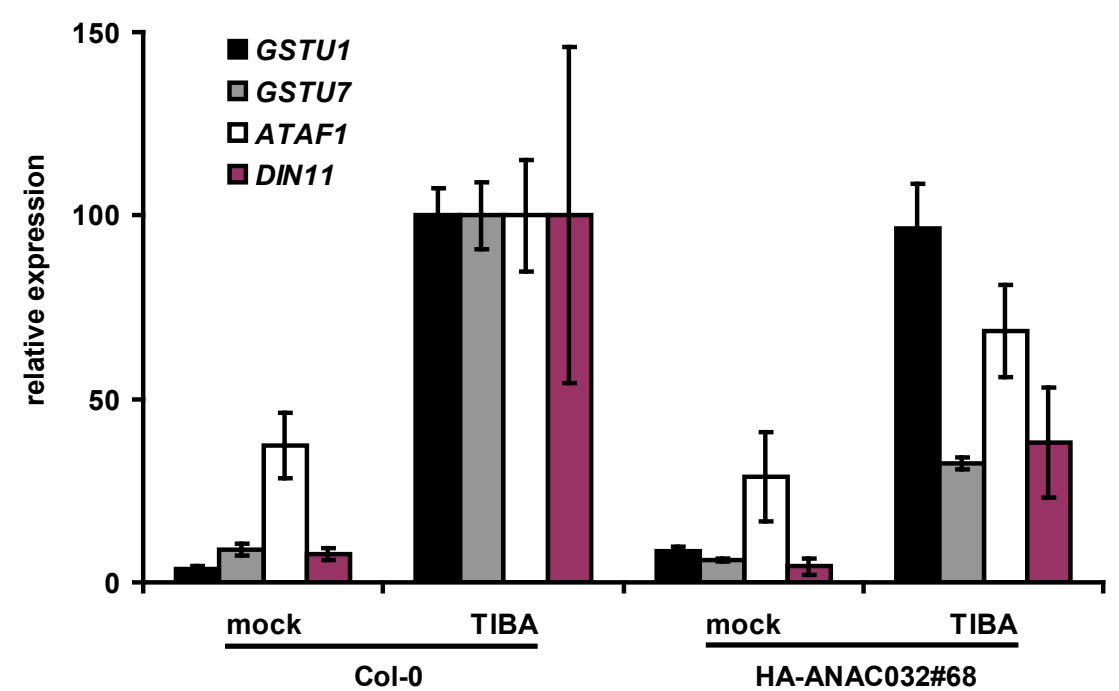

Figure 4. 30: Transcript levels of GSTU1, GSTU7, ATAF1 and DIN11 in HA-ANAC032overexpressing plants in response to TIBA

Quantitative real-time RT-PCR analysis of GSTU1, GSTU7, ATAF1 and DIN11 transcript levels in transgenic plants ectopically expressing HA-ANAC032 after treatment with $100 \mu \mathrm{M}$ TIBA. $8 \mathrm{~h}$ after induction, whole rosettes were harvested for RNA isolation. Transcript levels were normalized to the housekeeping gene UBQ5. Each bar represents the average \pm SEM of two to four independent plants. The average transcript level of the TIBA-treated Col-0 plants was set to 100 .

While GSTU1 transcription was not influenced in ANAC032\#68 plants, neither in mock-treated nor in TIBA-treated plants, GSTU7 transcript levels were slightly reduced in mock-treated ANAC032\#68 plants and reduced to about $40 \%$ after TIBA treatment. ATAF1 transcript levels varied only slightly between HA-ANA032 overexpressing and wild-type plants. These findings indicate that ANAC032-dependent regulation does not influence all SCL14 target genes. The COI1-dependent but SCL14-independent gene DIN11 also shows a reduction in transcript levels to about $40 \%$ in the HA-ANAC032overexpressing plants. Still, in comparison to CYP81D11, this effect is relatively weak, 
demonstrating that also among COI1-dependent TIBA-inducible genes the repression by ANAC032 is not homogeneous.

\subsection{ANAC032 strongly represses CYP81D11, VSP2 and PDF1.2 transcript levels in response to MeJA}

As CYP81D11 is not only activated by xenobiotic stress but also by MeJA (Mueller et al. 2008) (Figure 4. 1), the impact of ANAC032 overexpression on MeJA-mediated CYP81D11 expression was investigated. In addition, expression of the JA marker gene VSP2 and the JA/ET-induced gene PDF1.2, as well as DIN11, was monitored. The HAANAC032-overexpressing lines \#47 and \#67 were grown for 6-7 weeks on soil and treated with gaseous MeJA for $24 \mathrm{~h}$; subsequently, quantitative real-time RT-PCR was performed.

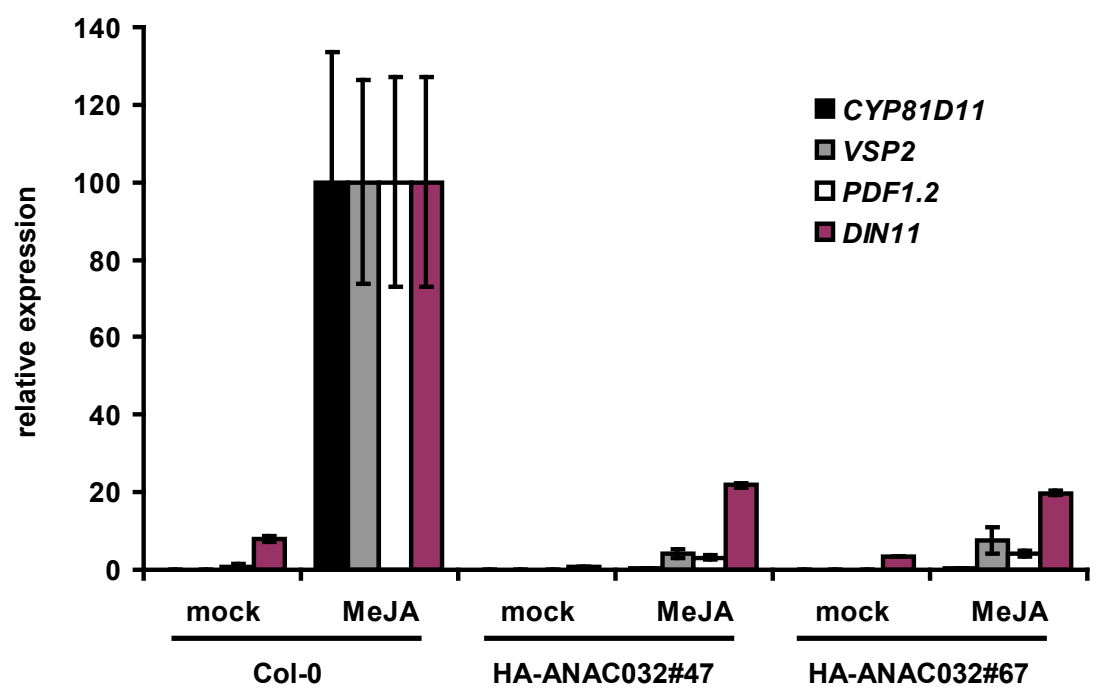

Figure 4. 31: Expression analysis of CYP81D11, VSP2 and PDF1.2 after MeJA treatment in plants overexpressing HA-ANAC032

Quantitative real-time RT-PCR analysis of CYP81D11, VSP2, PDF1.2 and DIN11 transcript levels (normalized to the housekeeping gene $U B Q 5$ ) in Col-0 wild-type plants and plants ectopically expressing HA-ANAC032 controlled by the CMV35S promoter. 6-7-week-old soil-grown plants were treated with gaseous MeJA ( $1 \mu \mathrm{L} / \mathrm{L}$ air) for $24 \mathrm{~h}$. During MeJA treatment, the plants were kept in a gas-proof tank; liquid MeJA was applied to Whatman paper that was attached to the inner glass surface, and evaporated into the gas phase. Whole rosettes were harvested for RNA isolation. Transcript values of MeJA-treated Col-0 plants were set to 100. Each bar represents the average \pm SEM of two to four biological replicates. In case of the $V S P 2$ gene, no transcript levels could be detected in mock-treated plants.

CYP81D11 expression in response to MeJA was most strongly reduced $(<0.4 \%)$ in HAANAC032 plants compared to the wild type. The expression of VSP2 and PDF1.2 was also strongly reduced by ANAC032 overexpression, although the effect was not as 
striking (VSP: $>8 \%$; PDF: $>5 \%$ ) as for CYP81D11. DIN11 expression in response to MeJA was less severely affected in the ANAC032-overexpressing plants. Transcript levels remained at about $20 \%$ of the wild-type levels. The transcript levels in mocktreated samples were reduced for all of the genes (VSP2 could not be detected), although this occurred to different extents. These results lead to the conclusion that JAdependent gene expression might in general be reduced by ANAC032.

\subsection{6 ataf1/anac032 double-knockout mutants do not affect CYP81D11 expression}

Overexpression of ATAF1 and ANAC032 strongly represses CYP81D11 expression. Therefore, the question should be answered whether knockout mutants of ATAF1 and ANAC032 exhibit increased CYP81D11 expression, as it would be expected in the absence of a negative regulator. For ATAF1, T-DNA insertion lines, which do not contain the intact ATAF1 mRNA, have already been published: ataf1-1 and ataf1-2 (Lu et al. 2007). Both lines contain a T-DNA insertion in the third exon. For ANAC032, T-DNA insertion lines obtained from the Salk Institute were used: salk_012253, which contains a T-DNA insertion in the first exon, and salk_132588, which is interrupted within exon 3 (Figure 4. 32).

To ensure that no intact mRNA is produced in any of the used T-DNA insertion mutants, homozygous individuals were treated with TIBA to induce ATAF1 and ANAC032 expression, RNA was extracted for cDNA preparation, and PCR analyses were performed using primers specific for the ATAF1 and ANAC032 transcripts (Figure 4. 32C). 


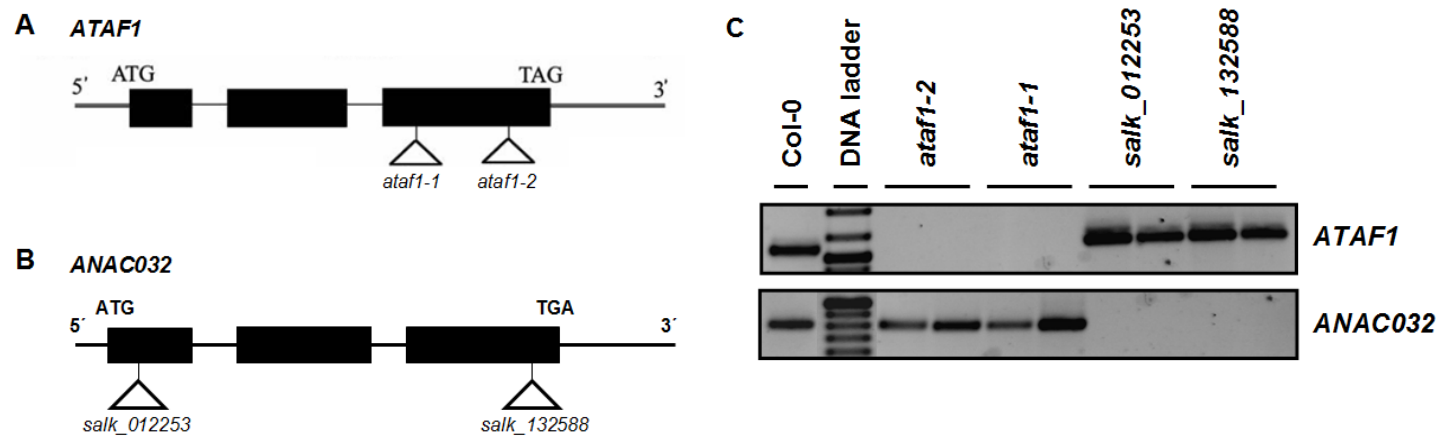

Figure 4. 32: Localization of T-DNA insertions in ATAF1 and ANAC032

(A, B): Schematic illustration of the ATAF1 and NAC032 genes. Black boxes indicate exons while UTRs and introns are depicted by thin lines. Triangles demonstrate the positions of T-DNA insertions; the designations of the mutants are indicated. (A) The ATAF1 gene and the T-DNA positions in the mutants ATAF1-1 and ATAF1-2 (Lu et al. 2007). (B) The ANAC032 gene and the T-DNA positions in the mutant lines salk 012253 and salk 132588.

(C) PCR was performed with $A T A F 1$ - and ANAC032-specific primers using cDNA obtained from 6-7week-old TIBA-treated Col-0, atafl-1, ataf1-2, salk_012253, and salk_132588 plants. Two independent individuals per mutant line were tested. The PCR products were analyzed by electrophoresis and stained by ethidium bromide. The fat band of the DNA ladder exhibits a size of $1 \mathrm{~kb}$.

Figure 4. 32C demonstrates that the T-DNA insertion lines contain insertions in the $A T A F 1$ and $A N A C 032$ genes. These T-DNA insertion lines indeed do not produce the corresponding transcripts and thus are real knockout lines.

Since functional homology between ATAF1 and ANAC032 is assumed, double mutants expressing neither ATAF1 nor ANAC032 were generated by crossing the abovedescribed T-DNA insertion lines. The ataf1-1/salk_132588 and ataf1-2/salk_012253 double mutants were grown on soil for 6-7 weeks and treated which TIBA for $8 \mathrm{~h}$, or with MeJA for $24 \mathrm{~h}$. CYP81D11 transcript levels were monitored by quantitative realtime RT-PCR (Figure 4. 33). 


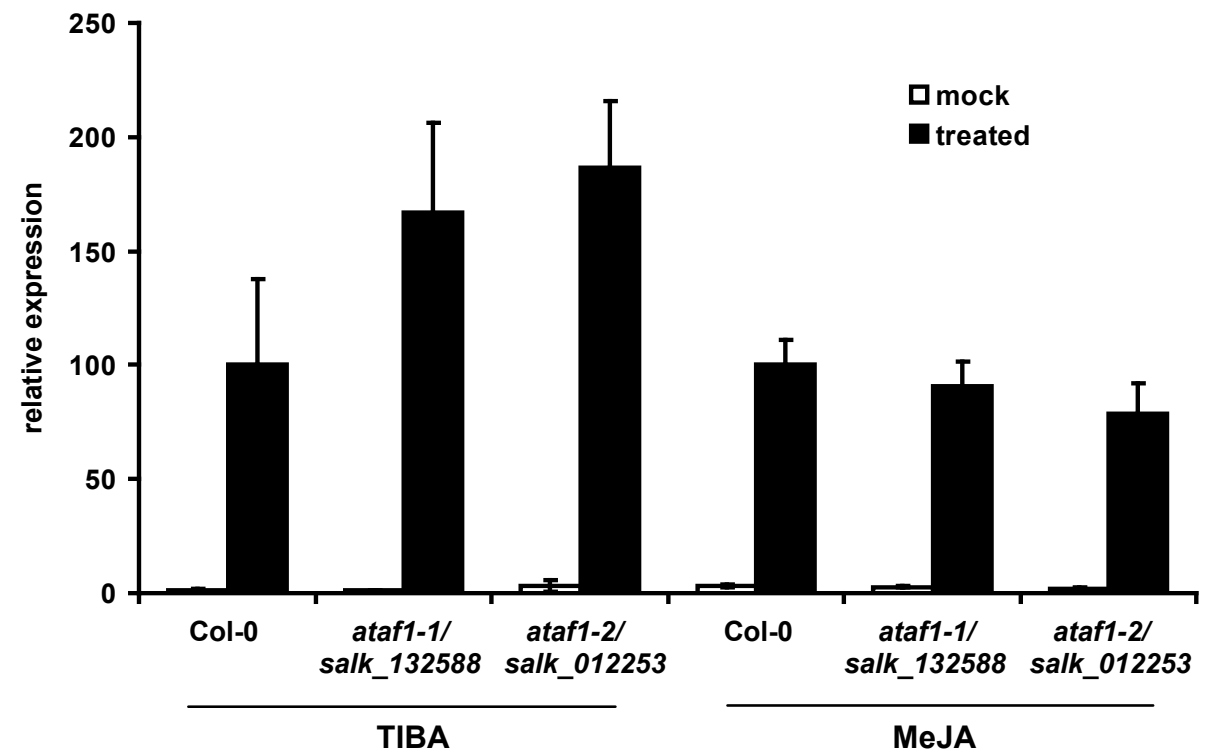

Figure 4. 33: Expression of CYP81D11 in ataf1/anac032 mutants in response to TIBA and MeJA Quantitative real-time RT-PCR analysis of CYP81D11 transcript levels (normalized to the housekeeping gene UBQ5) in Col-0 wild-type and ataf1/anac032 mutant plants (ataf1-1/salk_132588 and ataf12/salk_012253). 6-7-week-old soil-grown plants were either sprayed with $100 \mu \mathrm{m}$ TIBA for $8 \mathrm{~h}$ or treated with gaseous MeJA ( $1 \mu \mathrm{L} / \mathrm{L}$ air) for $24 \mathrm{~h}$. Whole rosettes were harvested for RNA isolation and cDNA synthesis. Transcript values in treated Col-0 plants were set to 100. Each bar represents the average \pm SEM of three or four biological replicates.

The ataf1/anac032 double mutants show no altered CYP81D11 transcript levels, neither in response to TIBA nor to MeJA. This indicates that further functional redundancy among ATAF1, ANAC032 and other NAC transcription factors might exist. The most likely candidates that might have overlapping functions are the two other ATAF family members, ATAF2 and ANAC102. 


\section{Discussion}

CYP81D11 belongs to the most strongly induced genes in response to different chemical stimuli. Moreover, two kinds of regulatory proteins, namely the TGA class II transcription factors and the GRAS protein SCL14, are already known to regulate this gene, establishing it as a marker gene for the response to xenobiotics. In contrast to other TGA/SCL14 target genes, CYP81D11 is activated by JA in a COI1-dependent manner. Interestingly, COI1 is also required for the induction by the xenobiotics TIBA and BOA. This finding pompted us to investigate the role of COI1 in response to xenobiotics.

\subsection{TIBA as an inducer of xenobiotic stress}

TIBA was chosen for the experiments as it is listed as a strong inducer of CYP81D11. Since it also functions as an auxin transport inhibitor, we tested whether it can be replaced by other chemicals. Cis-jasmone (CJ) induces CYP81D11 expression very strongly, but this induction was reported to be independent of the COI1 protein (Bruce et al. 2008). This was also the case for the herbicide safener benoxacor (Figure 6. 1). Phytoprostanes, which are also very strong and COI1-dependent inducers of CYP81D11 (Mueller et al. 2008), are not commercially available.

When the allelochemical BOA (Baerson et al. 2005) was tested, it was shown that in the coil-t mutant CYP81D11 expression was more severely reduced than in the dde2-2 mutant (Figure 4. 8). These results are consistent with the effects observed after TIBA treatment, although the chemical structures of TIBA and BOA are not related. In comparison to TIBA, the induction of CYP81D11 achieved by BOA treatment was rather weak; thus, our experiments were continued with TIBA.

It has previously been shown that a subset of JA-inducible genes is additionally induced by auxins. To further rule out that TIBA-induced activation is due to its potentially functional auxin-like structure, we tested several auxin-related conditions for their ability to influence CYP81D11 expression (Thimann \& Bonner 1948). In contrast to TIBA, the native auxin indole-3-acetic acid (IAA) showed no effect on CYP81D11 expression (Figure 6.3). Jasplakinolide, an actin stabilizer which leads to similar effects 
like TIBA regarding growth and auxin transport (Dhonukshe et al. 2008), was also not efficient in inducing CYP81D11 expression (Figure 6. 2). Transgenic plants overexpressing the dominant-negative AXR3 protein, a repressor of the auxin response, under the control of a heat shock promoter (Ouellet et al. 2001; Knox et al. 2003) were treated with TIBA. Expression of AXR3-1 had no effect on the TIBA-induced CYP81D11 expression (Figure 6.4). Also the tissue-specific expression patterns of DR5:GUS, a commonly used synthetic auxin marker (Ulmasov et al. 1997), and CYP81D11:GUS in transgenic plants were investigated. No similar expression in root tips, either untreated or treated with TIBA, was observed (Figure 6. 5). These observations led to the conclusion that TIBA does not interact with the auxin signaling pathway to induce CYP81D11 expression. We rather assume that its electrophilic properties, exhibited by its halogen-substituted aromatic ring, lead to the activation of the detoxification program. This assumption is supported by the fact that TIBA treatment induces a large number of xenobiotic-responsive genes (including CYP81D11), which were also found to be expressed under a variety of oxidative stress conditions (Fode 2008). Thus, in this thesis, TIBA was used as an inducer of xenobiotic stress.

\subsection{Basal JA levels and $\mathrm{JA}$ signalling are required for full induction of CYP81D11 in response to TIBA}

TIBA treatment does not lead to the accumulation of JA-Ile. Nevertheless, JA-Iledeficient mutants (dde2-2 and jar1-1) show a notable reduction in CYP81D11 expression in response to TIBA (Figure 4. 9). Thus, it is concluded that the basal JA-Ile levels are important for maximal CYP81D11 expression.

Another JA-deficient mutant often used to investigate JA-responsive processes is the fad3, 7,8 mutant, which is impaired in the production of the JA precursor linolenic acid (McConn \& Browse 1996b; Nibbe et al. 2002; Cipollini et al. 2004; Jakob et al. 2007). Surprisingly, in response to TIBA, this mutant behaved like the wild type with respect to the expression of CYP81D11 (Figure 6. 6). This finding contradicts the results obtained from the JA biosynthesis mutants dde2-2 and jarl-1. Furthermore, no changes in CYP81D11 transcript levels were observed in uninduced plants. As the expression of classical JA-responsive genes like VSP was impaired in the fad3, 7,8 plants (McConn et al. 1997b), it was concluded that indeed no JA-dependent gene regulation takes place. 
FAD3, 7,8 code for fatty acid desaturases, catalyzing the desaturation of dienoic fatty acids $(16: 2,18: 2)$ to trienoic fatty acids $(16: 3,18: 3)$ including linolenic acid. In the $\mathrm{fad} 3,7,8$ triple mutant it has been shown that dienoic fatty acids are accumulated (McConn \& Browse 1996b). A possible explanation may be a compensation of the reduced CYP81D11 expression due to the lack of JA. This might occur if the accumulation of dienoic fatty acids is somehow capable of inducing CYP81D11. Under oxidative-stress conditions, unsaturated fatty acids are common targets for oxidation, and it was indeed shown that trienoic fatty acids are an important sink for reactive oxygen species. Thus, the $f a d 3,7,8$ mutant accumulates $\mathrm{H}_{2} \mathrm{O}_{2}$ compared to the dde2-2 mutant (Mène-Saffrané et al. 2009). As CYP81D11 is inducible by $\mathrm{H}_{2} \mathrm{O}_{2}$ (Fode 2008), this might indeed mask the reduced CYP81D11 expression that is expected due to the lack of JA.

In transgenic JAZA3A plants and in the jin1-1 mutant (Figure 4. 10), the same reduction of CYP81D11 expression was observed as in dde2-2 and jar1-1 (Figure 4. 9). This indicates that $\mathrm{JAZ}$ degradation and the MYC2 transcription factor are required for the TIBA-activated CYP81D11 expression depending on basal JA-Ile levels.

In previous studies, JAZ degradation was only observed in response to accumulated JA levels. Nevertheless, since TIBA-induced plants contain basal levels of JA-Ile, it can be presumed that a constant turnover of JAZ proteins takes pace. Thus, an imaginable scenario may be that JAZ proteins constantly release MYC2 before being replaced, thus providing access for interactors mediating transcription. This co-activation might be an important step for the activation of JA-regulated genes by stimuli that do not lead to increased JA-levels, as for example the expression of PDF 1.2 in response to ET (Zander et al. 2010).

An alternative explanation could be that the ubiquitination of JAZ proteins induced by JA-Ile not only leads to the degradation of JAZ proteins but that ubiquitinated JAZ proteins act as transcriptional activators. In yeast, it has been reported that the VP16 transcription factor is activated by ubiquitination prior to subsequent degradation. Furthermore, the direct fusion of VP16 to ubiquitin led to transcriptional activation independent of protein degradation. Thus, it was demonstrated that ubiquitination can generate active but short-lived transcriptional activators (Salghetti et al. 2001). Assuming a comparable mechanism for JAZ proteins, basal JA-Ile levels would lead to a constant production of transcriptional activators that function as constitutive coactivators. 
Microarray analysis revealed that the expression of 73 TIBA-inducible genes requires the COI1 protein (Figure 4. 13). Furthermore, none of the seven more closely investigated genes depends on a JA-Ile-independent COI1 function (Figure 4. 14). It is concluded that at least the majority of these genes require basal JA-Ile levels for TIBAinduced expression.

However, in contrast to CYP81D11, DIN11 expression is not compromised in the jin1-1 mutant (Figure 6. 7). This indicates that, although the induction of all of these genes needs basal JA-Ile levels, different mechanisms of gene activation may exist. Other transcription factors (possible homologs of MYC2) acting downstream of COI1 have been postulated before (Berger et al. 1996; Lorenzo et al. 2004). Thus, processes comparable to those speculated for the CYP81D11 promoter may activate DIN11 expression, although another transcriptional activator would be involved.

\section{Col-0}

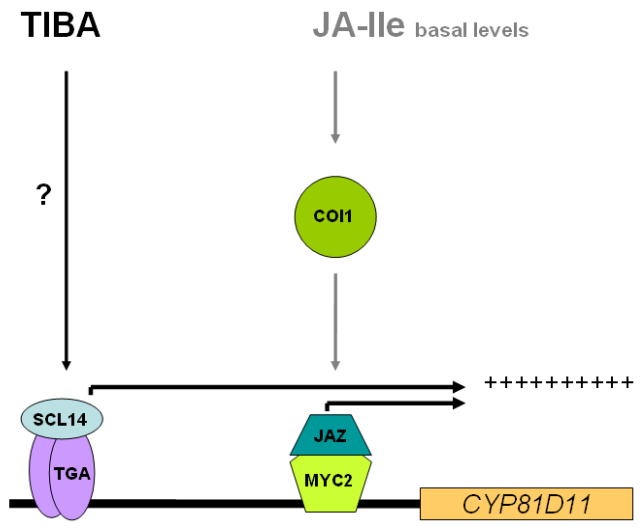

jin1-1

TIBA

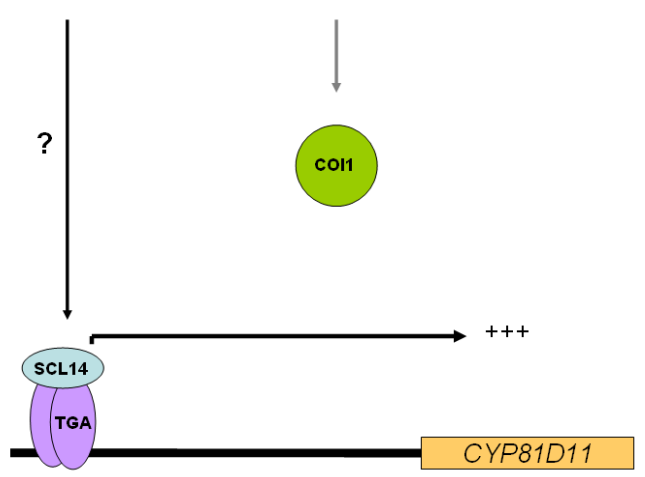

dde2-2 / jar1-1

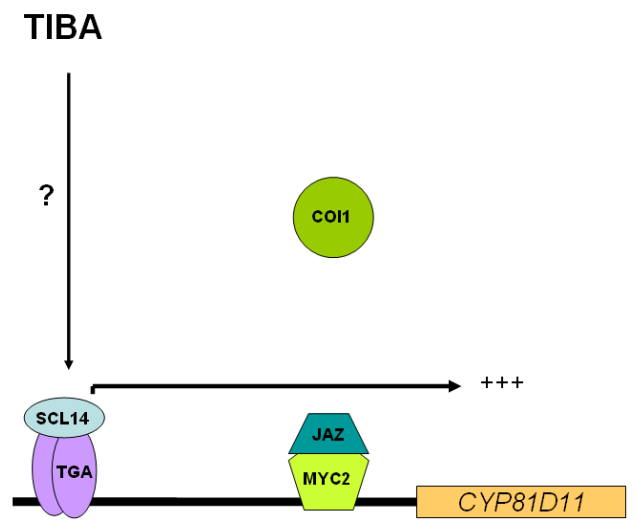

$\mathrm{JAZ1} \triangle 3 \mathrm{~A}$

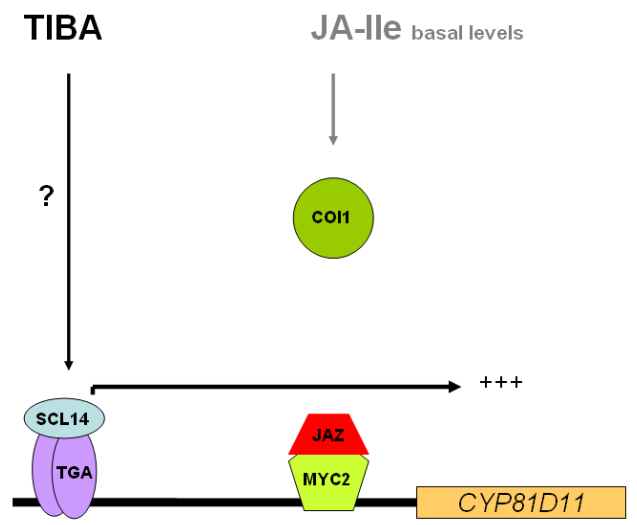

Figure 5. 1: Scheme of the CYP81D11 regulation on different genetic backgrounds

The scheme shows the CYP81D11 promoter in the wild type, the dde2-2, jar1-1 or jin1-1 mutant, and in transgenic JAZ1 $\triangle 3 \mathrm{~A}$ plants. The number of + signs indicates the strength of induction. 


\subsection{CYP81D11 is regulated by a JA-Ile-independent COI1 function}

The common function so far associated with the COI1 protein is the degradation of JAZ proteins in response to accumulated JA-Ile levels. An additional function of COI1 as a regulator of a large group of JA-inducible genes requiring basal JA-Ile levels was discussed above. In response to TIBA, BOA, and protoplasting, a JA-Ile-independent function was shown for the regulation of CYP81D11 (Figure 4. 8, Figure 4. 20). Recently, a JA-Ile-independent function of the COI1 protein has been reported for ETinduced inhibition of root growth (Adams \& Turner 2010). While wild-type plants as well as JA synthesis and signaling mutants (dde2, opr3 (12-oxophytodienoic acid reductase), jarl and jinl) exhibited strong root growth inhibition on ET (ACC)supplemented media, this effect was reduced in the coil-16 mutant. The effects of coil16 and ET-insensitive mutants on reducing root growth inhibition were additive. Thus, it was concluded that COI1 acts by a pathway independent of the known ET signal transduction.

Less severe inhibition of root growth was also observed in coil-16 mutants complemented with COI1 proteins with a mutated LRR domain, that contains the binding site for JA-Ile. In contrast to this, normal root growth inhibition occurred in coil-16 mutants complemented with a COI1 protein that was unable to assemble the SCF complex. These results indicate a COI1 function that requires its ligand binding site but not the SCF complex. An interaction of COI1 with ethylene-related components to regulate root growth without forming an SCF complex was postulated.

In this thesis, a more severe reduction of CYP81D11 expression in response to TIBA, the allelochemical BOA (Figure 4. 8), and protoplasting (Figure 4. 20) was observed for the coil-t mutant compared to the JA-Ile synthesis mutants. In case of protoplasts, but not after TIBA treatment, this effect was also observed for DIN11. It is concluded that JA-Ile only contributes to part of the COI1 function in regulating CYP81D11 expression, and that another part is independent of JA-Ile. Furthermore, this COI1 function is independent of known downstream signaling events, such as degradation of JAZ proteins and transcriptional activation via MYC2 (Figure 4. 10).

For the JA-Ile-independent COI1 function in response to ET, Adams and Turner (2010) speculated about the binding of ethylene-related components to the ligand binding site of the COI1 protein. To determine if in protoplasts COI1 exhibits a function independent of substrate binding (to this binding site), complementation of coil 
protoplasts with a COI1 protein mutated in the ligand binding site was performed (Figure 6. 10). Unfortunately, contradictory results were obtained in these experiments. The first attempt showed complementation of CYP81D11 and DIN11 expression by the wild-type COI1 and by a COI1 protein exhibiting alterations in the JA-Ile binding site. In contrast to this, repetition of this experiment showed no complementation by the mutated COI1. In a third experiment, CYP81D11 but not DIN11 expression was increased by the altered protein. Thus, no conclusion could be drawn regarding the requirement of the JA-Ile binding site and regarding a putative new COI1 ligand produced in protoplasts and in response to TIBA and BOA. Due to their different structures, and due to the fact that the JA-Ile-independent COI1 function was also observed in protoplasts without any chemical treatment, direct binding of TIBA or BOA to COI1 seems unlikely. To obtain further information about the kind of JA-Ileindependent function exhibited by COI1 in this case, transgenic plants carrying COI1 proteins will be used that are either unable to assemble the SCF complex or are altered within the LRR domain.

Inhibition of the proteasome-dependent protein degradation reduces the expression of CYP81D11 in protoplasts (Figure 4. 24). The decrease caused by MG132 in wild-type plants is more severe than the reduction of CYP81D11 expression in the dde2-2 mutant (Figure 4. 20). This demonstrates that proteasomal degradation independent of JA-Iledependent JAZ degradation plays a role in CYP81D11 activation. In this context, it may be possible to speculate about protein degradation in response to the JA-Ile-independent COI1 function. Still, as proteasome-dependent degradation is involved in a variety of regulatory pathways, COI1-independent processes have to be considered. Thus, no final conclusion about protein degradation in response to the JA-Ile-independent COI1 function can be made so far. 


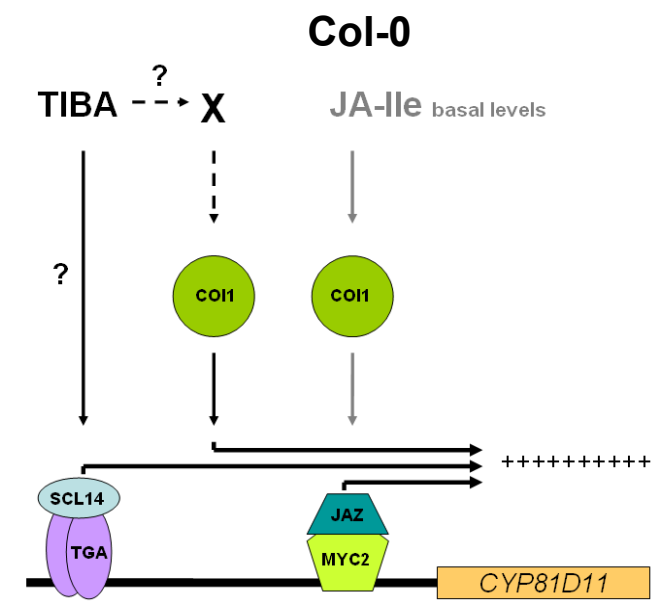

dde2-2

coi1-t
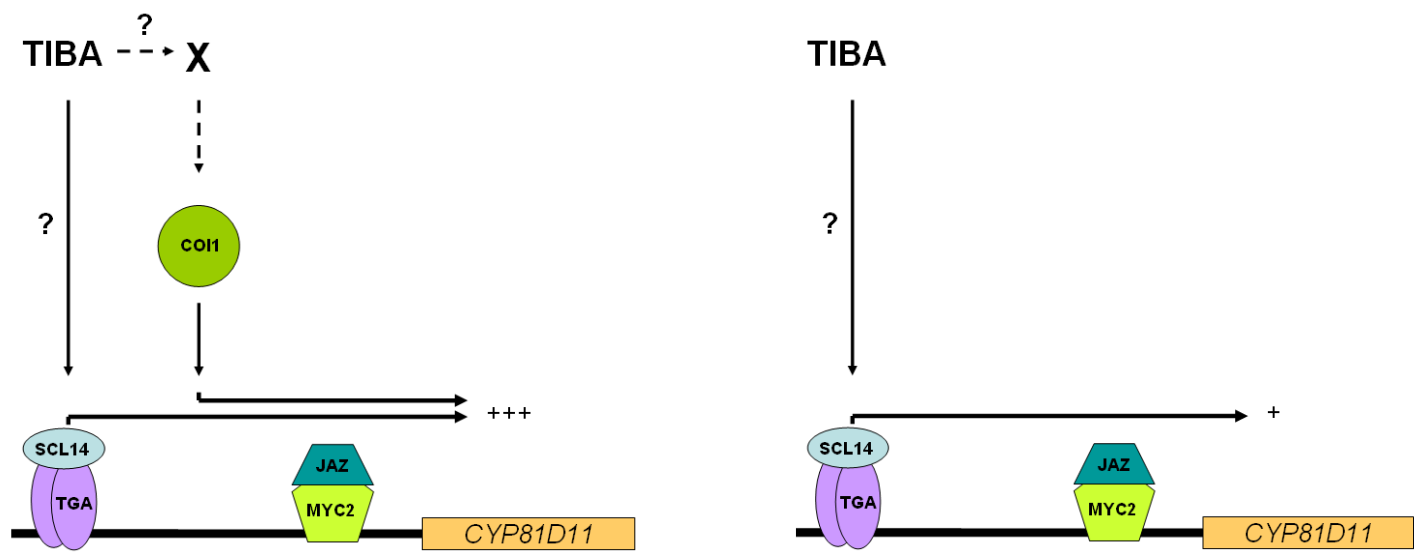

Figure 5. 2: Scheme of the CYP81D11 regulation on different genetic backgrounds

The scheme shows the CYP81D11 promoter in the wild-type, the $d d e 2-2$ and coil- $t$ mutant. The number of + indicates the strength of the induction.

\subsection{Function of the G-box for CYP81D11 expression}

Transgenic plants containing the CYP81D11 promoter mG-box reporter construct showed no increased reporter gene expression in response to MeJA treatment (Figure 4. 11), demonstrating that the G-box is essential for activation of the CYP81D11 promoter by JA.

In coil-t protoplasts, the reporter gene activity of this MeJA-insensitive mG-box construct is further reduced in comparison to wild-type protoplasts (Figure 4. 12). It is concluded that the JA-Ile-independent COI1 function is mediated by another promoter element. This is consistent with the independency of this function from MYC2 and JAZ protein degradation in intact TIBA-treated plants (Figure 4. 10). The possibility that the as-1-like element is targeted by COI1 was excluded as the activity of the constructs 
containing the mutated as-1-like element (mas-1 and the mas-1/mG-box) is still strongly reduced in the coil-t mutant (Figure 4. 12).

Also in dde2-2 protoplasts, a reduced activity of the mG-box construct was observed (Figure 6. 8). This reduction was less severe than in the coil-t protoplasts. Although these results exhibited higher variation than those obtained for coil-t protoplasts, it was concluded that not only the JA-Ile-independent COI1 function acts via a promoter element independent of the double G-box, but also basal JA levels act partially via additional elements or possibly in an indirect manner.

\section{WT promoter}

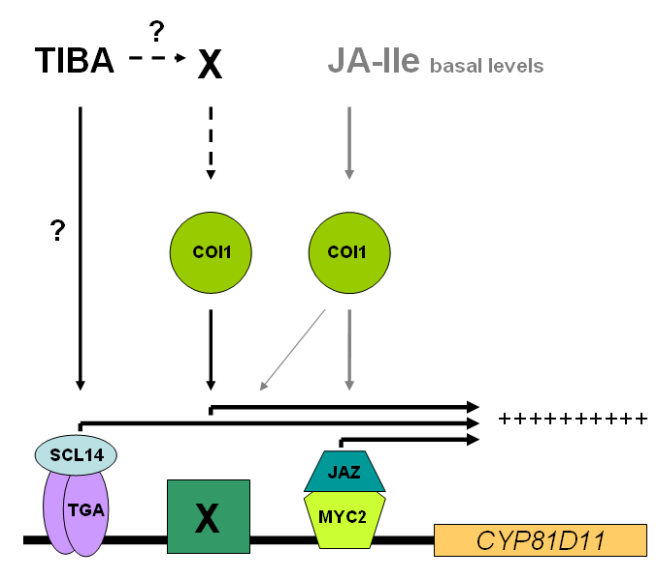

mG-box promoter

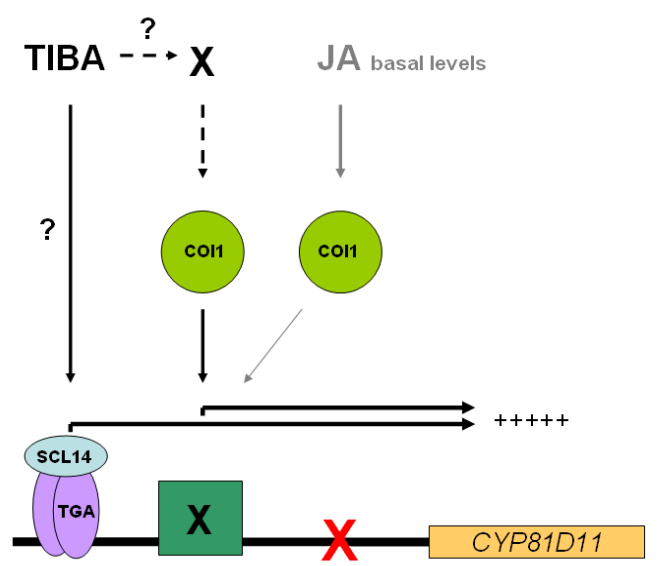

Figure 5. 3: Scheme of the CYP81D11 wild-type and mG-box promoter regulation

The scheme shows the CYP81D11 WT and mG-box promoter constructs in the wild type. The number of + signs indicates the strength of induction.

\subsection{Expression of $\mathrm{JA}$-responsive genes in protoplasts}

In this study, high JA-Ile levels in protoplasts were demonstrated (Figure 4. 22). Still, compared to intact leaves, reduced expression of several well-investigated JAresponsive genes was shown (Figure 4. 21). In contrast to this, CYP81D11 and DIN11 were strongly induced in protoplasts compared to intact leaves (Figure 4. 20, Figure 4. 21), but neither CYP81D11 and DIN11 nor MYC2 were induced by additional coronatine treatment (Figure 4. 23). It is concluded that the activation of JA-inducible genes is not functional in protoplasts.

The JAZ proteins, which are degraded by the $26 \mathrm{~S}$ proteasome in a $\mathrm{SCF}^{\mathrm{COI1}}$-dependent manner, are known repressors of JA signal transduction (Thines et al. 2007; Chini et al. 2007). Stabilization of JAZ proteins might either occur due to inhibition of their 
degrading pathway or by expression of a dominant-negative JAZ protein lacking the Jas domain. These kinds of proteins have been shown to exist not only as truncated mutant versions but also endogenously as splice variants (Chung \& Howe 2009). Nevertheless, a complete inhibition of JAZ degradation in protoplasts can be excluded, as coronatine treatment led to JAZ1-GUS degradation (Figure 4. 23) while the inhibition of the $26 \mathrm{~S}$ proteasome by the proteasome inhibitor MG132 caused the accumulation of JAZ1-GUS (Figure 4. 24).

Although the coronatine treatment did not lead to increased CYP81D11 and DIN11 expression (Figure 4. 23), inhibition of the proteasome-dependent protein degradation reduced the expression of these genes in protoplasts (Figure 4. 24). This indicates that protein degradation is involved in CYP81D11 and DIN11 expression in protoplasts. The reduced levels of CYP81D11 and DIN11 expression in dde2-2 protoplast compared with the wild type indicate that JA-Ile contributes to the activation of these genes in response to protoplasting (Figure 4. 20). Still, the reduced expression of JA marker genes demonstrates that activation of CYP81D11 and DIN11 occurs in an alternative manner. Furthermore, the more severe reduction in the coil- $t$ mutant compared with the dde2-2 mutant shows the contribution of a JA-Ile-independent COI1 function.

\subsection{A large group of genes is induced by TIBA in a COI1- and JA-Ile-dependent manner}

Microarray analyses revealed that the expression of 73 TIBA-inducible genes depends on COI1 (Figure 4. 13). Furthermore, as none of the seven further investigated genes requires a JA-Ile-independent COI1 function, it is concluded that at least the majority of these genes require basal JA-Ile levels for TIBA-induced expression. Functional categorization of these genes revealed that a large part of them is involved in the JAdependent stress response (Figure 4. 19), in many cases either as component of the JA synthesis cascade or as JA signaling component (Table 6. 5). Especially the upregulation of the JA synthesis genes was rather unexpected as JA-Ile did not accumulate. Consistently, not all genes needed for JA biosynthesis are up-regulated.

Consistent with the high number of JA-responsive stress-inducible genes, analyses using the Genevestigator database revealed that nearly all of the COI1-dependent genes identified in response to TIBA are inducible by JA. Further conditions that are not 
connected to JA accumulation but induced at least the majority of these genes were not identified.

In addition to TIBA, DIN11 is up-regulated in response to extended darkness. Under these conditions, JA-Ile levels remain very low; nevertheless, also this induction depends on COI1 (Figure 6. 9). It is therefore concluded that basal JA-Ile levels contribute to full induction of COI1-dependent genes in response to different stimuli.

In contrast to CYP81D11, the other TIBA-inducible genes regulated in a COI1dependent manner are not listed among the BOA-induced or phytoprostane-induced genes related to detoxification (Baerson et al. 2005; Mueller et al. 2008), with the exception of only one gene, at3g04000 (coding for a short-chain dehydrogenase/reductase (SDR) family protein), which was listed among the detoxification-related BOA-responsive genes. In contrast to this, $30 \%$ of the COI1independent TIBA-inducible genes were included in at least one of those groups. Thus, it was concluded that the COI1-dependent TIBA-inducible genes are not part of the common, broad-specificity detoxification response postulated for phytoprostanes, BOA and TIBA (Baerson et al. 2005; Mueller et al. 2008; Fode 2008).

TIBA is an auxin transport inhibitor and potentially a functional auxin (Thimann \& Bonner 1948; Dhonukshe et al. 2008); thus, induction of this group of genes due to an auxin-related function of TIBA is possible. As mentioned before, it was shown that a subset of JA-inducible genes ( $L O X 2$, AtVSP and AOS) is induced by auxin. Nevertheless, none of these genes is among the COI1-dependent, TIBA-induced genes found in this array.

Furthermore, the Genevestigator data indicate no induction of the most COI1-dependent genes in response to either the auxins IAA (indole-3-acetic acid) and NAA (1naphthaleneacetic acid) or the auxin transport inhibitor NPA $(N-1$-naphthylphthalamic acid). MAPMAN analyses revealed four genes involved in JA metabolism, with only one taking part in the biosynthesis of auxin (and one in SA metabolism). Therefore, it seems unlikely that the activity of TIBA as putatively active auxin or as auxin transport inhibitor is the critical factor for the induction of these genes. 


\subsection{CYP81D11 is co-regulated with COI1-independent genes}

Cluster analyses were used to identify COI1-dependent TIBA-inducible genes coregulated with CYP81D11. No COI1-dependent TIBA-inducible genes were identified that were co-regulated with CYP81D11 in response to diverse stimuli (Figure 4. 15). In contrast to this, when CYP81D11 expression was compared to the COI1-independent TIBA-inducible genes, it was grouped with three other genes (Figure 4. 16). Two of them, a gene coding for a UDP-glycosyltransferase (UGT73C6) and a gene coding for a glutathione $S$-transferase (GSTU1), are putatively involved in detoxification. This is consistent with the fact that CYP81D11 is strongly induced by different xenobiotics. Furthermore, GSTU1 has been identified as a TIBA-inducible SCL14-dependent gene (Fode 2008). The other two genes most closely co-regulated with CYP81D11 have not been shown to depend on SCL14.

The co-regulation of CYP81D11 with other TGA2,5,6/SCL14 target genes was supported by a time course experiment after TIBA treatment (Figure 4. 17). While the COI1-dependent TIBA-inducible genes JAZ10 and DIN11 reached their maximal expression at $8 \mathrm{~h}$ after TIBA treatment, the highest transcription levels (among the investigated time points) of CYP81D11, GSTU1, GSTU7 and ANAC032 were observed after $24 \mathrm{~h}$. At this time point, the JAZ10 and DIN11 levels had already decreased again. The variations in the JAZ10 and DIN11 expression kinetics in comparison to those of CYP81D11, GSTU1, GSTU7 and ANAC032 imply that different regulatory mechanisms work for these genes in response to TIBA.

The direct TGA2,5,6 target gene, GSTU7, which is induced by TIBA, BOA, phytoprostanes and CJ, was expected to be co-regulated with CYP81D11. Nevertheless, this was not reflected by the hierarchical cluster analyses, indicating that the coregulation of CYP81D11 and GSTU7 (Fode et al. 2008) is restricted to only a subset of stimuli.

The co-regulation with COIl-independent genes indicates a unique position of CYP81D11 among the xenobiotic-inducible genes. Figure 5.4 summarizes the different induction patters for CYP81D11, other TGA/SCL14-dependent genes, and other COI1dependent TIBA-inducible genes. 


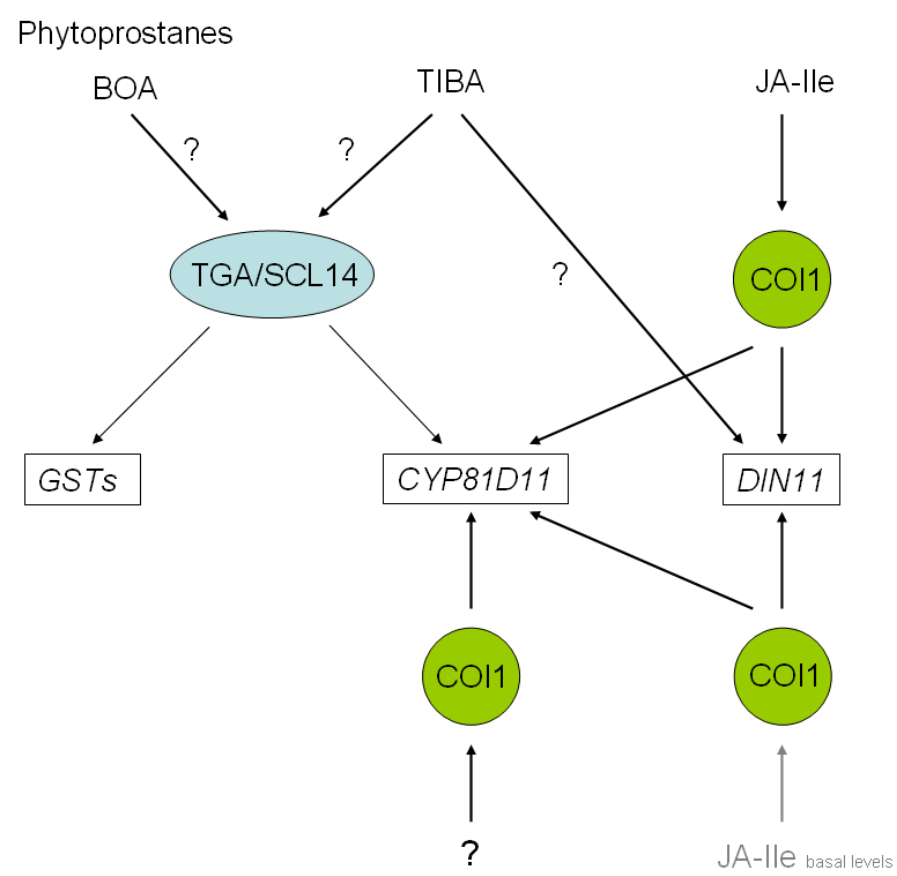

Figure 5. 4: Model of regulation of different classes of TIBA inducible genes

Mode of activation of TGA/SCL-dependent TIBA-inducible genes (represented by GSTs), of CYP81D11 and of COI1-dependent TIBA-inducible genes (represented by DIN11). TIBA and phytoprostanes (and BOA) induce a subset of detoxification genes in a TGA2,5,6(/SCL14)-dependent manner. One of these genes is CYP81D11, but it is additionally activated by increased JA-Ile levels, e.g. after MeJA treatment. This induction requires COI1. Furthermore, also the induction by TIBA, BOA and phytoprostanes (Mueller et al. 2008) requires COI1. In this context, two new COI1 functions have been identified: (i) a COI1 function requiring basal JA-Ile levels, which is involved in the activation of a large group of TIBAinducible genes including CYP81D11 and DIN11; (ii) a JA-Ile-independent COI1 function, which coactivates $C Y P 81 D 11$ expression in response TIBA and BOA. So far, it could not be elucidated whether a new COI1 ligand is involved in this function ("'?").

Two more steps depicted in this scheme (also marked with "?") have not been deciphered so far: It is not yet clear (i) whether the TGA/SCL14 complex is activated upon chemical stress or whether it is a constitutive activator and regulatory steps are carried out by other yet unknown components; (ii) by which pathway DIN11 (and other SCL14-independent genes) is activated in response to TIBA.

\section{$5.8 \quad$ ANAC032 negatively regulates CYP81D11 expression}

ATAF1 and ANAC032 are both SCL14-dependent and up-regulated genes in response to TIBA. Thus, their influence on other TIBA-inducible genes was investigated. NAC proteins represent a large family of transcription factors that are involved in developmental processes and defense and abiotic-stress responses (Olsen et al. 2005). In the last years, several studies investigating the role of ATAF1 in abiotic stress and defense responses were performed. Due to many contradictory results, a clear picture of ATAF1 function cannot be drawn. A consistent observation is the up-regulation of ATAF1 expression in response to drought and ABA. The role of ATAF1 in the drought 
stress response is controversial. In two studies, ABA hypersensitivity and a higher recovery rate after drought stress were shown for knockout mutants of ATAF1 compared to the wild type (Lu et al. 2007; Jensen et al. 2008). In another study, ATAF1 overexpressors mediated increased drought resistance and were hypersensitive to ABA, while no differences were observed for the same mutants compared to wild-type plants (Wu et al. 2009). At least for the drought tolerance experiments in two of the studies, the experimental setups were quite similar (Wu et al. 2009; $\mathrm{Lu}$ et al. 2007). In agreement with the role of ATAF1 as a negative regulator of the ABA response, an ATAF1-dependent decrease of ABA levels was observed in response to infection with the non-host pathogen Blumeria graminis f. sp. hordei. Thus, an ATAF1 function in crosstalk between abiotic stress and pathogen resistance was concluded (Jensen et al. 2008). Further evidence for an involvement of ATAF1 in pathogen resistance was provided by Botrytis cinerea infection experiments. Overexpressors of ATAF1 showed enhanced susceptibility to this necrotrophic fungus (Wu et al. 2009; Wang et al. 2009), while transgenic lines expressing an ATAF1 repressor domain fusion protein exhibited increased resistance (Wang et al. 2009). Nevertheless, the expression patterns of the pathogen-related genes $P D F 1.2$ and $P R 1$ differed among the studies. Wang et al. (2009) showed decreased PDF1.2 and PRI levels in the overexpressor and increased levels in the repressor fusion lines compared to the wild type, while $\mathrm{Wu}$ et al. (2009) demonstrated unaffected $P D F 1.2$ levels either in the overexpressor lines or in the knockout plants. Hence, $P R I$ expression was stronger in the overexpressor and weaker in the mutant. However, the differences in the expression of $P R$ genes were relatively weak in both studies. Furthermore, one study used drop inoculation while in the other study spray inoculation was used.

Due to the sterility of the ATAF1-overexpressing plants used in this thesis, only uninduced levels of CYP81D11 were investigated. Still, strong reduction of CYP81D11 expression was observed (Figure 4. 25). The same effects were shown for ANAC032overexpressing plants, but as here a few plants were fertile, further experiments were performed with those lines. Severe reduction of CYP81D11 transcript levels was observed in response to TIBA (Figure 4.29) and to JA (Figure 4. 31). Among the TIBAinducible genes, the observed effects differed strongly. CYP81D11 was the only investigated SCL14-dependent gene that showed these severe effects. While GSTU1 was not influenced at all, GSTU7 expression was reduced to about one-third and ATAF1 showed only a slight reduction (Figure 4. 30). Also the expression of the gene 
DIN11, whose induction by TIBA is independent of TGA2,5,6 and SCL14, was reduced to about $40 \%$ in the ANAC032-overexpressing plants. These results indicate that TGA class II transcription factor- and SCL14-dependent gene regulation is independent of regulation by ANAC032.

Even stronger suppression of CYP81D11 expression (0.4\%) occurred in the ANAC032 overexpressors in response to MeJA, and also VSP2 and PDF1.2 expression were strongly compromised (to less than $10 \%$ ) (Figure 4. 31). DIN11 was again less severely influenced, but still expression was reduced to about $20 \%$. All the genes tested in response to MeJA are COI1 dependent. Thus, it seems possible that ANAC032 somehow interferes with the COI1 function.

ATAF1 was shown to be involved in ABA signaling and in the crosstalk between the abiotic-stress and the pathogen response. As also ANAC032 is inducible by ABA, a negative effect of the ABA signaling response at least on JA-responsive genes seems feasible. For JA/ET-inducible genes, a negative effect of ABA has been shown before (Anderson et al. 2004). Although in the same experiments VSP2 as an only JA-inducible gene was positively affected, it cannot be excluded that the repressing effect of ANAC032 is associated with ABA signaling.

Although in this thesis only genes that are negatively influenced by ANAC032 were shown, it is likely that ANAC032 is a positive transcriptional regulator. For ATAF1, transcriptional activation capacity was shown in yeast ( $\mathrm{Lu}$ et al. 2007). Furthermore, ATAF1 repressor domain fusions were shown to exhibit contrary effects to the overexpressed wild-type protein, indicating an activating function of ATAF1 in plants (Wang et al. 2009). Thus, the transcriptional repression in the ATAF1- and ANAC032overexpressing plants observed in this thesis was most certainly mediated by a repressor whose expression is activated directly or indirectly by ATAF1 and ANAC032.

ATAF1 and ANAC032 are the two closest homologues of the ATAF subfamily, but also ATAF2 and ANAC102, the two other members of this family, show high sequence identity. Furthermore, $A T A F 1, A N A C 032$ and $A N A C 102$ group together in biclustering analyses in response to a broad range of treatments including Botrytis cinerea infection, $\mathrm{H}_{2} \mathrm{O}_{2}$, TIBA, or MeJA treatment, wounding, drought and ABA treatment (Kleinow et al. 2009). Additionally, no single mutant from the ATAF subfamily shows any developmental phenotype, which is in contrast to the overexpressing plants. Thus, it was concluded that the members of the ATAF subfamily exhibit redundant or at least 
overlapping functions. Although phenotypes with resistance to drought or pathogens were observed for both the ataf1 ( $\mathrm{Lu}$ et al. 2007; Jensen et al. 2008) and the ataf2 (Delessert et al. 2005) single mutants, the fact that a repressor fusion of ATAF1 showed more severe effects than the knockout mutant further supports this assumption.

In this thesis, ataf1/anac032 double mutants neither show developmental defects nor do they affect CYP81D11 expression (Figure 4. 33). These results indicate that, at least in response to TIBA and MeJA, functional redundancy exists not only between ATAF1 and ANAC032 but may also include ANAC102 and/or ATAF2.

\subsection{ATAF1- and ANAC032-overexpressing plants exhibit severe growth and developmental phenotypes.}

The ATAF1 and ANAC032 overexpressors generated in this thesis both show severe dwarfism, curly upwards-bent leaves exhibiting early yellowing mostly between the vessels and at the edges, late flowering, short inflorescences, sterility, and an extended lifetime (Figure 4. 25, Figure 4. 26). This phenotype was even a bit stronger in the ATAF1-overexpressing plants which showed increased branching; however, these phenotypes were largely similar. This observation further supports the hypothesis of functional redundancy.

To a certain extent, similar phenotypes were described for ATAF1 overexpressors in the literature (Wu et al. 2009), but also ATAF1-overexpressing plants with only more round leaves and no developmental phenotype have been described (Wang et al. 2009). Nevertheless, referring to the transcript levels, the overexpression in this case does not seem to be very strong. So far, none of the studies using ATAF1-overexpressing lines have offered a full explanation. Wu et al. (2009) reasoned that delayed flowering might be connected to an involvement of ATAF1 in the ABA response, as also the overexpression of other transcription factors involved in $\mathrm{ABA}$ signaling (ABI3 and ABF4) exhibited a late flowering phenotype (Kang et al. 2002; Zhang et al. 2005). Additionally, growth retardation was described for ABF4-overexpressing plants. As a reason for this phenotype, a constitutively activated ABA response was assumed. However, at least in the ANAC032-overexpressing plants, no alteration of the ABAresponsive gene COR78 was observed (Figure 6.11).

In this thesis, many JA-responsive genes were repressed in the ANAC032overexpressing plants. This may be a reason for their sterile phenotype, as JA synthesis 
and some JA signaling mutants exhibit male sterility (Park et al. 2002; Xie et al. 1998; McConn \& Browse 1996b). Nevertheless, none of the mutants involved in JA synthesis or signaling exhibited dwarfism or curly, early yellowing leaves. Thus, it is concluded that other developmental processes independent of ABA and JA are influenced as well. Although examples for dwarf mutants have been described with the involvement of many pathways, dwarf phenotypes have most frequently been described for mutants with defects in the synthesis or signaling of either gibberellic acid (GA) (Schwechheimer 2008; Ueguchi-Tanaka et al. 2007) or brassinosteroids (BRs) (Choe et al. 1998; Choe et al. 2000; Kwon \& Choe 2005). GA is essential for normal plant growth regulation. Mutants in GA signaling or synthesis exhibit a characteristic dwarf phenotype with darker leaves, decreased apical dominance, and late flowering. Additionally, seed germination is impaired in those mutants (Harberd et al. 2009; Richards et al. 2001). Mutants associated with brassinosteroids were reported to exhibit a short robust stature, reduced fertility, a prolonged life span, and leaves with darker green color and a round and curled shape (Kwon \& Choe 2005). For many characteristics, ATAF1 and ANAC032 overexpressors seem to resemble mutants associated with BRs, still BR and GA mutants exhibit darker green leaves compared to the wild type, while leaves of ATAF1 and ANAC032 overexpressors are more yellowish. However, whether ATAF1 and ANAC032 influence GA or BR synthesis or signal transduction remains to be elucidated. 


\section{Supplemental data}

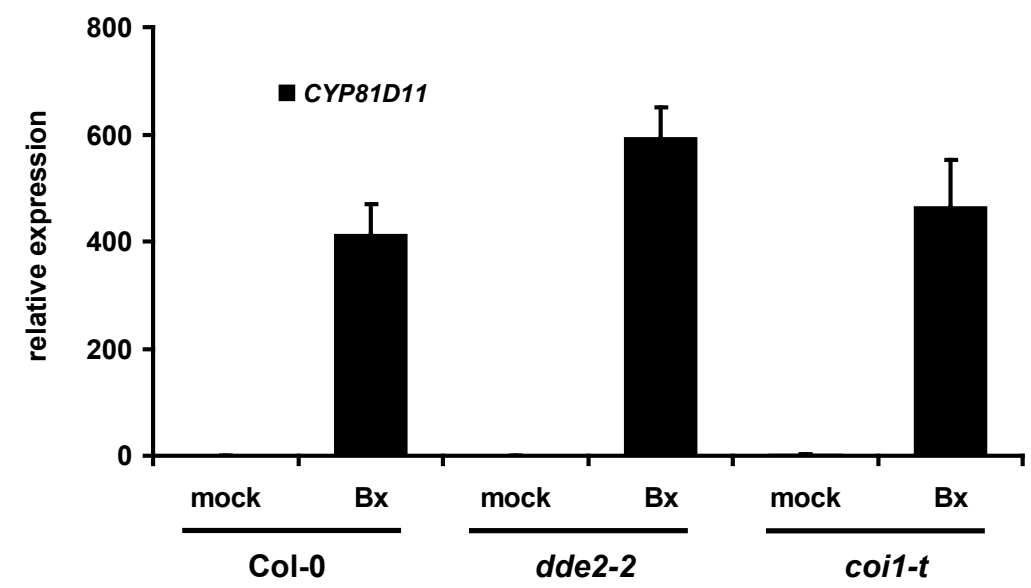

Figure 6. 1: Expression analysis of CYP81D11 in the $d d e 2-2$ and coil-t mutants in response to benoxacor

Quantitative real-time RT-PCR analysis of relative CYP81D11 transcript levels (normalized to the housekeeping gene UBQ5) in Col-0 (WT), dde2-2 and coil-t mutant plants. 6-7-week-old plants were sprayed with $50 \mu \mathrm{M}$ benoxacor $(\mathrm{Bx})$ or $0.1 \%$ DMSO (mock) and incubated for $8 \mathrm{~h}$. Whole rosettes were harvested for RNA isolation. Transcript values in mock treated Col-0 plants were set to 1. Every bar represents the average \pm SEM of four (two for coil- $t$ mock) biological replicates.

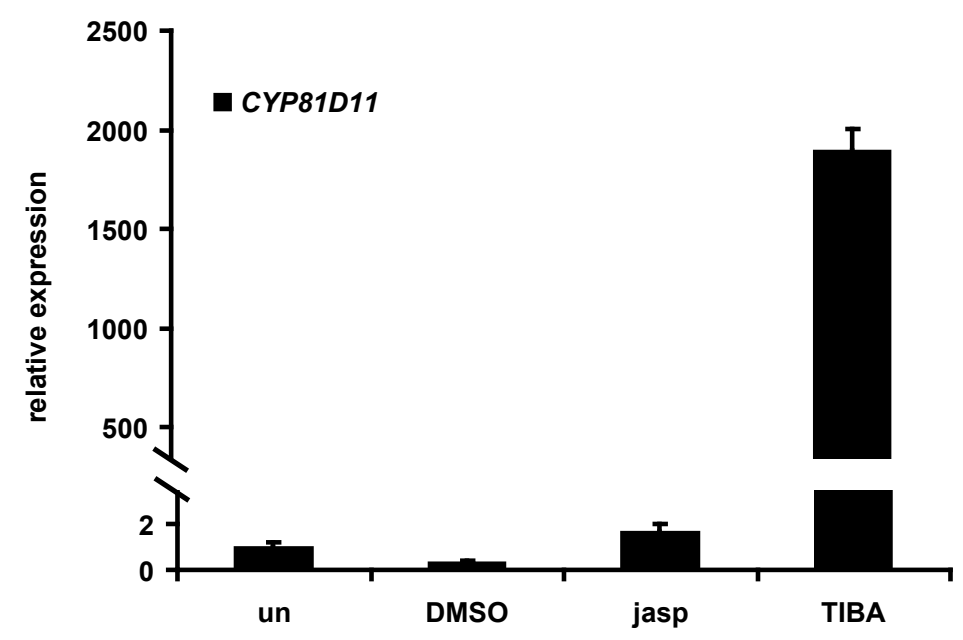

Figure 6. 2: CYP81D11 transcript levels in Col-0 leaves in response to TIBA and jasplakinolide

Quantitative real time RT-PCR analyses of CYP81D11 transcript levels (normalized to the housekeeping gene UBQ5). Plants were grown on soil under $12 \mathrm{~h}$ light/12 h dark for six weeks. Leaves were cut and petioles were submerged in $\mathrm{H}_{2} \mathrm{O}$ (un), $1 \%$ DMSO, in $10 \mu \mathrm{M}$ jasplakinolide in $1 \%$ DMSO (jasp) or $100 \mu \mathrm{M}$ TIBA in $0,1 \%$ DMSO for $24 \mathrm{~h}$. Transcript values of untreated plants were set to 1 . Every bar represents the average \pm SEM of four biological replicates. 


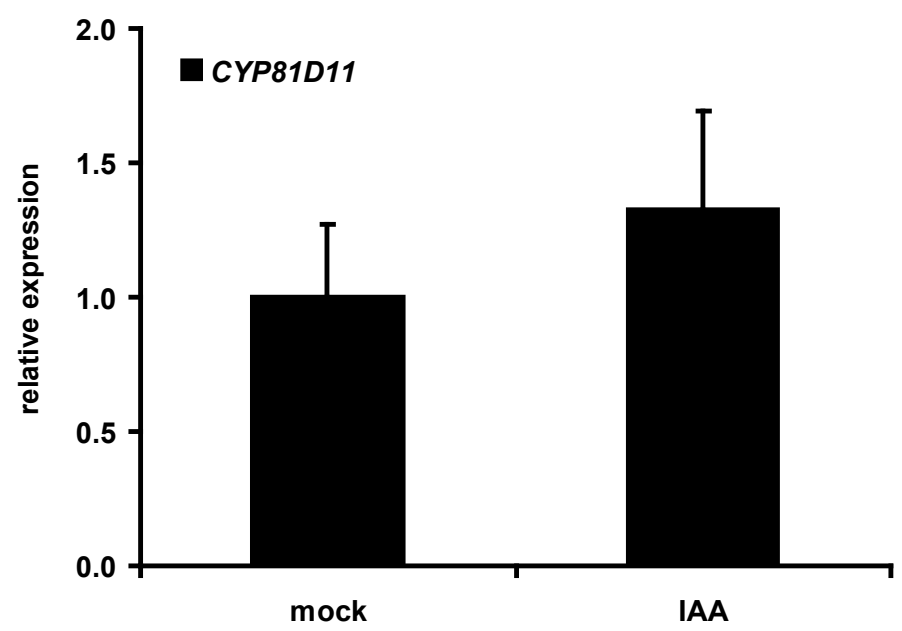

Figure 6. 3: Expression analysis of CYP81D11 in response to IAA

Quantitative real-time RT-PCR analysis of relative CYP81D11 transcript levels (normalized to the housekeeping gene UBQ5) in Col-0 plants. 6-7-week-old plants were sprayed with $10 \mu \mathrm{M}$ IAA or $\mathrm{H}_{2} \mathrm{O}$ (mock). Whole rosettes were harvested for RNA isolation. Transcript values in mock treated plants were set to 1 . Every bar represents the average \pm SEM of four biological replicates

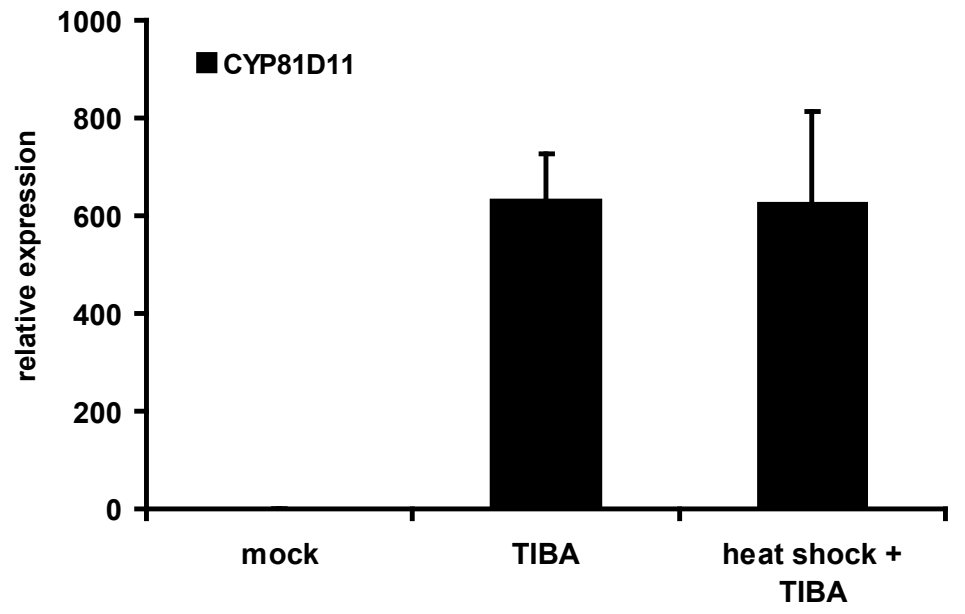

Figure 6. 4: Transcripti levels of CYP81D11 in the transgenic $H S: A X R 3-1$ plants in response to TIBA

Quantitative real-time RT-PCR analysis of relative CYP81D11 transcript levels (normalized to the housekeeping gene $U B Q 5$ ) in transgenic $H S: A X R 3-1$ plants. 6-7-week-old plants were kept in the dark at $20^{\circ} \mathrm{C}$ (mock and TIBA) or in the dark at $37^{\circ} \mathrm{C}$ for $2 \mathrm{~h}$ and were subsequently sprayed with $100 \mu \mathrm{M}$ TIBA and incubated for $8 \mathrm{~h}$ in the light. The heat shock was performed to induce the expression of $A X R 3-1$ which is regulated by a heat shock promoter. Whole rosettes were harvested for RNA isolation. Transcript values in mock treated Col-0 plants were set to 1 . Every bar represents the average \pm SEM of four biological replicates. 


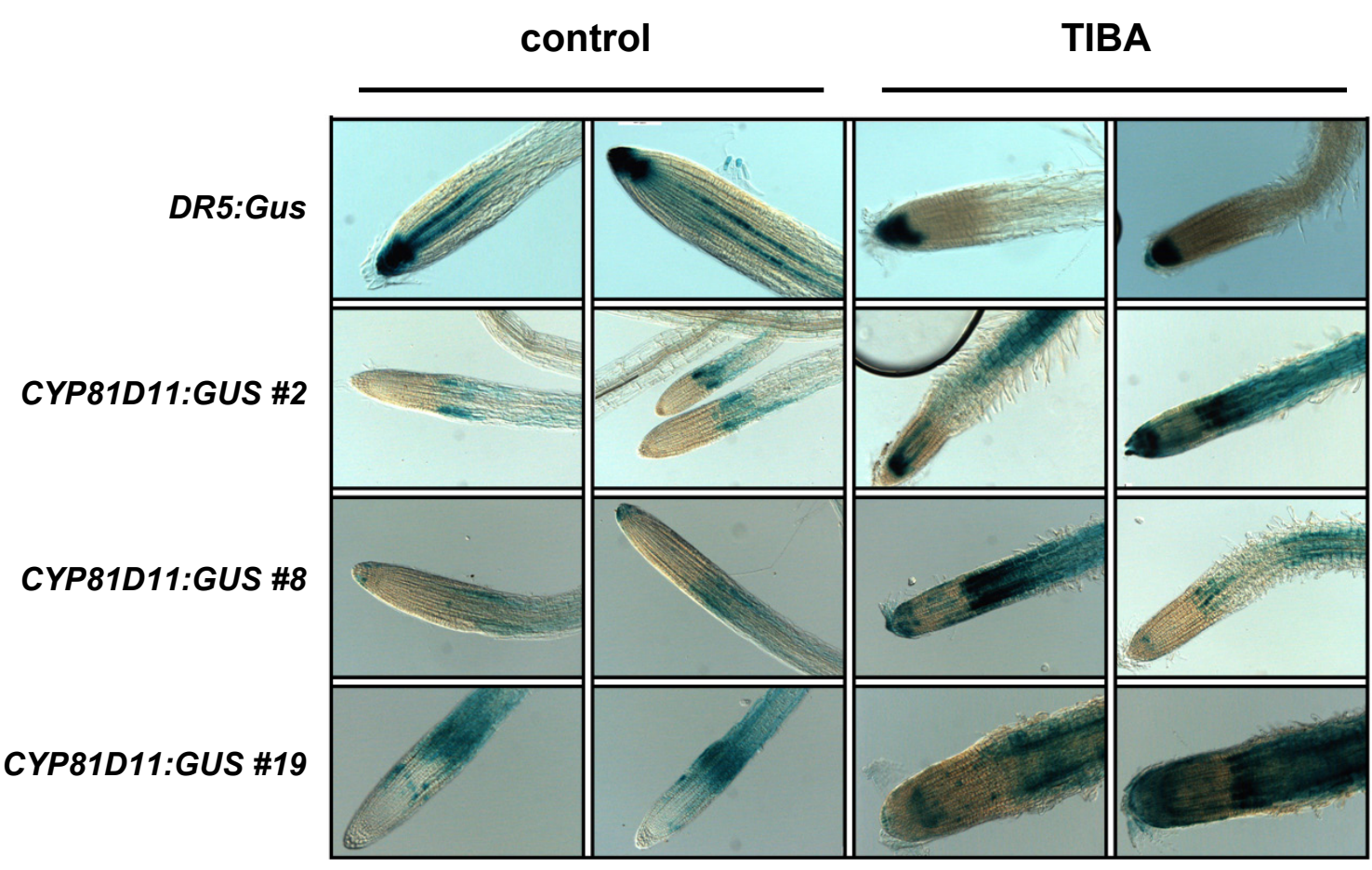

Figure 6. 5: Histochemical staining for GUS activity in root tips of transgenic DR5:GUS and CYP81D11: GUS plants

Root tips of transgenic plants plants containing DR5:GUS and CYP81D11:GUS transcriptional fusion constructs were staind with the GUS substate X-gluc (5-bromo, 4-chloro, 3-indoyl $\beta$-glucuronide) to determine tissue specific GUS activity. Seadlings were grown for 14 days (under $14 \mathrm{~h} \mathrm{light} / 10 \mathrm{~h}$ dark) on MS agar either supplemented with $5 \mu \mathrm{M}$ TIBA or without any additives. Representative pictures of three indenpendet CYP81D11:GUS lines are displayed.

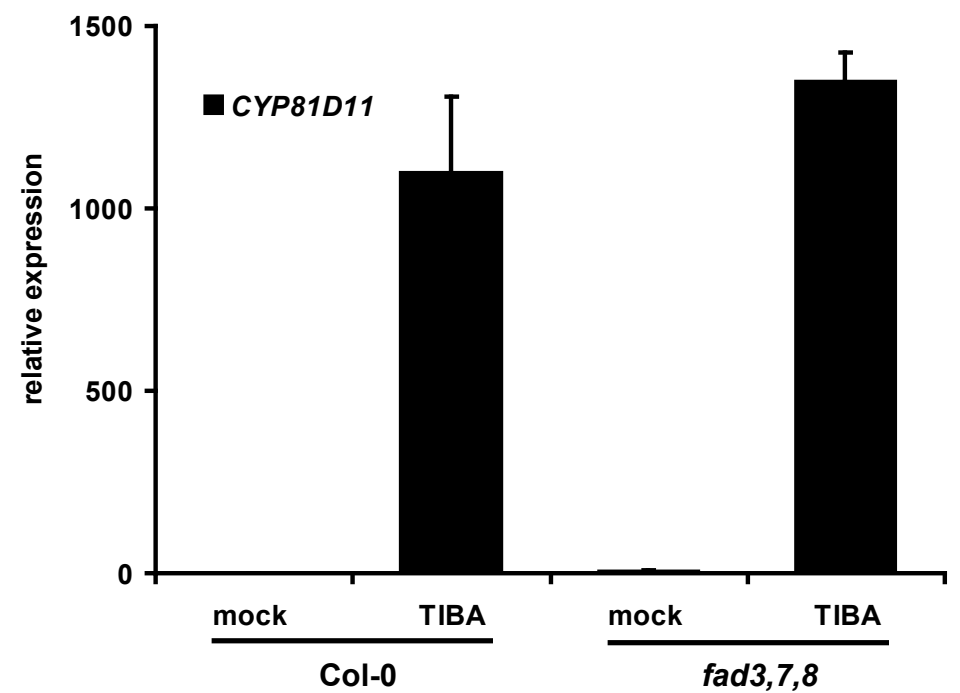

Figure 6. 6: Expression analysis of CYP81D11 in the $f a d 3,7,8$ mutant in response to TIBA

Quantitative real-time RT-PCR analysis of relative CYP81D11 transcript levels (normalized to the housekeeping gene UBQ5) in Col-0 (WT) and fad3,7,8 mutant plants. 6-7-week-old plants were sprayed with $100 \mu \mathrm{M}$ TIBA or $0,1 \%$ DMSO and incubated for $8 \mathrm{~h}$. Whole rosettes were harvested for RNA isolation. Transcript values in mock treated Col-0 plants were set to 1 . Every bar represents the average \pm SEM of three (Col-0 TIBA) or four biological replicates. 


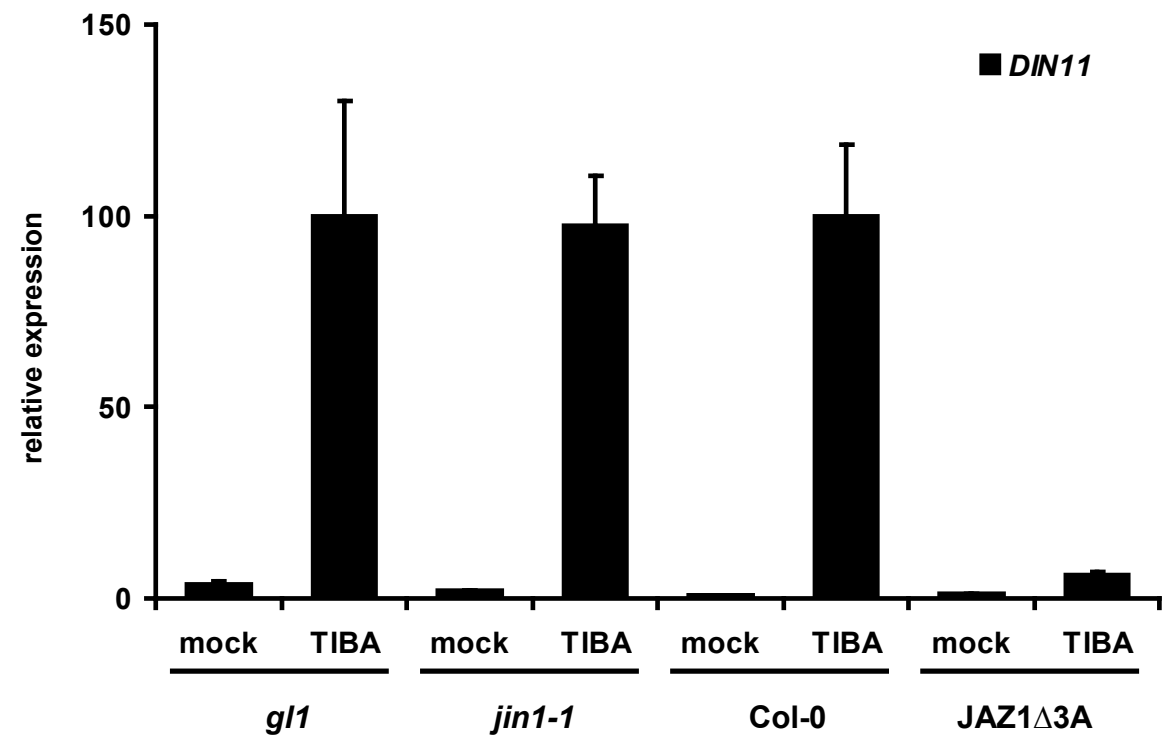

Figure 6. 7: Expression analysis of DIN11 in plants deficient in JA signal transduction after TIBA

Quantitative real-time RT-PCR analysis of relative DIN11 transcript levels (normalized to the housekeeping gene UBQ5) in gll ("wild-type") and jin1-1 mutant plants as well as Col-0 (wild-type) plants ectopically expressing JAZ $\Delta 3 \mathrm{~A}$, a JAZ1 protein lacking the Jas domain. 6-7-week-old plants were sprayed with $100 \mu \mathrm{M}$ TIBA and whole rosettes were harvested for RNA isolation after $8 \mathrm{~h}$. Transcript values in mock-treated Col-0 plants were set to 1. Every bar represents the average \pm SEM of four (glland jin 1-1), five (Col-0 mock) six (Col-0 TIBA and JAZ1 $\Delta 3$ A TIBA) or seven (JAZ1 $\Delta 3 \mathrm{~A}$ mock) biological replicates. 
A

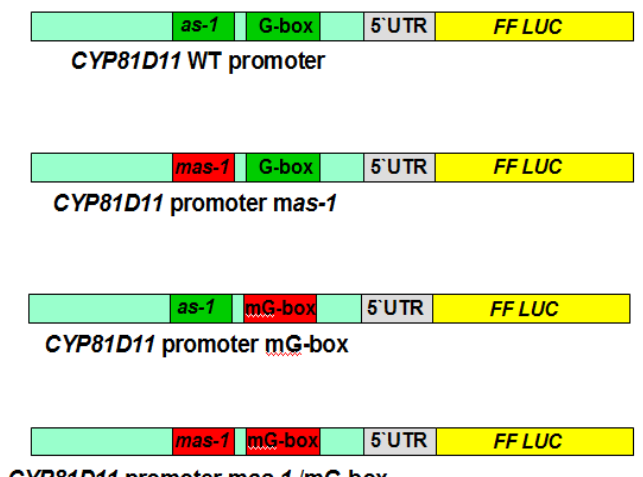

CYP81D11 promoter mas-1/mG-box
B

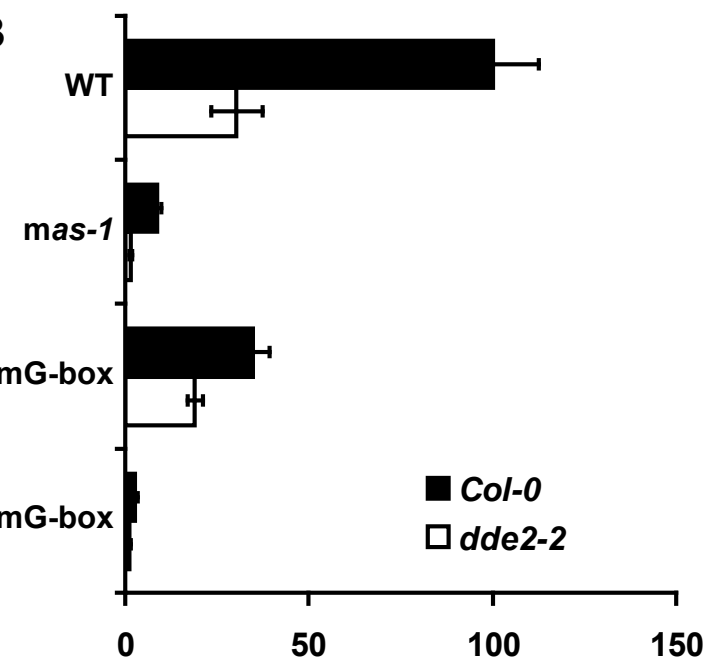

rel. activity firefly / renilla

Figure 6. 8: Transient expression analysis of distinct CYP81D11 promoter constructs carrying sequence alterations at the site of the as-1-like element and the site of the G-boxes

(A) Schematic illustration of the distinct CYP81D11 promoter:firefly luciferase constructs used for protoplast transfection. The light blue box indicates an $894 \mathrm{bp}$ fragment upstream of the CYP81D11 transcription start site, wild-type sequences of the $a s-1$ element (position -243 to -225) and the double Gbox (position -206 to -193) are marked in green, while the altered sequences are depicted by red boxes. The grey box marks the 5'UTR of the CYP81D11 gene and the yellow box indicates the firefly luciferase (FF LUC) reporter gene. The construct referred to as WT contains the $894 \mathrm{bp}$ fragment upstream of the CYP81D11 transcription start site and the $5^{\prime}$ UTR of the CYP81D11 gene. The mas- 1 construct contains sequence alteration within the as-1 element (position -243 to -225 ), while the mG-box construct contains alterations in the sequence of the double G-box (position -206 to -193). The mas-1/mG-box construct exhibits alterations in both elements

(B) Luciferase activities obtained from transfection of distinct promoter:firefly luciferase constructs in A. thaliana Col-0 and dde2-2 protoplasts. Leaves of 7-week-old soil-grown and non-induced plants were used for protoplast isolation. The x-coordinate demonstrate the ratio of the firefly luciferase activity to the internal Renilla luciferase standard.

Table 6. 1: Genes being TIBA-inducible in a COI1 dependent manner

COI1-dependent TIBA-inducible genes sorted due to their TIBA inducibility. COI1 dependency and Pvalues are indicated.

\begin{tabular}{||l|l|l|c|c|c|c||}
\hline Gene code & Symbol & $\underline{\text { Description }}$ & $\frac{\underline{\text { Col-0 TIBA/ }}}{\underline{\text { Col-0 mock }}}$ & $\frac{\text { P-value }}{\text { coil-t TIBA/ }}$ & $\underline{\text { Col-0 TIBA }}$ & $\frac{\text { P-value }}{||}$ \\
\hline at3g28740 & CYP81D11 & monooxygenase & 55.64 & $8.6 \mathrm{E}-09$ & 0.12 & $1.0 \mathrm{E}-05$ \\
\hline at1g43160 & RAP2.6 & transcription factor & 30.96 & $1.1 \mathrm{E}-12$ & 0.03 & $9.3 \mathrm{E}-13$ \\
\hline at5g13220 & JAZ10 & jasmonate-ZIM-domain protein & 28.62 & $2.0 \mathrm{E}-10$ & 0.02 & $4.8 \mathrm{E}-11$ \\
\hline at3g49620 & DIN11 & oxidoreductase & 23.70 & $3.5 \mathrm{E}-07$ & 0.01 & $1.2 \mathrm{E}-08$ \\
\hline at1g10585 & & transcription factor & 18.92 & $1.4 \mathrm{E}-10$ & 0.06 & $3.4 \mathrm{E}-10$ \\
\hline at5g63450 & CYP94B1 & monooxygenase & 16.61 & $7.1 \mathrm{E}-12$ & 0.06 & $7.0 \mathrm{E}-12$ \\
\hline at2g34600 & JAZ7 & jasmonate-ZIM-domain protein & 12.90 & $7.2 \mathrm{E}-09$ & 0.07 & $5.1 \mathrm{E}-09$ \\
\hline at4g21680 & & $\begin{array}{l}\text { proton-dependent oligopeptide } \\
\text { transport (POT) family protein }\end{array}$ & 10.93 & $2.9 \mathrm{E}-10$ & 0.12 & $1.4 \mathrm{E}-09$ \\
\hline at3g23550 & & MATE efflux family protein & 9.95 & $3.1 \mathrm{E}-10$ & 0.10 & $3.1 \mathrm{E}-10$ \\
\hline at3g09940 & ATMDAR3 & monodehydroascorbate reductase & 8.92 & $1.4 \mathrm{E}-07$ & 0.07 & $1.8 \mathrm{E}-08$ \\
\hline at3g48520 & CYP94B3 & monooxygenase & 8.86 & $5.7 \mathrm{E}-09$ & 0.11 & $5.7 \mathrm{E}-09$ \\
\hline
\end{tabular}




\begin{tabular}{|c|c|c|c|c|c|c|}
\hline Gene code & $\underline{\text { Symbol }}$ & Description & $\frac{\text { Col-0 TIBA/ }}{\text { Col-0 mock }}$ & $\underline{\text { P-value }}$ & $\frac{\text { coil-t } t \text { TIBA/ }}{\text { Col-0 TIBA }}$ & $\underline{\text { P-value }}$ \\
\hline at $5 \mathrm{~g} 67080$ & MAPKKK19 & protein kinase & 8.39 & $1.1 \mathrm{E}-08$ & 0.12 & $1.1 \mathrm{E}-08$ \\
\hline at $5 \mathrm{~g} 05600$ & & $\begin{array}{l}\text { oxidoreductase, } 2 \mathrm{OG}-\mathrm{Fe}(\mathrm{II}) \text { oxygenase } \\
\text { family protein }\end{array}$ & 8.03 & $4.8 \mathrm{E}-10$ & 0.02 & $3.0 \mathrm{E}-13$ \\
\hline at3g57520 & AtSIP2 & hydrolase & 7.63 & $1.1 \mathrm{E}-06$ & 0.28 & $1.2 \mathrm{E}-04$ \\
\hline at4g37410 & CYP81F4 & monooxygenase & 7.61 & 2.3E-09 & 0.04 & $1.0 \mathrm{E}-11$ \\
\hline at1g06620 & & $\begin{array}{l}\text { 2-oxoglutarate-dependent dioxygenase, } \\
\text { putative }\end{array}$ & 7.05 & $1.2 \mathrm{E}-09$ & 0.11 & 2.7E-10 \\
\hline at3g47340 & $A S N 1$ & asparagine synthase & 6.75 & $9.0 \mathrm{E}-05$ & 0.24 & $1.1 \mathrm{E}-03$ \\
\hline at2g29460 & ATGSTU4 & glutathione transferase & 6.71 & $1.3 \mathrm{E}-05$ & 0.22 & $1.1 \mathrm{E}-04$ \\
\hline at5g61160 & $A A C T 1$ & acyltransferase & 6.61 & $1.2 \mathrm{E}-06$ & 0.07 & 2.4E-08 \\
\hline at5g44050 & & MATE efflux family protein & 6.17 & $1.6 \mathrm{E}-07$ & 0.12 & $3.5 \mathrm{E}-08$ \\
\hline at $\lg 30135$ & JAZ8 & jasmonate-ZIM-domain protein & 5.96 & $1.1 \mathrm{E}-05$ & 0.14 & $3.9 \mathrm{E}-06$ \\
\hline at1g70700 & JAZ9 & jasmonate-ZIM-domain protein & 5.86 & $3.1 \mathrm{E}-10$ & 0.04 & $1.3 \mathrm{E}-13$ \\
\hline at1g17380 & JAZ5 & jasmonate-ZIM-domain protein & 5.71 & 7.8E-09 & 0.10 & $2.2 \mathrm{E}-10$ \\
\hline at5g19110 & & $\begin{array}{l}\text { extracellular dermal glycoprotein- } \\
\text { related }\end{array}$ & 5.70 & 3.4E-09 & 0.11 & $2.0 \mathrm{E}-10$ \\
\hline at5g38120 & & $\begin{array}{l}\text { 4-coumarate--CoA ligase family } \\
\text { protein }\end{array}$ & 5.26 & $5.9 \mathrm{E}-10$ & 0.16 & $1.7 \mathrm{E}-10$ \\
\hline $\begin{array}{l}\text { at3g44860/ } \\
\text { at3g44870 }\end{array}$ & $\begin{array}{l}\text { FAMT / } \\
-\end{array}$ & $\begin{array}{l}\text { S-adenosylmethionine-dependent } \\
\text { methyltransferas } \\
\text { S-adenosyl-L-methionine:carboxyl } \\
\text { methyltransferase family protein }\end{array}$ & 5.25 & $5.8 \mathrm{E}-10$ & 0.04 & $1.0 \mathrm{E}-13$ \\
\hline $\begin{array}{l}\text { at1g51760/ } \\
\text { atlg51780 }\end{array}$ & $\begin{array}{l}\text { IAR3 / } \\
\text { ILL5 }\end{array}$ & $\begin{array}{l}\text { IAA-Ala conjugate hydrolase / } \\
\text { IAA-amino acid conjugate hydrolase }\end{array}$ & 5.25 & $6.4 \mathrm{E}-09$ & 0.12 & $3.7 \mathrm{E}-10$ \\
\hline at4g16260 & & $\begin{array}{l}\text { hydrolase, hydrolyzing O-glycosyl } \\
\text { compounds }\end{array}$ & 5.24 & 4.7E-06 & 0.08 & 3.4E-08 \\
\hline at3g04000 & & $\begin{array}{l}\text { short-chain dehydrogenase/reductase } \\
\text { (SDR) family protein }\end{array}$ & 5.14 & $9.0 \mathrm{E}-07$ & 0.24 & 4.3E-06 \\
\hline at2g39030 & & $\begin{array}{l}\text { GCN5-related N-acetyltransferase } \\
\text { (GNAT) family protein }\end{array}$ & 5.11 & $5.1 \mathrm{E}-07$ & 0.06 & 7.7E-10 \\
\hline at1g64160 & & $\begin{array}{l}\text { disease resistance-responsive family } \\
\text { protein }\end{array}$ & 5.10 & $1.5 \mathrm{E}-09$ & 0.22 & 3.6E-09 \\
\hline at4g24350 & & phosphorylase family protein & 5.02 & $1.5 \mathrm{E}-07$ & 0.09 & $1.6 \mathrm{E}-09$ \\
\hline at 1 g17420 & $L O X 3$ & lipoxygenase & 4.97 & $1.9 \mathrm{E}-10$ & 0.16 & 3.4E-11 \\
\hline $\begin{array}{l}\text { at } 4 \mathrm{~g} 24340 / \\
\text { at4g24350 }\end{array}$ & & $\begin{array}{l}\text { phosphorylase family protein / } \\
\text { phosphorylase family protein }\end{array}$ & 4.88 & $1.6 \mathrm{E}-07$ & 0.10 & 2.0E-09 \\
\hline at $2 \mathrm{~g} 26020$ & $P D F 1.2 b$ & plant defensin & 4.77 & $2.0 \mathrm{E}-05$ & 0.06 & 3.6E-08 \\
\hline at4g30450 & & glycine-rich protein & 4.71 & $5.1 \mathrm{E}-07$ & 0.28 & $3.9 \mathrm{E}-06$ \\
\hline at4g02360 & & unknown protein & 4.68 & 3.9E-09 & 0.15 & $3.5 \mathrm{E}-10$ \\
\hline at1g72520 & & lipoxygenase, putative & 4.65 & $6.6 \mathrm{E}-10$ & 0.27 & 4.2E-09 \\
\hline at3g25780 & $A O C 3$ & & 4.54 & $4.6 \mathrm{E}-08$ & 0.18 & 9.4E-09 \\
\hline at5g24420 & & $\begin{array}{l}\text { glucosamine/galactosamine-6- } \\
\text { phosphate isomerase-related }\end{array}$ & 4.46 & $3.5 \mathrm{E}-06$ & 0.03 & 2.9E-10 \\
\hline at5g64530 & ANAC104 & transcription factor & 4.23 & $1.9 \mathrm{E}-08$ & 0.28 & 9.3E-08 \\
\hline at4g30460 & & glycine-rich protein & 4.06 & 7.6E-09 & 0.26 & 1.4E-08 \\
\hline at2g39330 & JAL23 & & 4.04 & 4.7E-07 & 0.06 & $1.3 \mathrm{E}-10$ \\
\hline at $2 \mathrm{~g} 43520$ & ATTI2 & serine-type endopeptidase inhibitor & 4.01 & 7.7E-07 & 0.29 & $2.9 \mathrm{E}-06$ \\
\hline at3g55970 & & $\begin{array}{l}\text { oxidoreductase, } 2 \mathrm{OG}-\mathrm{Fe}(\mathrm{II}) \text { oxygenase } \\
\text { family protein }\end{array}$ & 3.98 & $9.4 \mathrm{E}-06$ & 0.08 & $1.3 \mathrm{E}-08$ \\
\hline at5g06870 & $P G I P 2$ & protein binding & 3.96 & $2.6 \mathrm{E}-10$ & 0.05 & $1.1 \mathrm{E}-14$ \\
\hline
\end{tabular}




\begin{tabular}{|c|c|c|c|c|c|c|}
\hline Gene code & $\underline{\text { Symbol }}$ & Description & $\begin{array}{l}\text { Col-0 TIBA/ } \\
\text { Col-0 mock } \\
\end{array}$ & $\underline{\text { P-value }}$ & $\frac{\text { coil-t TIBA/ }}{\text { Col-0 TIBA }}$ & $\underline{\text { P-value }}$ \\
\hline at2g29440 & ATGSTU6 & glutathione transferase & 3.91 & 7.4E-08 & 0.21 & $1.7 \mathrm{E}-08$ \\
\hline atlg54890 & & $\begin{array}{l}\text { late embryogenesis abundant protein- } \\
\text { related }\end{array}$ & 3.89 & $7.0 \mathrm{E}-10$ & 0.27 & $9.5 \mathrm{E}-10$ \\
\hline $\begin{array}{l}\text { at4g11320/ } \\
\text { at4g11310 }\end{array}$ & & $\begin{array}{l}\text { cysteine proteinase, putative / } \\
\text { cysteine proteinase, putative }\end{array}$ & 3.88 & $2.6 \mathrm{E}-06$ & 0.06 & $6.2 \mathrm{E}-10$ \\
\hline at1g76640 & & calmodulin-related protein, putative & 3.85 & $1.4 \mathrm{E}-07$ & 0.23 & 5.9E-08 \\
\hline at2g47180 & AtGolS1 & $\begin{array}{l}\text { transferase, transferring glycosyl/ } \\
\text { hexosyl groups }\end{array}$ & 3.84 & $1.0 \mathrm{E}-05$ & 0.16 & 3.7E-07 \\
\hline at1g76790 & & O-methyltransferase family 2 protein & 3.82 & $3.3 \mathrm{E}-05$ & 0.09 & 5.7E-08 \\
\hline at1g66760 & & MATE efflux family protein & 3.80 & $4.0 \mathrm{E}-07$ & 0.17 & $1.4 \mathrm{E}-08$ \\
\hline at4g17470 & & $\begin{array}{l}\text { palmitoyl protein thioesterase family } \\
\text { protein }\end{array}$ & 3.72 & $3.9 \mathrm{E}-03$ & 0.03 & 4.7E-07 \\
\hline at1g19180 & $J A Z 1$ & jasmonate-ZIM-domain protein & 3.59 & $2.1 \mathrm{E}-05$ & 0.05 & $1.4 \mathrm{E}-09$ \\
\hline $\begin{array}{l}\text { at1g53903/ } \\
\text { at1g53885 }\end{array}$ & & $\begin{array}{l}-/ \\
\text { senescence-associated protein-related }\end{array}$ & 3.58 & 4.7E-04 & 0.03 & $1.1 \mathrm{E}-08$ \\
\hline at1g11580 & ATPMEPCRA & enzyme inhibitor, pectinesterase & 3.57 & 3.4E-08 & 0.07 & $5.1 \mathrm{E}-12$ \\
\hline at1g07260 & $U G T 71 C 3$ & UDP-glycosyltransferase & 3.57 & $1.2 \mathrm{E}-06$ & 0.24 & 4.0E-07 \\
\hline at $4 \mathrm{~g} 01080$ & & unknown protein & 3.55 & $1.9 \mathrm{E}-04$ & 0.10 & 3.9E-07 \\
\hline at1g19670 & ATCLH1 & chlorophyllase & 3.52 & 4.1E-05 & 0.04 & $1.2 \mathrm{E}-09$ \\
\hline at $\lg 06160$ & ORA59 & transcription factor & 3.52 & $7.5 \mathrm{E}-05$ & 0.25 & $3.0 \mathrm{E}-05$ \\
\hline at4g10390 & & protein kinase family protein & 3.51 & $2.0 \mathrm{E}-08$ & 0.23 & 2.9E-09 \\
\hline at $1 \mathrm{~g} 23850$ & & unknown protein & 3.51 & $3.6 \mathrm{E}-07$ & 0.24 & $9.1 \mathrm{E}-08$ \\
\hline at4g22470 & & $\begin{array}{l}\text { protease inhibitor, seed storage/lipid } \\
\text { transfer protein (LTP) family protein }\end{array}$ & 3.45 & $1.3 \mathrm{E}-05$ & 0.29 & $1.2 \mathrm{E}-05$ \\
\hline at5g38710 & & proline oxidase, putative & 3.44 & $6.7 \mathrm{E}-07$ & 0.24 & $1.6 \mathrm{E}-07$ \\
\hline at3g51450 & & strictosidine synthase family protein & 3.30 & $1.6 \mathrm{E}-06$ & 0.05 & $2.7 \mathrm{E}-11$ \\
\hline atlg61120 & TPSO4 & (E,E)-geranyllinalool synthas & 3.25 & $3.4 \mathrm{E}-06$ & 0.20 & 9.3E-08 \\
\hline at1g32640 & ATMYC2 & transcription factor & 3.24 & $2.8 \mathrm{E}-08$ & 0.09 & $3.7 \mathrm{E}-12$ \\
\hline at4g13410 & ATCSLA15 & $\begin{array}{l}\text { cellulose synthase; transferase, } \\
\text { transferring glycosyl groups }\end{array}$ & 3.14 & $2.5 \mathrm{E}-06$ & 0.19 & 4.6E-08 \\
\hline at $1 \mathrm{~g} 72450$ & JAZ6 & jasmonate-ZIM-domain protein & 3.06 & $1.9 \mathrm{E}-05$ & 0.11 & $1.1 \mathrm{E}-08$ \\
\hline at $2 \mathrm{~g} 06050$ & OPR 3 & 12-oxophytodienoate reductase & 3.04 & $4.3 \mathrm{E}-07$ & 0.10 & $8.3 \mathrm{E}-11$ \\
\hline at4g36110 & & auxin-responsive protein, putative & 3.03 & $9.6 \mathrm{E}-07$ & 0.24 & $5.1 \mathrm{E}-08$ \\
\hline at2g24850 & TAT3 & $\begin{array}{l}\text { L-tyrosine:2-oxoglutarate } \\
\text { aminotransferaseauxin-responsive } \\
\text { protein, putative; transaminase }\end{array}$ & 3.02 & $9.4 \mathrm{E}-04$ & 0.06 & $8.3 \mathrm{E}-08$ \\
\hline
\end{tabular}


Table 6. 2: Genes being TIBA-inducible in a COI1 dependent manner

COI1-dependent TIBA-inducible genes are sorted due to their bin numbers. TIBA inducibility and COI1 dependency are indicated.

\begin{tabular}{|c|c|c|c|c|}
\hline Gene code & $\underline{\text { Symbol }}$ & $\underline{\text { Description }}$ & $\frac{\text { Col-0 TIBA/ }}{\text { Col-0 mock }}$ & $\frac{\text { coil-t } \text { TIBA/ }}{\text { Col-0 TIBA }}$ \\
\hline at4g13410 & ATCSLA15 & 10.2 cell wall.cellulose synthesis & 3.14 & 0.19 \\
\hline at5g06870 & PGIP2 & $\begin{array}{l}\text { 10.6.3 cell wall.degradation.pectate lyases and } \\
\text { polygalacturonases }\end{array}$ & 3.96 & 0.05 \\
\hline at $\lg 11580$ & ATPMEPCRA & 10.8.1 cell wall.pectin*esterases.PME & 3.57 & 0.07 \\
\hline at3g47340 & ASN1 & $\begin{array}{l}\text { 13.1.3.1.1 amino acid metabolism.synthesis.aspartate } \\
\text { family.asparagine.asparagine synthetase }\end{array}$ & 6.75 & 0.24 \\
\hline at5g38710 & & $\begin{array}{l}\text { 13.2.2.2 amino acid metabolism.degradation.glutamate } \\
\text { family.proline }\end{array}$ & 3.44 & 0.24 \\
\hline at $2 \mathrm{~g} 24850$ & TAT3 & 15.2 metal handling.binding, chelation and storage & 3.02 & 0.06 \\
\hline at1g61120 & TPS04 & 16.1.5 secondary metabolism.isoprenoids.terpenoids & 3.25 & 0.20 \\
\hline at1g76790 & & 16.10 secondary metabolism.simple phenols & 3.82 & 0.09 \\
\hline at5g38120 & & $\begin{array}{l}\text { 16.2.1.3 secondary metabolism.phenylpropanoids.lignin } \\
\text { biosynthesis.4CL }\end{array}$ & 5.26 & 0.16 \\
\hline at3g51450 & & 16.4.1 secondary metabolism.N misc.alkaloid-like & 3.30 & 0.05 \\
\hline at5g05600 & & 16.8.1 secondary metabolism.flavonoids.anthocyanins & 8.03 & 0.02 \\
\hline at5g61160 & AACT1 & 16.8.1 secondary metabolism.flavonoids.anthocyanins & 6.61 & 0.07 \\
\hline at3g55970 & & 16.8.1 secondary metabolism.flavonoids.anthocyanins & 3.98 & 0.08 \\
\hline $\begin{array}{l}\text { at1g51760, } \\
\text { at1g51780 }\end{array}$ & IAR3 / ILL5 & 17.2.1 hormone metabolism.auxin.synthesis-degradation & 5.25 & 0.12 \\
\hline at4g36110 & & $\begin{array}{l}\text { 17.2.3 hormone metabolism.auxin.induced-regulated- } \\
\text { responsive-activated }\end{array}$ & 3.03 & 0.24 \\
\hline at1g06160 & ORA59 & 17.5.2 hormone metabolism.ethylene.signal transduction & 3.52 & 0.25 \\
\hline at1g17420 & LOX3 & $\begin{array}{l}\text { 17.7.1.2 hormone metabolism.jasmonate.synthesis- } \\
\text { degradation.lipoxygenase }\end{array}$ & 4.97 & 0.16 \\
\hline at1g72520 & & $\begin{array}{l}\text { 17.7.1.2 hormone metabolism.jasmonate.synthesis- } \\
\text { degradation.lipoxygenase }\end{array}$ & 4.65 & 0.27 \\
\hline at3g25780 & AOC3 & $\begin{array}{l}\text { 17.7.1.4 hormone metabolism.jasmonate.synthesis- } \\
\text { degradation.allene oxidase cyclase }\end{array}$ & 4.54 & 0.18 \\
\hline at $2 \mathrm{~g} 06050$ & OPR3 & $\begin{array}{l}\text { 17.7.1.5 hormone metabolism.jasmonate.synthesis- } \\
\text { degradation.12-Oxo-PDA-reductase }\end{array}$ & 3.04 & 0.10 \\
\hline $\begin{array}{l}\text { at3g44860, } \\
\text { at3g44870 }\end{array}$ & FAMT / - & $\begin{array}{l}\text { 17.8.1 hormone metabolism.salicylic acid.synthesis- } \\
\text { degradation AND } 29.4 \text { protein.postranslational } \\
\text { modification }\end{array}$ & 5.25 & 0.04 \\
\hline at1g19670 & ATCLH1 & 20.1 stress.biotic AND 20.2.4 stress.abiotic.touch/wounding & 3.52 & 0.04 \\
\hline at1g64160 & & 20.1.7 stress.biotic.PR-proteins & 5.10 & 0.22 \\
\hline at $2 \mathrm{~g} 26020$ & PDF1.2b & 20.1.7.12 stress.biotic.PR-proteins.plant defensins & 4.77 & 0.06 \\
\hline at $2 \mathrm{~g} 43520$ & ATTI2 & 20.1.7.12 stress.biotic.PR-proteins.plant defensins & 4.01 & 0.29 \\
\hline at1g06620 & & 21.2 redox.ascorbate and glutathione & 7.05 & 0.11 \\
\hline at3g09940 & ATMDAR3 & 21.2.1 redox.ascorbate and glutathione.ascorbate & 8.92 & 0.07 \\
\hline at $3 \mathrm{~g} 28740$ & CYP81D11 & 26.10 misc.cytochrome $\mathrm{P} 450$ & 55.64 & 0.12 \\
\hline at5g63450 & CYP94B1 & 26.10 misc.cytochrome $\mathrm{P} 450$ & 16.61 & 0.06 \\
\hline at3g48520 & CYP94B3 & 26.10 misc.cytochrome $\mathrm{P} 450$ & 8.86 & 0.11 \\
\hline at4g37410 & CYP81F4 & 26.10 misc.cytochrome $\mathrm{P} 450$ & 7.61 & 0.04 \\
\hline at2g39330 & JAL23 & 26.16 misc.myrosinases-lectin-jacalin & 4.04 & 0.06 \\
\hline at1g07260 & UGT71C3 & 26.2 misc.UDP glucosyl and glucoronyl transferases & 3.57 & 0.24 \\
\hline
\end{tabular}




\begin{tabular}{|c|c|c|c|c|}
\hline Gene code & $\underline{\text { Symbol }}$ & $\underline{\text { Description }}$ & $\frac{\text { Col-0 TIBA/ }}{\underline{\text { Col-0 mock }}}$ & $\frac{\text { coil-t TIBA }}{\text { Col-0 TIBA }}$ \\
\hline at4g22470 & & $\begin{array}{l}26.21 \text { misc.protease inhibitor/seed storage/lipid transfer } \\
\text { protein (LTP) family protein }\end{array}$ & 3.45 & 0.29 \\
\hline at3g04000 & & 26.22 misc.short chain dehydrogenase/reductase (SDR) & 5.14 & 0.24 \\
\hline at $2 \mathrm{~g} 39030$ & & 26.24 misc.GCN5-related N-acetyltransferase & 5.11 & 0.06 \\
\hline at4g16260 & & $\begin{array}{l}\text { 26.4.1 misc.beta } 1,3 \text { glucan hydrolases.glucan endo-1,3-beta- } \\
\text { glucosidase }\end{array}$ & 5.24 & 0.08 \\
\hline at2g29460 & ATGSTU4 & 26.9 misc.glutathione $\mathrm{S}$ transferases & 6.71 & 0.22 \\
\hline at2g29440 & ATGSTU6 & 26.9 misc.glutathione $\mathrm{S}$ transferases & 3.91 & 0.21 \\
\hline at1g43160 & RAP2.6 & $\begin{array}{l}\text { 27.3.3 RNA.regulation of transcription.AP2/EREBP, } \\
\text { APETALA2/Ethylene-responsive element binding } \\
\text { protein family }\end{array}$ & 30.96 & 0.03 \\
\hline at 1 g10585 & & $\begin{array}{l}\text { 27.3.6 RNA.regulation of transcription.bHLH,Basic Helix- } \\
\text { Loop-Helix family }\end{array}$ & 18.92 & 0.06 \\
\hline at5g67080 & MAPKKK19 & 29.4 protein.postranslational modification & 8.39 & 0.12 \\
\hline at4g17470 & & 29.4 protein.postranslational modification & 3.72 & 0.03 \\
\hline at1g32640 & ATMYC2 & 29.4 protein.postranslational modification & 3.24 & 0.09 \\
\hline $\begin{array}{l}\text { at4g11320, } \\
\text { at4g11310 }\end{array}$ & & 29.5.3 protein.degradation. cysteine protease & 3.88 & 0.06 \\
\hline at $2 \mathrm{~g} 47180$ & AtGolS1 & $\begin{array}{l}\text { 3.1.1.1 minor } \mathrm{CHO} \text { metabolism.raffinose family.galactinol } \\
\text { synthases.known }\end{array}$ & 3.84 & 0.16 \\
\hline at3g57520 & AtSIP2 & $\begin{array}{l}\text { 3.1.2.2 minor } \mathrm{CHO} \text { metabolism.raffinose family.raffinose } \\
\text { synthases.putative }\end{array}$ & 7.63 & 0.28 \\
\hline at4g10390 & & 30.2.99 signalling.receptor kinases.misc & 3.51 & 0.23 \\
\hline at1g76640 & & 30.3 signalling.calcium & 3.85 & 0.23 \\
\hline at1 554890 & & 33.2 development.late embryogenesis abundant & 3.89 & 0.27 \\
\hline at3g49620 & DIN11 & 33.99 development.unspecified & 23.70 & 0.01 \\
\hline at5g64530 & ANAC104 & 33.99 development.unspecified & 4.23 & 0.28 \\
\hline $\begin{array}{l}\text { at1g53903, } \\
\text { at1g53885 }\end{array}$ & & 33.99 development.unspecified & 3.58 & 0.03 \\
\hline at4g21680 & & 34.13 transport.peptides and oligopeptides & 10.93 & 0.12 \\
\hline at3g23550 & & 34.99 transport.misc & 9.95 & 0.10 \\
\hline at5g44050 & & 34.99 transport.misc & 6.17 & 0.12 \\
\hline at1 666760 & & 34.99 transport.misc & 3.80 & 0.17 \\
\hline at5g19110 & & 35.1 not assigned.no ontology & 5.70 & 0.11 \\
\hline at4g24350 & & 35.1 not assigned.no ontology & 5.02 & 0.09 \\
\hline $\begin{array}{l}\text { at } 4 \mathrm{~g} 24340, \\
\text { at4g24350 }\end{array}$ & & 35.1 not assigned.no ontology & 4.88 & 0.10 \\
\hline at4g30450 & & 35.1.40 not assigned.no ontology.glycine rich proteins & 4.71 & 0.28 \\
\hline at4g30460 & & 35.1.40 not assigned.no ontology.glycine rich proteins & 4.06 & 0.26 \\
\hline at5g13220 & JAZ10 & 35.2 not assigned.unknown & 28.62 & 0.02 \\
\hline at $2 \mathrm{~g} 34600$ & JAZ7 & 35.2 not assigned.unknown & 12.90 & 0.07 \\
\hline at1 30135 & JAZ8 & 35.2 not assigned.unknown & 5.96 & 0.14 \\
\hline at1 770700 & JAZ9 & 35.2 not assigned.unknown & 5.86 & 0.04 \\
\hline at1g17380 & JAZ5 & 35.2 not assigned.unknown & 5.71 & 0.10 \\
\hline at $4 \mathrm{~g} 02360$ & & 35.2 not assigned.unknown & 4.68 & 0.15 \\
\hline at1g19180 & JAZ1 & 35.2 not assigned.unknown & 3.59 & 0.05 \\
\hline at4g01080 & & 35.2 not assigned.unknown & 3.55 & 0.10 \\
\hline at1 223850 & & 35.2 not assigned.unknown & 3.51 & 0.24 \\
\hline
\end{tabular}




\begin{tabular}{|c|c|c|c|c|}
\hline Gene code & $\underline{\text { Symbol }}$ & $\underline{\text { Description }}$ & $\begin{array}{l}\text { Col-0 TIBA/ } \\
\text { Col-0 mock } \\
\end{array}$ & $\begin{array}{l}\text { coil-t } t \text { TIBA/ } \\
\text { Col-0 TIBA } \\
\end{array}$ \\
\hline at $\lg 72450$ & JAZ6 & 35.2 not assigned.unknown & 3.06 & 0.11 \\
\hline at $5 \mathrm{~g} 24420$ & & 7.1.2 OPP.oxidative PP.6-phosphogluconolactonase & 4.46 & 0.03 \\
\hline
\end{tabular}

Table 6. 3: Genes being TIBA-inducible in a COI1-independent manner

Genes were sorted due to their TIBA indicibility, P-values are indicated

\begin{tabular}{|c|c|c|c|c|}
\hline Gene code & $\underline{\text { Symbol }}$ & $\underline{\text { Description }}$ & $\frac{\text { Col-0 TIBA / }}{\text { Col-0 mock }}$ & p-value \\
\hline at2g23170 & GH3.3 & indole-3-acetic acid amido synthetase & 46.94 & $5.1 \mathrm{E}-12$ \\
\hline at1g17170 & ATGSTU24 & glutathione transferase & 28.98 & 7.2E-08 \\
\hline at1g05680 & & UDP-glucosyl transferase family protein & 20.43 & $2.1 \mathrm{E}-05$ \\
\hline at $5 \mathrm{~g} 13330$ & Rap2.6L & transcription factor & 17.94 & 7.0E-13 \\
\hline at2g29490 & ATGSTU1 & glutathione transferase & 16.51 & $8.2 \mathrm{E}-08$ \\
\hline at $2 \mathrm{~g} 22860$ & ATPSK2 & growth factor & 14.17 & $2.2 \mathrm{E}-10$ \\
\hline at5g49480 & ATCP1 & calcium ion binding & 12.73 & $1.4 \mathrm{E}-10$ \\
\hline $\begin{array}{l}\text { at4g34131, } \\
\text { at4g34135 }\end{array}$ & $\begin{array}{l}\text { UGT73B3 / } \\
\text { UGT73B2 }\end{array}$ & $\begin{array}{l}\text { UDP-glycosyltransferase / } \\
\text { UDP-glucosyltransferase }\end{array}$ & 11.43 & $6.7 \mathrm{E}-10$ \\
\hline at1g05560 & UGT1 & UDP-glucosyltransferase & 11.39 & $1.9 \mathrm{E}-08$ \\
\hline at5g52900 & & unknown protein & 10.69 & $1.4 \mathrm{E}-11$ \\
\hline at3g30775 & ERD5 & proline dehydrogenase & 9.73 & 2.7E-06 \\
\hline at1g30040 & ATGA2OX2 & gibberellin 2-beta-dioxygenase & 9.46 & 2.9E-11 \\
\hline at1g77450 & ANAC032 & transcription factor & 9.10 & 4.8E-07 \\
\hline $\begin{array}{l}\text { at1g76680, } \\
\text { at1g76690 }\end{array}$ & $\begin{array}{l}\text { OPR1 / } \\
\text { OPR2 }\end{array}$ & 12-oxophytodienoate reductase / & 9.03 & 1.4E-09 \\
\hline at2g15480 & UGT73B5 & UDP-glucosyltransferase & 8.39 & 4.9E-08 \\
\hline at2g29420 & ATGSTU7 & glutathione transferase & 7.97 & $1.4 \mathrm{E}-08$ \\
\hline at4g01870 & & tolB protein-related & 7.61 & $1.5 \mathrm{E}-06$ \\
\hline at $4 \mathrm{~g} 13180$ & & short-chain dehydrogenase/reductase & 7.21 & 5.3E- 08 \\
\hline at1g35910 & & trehalose-6-phosphate phosphatase, putative & 6.79 & 2.4E-08 \\
\hline at $\lg 15380$ & & lactoylglutathione lyase family protein & 6.45 & 4.0E-06 \\
\hline at2g17500 & & auxin efflux carrier family protein & 6.25 & $2.5 \mathrm{E}-06$ \\
\hline at3g14990 & & $\begin{array}{l}\text { 4-methyl-5(b-hydroxyethyl)-thiazole monophosphate } \\
\text { biosynthesis protein, putative }\end{array}$ & 6.01 & $1.5 \mathrm{E}-09$ \\
\hline at5g62280 & & unknown protein & 5.95 & $1.9 \mathrm{E}-05$ \\
\hline at5g02760 & & protein phosphatase $2 \mathrm{C}$ family protein / & 5.50 & $1.7 \mathrm{E}-07$ \\
\hline at4g34138 & UGT73B1 & UDP-glycosyltransferase & 5.34 & $1.1 \mathrm{E}-07$ \\
\hline $\begin{array}{l}\text { at1g59500, } \\
\text { at4g37390 }\end{array}$ & $\begin{array}{l}\mathrm{GH} 3.4 / \\
\mathrm{GH} 3.2\end{array}$ & $\begin{array}{l}\text { indole-3-acetic acid amido synthetase / indole-3- } \\
\text { acetic acid amido synthetase }\end{array}$ & 5.31 & $2.0 \mathrm{E}-06$ \\
\hline at1g67810 & SUFE2 & enzyme activator & 5.24 & 7.9E-07 \\
\hline at 1 001720 & ATAF1 & transcription factor & 5.20 & $1.0 \mathrm{E}-08$ \\
\hline at1g79410 & AtOCT5 & carbohydrate transmembrane transporter & 5.11 & $1.2 \mathrm{E}-06$ \\
\hline at1g02850 & BGLU11 & hydrolase & 5.03 & $1.8 \mathrm{E}-06$ \\
\hline at1g80840 & WRKY40 & transcription factor & 5.02 & $5.9 \mathrm{E}-08$ \\
\hline
\end{tabular}




\begin{tabular}{|c|c|c|c|c|}
\hline Gene code & $\underline{\text { Symbol }}$ & Description & $\begin{array}{l}\text { Col-0 TIBA / } \\
\text { Col-0 mock } \\
\end{array}$ & p-value \\
\hline at4g20860 & & FAD-binding domain-containing protein & 4.87 & 2.2E- -05 \\
\hline at $5 \mathrm{~g} 61820$ & & molecular function unknown & 4.86 & 7.8E-08 \\
\hline at5g14730 & & unknown protein & 4.85 & 7.1E-07 \\
\hline at $1 \mathrm{~g} 10070$ & ATBCAT-2 & branched-chain-amino-acid transaminase & 4.81 & $4.5 \mathrm{E}-06$ \\
\hline $\begin{array}{l}\text { at4g34131, } \\
\text { at4g34135 }\end{array}$ & $\begin{array}{l}\text { UGT73B3 / } \\
\text { UGT73B2 }\end{array}$ & UDP-glycosyltransferase / UDP-glucosyltransferase & 4.71 & $6.7 \mathrm{E}-10$ \\
\hline at $5 \mathrm{~g} 07440$ & GDH2 & glutamate dehydrogenase & 4.71 & 3.0E-07 \\
\hline $\begin{array}{l}\text { at } 2 \mathrm{~g} 36800 \\
\text { at2g36790 }\end{array}$ & $\begin{array}{l}\text { DOGT1/ } \\
\text { UGT73C6 }\end{array}$ & UDP-glycosyltransferase / UDP-glucosyltransferase & 4.63 & $6.9 \mathrm{E}-06$ \\
\hline at5g57560 & TCH4 & hydrolase & 4.59 & $5.3 \mathrm{E}-06$ \\
\hline at $2 \mathrm{~g} 40200$ & & basic helix-loop-helix (bHLH) family protein & 4.56 & 4.9E-09 \\
\hline at5g63790 & ANAC102 & transcription factor & 4.52 & $8.3 \mathrm{E}-08$ \\
\hline at2g36380 & PDR6 & ATPase & 4.52 & $1.1 \mathrm{E}-10$ \\
\hline at3g26830 & PAD3 & $\begin{array}{l}\text { dihydrocamalexic acid decarboxylase/ } \\
\text { monooxygenase }\end{array}$ & 4.31 & $5.2 \mathrm{E}-05$ \\
\hline at1g72900 & & disease resistance protein (TIR-NBS class), putative & 4.30 & $5.2 \mathrm{E}-09$ \\
\hline at $2 \mathrm{~g} 31750$ & UGT74D1 & UDP-glycosyltransferase & 4.27 & 8.7E- 08 \\
\hline at2g19800 & MIOX2 & inositol oxygenase & 4.20 & 7.3E-05 \\
\hline at1g76600 & & unknown protein & 4.16 & $1.8 \mathrm{E}-09$ \\
\hline at1g19020 & & unknown protein & 4.06 & $1.0 \mathrm{E}-05$ \\
\hline at4g21850 & ATMSRB9 & $\begin{array}{l}\text { methionine sulfoxide reductase domain-containing } \\
\text { protein }\end{array}$ & 4.05 & $1.7 \mathrm{E}-05$ \\
\hline at3g09270 & ATGSTU8 & glutathione transferase & 4.04 & 5.7E-05 \\
\hline at 1 g76410 & ATL8 & protein binding & 4.04 & $1.8 \mathrm{E}-07$ \\
\hline at5g47370 & HAT2 & transcription factor & 4.03 & $1.2 \mathrm{E}-07$ \\
\hline at5g11160 & APT5 & adenine phosphoribosyltransferase & 4.01 & $1.2 \mathrm{E}-07$ \\
\hline at1g14130 & & 2-oxoglutarate-dependent dioxygenase, putative & 3.99 & 4.1E- 08 \\
\hline at1g61820 & BGLU46 & hydrolase & 3.94 & $3.0 \mathrm{E}-05$ \\
\hline at1g22400 & UGT85A1 & UDP-glycosyltransferase & 3.89 & 5.3E-06 \\
\hline at5g22300 & NIT4 & 3-cyanoalanine hydratase/ cyanoalanine nitrilase & 3.84 & $5.5 \mathrm{E}-05$ \\
\hline at4g25810 & XTR6 & hydrolase & 3.78 & 2.3E-06 \\
\hline $\begin{array}{l}\text { at2g32190, } \\
\text { at2g32210 }\end{array}$ & & $\begin{array}{l}\text { unknown protein / } \\
\text { unknown protein }\end{array}$ & 3.75 & $1.9 \mathrm{E}-03$ \\
\hline at3g56980 & BHLH039 & transcription factor & 3.66 & 7.4E-04 \\
\hline at2g37760 & & aldo/keto reductase family protein & 3.63 & $2.2 \mathrm{E}-05$ \\
\hline at5g17860 & CAX7 & calcium:sodium antiporter & 3.51 & 4.7E-04 \\
\hline at4g15490 & UGT84A3 & UDP-glycosyltransferase & 3.50 & $5.8 \mathrm{E}-05$ \\
\hline at4g15550 & IAGLU & UDP-glycosyltransferase & 3.50 & $1.1 \mathrm{E}-05$ \\
\hline at $2 \mathrm{~g} 44810$ & DAD1 & phospholipase A1/ triacylglycerol lipase & 3.50 & 3.6E-07 \\
\hline at4g37610 & BT5 & transcription regulator & 3.49 & $6.8 \mathrm{E}-05$ \\
\hline at1g33110 & & MATE efflux family protein & 3.48 & $1.5 \mathrm{E}-05$ \\
\hline at3g46280 & & protein kinase-related & 3.46 & 4.7E-05 \\
\hline at1g75750 & GASA1 & & 3.45 & 4.7E-04 \\
\hline at $2 \mathrm{~g} 15490$ & UGT73B4 & UDP-glucosyltransferase & 3.41 & $1.5 \mathrm{E}-04$ \\
\hline at4g28085 & & unknown protein & 3.40 & 2.6E-07 \\
\hline at4g37370 & CYP81D8 & monooxygenase & 3.40 & $2.5 \mathrm{E}-06$ \\
\hline
\end{tabular}




\begin{tabular}{|c|c|c|c|c|}
\hline Gene code & $\underline{\text { Symbol }}$ & $\underline{\text { Description }}$ & $\frac{\text { Col-0 TIBA / }}{\text { Col-0 mock }}$ & p-value \\
\hline at5g65380 & & ripening-responsive protein, putative & 3.36 & $3.8 \mathrm{E}-09$ \\
\hline at4g15610 & & integral membrane family protein & 3.35 & $1.5 \mathrm{E}-04$ \\
\hline at $3 g 18560$ & & unknown protein & 3.34 & $3.5 \mathrm{E}-07$ \\
\hline at4g17500 & ATERF-1 & transcription activator & 3.32 & $1.5 \mathrm{E}-06$ \\
\hline at2g29500 & & $17.6 \mathrm{kDa}$ class I small heat shock protein & 3.32 & 4.4E-05 \\
\hline at1g27730 & ZAT10 & transcription factor & 3.31 & 4.4E-07 \\
\hline at $5 \mathrm{~g} 41080$ & & $\begin{array}{l}\text { glycerophosphoryl diester phosphodiesterase family } \\
\text { protein }\end{array}$ & 3.30 & $9.0 \mathrm{E}-06$ \\
\hline at5g 57220 & CYP81F2 & monooxygenase & 3.29 & $1.5 \mathrm{E}-07$ \\
\hline at5g04340 & $\mathrm{C} 2 \mathrm{H} 2$ & transcription factor & 3.29 & 3.2E-07 \\
\hline at4g24570 & DIC2 & mitochondrial substrate carrier family protein & 3.29 & $5.0 \mathrm{E}-09$ \\
\hline at5g16970 & AT-AER & 2-alkenal reductase & 3.29 & $1.3 \mathrm{E}-06$ \\
\hline at $2 \mathrm{~g} 37770$ & & $\begin{array}{l}\text { aldo/keto reductase family protein | chr2:15834867- } \\
\text { 15836881 FORWARD }\end{array}$ & 3.28 & 9.9E-05 \\
\hline at1g26380 & & FAD-binding domain-containing protein & 3.24 & $9.5 \mathrm{E}-06$ \\
\hline at $5 \mathrm{~g} 13750$ & ZIFL1 & tetracycline:hydrogen antiporter & 3.24 & $3.5 \mathrm{E}-07$ \\
\hline at4g39670 & & glycolipid transporter & 3.22 & 3.6E-05 \\
\hline at2g22880 & & VQ motif-containing protein & 3.21 & $8.2 \mathrm{E}-07$ \\
\hline at3g62150 & PGP21 & ATPase & 3.21 & $1.1 \mathrm{E}-04$ \\
\hline at5g64570 & XYL4 & hydrolase & 3.20 & $8.5 \mathrm{E}-05$ \\
\hline at5g20250 & DIN10 & hydrolase & 3.19 & $3.5 \mathrm{E}-04$ \\
\hline at1 666860 & & hydrolase & 3.18 & $1.3 \mathrm{E}-04$ \\
\hline $\begin{array}{l}\text { at } 4 \mathrm{~g} 37530, \\
\text { at4g37520 }\end{array}$ & & $\begin{array}{l}\text { peroxidase, putative / } \\
\text { peroxidase } 50\end{array}$ & 3.16 & $1.7 \mathrm{E}-05$ \\
\hline at1g05575 & & unknown protein & 3.15 & $1.0 \mathrm{E}-06$ \\
\hline at2g44790 & $\mathrm{UCC} 2$ & electron carrier & 3.10 & $8.7 \mathrm{E}-05$ \\
\hline at 1 g77380 & AAP3 & amino acid transmembrane transporter & 3.07 & $1.3 \mathrm{E}-08$ \\
\hline at4g21990 & APR3 & adenylyl-sulfate reductase & 3.04 & $1.2 \mathrm{E}-05$ \\
\hline at $5 \mathrm{~g} 16080$ & AtCXE17 & hydrolase & 3.02 & $1.3 \mathrm{E}-07$ \\
\hline at $2 \mathrm{~g} 47000$ & MDR4 & ATPase / xenobiotic-transporting ATPase & 3.02 & $2.6 \mathrm{E}-04$ \\
\hline at1g09970 & LRR XI-23 & protein kinase & 3.01 & $2.2 \mathrm{E}-05$ \\
\hline
\end{tabular}


Table 6. 4: Genes being TIBA-inducible in a COI1-independent manner

Genes were sorted due to their TIBA bin numbers, TIBA inducibility is indicated

\begin{tabular}{|c|c|c|c|}
\hline$\underline{\text { Gene code }}$ & $\underline{\text { Symbol }}$ & $\underline{\text { Description }}$ & $\underline{\text { Col-0 TIBA / }}$ \\
\hline at5g64570 & XYL4 & 10.6.2 cell wall.degradation.mannan-xylose-arabinose-fucose & 3.20 \\
\hline at5g57560 & $\mathrm{TCH} 4$ & 10.7 cell wall.modification & 4.59 \\
\hline at $4 \mathrm{~g} 25810$ & XTR6 & 10.7 cell wall.modification & 3.78 \\
\hline at5g41080 & & $\begin{array}{l}\text { 11.9.3.3 lipid metabolism.lipid degradation .lysophospholipases. } \\
\text { glycerophosphodiester phosphodiesterase }\end{array}$ & 3.30 \\
\hline at5g07440 & GDH2 & 12.3.1 N-metabolism. N-degradation.glutamate dehydrogenase & 4.71 \\
\hline at1g10070 & АТВСАТ-2 & $\begin{array}{l}\text { 13.1.4.1.4 amino acid metabolism.synthesis.branched chain } \\
\text { group.common.branched-chain amino acid aminotransferase } \\
\text { AND 18.4.1 Co-factor and vitamine metabolism. } \\
\text { pantothenate.branched-chain amino acid aminotransferase }\end{array}$ & 4.81 \\
\hline at3g30775 & ERD5 & 13.2.2.2 amino acid metabolism.degradation.glutamate family.proline & 9.73 \\
\hline at4g21990 & APR3 & 14.2 S-assimilation.APR & 3.04 \\
\hline at5g57220 & CYP81F2 & $\begin{array}{l}\text { 16.5.1.1.3.4 secondary metabolism.sulfur- } \\
\text { containing.glucosinolates. synthesis.indole.synthesis.cytochrome } \\
\text { P450 monooxygenase AND } 26.10 \text { misc.cytochrome P450 }\end{array}$ & 3.29 \\
\hline at5g22300 & NIT4 & $\begin{array}{l}\text { 16.5.1.3.3 secondary metabolism.sulfur-containing } \\
\text {.glucosinolates.degradation.nitrilase AND } 26.8 \text { misc.nitrilases, } \\
\text { *nitrile lyases, berberine bridge enzymes, reticuline oxidases, } \\
\text { troponine reductases }\end{array}$ & 3.84 \\
\hline $\begin{array}{l}\text { at } 2 \mathrm{~g} 36800, \\
\text { at2g36790 }\end{array}$ & $\begin{array}{l}\text { DOGT1 / } \\
\text { UGT73C6 }\end{array}$ & $\begin{array}{l}\text { 16.8.4 secondary metabolism.flavonoids.flavonols AND } 20.1 \\
\text { stress.biotic }\end{array}$ & 4.63 \\
\hline at1g05560 & UGT1 & 17.2.1 hormone metabolism.auxin.synthesis-degradation & 11.39 \\
\hline at2g23170 & GH3.3 & $\begin{array}{l}\text { 17.2.3 hormone metabolism.auxin.induced-regulated-responsive- } \\
\text { activated }\end{array}$ & 46.94 \\
\hline $\begin{array}{l}\text { at1g59500, } \\
\text { at4g37390 }\end{array}$ & GH3.4 / GH3.2 & $\begin{array}{l}\text { 17.2.3 hormone metabolism.auxin.induced-regulated-responsive- } \\
\text { activated }\end{array}$ & 5.31 \\
\hline at1g22400 & UGT85A1 & 17.4.1 hormone metabolism.cytokinin.synthesis-degradation & 3.89 \\
\hline at4g17500 & ATERF-1 & 17.5.2 hormone metabolism.ethylene.signal transduction & 3.32 \\
\hline at1g30040 & ATGA2OX2 & $\begin{array}{l}\text { 17.6.1.13 hormone metabolism.gibberelin.synthesis-degradation.GA2 } \\
\text { oxidase }\end{array}$ & 9.46 \\
\hline at 1 g75750 & GASA1 & $\begin{array}{l}\text { 17.6.3 hormone metabolism.gibberelin.induced-regulated-responsive- } \\
\text { activated }\end{array}$ & 3.45 \\
\hline at $2 \mathrm{~g} 44810$ & DAD1 & 17.7.1.1 hormone metabolism.jasmonate.synthesis-degradation.lipases & 3.50 \\
\hline $\begin{array}{l}\text { at1g76680, } \\
\text { at1g76690 }\end{array}$ & OPR1 / OPR2 & $\begin{array}{l}\text { 17.7.1.5 hormone metabolism.jasmonate.synthesis-degradation.12- } \\
\text { Oxo-PDA-reductase }\end{array}$ & 9.03 \\
\hline at 1 g05680 & & 17.8.1 hormone metabolism.salicylic acid.synthesis-degradation & 20.43 \\
\hline at3g14990 & & 18.2 Co-factor and vitamine metabolism.thiamine & 6.01 \\
\hline at1g67810 & SUFE2 & 18.7 Co-factor and vitamine metabolism.iron-sulphur clusters & 5.24 \\
\hline at1g72900 & & 20.1.7 stress.biotic.PR-proteins & 4.30 \\
\hline at4g21850 & ATMSRB9 & 20.2 stress.abiotic & 4.05 \\
\hline at $2 \mathrm{~g} 29500$ & & 20.2.1 stress.abiotic.heat & 3.32 \\
\hline at5g11160 & APT5 & $\begin{array}{l}\text { 23.3.1.1 nucleotide.metabolism.salvage. phosphoribosyltransferases } \\
\text {.apt }\end{array}$ & 4.01 \\
\hline at5g16080 & AtCXE17 & 24 Biodegradation of Xenobiotics & 3.02 \\
\hline at 1 g15380 & & 24.2 Biodegradation of Xenobiotics.lactoylglutathione.lyase & 6.45 \\
\hline at3g26830 & PAD3 & 26.10 misc.cytochrome $\mathrm{P} 450$ & 4.31 \\
\hline at4g37370 & CYP81D8 & 26.10 misc.cytochrome $\mathrm{P} 450$ & 3.40 \\
\hline at $4 \mathrm{~g} 37530$, & & 26.12 misc.peroxidases & 3.16 \\
\hline
\end{tabular}




\begin{tabular}{|c|c|c|c|}
\hline Gene code & $\underline{\text { Symbol }}$ & $\underline{\text { Description }}$ & $\begin{array}{l}\text { Col-0 TIBA / } \\
\text { Col-0 mock } \\
\end{array}$ \\
\hline \multicolumn{4}{|l|}{ at4g37520 } \\
\hline at2g44790 & UCC2 & 26.19 misc.plastocyanin-like & 3.10 \\
\hline $\begin{array}{l}\text { at } 4 \mathrm{~g} 34131, \\
\text { at4g34135 }\end{array}$ & $\begin{array}{l}\text { UGT73B3 / } \\
\text { UGT73B2 }\end{array}$ & 26.2 misc.UDP glucosyl and glucoronyl transferases & 11.43 \\
\hline at $2 \mathrm{~g} 15480$ & UGT73B5 & 26.2 misc.UDP glucosyl and glucoronyl transferases & 8.39 \\
\hline at4g34138 & UGT73B1 & 26.2 misc.UDP glucosyl and glucoronyl transferases & 5.34 \\
\hline at $2 \mathrm{~g} 31750$ & UGT74D1 & 26.2 misc.UDP glucosyl and glucoronyl transferases & 4.27 \\
\hline at4g15490 & UGT84A3 & 26.2 misc.UDP glucosyl and glucoronyl transferases & 3.50 \\
\hline at4g15550 & IAGLU & 26.2 misc.UDP glucosyl and glucoronyl transferases & 3.50 \\
\hline at2g15490 & UGT73B4 & 26.2 misc.UDP glucosyl and glucoronyl transferases & 3.41 \\
\hline at4g13180 & & 26.22 misc.short chain dehydrogenase/reductase (SDR) & 7.21 \\
\hline at1g02850 & BGLU11 & 26.3 misc.gluco-, galacto- and mannosidases & 5.03 \\
\hline at1g61820 & BGLU46 & 26.3 misc.gluco-, galacto- and mannosidases & 3.94 \\
\hline at $\lg 14130$ & & 26.7 misc.oxidases - copper, flavone etc. & 3.99 \\
\hline at5g16970 & AT-AER & 26.7 misc.oxidases - copper, flavone etc. & 3.29 \\
\hline at4g20860 & & $\begin{array}{l}26.8 \text { misc.nitrilases, *nitrile lyases, berberine bridge enzymes, } \\
\text { reticuline oxidases, troponine reductases }\end{array}$ & 4.87 \\
\hline at1g26380 & & $\begin{array}{l}26.8 \text { misc.nitrilases, *nitrile lyases, berberine bridge enzymes, } \\
\text { reticuline oxidases, troponine reductases }\end{array}$ & 3.24 \\
\hline at1g17170 & ATGSTU24 & 26.9 misc.glutathione $\mathrm{S}$ transferases & 28.98 \\
\hline at2g29490 & ATGSTU1 & 26.9 misc.glutathione $\mathrm{S}$ transferases & 16.51 \\
\hline at2g29420 & ATGSTU7 & 26.9 misc.glutathione $\mathrm{S}$ transferases & 7.97 \\
\hline at3g09270 & ATGSTU8 & 26.9 misc.glutathione $\mathrm{S}$ transferases & 4.04 \\
\hline at1g27730 & ZAT10 & 27.3.11 RNA.regulation of transcription.C2H2 zinc finger family & 3.31 \\
\hline at $5 \mathrm{~g} 04340$ & $\mathrm{C} 2 \mathrm{H} 2$ & 27.3.11 RNA.regulation of transcription.C2H2 zinc finger family & 3.29 \\
\hline at5g47370 & HAT2 & $\begin{array}{l}\text { 27.3.22 RNA.regulation of transcription.HB,Homeobox transcription } \\
\text { factor family }\end{array}$ & 4.03 \\
\hline at5g13330 & Rap2.6L & $\begin{array}{l}\text { 27.3.3 RNA.regulation of transcription.AP2/EREBP, } \\
\text { APETALA2/Ethylene-responsive element binding protein family }\end{array}$ & 17.94 \\
\hline at1g80840 & WRKY40 & $\begin{array}{l}\text { 27.3.32 RNA.regulation of transcription.WRKY domain transcription } \\
\text { factor family }\end{array}$ & 5.02 \\
\hline at $2 \mathrm{~g} 40200$ & & $\begin{array}{l}\text { 27.3.6 RNA.regulation of transcription.bHLH,Basic Helix-Loop-Helix } \\
\text { family }\end{array}$ & 4.56 \\
\hline at3g56980 & BHLH039 & $\begin{array}{l}\text { 27.3.6 RNA.regulation of transcription.bHLH,Basic Helix-Loop-Helix } \\
\text { family }\end{array}$ & 3.66 \\
\hline at $5 \mathrm{~g} 02760$ & & 29.4 protein.postranslational modification & 5.50 \\
\hline at $1 \mathrm{~g} 76410$ & ATL8 & 29.5.11.4.2 protein.degradation.ubiquitin.E3.RING & 4.04 \\
\hline at4g37610 & BT5 & $\begin{array}{l}\text { 29.5.11.4.5.2 protein.degradation.ubiquitin.E3.BTB/POZ } \\
\text { Cullin3.BTB/POZ }\end{array}$ & 3.49 \\
\hline at5g20250 & DIN10 & $\begin{array}{l}\text { 3.1.2.2 minor } \mathrm{CHO} \text { metabolism.raffinose family.raffinose } \\
\text { synthases.putative }\end{array}$ & 3.19 \\
\hline at $1 \mathrm{~g} 35910$ & & 3.2.2 minor $\mathrm{CHO}$ metabolism.trehalose.TPP & 6.79 \\
\hline at $2 \mathrm{~g} 19800$ & MIOX2 & 3.4.4 minor CHO metabolism.myo-inositol.myo inositol oxygenases & 4.20 \\
\hline at $2 \mathrm{~g} 37760$ & & 3.5 minor CHO metabolism.others & 3.63 \\
\hline at2g37770 & & 3.5 minor $\mathrm{CHO}$ metabolism.others & 3.28 \\
\hline at1g09970 & LRR XI-23 & 30.2.11 signalling.receptor kinases.leucine rich repeat XI & 3.01 \\
\hline at $3 \mathrm{~g} 46280$ & & 30.2.99 signalling.receptor kinases.misc & 3.46 \\
\hline at5g49480 & ATCP1 & 30.3 signalling.calcium & 12.73 \\
\hline
\end{tabular}




\begin{tabular}{|c|c|c|c|}
\hline Gene code & $\underline{\text { Symbol }}$ & $\underline{\text { Description }}$ & $\begin{array}{l}\text { Col-0 TIBA } / \\
\text { Col-0 mock } \\
\end{array}$ \\
\hline at $2 \mathrm{~g} 22860$ & ATPSK2 & 33.99 development.unspecified & 14.17 \\
\hline at1g77450 & anac032 & 33.99 development.unspecified & 9.10 \\
\hline at1g01720 & ATAF1 & 33.99 development.unspecified & 5.20 \\
\hline at5g63790 & ANAC102 & 33.99 development.unspecified & 4.52 \\
\hline at5g65380 & & 33.99 development.unspecified & 3.36 \\
\hline at $2 \mathrm{~g} 36380$ & PDR6 & 34.16 transport. $\mathrm{ABC}$ transporters and multidrug resistance systems & 4.52 \\
\hline at3g62150 & PGP21 & 34.16 transport. $\mathrm{ABC}$ transporters and multidrug resistance systems & 3.21 \\
\hline at2g47000 & MDR4 & 34.16 transport. $\mathrm{ABC}$ transporters and multidrug resistance systems & 3.02 \\
\hline at1g79410 & AtOCT5 & 34.2 transporter.sugars & 5.11 \\
\hline at $5 \mathrm{~g} 17860$ & CAX7 & 34.21 transport.calcium & 3.51 \\
\hline at1g77380 & AAP3 & 34.3 transport.amino acids & 3.07 \\
\hline at $2 \mathrm{~g} 17500$ & & 34.99 transport.misc & 6.25 \\
\hline at $\lg 33110$ & & 34.99 transport.misc & 3.48 \\
\hline at $5 \mathrm{~g} 13750$ & ZIFL1 & 34.99 transport.misc & 3.24 \\
\hline at4g01870 & & 35.1 not assigned.no ontology & 7.61 \\
\hline at $4 \mathrm{~g} 15610$ & & 35.1 not assigned.no ontology & 3.35 \\
\hline at $2 \mathrm{~g} 22880$ & & 35.1 not assigned.no ontology & 3.21 \\
\hline at5g 52900 & & 35.2 not assigned.unknown & 10.69 \\
\hline at5g62280 & & 35.2 not assigned.unknown & 5.95 \\
\hline at5g61820 & & 35.2 not assigned.unknown & 4.86 \\
\hline \multirow[t]{2}{*}{ at5g14730 } & & 35.2 not assigned.unknown & 4.85 \\
\hline & & 35.2 not assigned.unknown & 4.71 \\
\hline at 1 g76600 & & 35.2 not assigned.unknown & 4.16 \\
\hline at $\lg 19020$ & & 35.2 not assigned.unknown & 4.06 \\
\hline $\begin{array}{l}\text { at2g32190, } \\
\text { at2g32210 }\end{array}$ & & 35.2 not assigned.unknown & 3.75 \\
\hline at $4 \mathrm{~g} 28085$ & & 35.2 not assigned.unknown & 3.40 \\
\hline at $3 g 18560$ & & 35.2 not assigned.unknown & 3.34 \\
\hline at $4 \mathrm{~g} 39670$ & & 35.2 not assigned.unknown & 3.22 \\
\hline at1g66860 & & 35.2 not assigned.unknown & 3.18 \\
\hline at1g05575 & & 35.2 not assigned.unknown & 3.15 \\
\hline at4g24570 & DIC2 & $\begin{array}{l}9.8 \text { mitochondrial electron transport / ATP synthesis.uncoupling } \\
\text { protein }\end{array}$ & 3.29 \\
\hline
\end{tabular}


Table 6. 5: COI1-dependent TIBA-inducible genes classified as stress responsive

List of COI1-dependent TIBA-inducible genes classified as "stress responsive" by the TAIR GO classification database tool. Genes additionally classified as "responsive to abiotic or biotic stimuli" are marked in grey.

\begin{tabular}{|c|c|c|c|c|c|c|}
\hline$\underline{\text { Gene code }}$ & $\underline{\text { Symbol }}$ & $\underline{\text { Description }}$ & $\begin{array}{l}\text { Col-0 TIBA/ } \\
\text { Col-0 mock } \\
\end{array}$ & p-value & $\underline{\text { coil-t TIBA/ }}$ & p-value \\
\hline at3g28740 & CYP81D11 & monooxygenase & 55.64 & $8.6 \mathrm{E}-09$ & 0.12 & $1.0 \mathrm{E}-05$ \\
\hline at $\lg 43160$ & $R A P 2.6$ & transcription factor & 30.96 & $1.1 \mathrm{E}-12$ & 0.03 & $9.3 \mathrm{E}-13$ \\
\hline at5g13220 & $J A Z 10$ & jasmonate-ZIM-domain protein & 28.62 & $2.0 \mathrm{E}-10$ & 0.02 & $4.8 \mathrm{E}-11$ \\
\hline at3g49620 & DIN11 & oxidoreductase & 23.70 & $3.5 \mathrm{E}-07$ & 0.01 & $1.2 \mathrm{E}-08$ \\
\hline at2g34600 & $J A Z 7$ & jasmonate-ZIM-domain protein & 12.90 & 7.2E-09 & 0.07 & 5.1E-09 \\
\hline at3g09940 & ATMDAR3 & monodehydroascorbate reductase & 8.92 & $1.4 \mathrm{E}-07$ & 0.07 & $1.8 \mathrm{E}-08$ \\
\hline at3g47340 & $A S N 1$ & asparagine synthase & 6.75 & $9.0 \mathrm{E}-05$ & 0.24 & $1.1 \mathrm{E}-03$ \\
\hline $\begin{array}{l}\text { at1g51760/ } \\
\text { at1g51780 }\end{array}$ & $\begin{array}{l}\text { IAR3 / } \\
\text { ILL5 }\end{array}$ & $\begin{array}{l}\text { IAA-Ala conjugate hydrolase / } \\
\text { IAA-amino acid conjugate hydrolase }\end{array}$ & 5.25 & $6.4 \mathrm{E}-09$ & 0.12 & $3.7 \mathrm{E}-10$ \\
\hline at4g16260 & & $\begin{array}{l}\text { hydrolase, hydrolyzing O-glycosyl } \\
\text { compounds }\end{array}$ & 5.24 & $4.7 \mathrm{E}-06$ & 0.08 & 3.4E-08 \\
\hline at1g64160 & & $\begin{array}{l}\text { disease resistance-responsive family } \\
\text { protein }\end{array}$ & 5.10 & $1.5 \mathrm{E}-09$ & 0.22 & 3.6E-09 \\
\hline at4g24350 & & phosphorylase family protein & 5.02 & $1.5 \mathrm{E}-07$ & 0.09 & $1.6 \mathrm{E}-09$ \\
\hline at1 177420 & $L O X 3$ & lipoxygenase & 4.97 & $1.9 \mathrm{E}-10$ & 0.16 & $3.4 \mathrm{E}-11$ \\
\hline at $2 \mathrm{~g} 26020$ & $P D F 1.2 b$ & plant defensin & 4.77 & $2.0 \mathrm{E}-05$ & 0.06 & 3.6E-08 \\
\hline at1 72520 & & lipoxygenase, putative & 4.65 & $6.6 \mathrm{E}-10$ & 0.27 & 4.2E-09 \\
\hline at3g25780 & AOC3 & & 4.54 & 4.6E- 08 & 0.18 & $9.4 \mathrm{E}-09$ \\
\hline at2 $\mathrm{g} 43520$ & ATTI2 & serine-type endopeptidase inhibitor & 4.01 & 7.7E-07 & 0.29 & 2.9E-06 \\
\hline at5g06870 & $P G I P 2$ & protein binding & 3.96 & $2.6 \mathrm{E}-10$ & 0.05 & $1.1 \mathrm{E}-14$ \\
\hline at2g47180 & AtGolS1 & $\begin{array}{l}\text { transferase, transferring glycosyl/ hexosyl } \\
\text { groups }\end{array}$ & 3.84 & $1.0 \mathrm{E}-05$ & 0.16 & $3.7 \mathrm{E}-07$ \\
\hline at1g66760 & & MATE efflux family protein & 3.80 & $4.0 \mathrm{E}-07$ & 0.17 & $1.4 \mathrm{E}-08$ \\
\hline at1g19180 & $J A Z 1$ & jasmonate-ZIM-domain protein & 3.59 & $2.1 \mathrm{E}-05$ & 0.05 & $1.4 \mathrm{E}-09$ \\
\hline at1 g19670 & ATCLH1 & chlorophyllase & 3.52 & 4.1E-05 & 0.04 & $1.2 \mathrm{E}-09$ \\
\hline at $1 \mathrm{~g} 06160$ & ORA59 & transcription factor & 3.52 & $7.5 \mathrm{E}-05$ & 0.25 & $3.0 \mathrm{E}-05$ \\
\hline at4g10390 & & protein kinase family protein & 3.51 & $2.0 \mathrm{E}-08$ & 0.23 & 2.9E-09 \\
\hline at1g61120 & TPS04 & (E,E)-geranyllinalool synthas & 3.25 & $3.4 \mathrm{E}-06$ & 0.20 & $9.3 \mathrm{E}-08$ \\
\hline atlg32640 & ATMYC2 & transcription factor & 3.24 & $2.8 \mathrm{E}-08$ & 0.09 & $3.7 \mathrm{E}-12$ \\
\hline at1g72450 & JAZ6 & jasmonate-ZIM-domain protein & 3.06 & $1.9 \mathrm{E}-05$ & 0.11 & $1.1 \mathrm{E}-08$ \\
\hline at $2 \mathrm{~g} 06050$ & $O P R 3$ & 12-oxophytodienoate reductase & 3.04 & $4.3 \mathrm{E}-07$ & 0.10 & $8.3 \mathrm{E}-11$ \\
\hline at2g24850 & TAT3 & $\begin{array}{l}\text { L-tyrosine:2-oxoglutarate } \\
\text { aminotransferaseauxin-responsive } \\
\text { protein, putative; transaminase }\end{array}$ & 3.02 & $9.4 \mathrm{E}-04$ & 0.06 & 8.3E-08 \\
\hline
\end{tabular}



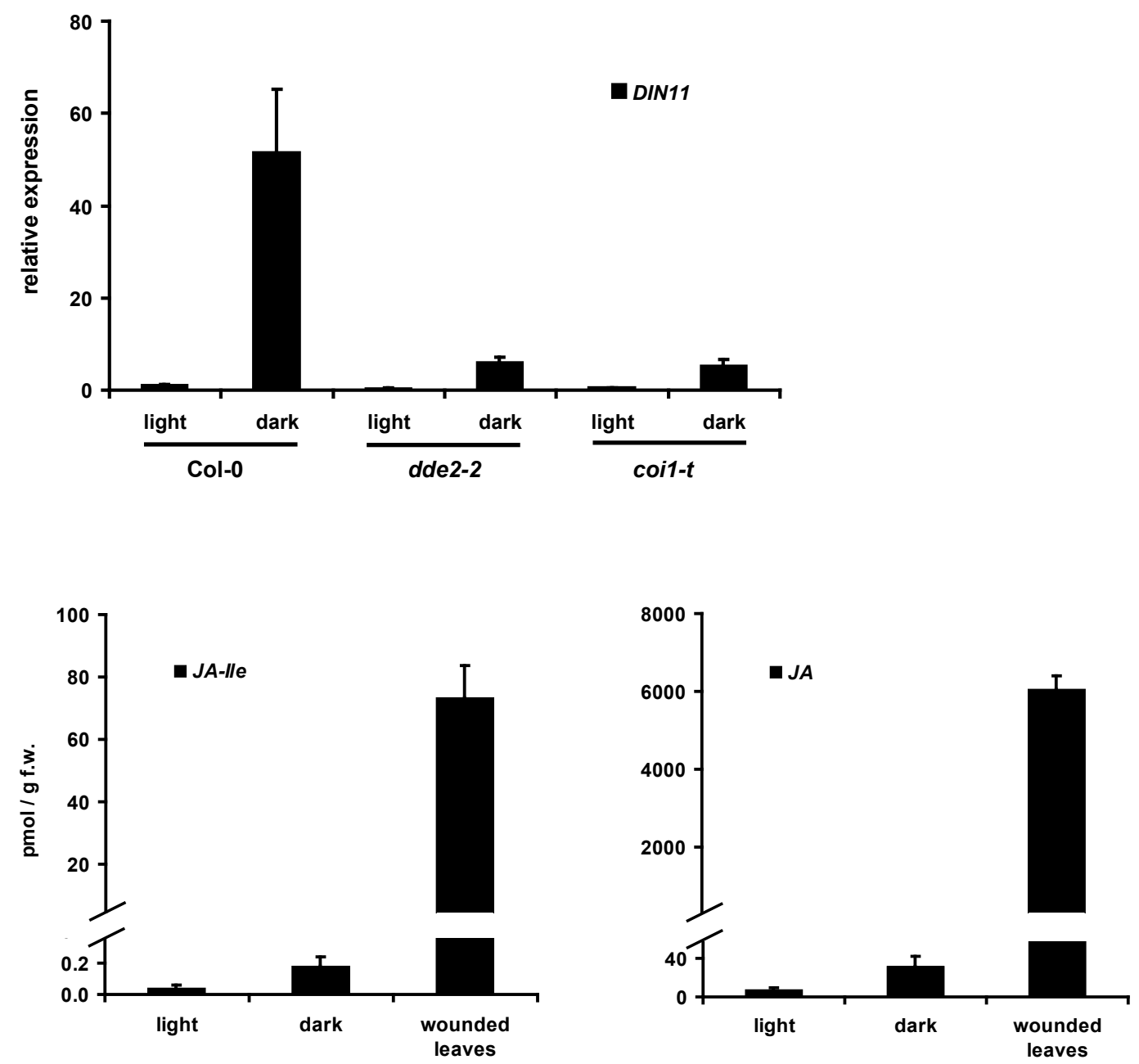

Figure 6. 9: DIN11 expression and JA/JA-Ile levels in response to extended darkness

6-7-week-old soil grown plants ( $12 \mathrm{~h}$ light/12 h dark) were kept in the dark for $36 \mathrm{~h}$ (dark), while control plants remained under normal light cycle (light). Whole rosettes were harvested when the light period started.

(A) Quantitative real time PCR analysis of DIN11 transcript levels (normalized to the housekeeping gene $U B Q 5)$. Every bar represents the average \pm SEM of 4 biological replicates.

(B) Determination of JA-Ile and JA levels by HPLC-MS/MS was performed of Col-0 wild-type plants. As a control, leaves were wounded by squeezing with forceps and incubated for $2 \mathrm{~h}$. In this case only wounded leaves were harvested. For light and dark every bar represents the average \pm SEM of 4 biological replicates. Wounding experiment was only performed with 2 biological replicates. JA-Ile and JA amounts are depicted as $\mathrm{pmol} / \mathrm{g}$ fresh weight. 

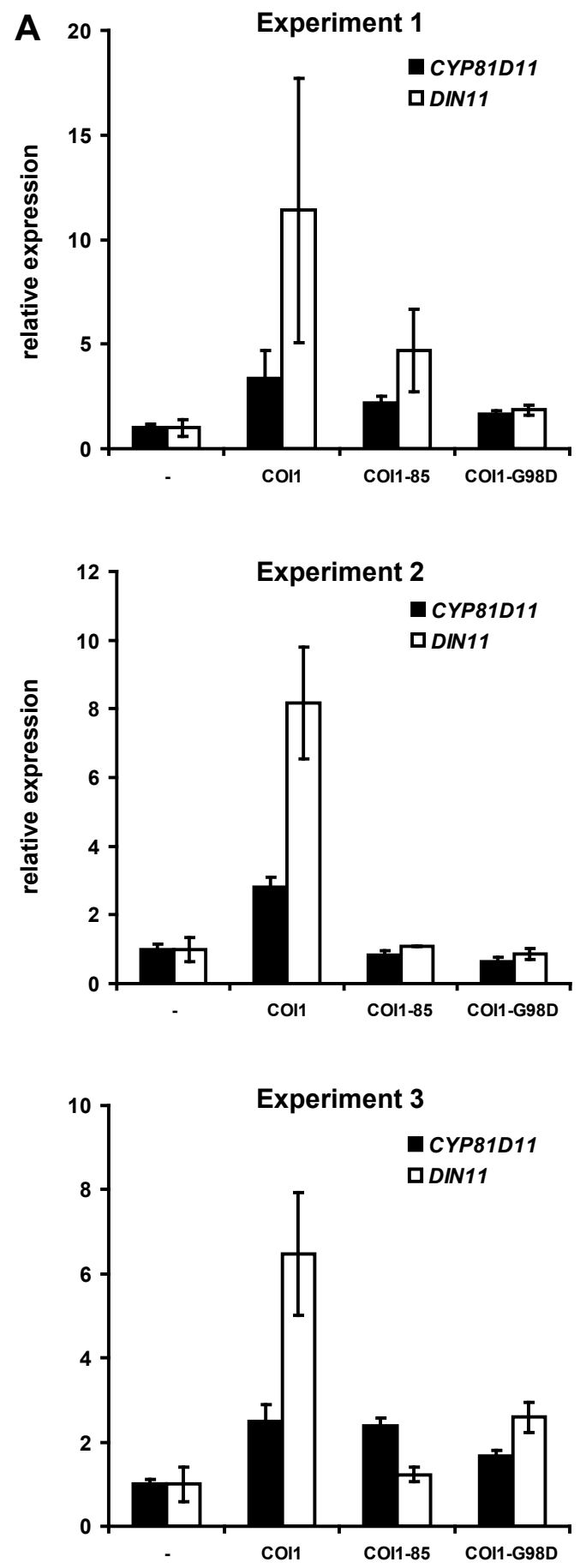

B
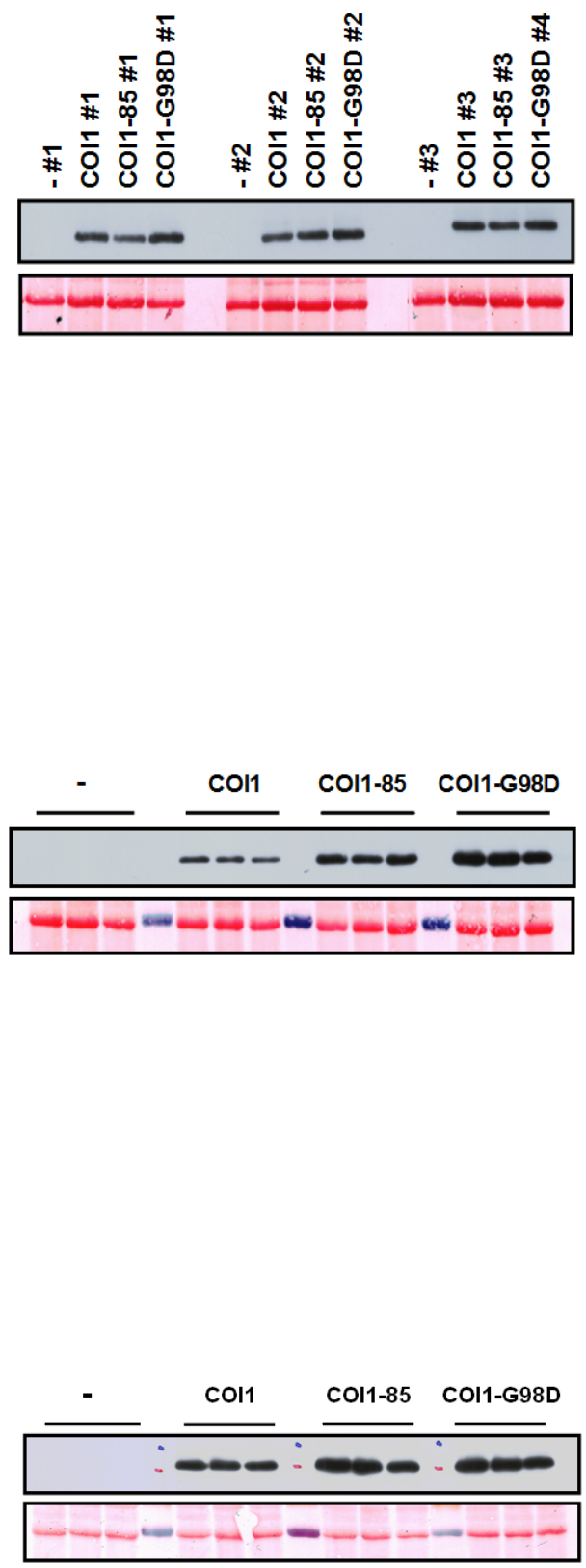

Figure 6. 10: Complementation of the CYP81D11 and DIN11 expression in the coil-t mutant by distinct COI1 proteins

coil-t protoplasts were transfected with vectors carrying the genes for COI1 as well as for two mutated COI1 proteins COI1-85, which exhibits amino acid substitution of aa85-88 from RAAM to HFAD, and COI1-G98D, which exhibits an amino acid exchange of aa98 from G to D (Yan et al. 2009) all COI1 proteins were fused to an HA tag. - indicates the empty vector control. Transfected protoplasts were incubated over night $(16 \mathrm{~h})$ before RNA was isolated or protein extracts were prepared. Three independent experimentes are depicted.

A: Quantitative real time PCR of CYP81D11 and DIN11 (normalized to the housekeeping gene UBQ5). Every bar represents the average \pm SEM of three samples (for CYP81D11 experiment 1 COI-85; for DIN11 experiment 1 empty vector, COI- 85 and experiment 3 empty vector only two replicates exhibited detectable transcript levels). Average of the transcript levels of the empty vector control samples was set to 1 .

B: Western blot analyses using an HA antibody. Ponceau red staining of the membrane is indicated as a loading control. 


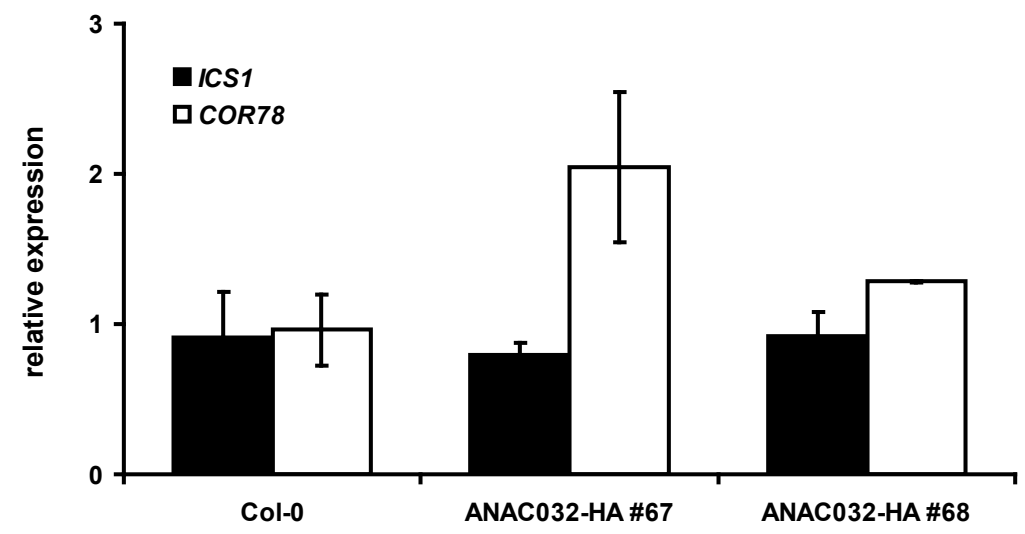

Figure 6. 11: ICS1 and COR78 transcript levels in ANAC032-overexpressing plants

Quantitative real-time RT-PCR analysis of $I C S 1$ and $C O R 78$ transcript levels (normalized to the housekeeping gene UBQ5) in 6-7-week-old soil-grown Col-0 wild-type plants and plants ectopically expressing HA-ANAC032 controlled by the CMV35S promoter. Whole rosettes were harvested for RNA isolation. Transcript values Col-0 plants were set to 1 . Every bar represents the average \pm SEM of two (HA-ANAC032) or four (Col-0) biological replicates 


\section{$7 \quad$ References}

Abe, H. et al., 1997. Role of Arabidopsis MYC and MYB Homologs in Drought-and Abscisic Acid-Regulated Gene Expression. Plant Cell, 9(10), 1859-1868.

Abe, H. et al., 2003. Arabidopsis AtMYC2 (bHLH) and AtMYB2 (MYB) Function as Transcriptional Activators in Abscisic Acid Signaling. Plant Cell, 15(1), 63-78.

Adams, E. \& Turner, J., 2010. COI1, a jasmonate receptor, is involved in ethyleneinduced inhibition of Arabidopsis root growth in the light. Journal of Experimental Botany, 61(15), 4373 -4386.

Alvarez, S., Zhu, M. \& Chen, S., 2009. Proteomics of Arabidopsis redox proteins in response to methyl jasmonate. Journal of Proteomics, 73(1), 30-40.

Anderson, J.P. et al., 2004. Antagonistic interaction between abscisic acid and jasmonate-ethylene signaling pathways modulates defense gene expression and disease resistance in Arabidopsis. The Plant Cell, 16(12), 3460-3479.

Armstrong, R.N., 1991. Glutathione $S$-transferases: reaction mechanism, structure, and function. Chemical Research in Toxicology, 4(2), 131-140.

Asai, T. et al., 2000. Fumonisin B1-Induced Cell Death in Arabidopsis Protoplasts Requires Jasmonate-, Ethylene-, and Salicylate-Dependent Signaling Pathways. The Plant Cell, 12(10), 1823-1836.

Baerson, S.R. et al., 2005. Detoxification and transcriptome response in Arabidopsis seedlings exposed to the allelochemical benzoxazolin-2(3H)-one. The Journal of Biological Chemistry, 280(23), 21867-21881.

Beckers, G.J.M. \& Spoel, S.H., 2006. Fine-Tuning Plant Defence Signalling: Salicylate versus Jasmonate. Plant Biology (Stuttgart, Germany), 8(1), 1-10.

Berger, S., Bell, E. \& Mullet, J.E., 1996. Two Methyl Jasmonate-Insensitive Mutants Show Altered Expression of AtVsp in Response to Methyl Jasmonate and Wounding. Plant Physiology, 111(2), 525-531.

Bernard, P. et al., 1993. The F plasmid CcdB protein induces efficient ATP-dependent DNA cleavage by gyrase. Journal of Molecular Biology, 234(3), 534-541.

Bolle, C., 2004. The role of GRAS proteins in plant signal transduction and development. Planta, 218(5), 683-692.

Bostock, R.M., 2005. Signal crosstalk and induced resistance: straddling the line between cost and benefit. Annual Review of Phytopathology, 43, 545-580.

Bruce, T.J.A. et al., 2008. cis-Jasmone induces Arabidopsis genes that affect the chemical ecology of multitrophic interactions with aphids and their parasitoids. Proceedings of the National Academy of Sciences of the United States of 
America, 105(12), 4553-4558.

Butterbrodt, T., Thurow, C. \& Gatz, C., 2006. Chromatin immunoprecipitation analysis of the tobacco PR-1a- and the truncated CaMV 35S promoter reveals differences in salicylic acid-dependent TGA factor binding and histone acetylation. Plant Molecular Biology, 61(4-5), 665-674.

Chini, A. et al., 2007. The JAZ family of repressors is the missing link in jasmonate signalling. Nature, 448(7154), 666-671.

Choe, S. et al., 1998. The DWF4 gene of Arabidopsis encodes a cytochrome P450 that mediates multiple 22alpha-hydroxylation steps in brassinosteroid biosynthesis. The Plant Cell, 10(2), 231-243.

Choe, S. et al., 2000. Lesions in the sterol delta reductase gene of Arabidopsis cause dwarfism due to a block in brassinosteroid biosynthesis. The Plant Journal: For Cell and Molecular Biology, 21(5), 431-443.

Chung, H.S. \& Howe, G.A., 2009. A Critical Role for the TIFY Motif in Repression of Jasmonate Signaling by a Stabilized Splice Variant of the JASMONATE ZIMDomain Protein JAZ10 in Arabidopsis. Plant Cell, 21(1), 131-145.

Cipollini, D. et al., 2004. Salicylic acid inhibits jasmonic acid-induced resistance of Arabidopsis thaliana to Spodoptera exigua. Molecular Ecology, 13(6), 16431653.

Clough, S.J., 2005. Floral dip: agrobacterium-mediated germ line transformation. Methods Mol Biol. 2005;286:91-102.

Cole, D.J., 1994. Detoxification and activation of agrochemicals in plants. Pesticide Science, 42(3), 209-222.

Coleman, J., Blake-Kalff, M. \& Davies, E., 1997. Detoxification of xenobiotics by plants: chemical modification and vacuolar compartmentation. Trends in Plant Science, 2(4), 144-151.

De Vos, M. et al., 2005. Signal signature and transcriptome changes of Arabidopsis during pathogen and insect attack. Molecular Plant-Microbe Interactions: MPMI, 18(9), 923-937.

Delessert, C. et al., 2005. The transcription factor ATAF2 represses the expression of pathogenesis-related genes in Arabidopsis. The Plant Journal: For Cell and Molecular Biology, 43(5), 745-757.

Denison, M.S. \& Nagy, S.R., 2003. Activation of the aryl hydrocarbon receptor by structurally diverse exogenous and endogenous chemicals. Annual Review of Pharmacology and Toxicology, 43, 309-334.

Devoto, A. et al., 2005. Expression profiling reveals COI1 to be a key regulator of genes involved in wound- and methyl jasmonate-induced secondary metabolism, defence, and hormone interactions. Plant Molecular Biology, 58(4), 497-513. 
Dharmasiri, N., Dharmasiri, S. \& Estelle, M., 2005. The F-box protein TIR1 is an auxin receptor. Nature, 435(7041), 441-445.

Dhonukshe, P. et al., 2008. Auxin transport inhibitors impair vesicle motility and actin cytoskeleton dynamics in diverse eukaryotes. Proceedings of the National Academy of Sciences of the United States of America, 105(11), 4489-4494.

Dicke, M., 1999. Specificity of herbivore-induced plant defences. Novartis Foundation Symposium, 223, 43-54; discussion 54-59, 160-165.

Dixon, D.P. et al., 1998. Glutathione-mediated detoxification systems in plants. Current Opinion in Plant Biology, 1(3), 258-266.

Dohn, D.R. \& Krieger, R.I., 1981. Oxidative metabolism of foreign compounds by higher plants. Drug Metabolism Reviews, 12(1), 119-157.

Dombrecht, B. et al., 2007. MYC2 Differentially Modulates Diverse JasmonateDependent Functions in Arabidopsis. Plant Cell, 19(7), 2225-2245.

Ekman, D.R. et al., 2003. SAGE analysis of transcriptome responses in Arabidopsis roots exposed to 2,4,6-trinitrotoluene. Plant Physiology, 133(3), 1397-1406.

Ellis, C. \& Turner, J., 2002. A conditionally fertile coil allele indicates cross-talk between plant hormone signalling pathways in Arabidopsis thaliana seeds and young seedlings. Planta, 215(4), 549-556.

Farmer, E.E., Alméras, E. \& Krishnamurthy, V., 2003. Jasmonates and related oxylipins in plant responses to pathogenesis and herbivory. Current Opinion in Plant Biology, 6(4), 372-378.

Feys, B.J. \& Parker, J.E., 2000. Interplay of signaling pathways in plant disease resistance. Trends in Genetics: TIG, 16(10), 449-455.

Feys, B. et al., 1994. Arabidopsis Mutants Selected for Resistance to the Phytotoxin Coronatine Are Male Sterile, Insensitive to Methyl Jasmonate, and Resistant to a Bacterial Pathogen. The Plant Cell, 6(5), 751-759.

Fode, T. 2008. The GRAS Protein SCL14 and TGA Transcription Factors Interact to Regulate Stress-Inducible Promoters (Göttingen: Georg-August-Universität)

Fode, B. et al., 2008. The Arabidopsis GRAS protein SCL14 interacts with class II TGA transcription factors and is essential for the activation of stress-inducible promoters. The Plant Cell, 20(11), 3122-3135.

Fonseca, S. et al., 2009. (+)-7-iso-Jasmonoyl-L-isoleucine is the endogenous bioactive jasmonate. Nat Chem Biol, 5(5), 344-350.

Glazebrook, J., 2005. Contrasting mechanisms of defense against biotrophic and necrotrophic pathogens. Annual Review of Phytopathology, 43, 205-227. 
Guerineau, F., Benjdia, M. \& Zhou, D.X., 2003. A jasmonate-responsive element within the A. thaliana vsp1 promoter. Journal of Experimental Botany, 54(385), 11531162.

Hanahan, D., 1983. Studies on transformation of Escherichia coli with plasmids. Journal of Molecular Biology, 166(4), 557-580.

Harberd, N.P., Belfield, E. \& Yasumura, Y., 2009. The Angiosperm Gibberellin-GID1DELLA Growth Regulatory Mechanism: How an "Inhibitor of an Inhibitor" Enables Flexible Response to Fluctuating Environments. The Plant Cell, 21(5), 1328-1339.

J., R. et al., 2002. Abiotic and biotic stress differentially stimulate as-1 element activity in Arabidopsis. Plant Cell Reports, 21(2), 180-185.

Jakob, K., Kniskern, J.M. \& Bergelson, J., 2007. The role of pectate lyase and the jasmonic acid defense response in Pseudomonas viridiflava virulence. Molecular Plant-Microbe Interactions: MPMI, 20(2), 146-158.

Jensen, M.K. et al., 2008. Transcriptional regulation by an NAC (NAM-ATAF1,2CUC2) transcription factor attenuates ABA signalling for efficient basal defence towards Blumeria graminis f. sp. hordei in Arabidopsis. The Plant Journal: For Cell and Molecular Biology, 56(6), 867-880.

Johnson, C. et al., 2001. In vivo target promoter-binding activities of a xenobiotic stress-activated TGA factor. The Plant Journal: For Cell and Molecular Biology, 28(2), 237-243.

Kang, J. et al., 2002. Arabidopsis Basic Leucine Zipper Proteins That Mediate StressResponsive Abscisic Acid Signaling. Plant Cell, 14(2), 343-357.

Karimi, M., Inzé, D. \& Depicker, A., 2002. GATEWAY(TM) vectors for Agrobacterium-mediated plant transformation. Trends in Plant Science, 7(5), 193-195.

Katagiri, F., Lam, E. \& Chua, N., 1989. Two tobacco DNA-binding proteins with homology to the nuclear factor CREB. Nature, 340(6236), 727-730.

Kessler, A. \& Baldwin, I.T., 2002. Plant responses to insect herbivory: the emerging molecular analysis. Annual Review of Plant Biology, 53, 299-328.

Kleinow, T. et al., 2009. NAC domain transcription factor ATAF1 interacts with SNF1related kinases and silencing of its subfamily causes severe developmental defects in Arabidopsis. Plant Science, 177(4), 360-370.

Kliewer, S.A., Goodwin, B. \& Willson, T.M., 2002. The nuclear pregnane X receptor: a key regulator of xenobiotic metabolism. Endocrine Reviews, 23(5), 687-702.

Klinedinst, S. et al., 2000. A xenobiotic-stress-activated transcription factor and its cognate target genes are preferentially expressed in root tip meristems. Plant Molecular Biology, 42(5), 679-688. 
Knox, K., Grierson, C.S. \& Leyser, O., 2003. AXR3 and SHY2 interact to regulate root hair development. Development (Cambridge, England), 130(23), 5769-5777.

Kwon, M. \& Choe, S., 2005. Brassinosteroid biosynthesis anddwarf mutants. Journal of Plant Biology, 48(1), 1-15.

Larkin, J.C. et al., 1994. Roles of the GLABROUS1 and TRANSPARENT TESTA GLABRA Genes in Arabidopsis Trichome Development. The Plant Cell, 6(8), 1065-1076.

Leon-Reyes, A. et al., 2009. Ethylene modulates the role of NONEXPRESSOR OF PATHOGENESIS-RELATED GENES1 in cross talk between salicylate and jasmonate signaling. Plant Physiology, 149(4), 1797-1809.

Lohse, M. et al., 2010. Robin: An intuitive wizard application for R-based expression microarray quality assessment and analysis. Plant Physiol., pp.109.152553.

Lorenzo, O., Chico, J.M., Sánchez-Serrano, J.J. et al., 2004. JASMONATEINSENSITIVE1 encodes a MYC transcription factor essential to discriminate between different jasmonate-regulated defense responses in Arabidopsis. The Plant Cell, 16(7), 1938-1950.

Lorenzo, O. et al., 2003. ETHYLENE RESPONSE FACTOR1 integrates signals from ethylene and jasmonate pathways in plant defense. The Plant Cell, 15(1), 165178.

Lu, P. et al., 2007. A novel drought-inducible gene, ATAF1, encodes a NAC family protein that negatively regulates the expression of stress-responsive genes in Arabidopsis. Plant Molecular Biology, 63(2), 289-305.

de Lucas, M. et al., 2008. A molecular framework for light and gibberellin control of cell elongation. Nature, 451(7177), 480-484.

Matthes, M.C. et al., 2010. The transcriptome of cis-jasmone-induced resistance in Arabidopsis thaliana and its role in indirect defence. Planta, 232(5), 1163-1180.

McConn, M. et al., 1997. Jasmonate is essential for insect defense in Arabidopsis. Proceedings of the National Academy of Sciences of the United States of America, 94(10), 5473-5477.

McConn, M. \& Browse, J., 1996. The Critical Requirement for Linolenic Acid Is Pollen Development, Not Photosynthesis, in an Arabidopsis Mutant. The Plant Cell, 8(3), 403-416.

Melotto, M. et al., 2008. A critical role of two positively charged amino acids in the Jas motif of Arabidopsis JAZ proteins in mediating coronatine- and jasmonoyl isoleucine-dependent interactions with the COI1 F-box protein. The Plant Journal: For Cell and Molecular Biology, 55(6), 979-988.

Memelink, J., 2009. Regulation of gene expression by jasmonate hormones. Phytochemistry, 70(13-14), 1560-1570. 
Mène-Saffrané, L. et al., 2009. Nonenzymatic oxidation of trienoic fatty acids contributes to reactive oxygen species management in Arabidopsis. The Journal of Biological Chemistry, 284(3), 1702-1708.

Moon, J., Parry, G. \& Estelle, M., 2004. The ubiquitin-proteasome pathway and plant development. The Plant Cell, 16(12), 3181-3195.

Mosblech, A. 2010. Jasmonic acid perception by COI1 involves inositol polyphosphates in Arabidopsis thaliana. The Plant Journal. Accepted

Mueller, S. et al., 2008. General detoxification and stress responses are mediated by oxidized lipids through TGA transcription factors in Arabidopsis. The Plant Cell, 20(3), 768-785.

Ndamukong, I. et al., 2007. SA-inducible Arabidopsis glutaredoxin interacts with TGA factors and suppresses JA-responsive PDF1.2 transcription. The Plant Journal: For Cell and Molecular Biology, 50(1), 128-139.

Nguyen, T., Yang, C.S. \& Pickett, C.B., 2004. The pathways and molecular mechanisms regulating Nrf2 activation in response to chemical stress. Free Radical Biology \& Medicine, 37(4), 433-441.

Nibbe, M. et al., 2002. Cell death and salicylate- and jasmonate-dependent stress responses in Arabidopsis are controlled by single cet genes. Planta, 216(1), 120128.

Nomura, K., Melotto, M. \& He, S., 2005. Suppression of host defense in compatible plant-Pseudomonas syringae interactions. Current Opinion in Plant Biology, 8(4), 361-368.

Olsen, A.N. et al., 2005. NAC transcription factors: structurally distinct, functionally diverse. Trends in Plant Science, 10(2), 79-87.

Orozco-Cardenas, M. \& Ryan, C.A., 1999. Hydrogen peroxide is generated systemically in plant leaves by wounding and systemin via the octadecanoid pathway. Proceedings of the National Academy of Sciences of the United States of America, 96(11), 6553-6557.

Pape, S., Thurow, C. \& Gatz, C., 2010. The Arabidopsis thaliana PR-1 Promoter Contains Multiple Integration Sites for the Co-activator NPR1 and the Repressor SNI1. Plant Physiology. Available at: http://www.ncbi.nlm.nih.gov/pubmed/20935179 [Accessed December 2, 2010].

Park, J. et al., 2002. A knock-out mutation in allene oxide synthase results in male sterility and defective wound signal transduction in Arabidopsis due to a block in jasmonic acid biosynthesis. The Plant Journal: For Cell and Molecular Biology, 31(1), 1-12.

Parry, G. \& Estelle, M., 2006. Auxin receptors: a new role for F-box proteins. Current Opinion in Cell Biology, 18(2), 152-156. 
Pascuzzi, P. et al., 1998. Auxin-induced stress potentiates trans-activation by a conserved plant basic/leucine-zipper factor. The Journal of Biological Chemistry, 273(41), 26631-26637.

Pauwels, L. et al., 2010. NINJA connects the co-repressor TOPLESS to jasmonate signalling. Nature, 464(7289), 788-791.

Penninckx, I.A. et al., 1998. Concomitant activation of jasmonate and ethylene response pathways is required for induction of a plant defensin gene in Arabidopsis. The Plant Cell, 10(12), 2103-2113.

Poppenberger, B. et al., 2006. Heterologous expression of Arabidopsis UDPglucosyltransferases in Saccharomyces cerevisiae for production of zearalenone4-O-glucoside. Applied and Environmental Microbiology, 72(6), 4404-4410.

Pré, M. et al., 2008. The AP2/ERF domain transcription factor ORA59 integrates jasmonic acid and ethylene signals in plant defense. Plant Physiology, 147(3), $1347-1357$.

Pysh, L.D. et al., 1999. The GRAS gene family in Arabidopsis: sequence characterization and basic expression analysis of the SCARECROW-LIKE genes. The Plant Journal: For Cell and Molecular Biology, 18(1), 111-119.

Reymond, P. et al., 2000. Differential gene expression in response to mechanical wounding and insect feeding in Arabidopsis. The Plant Cell, 12(5), 707-720.

Richards, D.E. et al., 2001. HOW GIBBERELLIN REGULATES PLANT GROWTH AND DEVELOPMENT: A Molecular Genetic Analysis of Gibberellin Signaling. Annual Review of Plant Physiology and Plant Molecular Biology, 52, 67-88.

Sandermann Jr., H., 1992. Plant metabolism of xenobiotics. Trends in Biochemical Sciences, 17(2), 82-84.

Sandermann, H., 1994. Higher plant metabolism of xenobiotics: the 'green liver' concept. Pharmacogenetics, 4(5), 225-241.

Schwechheimer, C., 2008. Understanding gibberellic acid signaling--are we there yet? Current Opinion in Plant Biology, 11(1), 9-15.

Sheard, L.B. et al., 2010. Jasmonate perception by inositol-phosphate-potentiated COI1JAZ co-receptor. Nature. Available at: http://www.ncbi.nlm.nih.gov/pubmed/20927106 [Accessed October 27, 2010].

Sheen, J., 2001. Signal Transduction in Maize and Arabidopsis Mesophyll Protoplasts. Plant Physiol., 127(4), 1466-1475.

Siemsen, T. 2005. Die Bedeutung des Proteins Scarecrow-like 14 bei der Regulation der Transkription von Stressgenen (Göttingen: Georg-August-Universität) 
Spoel, S.H., Johnson, J.S. \& Dong, X., 2007. Regulation of tradeoffs between plant defenses against pathogens with different lifestyles. Proceedings of the National Academy of Sciences of the United States of America, 104(47), 18842-18847.

Spoel, S.H. et al., 2003. NPR1 modulates cross-talk between salicylate- and jasmonatedependent defense pathways through a novel function in the cytosol. The Plant Cell, 15(3), 760-770.

Staswick, P.E., Huang, J.F. \& Rhee, Y., 1991. Nitrogen and methyl jasmonate induction of soybean vegetative storage protein genes. Plant Physiology, 96(1), 130-136.

Staswick, P.E., Su, W. \& Howell, S.H., 1992. Methyl jasmonate inhibition of root growth and induction of a leaf protein are decreased in an Arabidopsis thaliana mutant. Proceedings of the National Academy of Sciences of the United States of America, 89(15), 6837-6840.

Staswick, P.E. \& Tiryaki, I., 2004. The Oxylipin Signal Jasmonic Acid Is Activated by an Enzyme That Conjugates It to Isoleucine in Arabidopsis. Plant Cell, 16(8), 2117-2127.

Suhita, D. et al., 2004. Cytoplasmic Alkalization Precedes Reactive Oxygen Species Production during Methyl Jasmonate- and Abscisic Acid-Induced Stomatal Closure. Plant Physiol., 134(4), 1536-1545.

Szemenyei, H., Hannon, M. \& Long, J.A., 2008. TOPLESS Mediates Auxin-Dependent Transcriptional Repression During Arabidopsis Embryogenesis. Science, 319(5868), 1384-1386.

Tan, X. et al., 2007. Mechanism of auxin perception by the TIR1 ubiquitin ligase. Nature, 446(7136), 640-645.

Thines, B. et al., 2007. JAZ repressor proteins are targets of the $\mathrm{SCF}(\mathrm{COI} 1)$ complex during jasmonate signalling. Nature, 448(7154), 661-665.

Thomma, B.P. et al., 1999. Requirement of functional ethylene-insensitive 2 gene for efficient resistance of Arabidopsis to infection by Botrytis cinerea. Plant Physiology, 121(4), 1093-1102.

Tian, C. et al., 2004. Genome-wide analysis of the GRAS gene family in rice and Arabidopsis. Plant Molecular Biology, 54(4), 519-532.

Tiryaki, I. \& Staswick, P.E., 2002. An Arabidopsis mutant defective in jasmonate response is allelic to the auxin-signaling mutant axr1. Plant Physiology, 130(2), 887-894.

Tiwari, S.B. et al., 2001. AUX/IAA proteins are active repressors, and their stability and activity are modulated by auxin. The Plant Cell, 13(12), 2809-2822.

Tiwari, S.B., Hagen, G. \& Guilfoyle, T.J., 2004. Aux/IAA proteins contain a potent transcriptional repression domain. The Plant Cell, 16(2), 533-543. 
Ueguchi-Tanaka, M. et al., 2007. Gibberellin receptor and its role in gibberellin signaling in plants. Annual Review of Plant Biology, 58, 183-198.

Ulmasov, T. et al., 1997. Aux/IAA proteins repress expression of reporter genes containing natural and highly active synthetic auxin response elements. The Plant Cell, 9(11), 1963-1971.

Wagner, U. et al., 2002. Probing the diversity of the Arabidopsis glutathione $S$ transferase gene family. Plant Molecular Biology, 49(5), 515-532.

Wang, X. et al., 2009. The Arabidopsis ATAF1, a NAC transcription factor, is a negative regulator of defense responses against necrotrophic fungal and bacterial pathogens. Molecular Plant-Microbe Interactions: MPMI, 22(10), 1227-1238.

$\mathrm{Wu}$, Y. et al., 2009. Dual function of Arabidopsis ATAF1 in abiotic and biotic stress responses. Cell Research, 19(11), 1279-1290.

Xie, D.X. et al., 1998. COI1: an Arabidopsis gene required for jasmonate-regulated defense and fertility. Science (New York, N.Y.), 280(5366), 1091-1094.

$\mathrm{Xu}$, L. et al., 2002. The SCF(COI1) ubiquitin-ligase complexes are required for jasmonate response in Arabidopsis. The Plant Cell, 14(8), 1919-1935.

Yan, J. et al., 2009. The Arabidopsis CORONATINE INSENSITIVE1 protein is a jasmonate receptor. The Plant Cell, 21(8), 2220-2236.

Zander, M. et al., 2010. Arabidopsis thaliana class-II TGA transcription factors are essential activators of jasmonic acid/ethylene-induced defense responses. The Plant Journal: For Cell and Molecular Biology, 61(2), 200-210.

Zhang, B. \& Singh, K.B., 1994. ocs element promoter sequences are activated by auxin and salicylic acid in Arabidopsis. Proceedings of the National Academy of Sciences of the United States of America, 91(7), 2507-2511.

Zhang, L. \& Xing, D., 2008. Methyl Jasmonate Induces Production of Reactive Oxygen Species and Alterations in Mitochondrial Dynamics that Precede Photosynthetic Dysfunction and Subsequent Cell Death. Plant and Cell Physiology, 49(7), 1092 $-1111$.

Zhang, X., Garreton, V. \& Chua, N., 2005. The AIP2 E3 ligase acts as a novel negative regulator of ABA signaling by promoting $\mathrm{ABI} 3$ degradation. Genes $\&$ Development, 19(13), 1532-1543.

Zhang, Y. et al., 2003. Knockout analysis of Arabidopsis transcription factors TGA2, TGA5, and TGA6 reveals their redundant and essential roles in systemic acquired resistance. The Plant Cell, 15(11), 2647-2653. 


\section{Acknowledgement}

An erster Stelle möchte ich Frau Prof. Dr. Christiane Gatz für die Möglichkeit danken, in ihrer Arbeitsgruppe meine Promotion absolvieren zu dürfen. Durch ihre innovativen Anregungen hat sie den größten Anteil an dieser Arbeit.

Weiter gilt mein Dank Herrn Prof. Dr. Ivo Feußner für die bereitwillige Teilnahme an meinem Thesis Committee und der Übernahme des Koreferats. Zudem bedanke ich mich bei ihm und seinen Mitarbeitern, Cornelia Göbel und Tim Iven für die Phytohormonmessungen, die meine Arbeit entscheidend vorangebracht haben.

Auch Frau Prof. Dr. Polle, Herrn Prof. Dr. Schirawski, Herrn Prof. Dr. Stülke und Herrn PD Dr. Teichmann möchte ich dafür danken, dass sie alle ohne zu zögern die Teilnahme an meiner Disputation zugesagt haben.

Bei Dr. Corinna Thurow bedanke ich mich für die ständige Hilfsbereitschaft, bei allen Problemen im Laboralltag. Ebenfalls immer zu Stelle gewesen wenn es brannte ist Dr. Guido Kriete. Danke, ohne dich wäre ich an den Computern verzweifelt.

Unseren TAs Ronald Scholz, Larissa Kunz, Anna Hermann und Annette Gunkel gebührt ebenfalls ein großes „Dankeschön“. Ohne Euch hätte ich nur einen Bruchteil dessen geschafft, was jetzt in dieser Arbeit steht.

Ein weiteres Danke geht an meine Bachelor-Studentin Helena Meier, von ihr stammt ein großer Teil der „NAC-Daten“. Du hast mir mit deiner Arbeit wirklich geholfen.

Nun zu den lieben Kollegen: bei Euch allen möchte ich mich ganz herzlich für die gute Stimmung, für die vielen offenen Ohren, wenn Arabidopsis mal wieder nicht mitgespielt hat, und für die Unterstützung bei den vielen kleinen Laborkatastrophen bedanken. Und auch wenn ich „Haven Shall Burn“, „Tool“, „Motörhead“, „Disturbed“, „Mastodon“ und „Rage Against the Mashine“ noch immer nicht auseinander halten kann, Martin und Sebastian, meistens habe ich gerne das Labor mit Euch geteilt. Katja, 
auch wenn Du vorzeitig aus unserem Labor ,,ausgezogen“ bist, möchte ich mich bei dir besonders dafür bedanken, dass Du nicht „nein“ sagen kannst. Du hast mir wirklich sehr geholfen.

Last, aber überhaupt gar nicht least, meine Familie: Euch habe ich nicht nur für die Schokolade, die Stutenkerle, das Früchtebrot und den Erdnusseintopf zu danken, von denen ich mich in den letzten Wochen ernährt habe. Eigentlich gilt mein Dank dem wofür all diese Kleinigkeiten standen: Eurer Unterstützung in allen Höhe und Tiefen meines bisherigen privaten und beruflichen Lebens. Ohne Euch hätte ich es nie hierher geschafft! 


\section{Curriculum Vitae}

\section{Persönliche Daten}

Name

Julia Köster

Geburtsdatum /-ort

22.04.1982 in Datteln

Staatsangehörigkeit

deutsch

\section{Studium}

Seit 02/2007

Dissertation: Regulation of the Cytochrome P450 Gene, CYP81D11, in Arabidopsis thaliana, Subjected to Chemical Stress

$11 / 2005$ bis $10 / 2006$

Diplomarbeit: Funktionelle Analyse der hyd-Gene in Chlamydomonas reinhardtii mittels RNAInterferenz $(1,7)$

09/2006

Diplomprüfungen: Pflanzenbiochemie $(1,7)$

$$
\begin{aligned}
& \text { Genetik }(1,3) \\
& \text { Botanik }(1,0) \\
& \text { Immunologie }(1,0)
\end{aligned}
$$

$09 / 2003$

Vordiplomsprüfungen (Gesamtnote: Gut)

2001-2006

Diplomstudiengang Biologie an der Ruhr-UniversitätBochum

Gesamtnote: sehr gut

\section{Schule}

1998-2001

Theodor-Heuss-Gymnasium, Waltrop

Abschluss: Abitur

Gesamtnote: 2,5

1992-1998

Städtische Realschule, Datteln

1988-1992

Grundschule 